\title{
ANALYTICAL AND EXPERIMENTAL METHODS OF DETERMINING HEAVY-ISOTOPE CONTENT OF OPERATING FUEL ELEMENTS
}

\author{
BY
}

\author{
Michael F. Valerino \\ Zoltan R. Rosztoczy
}

\begin{abstract}
Prepared for
THE U. S. ATOMIC ENERGY COMMISSION

Under

Contract No. AT(38-1)-207

Approved by: 4
\end{abstract}

NUCLEAR DIVISION

COMBUSTION ENGINEERING, INC.

Windsor, Connecticut

September 30, 1965 


\section{DISCLAIMER}

This report was prepared as an account of work sponsored by an agency of the United States Government. Neither the United States Government nor any agency Thereof, nor any of their employees, makes any warranty, express or implied, or assumes any legal liability or responsibility for the accuracy, completeness, or usefulness of any information, apparatus, product, or process disclosed, or represents that its use would not infringe privately owned rights. Reference herein to any specific commercial product, process, or service by trade name, trademark, manufacturer, or otherwise does not necessarily constitute or imply its endorsement, recommendation, or favoring by the United States Government or any agency thereof. The views and opinions of authors expressed herein do not necessarily state or reflect those of the United States Government or any agency thereof. 


\section{DISCLAIMER}

Portions of this document may be illegible in electronic image products. Images are produced from the best available original document. 
Although much of the information collected and analyzed in this report has been obtained from published sources, the objective of the study--to produce an up-to-date resume of the state of the art--has required also that data be gathered directly from designers and operators of the major commercial nuclear power plants. The information in Section VI-D and Appendix D was gathered in that way, as was much of the information in the other appendices and some of that in the. body of the report.

The authors express their appreciation to Miss Ann Forbes who provided invaluable aid in carrying out the calculations performed. We are grateful to those listed below, all of whom helped by supplying direct information or by discussion. The interpretations and evaluations of the information remain, of course, the responsibility of the authors.

E. L. Alexander

Power Reactor Development Company

L. Chajson

Atomic Power Division

Westinghouse Electric Corporation

W. R. Clancey

Atomic Products Division

General Electric Corporation

J. D. Cochran

Consumers Public Power District

P. A. Fleger

Duquesne Light Company

R. C. Gerber

Atomics International Division

North American Aviation, Inc.

R. L. Haueter

Consumers Power Company

P. S. Lacy

Atomic Energy Division

Allis-Chalmers Manufacturing Company

P. Matthew

Pacific Gas and Electric Company

R. J. McWhorter

Atomic Products Division

General Electric Company
G. H. Minton

Atomic Power Division

Westinghouse Electric Corporation

H. A. Morewitz

Atomics International Division

North American Aviation, Inc.

R. J. Nodvik

Atomic Power Division

Westinghouse Electric Corporation

A. E. Paulson

N. S. Savannah Technical Staff

F. J. Ross

Piqua Nuclear Power Facility

H. J. Rubinstein

Atomics International Division

North American Aviation, Inc.

K. R. Van Howe

General Atomic Division

General Dynamics Corporation

M. I. Waring

Consolidated Edison Company of New York

H. J. Williams

Saxton Nuclear Experimental Corporation

E. A. Willson

Northern States Power Company 
I. INTRODUCTION . . . . . . . . . . . . . $\because . . . \cdot \frac{\text { Page }}{1}$

II. SUMMARY . . . . . . . . . . . . . . . . . . . . 3

A. Experimental Errors in Isotopic Compósition Measurements : . 6

B. Experimental Errors in Burnup Determination . . . . . . 6

C. Individual Prediction Accuracies . . . . . . . . . . . 7

III. DESCRIPTION OF BASIC CALCULATIONAL METHODS . . . . . . . . . 13

A. Zero-Dimensional Analyses . . . . . . . . . . . 15

B. One-Dimensional Multigroup Analyses . . . . . . . . . 17

C. Two-Dimensional Multigroup Analyses . . . . . . . . 18

D. Three-Dimensional One-Group Analyses . . . . . . . . 20

E. Three-Dimensional Multigroup Analyses . . . . . . . . 21

F. Multigroup Synthesis . . . . . . . . . . . 22

IV. UTILIZATION OF IN-CORE AND OUT-OF-CORE MEASUREMENTS . . . . . . 25

A. Coolant Enthalpy Rise Measurements in Individual Fuel
Assemblies . . . . . . . . . . 25

B. In-Core Flux-Wire and Ion-Chamber Measurements . . . . . 26

C. Out-of-Core Gamma-Flux Scanning Measurements . . . . . . 27

V. ASSEMBLYWISE POWER OUTPUTS AIND FUEL EXPOSURE . . . . . . . . . . 29

A. Yankee Core I Pressurized Water Reactor . . . . . . . 29

B. Dresden, Humboldt Bay and RWE-Kahl Boiling Water Reactors. • $3 I$

C. Indian Point Pressurized Water Reactor . . . . . . . . . 31

D. Comparison of FIARE and PDQ Power Distributions . . . . . 33

VI. CALCULATED AND MEASURED HEAVY-ISOTOPIC COMPOSITIONS IN
OPERATING FUEL ELEMEINTS . . . . . . . . . . . . . . 36

A. Shippingport Pressurized Water Reactor . . . . . . . . 36

B. Vallecitos and Dresden Boiling Water Reactors . . . . . 38

C. Yankee Core I Pressurized Water Reactor . . . . . . . . 40

D. Heavy-Isotope Cross Section Data. . . . . . . . . . 45 
TABLE OF CONTENTS (Cont.)

VII. REFERENCES . . . . . . . . . . . . . . . . . . . 100 APPENDIX A

DESCRIPTION OF NUCLEAR CODES . . . . . . . . . . . . . . A-I

\section{APPENDIX B}

METHODS USED IN OPERATING POWER REACTORS TO MEASURE POWER AND

EXPOSURE DISTRIBUTIONS . . . . . . . . . . . . . . . B B-I

I. Carolinas-Virginia Tube Reactor, CVTR ........... B-I

II. Piqua and Hallam Reactors . . . . . . . . . . . . B-2

III. Yankee Core I. . . . . . . . . . . . . . . B-2

IV. Vallecitos Reactor, VBWR .............. . B-3

V. Dresden, Humboldt Bay and Big Rock Point Reactors . . . . . B-4

VI. Indian Point Reactor . . . . . . . . . . . . . B-5

APPENDIX C

MEASUREMENT ACCURACIES IN THE DETERMINATION OF EXPOSURE AND HEAVY-

ISOTOPIC COMPOSITION OF IRRADIATED FUEL SAMPLES . . . . . . . C C-1

I. Fuel Exposure Measurements ............... . C-I

II. Measurement of Heavy-Isotopic Composition ......... . C-4 APPEIVDIX D

ACCURACY OF PLANT MEASUREMENTS . . . . . . . . . . . . . D-I

I. Indian Point . . . . . . . . . . . . . . . D-2

II. Big Rock Point . . . . . . . . . . . . . . . D-3

III. Humboldt Bay . . . . . . . . . . . . . . . D-6

IV. Dresden I'. . . . . . . . . . . . . . . . D-6

V. Shippingport . . . . . . . . . . . . . . . . D $\mathrm{D}-7$

VI. Hallam . . . . . . . . . . . . . . . . . . . $\mathrm{D}-8$

VII. Pathfinder . . . . . . . . . . . . . . . . . D D 9

VIII.Saxton ...................... . . . . D-10

IX. Carolinas-Virginia . . . . . . . . . . . . . . D-10

X. Piqua . . . . . . . . . . . . . . . . . . . $\mathrm{D}-11$

XI. Yankee ...................... . . . D-12 
Table

I. ESTIMATED UNCERTAINTIES IN ISOTOPIC COMPOSITION DUE TO UNCERTAINTIES IN EVALUATION OF BATCH EXPOSURE . . . . . . . . 5

II. ESTIMATED OVERAIJ UNTERTAINTIES IN PREDICTED ISOTOPIC COMPOSITIONS . . . . . . . . . . . . . . . . ... . 5

III. MEASURED AND CEND-CALCULATED ISOTOPIC COMPOSITIONS IN

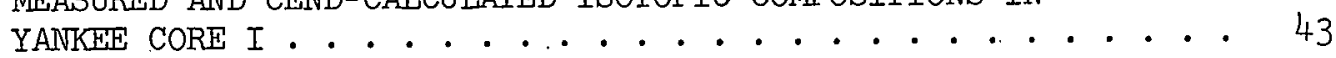

IV. PREDICTED VERSUS EXPERIMENTAL ISOTOPIC INVENTORY FOR SPENT.

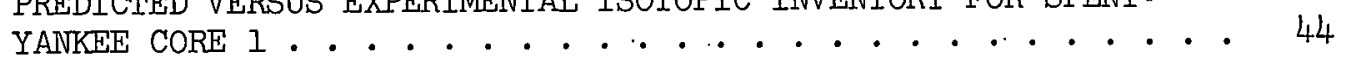

V. HEAVY-ISOTOPE MAXWELLIAN-AVERAGED CROSS SECTIONS AND INFINITELYDILUTE RESONAINCE INTEGRALS USED BY REACTOR DESIGNERS. . . . . 46

VI. STATISTICS ON VARIATIONS IN VALUES OF HEAVY-ISOTOPE NUCIEAR CONSTANTS USED BY VARIOUS REACTOR DESIGNERS . . . . . . . . . 50 APPENDIX C

C-1 UNCERTAINTIES IN FIJEL EXPOSURE MEASUREMTNTS . . . . . . . . . . C-3

C-2 PRECISION OF MASS SPECTROMETRIC DATA . . . . . . . . . C C-5

C-3 ACCURACIES OF ISOTOPIC CONTENT MEASUREMENTS . . . . . . . . c C-6 APPENDIX. D

D-1 ESTIMATED UNCERTAINTIES IN INDIAN POINT PRIMARY MEASUREMENTS. - D-4

D-2 ESTIMATED UNICERTAINTIES IN BIG ROCK POINT PRIMARY MEASUREMENTS ... . . . . . . . . . . . . . . D-5

D-3 ESTIMATED UNCERTATNTIES IN DRESDEN I POWER-LEVEL MEASUREMEIVT. • D-7

D-4 ESTIMATED UNCERTAINTIES IN PIQUA PRIMARY MEASUREMENTS . . . . . D-II 


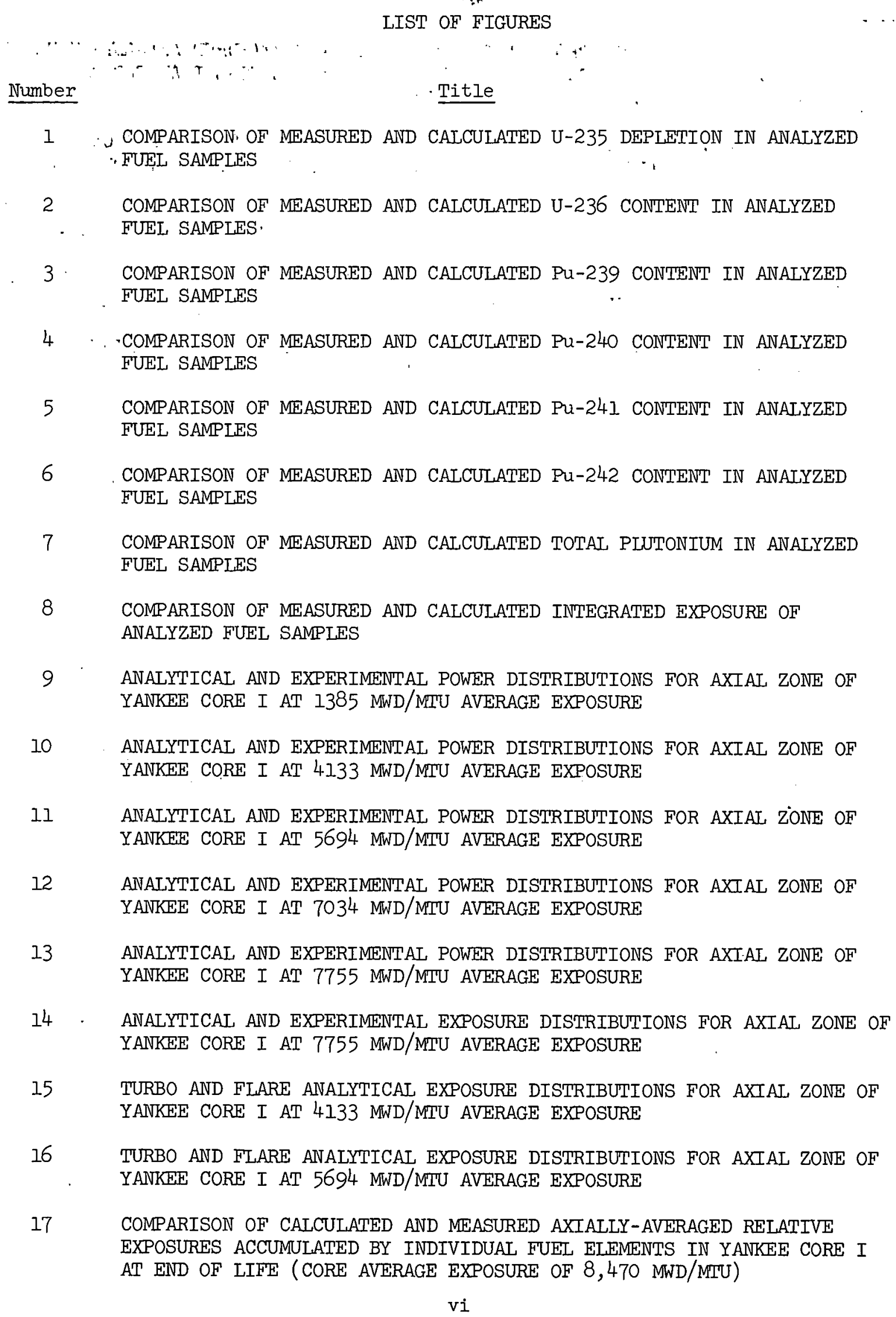

$1 \therefore$ COMPARISON OF MEASURED AIVD CALCULATED U-235 DEPLETION IN ANALYZED $\because$ FUĘL SAMPLES

2 COMPARISON OF MEASURED AND CALCULATED U-236 CONTENT IN ANALYZED FUEL SAMPLES,

3. COMPARISON OF MEASURED AND CALCULATED PU-239 CONTENT IN ANALYZED FUEL SAMPIES

4 - COMPARISON OF MEASURED AND CALCUIAATED PU-240 CONTENT IN ANALYZED FUEI SAMPIES

5 COMPARISON OF MEASURED AND CALCULATED PU-241 CONTENT IN ANALYZED FUEL SAMPIES

6 COMPARISON OF MEASURED AND CALCULATED PU-242 CONTENT IN ANALYZED FUEL SAMPLES

7 COMPARISON OF MEASURED AND CALCULATED TOTAL PLUTONIUM IN ANALYZED FUEL SAMPLES

8 COMPARISON OF MEASURED AND CALCULATED INTEGRATED EXPOSURE OF ANALYZED FUEL SAMPLES

9 ANALYTICAL AND EXPERIMEITAL POWER DISTRIBUTIONS FOR AXIAL ZONE OF YANKEE CORE I AT 1385 MWD/MIU AVERAGE EXPOSURE

10 ANALYTICAL AND EXPERIMENTAL POWER DISTRIBUTIONS FOR AXIAL ZONE OF YANKEE CORE I AT 4133 MWD/MIU AVERAGE EXPOSURE

I1 ANALYTICAL AND EXPERIMENTAL POWER DISTRIBUTIONS FOR AXIAL ZONE OF YAIKKEE CORE I AT $5694 \mathrm{MWD} / \mathrm{MTU}$ AVERAGE EXPOSURE

12 ANALYTICAL AND EXPERIMENTAL POWER DISTRIBUTIONS FOR AXIAL ZONE OF YANKEE CORE I AT $7034 \mathrm{MWD} / \mathrm{MTU}$ AVERAGE EXPOSURE

13 ANALYTICAL AND EXPERIMENTAL POWER DISTRIBUTIONS FOR AXI-AL ZONE OF YANKEE CORE I AT $7755 \mathrm{MWD} / \mathrm{MTU}$ AVERAGE EXPOSURE

14 ANALYTICAL AND EXPERIMENTAL EXPOSURE DISTRIBUTIONS FOR AXIAL ZONE OF YAINKEE CORE I AT 7755 MWD/MTU AVERAGE EXPOSURE

15 TURBO AND FLARE ANALYTICAL EXPOSURE DISTRIBUTIONS FOR AXIAL ZONE OF YANKEE CORE I AT $4133 \mathrm{MWD} / \mathrm{MPT}$ AVERAGE EXPOSURE

16 TURBO AND FLARE ANALYTICAL EXPOSURE DISTRIBUTIONS FOR AXIAL ZONE OF YANKEE CORE I AT 5694 MWD/MTU AVERAGE EXPOSURE

17 COMPARISON OF CALCULATED AND MEASURED AXIALLY-AVERAGED RELATIVE EXPOSURES ACCUMULATED BY INDIVIDUAL FUEL ELEMENTS IN YANKEE CORE I AT END OF LIFE (CORE AVERAGE EXPOSURE OF 8,470 MWD/MTU) 
PERCENTAGE DIFFERENCES BETWEEN CALCULATED AIND MEASURED AXIALLY-AVERAGED EXPOSURES OF INDIVIDUAL FUEL ELEMEIVTS IN YANKEE CORE I AT END OF LIFE (CORE AVERAGE EXPOSURE OF 8,470 MWD/MIU)

COMPARISON OF AXIAL DISTRIBUTION OF GROSS GÁMMA ACTIVITY AND CALCULATED AND MEASURED BURNUPS IN YANKEE CORE I ASYMPTOTIC CORE POSITION H3-C-f6 COMPARISON OF AXIAL DISTRIBUTION OF GROSS GAMMA ACTIVITY AND CALCULATED AND MEASURED BURNUPS IN YANKEE CORE I ASYMPTOTIC CORE POSITION F4-C-fI

21 COMPARISON OF AXIAL DISTRIBUTION OF GROSS GAMMA ACTIVITY AND CALCULATED AND MEASURED BURNUPS IN YANKEE CORE I ASYMPTOTIC, CORE POSITION G4-C-f6

22 " ANALYTICAL (FLARE) AND EXPERIMENTAL POWER DISTRIBUTIONS FOR DRESDEN (FROM REF 22); CLEAN CORE - 1/2 POWER

23 ANALYTICAL (FLARE) AND EXPERIMENTAL POWER DISTRIBUTIONS FOR HUMBOLDT BAY (FROM REF 22); CLEAN CORE, FULL POWER

24. ANALYTICAL (FTARE) AND EXPERIMENTAL POWER DISTRIBUTIONS IN RWE-KAHL AT SEVERAL FUEL EXPOSURES

25 COMPARISON OF CALCULATED AND MEASURED Ba-La ACTIVITIES AT AXIAL SCAN POSITION 2 IN OCTAINT OF INDIAN POINT REACTOR

26 COMPARISON OF CALCULATED AND MEASURED Ba-La ACTIVITIES AT AXIAL SCAN POSITION 7 IN OCTANT OF INDIAN POINT REACTOR

27 COMPARISON OF CALCULATED AND MEASURED Ba-La ACTIVITIES AT AXIAL SCAN POSITION 12 IN OCTANT OF INDIAN POINT REACTOR

28 COMPARISON OF CALCULATED AND MEASURED Ba-La ACTIVITIES AT AXIAL SCAN POSITION 18 IN OCTANT OF INDIAN POINT REACTOR

29 COMPARISON OF MEASURED AND CALCULATED Ba-La ACTIVITIES ALONG FUEL ELEMENT NO. 21 OF INDIAN POINT REACTOR

COMPARISON OF MEASURED AND CALCULATED Ba-La ACTIVITTIES ALONG FUEL LEMENT NO. 28 OF INDIAN POINT REACTOR

31 COMPARISON OF MEASURED AND CALCULATED Ba-Ia ACTIVITIES ALONG FUEL ELEMENT NO. $57^{\circ}$ OF INDIAN POINT REACTOR

32 COMPARISON OF MEASURED AND CALCULATED Ba-La ACTIVITIES ALONG FUEL ELEMENT NO. 62 OF INDIAN POINT REACTOR

33 COMPARISON OF CALCULATED AND MEASURED INTEGRATED Ba-La ACTIVITIES OF INDIAN POINT REACTOR

$34 \cdot$ COMPARISON OF FLARE AND DETAILED PDQ CALCULATIONS ON ASSEMBLYWISE POWER DISTRIBUTION FOR A BONUS BOILER CONFIGURATION. ALL CONTROL RODS OUT. 
35 COMPARISON OF FLARE AIND DETAILED PDQ CALCUIATIONS ON ASSEMBLYWISE POWER DISTRIBUTION FOR A BONUS BOILER CONFTGURATION. CENTER ROD IN.

36 COMPARISON OF FLARE AND DETAILED PDQ CALCULATIONS ON ASSEMBLYWISE POWER DISTRIBUTION FOR A BONUS BOILER CONFIGURATION. CENTER ROD PLUS CORNER RODS INT.

37 COMPARISON OF FLARE AND DETAIIED PDQ CALCULATIONS ON ASSEMBLYWISE POWER DISTRIBUTION FOR BIG ROCK POINT (CALCULATIONS BY GENERAL EEECTRIC)

38 COMPARISON OF MEASURED AND CALCULATED PERCENTAGE DEPLETION OF U-235 IN PWR BLANKET FUEL RODS (FROM REF 26)

39 COMPARISON OF MEASURED AND CALCULATED TOTAL PLUTONIUM CONTENTI IN PWR BLANKET FUEL RODS (FROM REF 26)

40 COMPARISON OF MEASURED AND CALCULATED Pu-239 CONTENT IN PWR BLANKET FUEL RODS (FROM REF 26)

4 COMPARISON OF MEASURED AND CALCULATED PU-240 CONTEINT IN PWR BLANVET FUEL RODS (FROM REF 26)

42 COMPARISON OF MEASURED AND CALCULATED PU-24I CONTE'NT IN PWR BLANKET FUEL RODS (FROM REF 26)

43 COMPARISON OF MEASURED AND CALCULATED PU-242 CONTENT IN PWR BLANKET FUEL RODS (FROM REF 26)

44 COMPARISON OF MEASURED AND CALCULATED TOTAL FISSIONS/U-235 FISSIONS IN PWR BLANKET FUEL RODS (FROM REF 26)

45 COMPARISON OF MEASURED AND CALCULATED BURNUP IN MEGAWATT DAYS/METRIC TON URANIUM IN PWR BLANKET FUEL RODS (FROM REF 26)

46 U-235 ATOM FRACTION AS A FUNCTION OF FUEL EXPOSURE IN VBWR (FROM REF 17)

47 U-236 ATOM FRACTION AS A FUNCTION OF FUEL EXPOSURE IN VBWR (FROM REF 17)

48 Pu-239/U-238 AS A FUNCTION OF FUEL EXPOSURE IN VBWR (FROM REF 17)

49 Pu-240/Pu-239 AS A FUNCTION OF FUEL EXPOSURE IN VBWR (FROM REF 17)

50 PU-241/Pu-240 AS A FUINCTION OF FUEL EXPOSURE IN VBWR (FROM REF 17)

51 Pu-242/Pu-241 AS A FUNCTION OF FUEL EXPOSURE IN VBWR (FROM REF 17)

52 TOTAL PU AS A FUNCTION OF FUEL EXPOSURE IN VBWR (FROM REF 17)

53 MEASURED AND COMPUTED ATOM RATIOS OF Pu-239/U-238 IN VBWR AND DRESDEN REACTORS (FROM REF 27)

54 MEASURED AND COMPUTED ATOM RATIOS OF Pu-240/Pu-239 IN VBWR AND DRESDEN REACTORS (FROM REF 27) 
55 MEASURED AND COMPUTED ATOM RATIOS OF Pu-241/Pu-240 IN VBWR AND DRESDEN REACTORS (FROM REF 27)

56 MEASURED AND COMPUTED ATOM RATIOS OF PU-242/Pu-24I IN -VBWR AND DRESDEN REACTORS (FROM REF 27)

57 MEASURED AND COMPUTED ATOM RATIOS OF U-236/U-235 IN VBWR AND DRESDEN REACTORS (FROM REF 27)

58 PLUTONIUM COMPOSITION IN THE ASYMPTOTIC NEUTRON SPECTRUM OF YANKEE CORE I

59 PU/U RATIOS IN THE ASYMPTOTIC NEUTRON SPECTRUM OF YANKEEE CORE I 


\section{INTRODUCTION}

The economic need exists to maintain accurate accountability of the irradiation exposure and isotopic-content of fuel elements in operating power reactors. The problem of accurately establishing the value of exposed fuel discharged from a reactor has become increasingly urgent with the large number of nuclear power plants going into operation in the immediate future. Generally, the fuel discharged from a power reactor is not immediately processed; hence, the value of the discharged fuel used in an interim settlement must be based on calculated fuel composition. With appreciable quantities of nuclear fuels involved, large discrepancies in the interim monetary settlements can arise depending on the accuracy of the fuel depletion calculations. Differences in monetary adjustments can arise from differences in the reactor physics methods, in the basic neutron cross section data, and in the interpretation of the reactor operating data. These differences are extremely difficult to identify; and, when identified, their overall effect on prediction results is not easily assessed.

There are also considerations other than economics. Both the U. S. Atomic Energy Commission and the International Atomic Energy Agency are committed to programs of safeguards designed to minimize the likelihood of undisclosed diversion of nuclear materials into clandestine weapons production. A knowledge of the nuclear material content of discharged reactor fuel is highly desirable for this safeguards control effort as a check on the accuracy of subsequent chemical measurements at the reprocessing plant.

As a first logical step towards development of practical fuel accounting procedures, the current calculational techniques used to predict heavy-isotope content of nuclear fuels exposed in power reactors are identified and, where possible, evaluated from the standpoint of estimating accuracies of predictions. Such estimations can best be made by comparison of calculational results with the results of fuel-composition measurements. A significant number of experimental measurements have been made to serve as preliminary bases for such comparisons. Many sources of experimental errors are involved in the isotopic-composition measurements; the measurement errors hence become an important part of the comparison between calculation and experiment and also need to be evaluated. In addition, the final determination of the value of the nuclear fuel is made during reprocessing on the basis of measurements of the isotopic composition of the reprocessed batch. Knowledge is required of the magnitude of the measurement inaccuracies involved in these measurements if the measurement results are to serve as a reliable measure of the value of the nuclear fuel.

Fuel depletion calculations are generally performed during reactor design primarily for the purpose of: (1) determining that sufficient excess reactivity is available for attainment of the design fuel exposure; and (2) verifying that the permissible hot-spot factors for the fuel rods are not exceeded during the fuel burnup. The information obtained in such design calculations on isotopic composition is considered to be only of secondary importance, as far as fuel accounting is concerned, inasmuch as it generally turns out that the reactor operation is different from that conceived during the design stage. The actual 
control-rod positions and withdrawal patterns cannot be predicted well enough during design to warrant specific detailed calculations on assemblywise exposures and isotopic contents; calculations for fuel accounting purposes can best be performed during and following reactor operation where advantage can be taken of the additional data accrued, such as actual control-rod positions, total energy production, measured flux and power distributions, etc.

This report presents the results of work performed at Combustion Engineering Nuclear Division for the U. S. Atomic Energy Commission under contract AT(38-I)207, Task Agreement No. VII, Phase I for the purpose of investigating available methods of calculating isotopic content of operating fuel elements in power reactors. The investigation is specifically aimed at exploring the feasibility of developing simple methods for testing the results of nuclear loss and production calculations in power reactors, using the maximum amount of actual reactor operating data as input. The general objectives of the work are: (I) to determine the capabilities and limitations of the present calculational methods; (2) to evaluate the accuracy of the techniques; and (3) to express, quantitatively, the agreement which may be expected between calculational results and results of a careful dissolution and chemical analysis. The problem of isotopic-content determination naturally divides into two general areas. One area involves the determination of the exposure level of the individual fuel assemblies, which, in turn, depends upon the history of the power distribution and the total thermal output of the reactor. The second area is the determination of the detailed burnup and production of the heavy isotopes as a function of exposure level. A comprehensive evaluation of published data and associated methods of analyses is presented herein for calculations in these two general areas. Information supplied through specific requests from the various reactor designers and operators is included in the evaluation. Where available, experimental data which have been obtained from operating power reactors are factored into the evaluation. These data include experimental measurements of flux and power distributions, exposures, and spent fuel isotopic composition as a function of exposure. Heavyisotope cross-section data used by the various reactor designers are compared to obtain an indication of their relative consistency.

The work reported herein was conducted during the period July 1, 1964 through July $1,1965$. 


\section{SUMMARY,}

Numerous nuclear codes are available for calculating the burnup and buildup of heavy isotopes in commercial power reactors. The computer codes cover a broad scope of analytical treatment ranging from zero-dimensional to three-dimensional multigroup analyses. In practice, the analyses carried out for the specific purpose of determining isotopic content of a batch of discharged fuel assemblies are usually confined to the zero- or one-dimensional domain. The more detailed and elaborate analyses are generally conducted to cope with anticipated reactor operational problems (generally related to shim, control rod, and fuel management) or to check and improve on the design methods when data on power and exposure distributions and/or isotopic composition have been obtained in experimental programs on the operating reactor.

The approaches used by the various operators (or designers) to report on the isotopic content of operating fuel assemblies are generally quite similar. A zero-dimensional multigroup code is usually used to generate curves or tables of isotopic concentration versus MWD/MTU fuel exposure corresponding to the average neutron spectra over the reactor core or over various portions of the reactor core in which the neutron spect.ra are sufficicntly different to justity separate consideration. The specific codes used are similar in calculational function but many were independently developed for the designer's own use and so have different code names. The designers are in general agreement as to what constitute the best present-day nuclear constants for the more prevalent isotopes contained in commercial power reactors. Differences in basic nuclear constants used by the various designers prevail for the higher isotopes in the isotopic chains; however, these higher isotopes (e.g., Pu24l, Pu242) are not present in sufficient abundance for the range of exposures presently encountered for the differences to affect fuel worth. An especially important source of uncertainty is due to the computed conversion ratio. Without specific experimental measurements on conversion ratio for the fuel-rod lattice geometry and material compositions used in the actual reactor, a one-standard deviation uncertainty of $\pm 5 \%$ must be assigned to the computed conversion ratio. This uncertainty directly reflects in an almost equal magnitude uncertainty in the net fissile material production.

Once the relationship between isotopic concentration and MWD/MTU fuel exposure has been established, it is necessary to obtain the average fuel exposure for the particular batch of fuel assemblies under consideration. In the CVTR, Piqua and Hallam reactors, the average fuel exposure for a group of fuel assemblies is directly obtained from continual measurements of assemblywise power output. In Dresden, Humboldt Bay and Big Rock Point, in-core ion chamber measurements in conjunction with the results of FLARE calculations have been utilized. In Yankee Core I, two-dimensional R-Z TURBO calculations were performed and checked against in-core flux wire measurements. In the Peach Bottom Reactor, the one-dimensional fuel depletion code, FEVER, is utilized. Note that TURBO and FEVER also provide isotopic compositions in addition to power and exposure distributions. In the Elk River and LaCrosse reactors, the relative assemblywise power outputs are estimated from the results of two-dimensional calculations performed during reactor design. 
The evaluation performed herein indicates that use of the FLARE code provides the best compromise for calculating relative assemblywise fuel exposures for use in fuel accounting. The FLARE code is simple and inexpensive to run on a routine basis and is flexible enough to handle the variety of control rod and refueling management s'chemes considered for use in present power reactors. FLARE calculations of axially-integrated assemblywise exposure distribution at end of Yankee Core I life (8,470 MW/MUU average exposure) compare very favorably with experimental distributions inferred from flux wire, isotopic composition, and Csl37 measurements. The differences between calculation and measurements are of the same order of magnitude as the differences among the measurements.

The available computer codes used for fuel depletion and heavy-isotope buildup are described in Section III and Appendix A. The experimental accuracies in exposure and isotopic-composition measurements are discussed in Appendix $C$ and are summarized in subsequent subsections $A$ and $B$.

Prediction accuracies can best be estimated for the pressurized-water and boiling-water reactors which are predominant in current commercial power production and for which significant experimental and operational data are available. Nearly the same accuracy of predictions as subsequently indicated for the water reactors should be obtainable for those other reactor types having thermal or near-thermal neutron spectra; however, no pertinent experimental data are as yet available to conclusively assure that this will definitely be the case. In addition, fast reactors pose unique problems with respect to nuclear loss and production processes so that the estimations of prediction accuracies presented herein are not representative of this reactor type.

Plant measurements of total power output are estimated to have accuracies of $\pm 1.5 \%$ to $\pm 3 \%$ with accuracies close to $\pm 1.5 \%$ being more usual. The accuracy of determining average exposure of a batch of fuel assemblies relative to average core exposure depends on the size of the batch. For about 20 fuel assemblies discharged from a large power reactor at any one time, this error is estimated to be less than about $\pm 5 \%$; with greater than 100 or so fuel assemblies discharged, the error is less than about $+2 \%$. Statistical combination of the uncertainties (using an accuracy of $\pm 1.8 \%$ in total power output) leads to an overall uncertainty (one standard deviation) in absolute average exposure value of a discharge batch of $\pm 2.7 \%$ for a large batch ( 2100 fuel assemblies) and of $\pm 5.3 \%$ for a small batch ( $\sim 20$ fuel assemblies). The corresponding errors in isotopic composition depend on the conversion ratio and total exposure. For conversion ratios in the range of those for Dresden and Yankee (which represents the usual range in present-day water reactors), the uncertainties in isotopic composition corresponding to the estimated uncertainties in batch exposure are given in Table $I$.

Uncertainties in the computed conversion ratio lead to about $\pm 5 \%$ uncertainty in total plutonium content; the corresponding uncertainty in U235 depletion is about $\pm 1.4 \%$. When the uncertainties in the $\mathrm{Pu}$ isotope effective cross sections are included, the overall uncertainties for constant exposure are increased to about $\pm 7 \%$ for total Pu content and about $\pm 2 \%$ for U235 depletion.

Statistical combination of the uncertainties associated with the exposure level of the discharge batch with the uncertainties associated with the conversion ratio and isotopic effective cross sections at constant exposure gives an estimate of the overall uncertainties involved. These overall uncertainties (one standard deviation) are tabulated in Table II.

The uncertainty values tabulated in Table II are reasonably consistent, in order of magnitude, with the standard-deviation values arrived at from calculated and measured isotopic compositions of fuel samples taken from a number of operating power reactors. These results are based on experience with the more 


\section{TABLE I}

ESTIMATED UNCERTAINTIES IN ISOTOPIC COMPOSITION DUE TO UNCERTAINTIES IN EVALUATION OF. BATCH EXPOSURE.

\begin{tabular}{l|c|c|c|c} 
& \multicolumn{4}{|c}{ UNCERTAINTY IN } \\
\cline { 2 - 5 } & U-235 DEPLETION & \multicolumn{2}{|c}{ TOTAL PU CONTENT } \\
\cline { 2 - 5 } & \multicolumn{2}{|c|}{ MWD/MTU } & \multicolumn{2}{|c}{ MWD/MTU } \\
\cline { 2 - 5 } & 10,000 & 20,000 & 10,000 & 20,000 \\
\hline $\begin{array}{l}\text { LARGE BATCH } \\
\text { ( } 100 \text { ASSEMBLIES) }\end{array}$ & $2.4 \%$ & $2.0 \%$ & $1.8 \%$ & $1.0 \%$ \\
\hline $\begin{array}{l}\text { SMALL BATCH } \\
\text { ( 20 ASSEMBLIES) }\end{array}$ & $4.6 \%$ & $3.9 \%$ & $3.5 \%$ & $1.9 \%$
\end{tabular}

TABLE II

ESTIMATED OVERALL UNCERTAINTIES IN PREDICTED ISOTOPIC COMPOSITIONS

\begin{tabular}{l|c|c|c|c} 
& \multicolumn{4}{|c}{ TOTAL UNCERTAINTY IN } \\
\cline { 2 - 5 } & U-235 DEPLETION & \multicolumn{2}{c}{ TOTAL Pu CONTENT } \\
\cline { 2 - 5 } & \multicolumn{2}{|c|}{ MWD/MTU } & \multicolumn{2}{|c}{ MWD/MTU } \\
\cline { 2 - 5 } & 10,000 & 20,000 & 10,000 & 20,000 \\
\hline LARGE BATCH & & & & \\
( $\geqslant 100$ ASSEMBLIES) & $3.2 \%$ & $2.8 \%$ & $7.3 \%$ & $7.1 \%$ \\
\hline $\begin{array}{l}\text { SMALL BATCH } \\
\text { ( 20 ASSEMBLIES) }\end{array}$ & $5.0 \%$ & $4.4 \%$ & $7.9 \%$ & $7.3 \%$
\end{tabular}


prominent water reactors; as previously discussed, they should nearly apply to the other reactor types that have near-thermal neutron spectra. The estimated individual prediction accuracies are discussed in more detail in subsection $C$.

The total-core isotopic inventories for spent Core I of Yankee were experimentally inferred by Westinghouse Electric Corporation from the results of isotopic composition measurements of a large number of fuel samples taken from the core (References 1 and 2). The average fuel exposure of the depleted core was $8,470 \mathrm{MWD} / \mathrm{MIU}$. Westinghouse compared the results inferred from the measurements with the results of calculations performed according to the Yankee design methods (R-Z TURBO calculation). The agreement in U235 depletion is within 3.5\% and in total $\mathrm{Pu}$ content within 2.1\%. Hence, the agreement obtained for the total Pu content is much better than expected on the basis of the foregoing uncertainty estimates whereas the agreement obtained in the U235 depletion is approximately as indicated by the estimates.

Estimates have been made by General Atomics of the accuracy of eventual prediction of heavy-isotope content in the Peach Bottom reactor core which is moderated by graphite and fueled with thorium containing fully-enriched U235. In arriving at the estimates, General Atomics assumed that the best available calculational methods are used and that sufficient data on reactivity behavior during core life are obtained to enable checking and appropriate revision of the calculations, notably of the thorium cross sections and nuclear parameters used. On these bases, General Atomics expects that eventual predictions of total core content at end of core life will be in error by about $\pm 4 \%$ for U233, $\pm 5 \%$ for $\mathrm{U} 235$ and $\pm 4 \%$ for total fissile uranium.

\section{A. Experimental Errors in Isotopic Composition Measurements}

Isotopic composition measurements consist of the determination of individual thorium and uranium isotopes in thoria fuels, and the determination of uranium and plutonium isotopes in urania fuels. Most of the experience in the past has been with uranium fuels, but the methods developed are equally applicable for thorium base fuels. Currently used techniques involve isotope dilution mass spectrometry. The accuracy of this method depends upon the spiking isotope calibration, on the mass spectrometric measurement, and on the abundance of the isotope. Measurements performed at various laboratories (Reference 2) indicate that an overall accuracy of $\pm 4 \%$ or less (two standard deviation) can be obtained for any fuel isotope with appreciable concentration. This accuracy value is that appropriate to the analysis of a single fuel sample whether the sample represents a dissolved batch of fuel assemblies at a chemical plant or a single fuel pellet in a laboratory. While no data are known for thorium fuels, it is believed that, after initial development, measurement accuracies comparable to that of urania fuels can be achieved.

\section{B. Experimental Errors in Burnup Determination}

Among the various methods used for burnup determination, the measurement of a selected fission product isotope as burnup indicator is the least expensive and most accurate technique. The highest accuracy has been indicated for the mass spectrometric determination of Neodymium 148. Using this technique, burnups are reported to have an accuracy of $\pm 2 \%$. Probably the most widely used method is the radiochemical determination of Cesium 137. Cesium analysis has the advantage that it does not require a mass spectrometer, but it is not as accurate as the NdI 48 method since part of the Cesium is in gaseous form in the fuel so that it migrates. Uncertainties of $\pm 6 \%$ have been reported for measurements of this type. 
All accuracies quoted are given for a single sample. If this sample represents a dissolved fuel assembly or group of fuel assemblies, the result is indicative for the entire unit. However, when individually dissolved pellets are analyzed, and assembly average or core average values are inferred from the measured data, analytically calculated weighting factors have to be used. Usually the uncertainty of the weighting factors is the limiting factor. Assuming $10 \%$ uncertainty in the single sample weighting factors and 5\% uncertainty in the assembly weighting factors, accuracies of $\pm 4 \%$ for a fuel assembly and $\pm 2 \%$ for a core can be obtained when 10 samples per assembly and 10 assemblies per core are analyzed.

\section{Individual Prediction Accuracies}

The overall accuracies of predictions depend on the uncertainties encountered in several areas (Reference 3). The important areas are listed as follows:

(1) Core total thermal energy output

(2) Exposure of discharge batch relative to average exposure over total core

(3) Average conversion ratio over discharge batch

(4) Average ratio of U238 fast fissions to total fissions over discharge batch

(5) Average ratio of U235 fissions to plutonium fissions over discharge batch

(6) Effective absorption to fission ratio of U235 averaged over discharge batch

(7) Energy release per fission

The errors involved in each of the foregoing areas must be statistically combined to obtain the overall uncertainty in the calculated uranium and plutonium content for the discharge batch. Because of the sparcity of experimental data presently available on heavy-isotope content of operating fuels, the individual errors assignable to the various areas listed above represent only estimates. Pertinent data on operating reactors are being accumulated so that more information will be obtained with time to permit refinements in the estimates of the errors involved. Of equal importance, the accumulation of more isotopic data of higher accuracy will give impetus to more extensive burnup analyses and thereby lead to better methods of calculation and more accurate predictions. The error estimates presented herein are based on the available information as of July 1965.

\section{(1) Determination of Core Total Thermal output}

The error estimates indicated in Appendix D are based on information supplied by the operators of the various U.S.A. commercial power reactors. The error in the determination of core total thermal output varies from $\pm 1.5 \%$ t.o $\pm 3.0 \%$. The most crucial plant measurement is that of the feedwater flow rate to the steam generators; an error in this quantity reflects directly as a nearly equal magnitude error in the reactor core power. Major emphasis has been directed by the reactor plant operators at this flow-measurement problem. It is especially important that no significant bias ( flow measurement device.

Except from heat balances, there is no practical way to check the accuracy of the core total power output during power operation. For reactor plants in which steam is not produced in the core for direct delivery to the turbine, the heat balance between the primary coolant system and the secondary (steam) system affords a means of checking the general accuracy of the core thermal power determination. Such heat balances are normal practice in steam plant operation. 
As part of the Yankee Core Evaluation Program, extensive isotopic and radiochemical analyses were performed of over 150 fuel samples selected from a large number of different regions of Yankee Core I. The pellet data were converted to regionwise data which, in turn, were integrated over the reactor core volume to obtain the total core burnup (References 1 and 2). These results provide the first opportunity of checking the usual calorimetric measurements of core total burnup. The values of average core burnup of Yankee Core I derived from the isotopic and radiochemical data are compared with the average core burnup measured calorimetrically, as follows:

Method

Plant Calorimetrics

Isotopic Analysis

Radiochemical Analysis (Cs137)
Ave. Core Burnup, MWD/MIU

$$
\begin{aligned}
& 8,470 \\
& 8,400 \\
& 8,440
\end{aligned}
$$

The three burnup values are in remarkable agreement, within 1\%. The plant calorimetric results have been estimated by the Yankee reactor operators to have an overall accuracy of better than $3 \%$.

(2) Exposure of Discharge Batch Relative to Average Total Core Exposure

The error involved in the determination of the relative exposure of the discharge batch depends on the number of assemblies in the batch and on the accuracies with which the assemblywise power distributions prevailing during core burnup can be calculated. Experimental data on assemblywise power and exposure distributions are meager. At Indian Point, measurements were made of the relative assembly power output just prior to the scheduled mid-life shutdown. The measured data are compared by Babcock and Wilcox with the results of calculations. The average value of the absolute value of differences between calculated and measured values, $|\bar{\Delta}|$, and the standard deviation of differences between calculated and measured values, $\sigma$, are:

$$
\begin{aligned}
|\bar{\Delta}| & =7.7 \% \\
\sigma & =8.7 \%
\end{aligned}
$$

The calculated relative power output of a single fuel assembly hence has a one standard deviation error of $\pm 8.7 \%$. For a large number of fuel assemblies in the discharge batch, the error of prediction for the batch as a whole is greatly reduced.

Flux wire data were continually taken during the burnup of Yankee Core I, so that relative assembly power outputs and accumulated exposures are available for comparison with calculations. Comparisons have been made by Westinghouse Electric Corporation of the measured data with the results of X-Y TURBO calculations for an axial slice of the core. The comparison results are tabulated as follows:

\begin{tabular}{crrr} 
Variable & MWD/MTU & $\underline{I \bar{\Delta} \mid, \%}$ & $\underline{\boldsymbol{\sigma}, \%}$ \\
\cline { 2 - 4 } Power & 1385 & 9.8 & 12.5 \\
" & 4133 & 5.0 & 5.9 \\
" & 5694 & 8.1 & 12.7 \\
" & 7034 & 10.7 & 12.4 \\
" & 7755 & 5.6 & 7.4 \\
Exposure & 7755 & 3.5 & 4.8
\end{tabular}


FLARE calculations have been made at CEND for comparison with the measured data for the axial slice. The comparison results are tabulated as follows:

\begin{tabular}{|c|c|c|c|}
\hline Variable & MWD/MLU & $|\bar{\Delta}|, \%$ & $\sigma, \%$ \\
\hline Power & 1385 & 6.3 & 8.3 \\
\hline 1 & 4133 & 4.3 & 5.3 \\
\hline$"$ & 5694 & 6.8 & 11.9 \\
\hline$"$ & 7034 & 8.9 & 11.0 \\
\hline$"$ & 7755 & 5.5 & 7.0 \\
\hline Exposure & 7755 & 3.5 & 4. \\
\hline
\end{tabular}

$\mathrm{X}-Y$ TURBO results on assemblywise exposure distributions are available at intermediate average exposure values. These results are compared with FLARE results obtained at corresponding average exposure values as follows:

\begin{tabular}{|c|c|c|c|}
\hline Variable & $\mathrm{MWD} / \mathrm{MIU}$ & $|\bar{\Delta}|, \%$ & $\sigma, \%$ \\
\hline Exposure & $\begin{array}{l}4133 \\
5694\end{array}$ & $\begin{array}{l}6.2 \\
4.6\end{array}$ & $\begin{array}{l}7.6 \\
5.4\end{array}$ \\
\hline
\end{tabular}

Experimental data are also available on axially-integrated assemblywise exposures at end of Yankee Core I life. Comparison of F'LARE results on assemblywise exposures with the average values derived from three different types of measurements gives:

$$
\begin{aligned}
& |\bar{\Delta}|=3.9 \% \\
& \sigma=4.7 \%
\end{aligned}
$$

Power distribution data have bcen obtained as part of the startup test programs on the Dresden, Humboldt Bay and RWE-Kahl reactors. These measurements were all at essentially zero exposure. In addition, power distribution measurements were made in RWE-Kahl several times during a period of operation in which about 4,000 MWD/MIU average core exposure was accumulated. The measured results have been compared with FLARE calculated results by General Electric; the comparison is summarized as follows:

\begin{tabular}{|c|c|c|c|}
\hline Reactor & Exposure Condition & $|\bar{\Delta}|, \%$ & $\sigma, \%$ \\
\hline Dresden & zero & 8.0 & 9.6 \\
\hline Humboldt & zero & 4.7 & 5.7 \\
\hline RWE & zero & 4.8 & 6.5 \\
\hline RWE & $\sim 2,000 \mathrm{MWD} / \mathrm{MIU}$ & 2.7 & 3.2 \\
\hline RWE & $\sim 4,000$ & 2.9 & 3.7 \\
\hline
\end{tabular}

Inasmuch as the FLARE nuclear code is a sufficiently simple code to use for fuel accounting purposes, it is of interest to compare the results of FLARE analyses to more exact analytical solutions. For this purpose, two-dimensional three-group detailed PDQ calculations were performed for a BONUS-boiler configuration with three different control rod patterns. FLARE handles three-dimensional problems with nearly the same ease as two-dimensional problems; however, performance of a three-dimensional analysis to nearly the same degree of detail obtainable with the two-dimensional PDQ is highly impractical. Hence, comparison of FLARE with more precise calculations must be carried out in the two-dimensional domain. The comparison results are summarized as follows: 
All rods out

Presence of a control rod in the BolvUS-boiler configuration results in a $35 \%$ loss in reactivity of adjacent fuel assemblies; hence, the BONUS calculations represent extremely severe cases with regard to the local changes in $k_{\infty}$ obtained. In general, fuel burnup effects will produce local variations of $k_{\infty}$ of less than $10 \%$, which are small compared to the control rod effects considered in the foregoing calculations.

The results of a similar comparison performed by General Electric for Big Rock Point gives:

$$
\begin{gathered}
|\bar{\Delta}|=7.7 \% \\
\sigma=10.0 \%
\end{gathered}
$$

The foregoing results indicate that the standard deviation, $\boldsymbol{\sigma}$, of the error in calculating assemblywise power distribution within an operating reactor core is about $10 \%$. Hence, the relative power output (and accumulated exposure) of a single fuel assembly can be calculated with a one standard deviation error of about $10 \%$. The error involved in calculating the average exposure of a batch of fuel assemblies depends on the size of the batch. If a statistical sample for a discharge batch of about 20 fuel assemblies from a large reactor is assumed, the calculated average exposure of the batch would have a one standard deviation error of $10 / \sqrt{20}= \pm 2.2 \%$. To allow for the fact that the discharged batch does not necessarily represent a statistical sample, the above calculated error is increased by an arbitrary factor of 2 , resulting in a probably more realistic estimate of the error of about $\pm 5 \%$. In a large power reactor, about 100 fuel assemblies or more may be discharged at a time; hence, the one standard deviation error, with the factor of 2 applied for deviation from a statistical sample, would be of the order of $\pm 2 \%$.

\section{(3) Uncertainties in Nuclear Parameters}

Measurements of average conversion ratio by the latest experimental techniques are subject to experimental exrors of the order of $3 \%$ to $4 \%$. A sufficiently large amount of data has not as yet been accumulated to permit confident estimate of the accuracies associated with calculation of conversion ratio. Present indications are that, with careful calculation, the average conversion ratio over a discharge batch can probably be determined to within $\pm 5 \%$.

Some experimental data have been obtained on the U238 to U235 fission ratio in individual isolated fuel rods containing no plutonium. Comparisons with the results of the usual calculational procedures used for water-moderated reactors indicate an uncertainty of prediction of about $\pm 10 \%$. It can be assumed that this same order of uncertainty applies in the calculation of the average ratio of U238 fast fissions to total fissions over the discharge batch.

The uncertainty in a calculated ratio of U235 fissions to plutonium fissions over a discharge batch can only be roughly estimated. An estimate for a batch of fuel assemblies discharged from Dresden in fuel cycle 1 has been made at General Electric (Reference 3). The estimated uncertainty (one standard deviation) amounts to $7.4 \%$ and is based on a statistical combination of the following assumed uncertainty values: 
$\pm 5 \%$ in ratio of $\mathrm{U} 235$ to $\mathrm{Pu} 239$ atom density

$\pm 2 \%$ in ratio of effective fission cross sections of U235 and Pu239 at $2200 \mathrm{~m} / \mathrm{sec}$.

$\pm 5 \%$ in ratio of effective cross sections

$\pm 1 \%$ for fissions in higher isotopes of Pu

other uncertainties involved with and in the use of the basic nuclear data are: $\pm 1 \%$ for the effective absorption to fission ratio for U235 and $\pm 2 \%$ for the energy of fission.

(4) Comparison of Calculated and Measured Isotopic Compositions

As further indication of the possible accuracies of predictions, comparisons are presented herein of calculated-versus-measured isotopic compositions in Shippingport, Vallecitos, Dresden and Yankee. The measurements and associated calculations were performed on individual fuel pellets of the reactor core. The comparison results are given in Figures 1 through 8 as plots of $\frac{\text { calculated-measured }}{\text { measured }} \times 100$ versus MWD/MIU exposure. The results reflect both the uncertainties in the individual measurements and in the calculations. The percentage difference between calculation and measurement fluctuate appreciable from fuel sample to fuel sample. At low exposures, the uncertainty in the measurement results is probably the important contributing factor for the fluctuations obtained.

Insufficient detail was available on the calculational results of Westinghouse on Yankee Core I; in particular, the relationship between U235 depletion and exposure is needed to obtain the calculated plutonium composition as a function of exposure. In view of the importance of the Westinghouse results as one piece of information for assessing the general order of accuracy of calculations and in view of the excellent agreement between the CEND and Westinghouse calculated results on $\mathrm{Pu} / \mathrm{U}$ mass ratio versus U235 depletion (Figure 59), the CEND-calculated relationship between U235 depletion and exposure was used for further interpretation of the Westinghouse-calculated results. Hence, these particular comparison results should be considered as tentative.

What is of importance for fuel accounting purposes is not the prediction of isotopic content in individual fuel pellets but rather the prediction for a batch of fuel assemblies which contains a large number of pellets. Hence, the individual differences between calculation and measurement indicated for the fuel pellets should be averaged to obtain the uncertainty of prediction corresponding to a batch of fuel assemblies. Of necessity it is assumed that the fuel pellets analyzed from any one reactor constitute a representative sample; hence, a simple averaging procedure is used with no weighting factors applied. The results of the averaging process are indicated in Figures 1 through 8.

The VBWR and Dresden data were obtained for relatively short exposures thereby involving low depletion of U235 and buildup of plutonium. As a result, the percentage uncertainties in the measurement results can be relatively large. The Shippingport data was obtained over a wide exposure range up to 16,000 MWD/MIU. Detailed and sophisticated calculations were performed in the analyses of these data. Hence, the one standard deviation values listed in the figures ( $5.3 \%$ and $6.3 \%$ for $\mathrm{U} 235$ depletion and total plutonium content, respectively) should be approximate indications of the accuracy of predictions presently attainable. Similar treatment of the available results of Westinghouse calculations in comparison with experimental data for Yankee Core I gives a standard deviation of $7.0 \%$ between measured and calculated total plutonium content. However, as previously discussed, much better prediction accuracy for total plutonium content was actually obtained by Westinghouse in their highly detailed 
evaluation of calculated and measured isotopic inventories of the spent total Yankee Core I. The CEND analyses of the Yankee Core I data represent a grossly simplified calculational approach; one standard deviation values of $8.2 \%$ and 9.0\% for U235 depletion and total piutonium buildup, respectively, are obtained for the foregoing treatment of the fuel-pellet data in comparison with calculational results. Another approach is to compare the calculational results at a given exposure value with the average of the measured data obtained at and in the neighborhood of the given exposure. This approach for comparing calculated and measured results averages out the fluctuations in the experimental data. On this basis, at 14,000 MWD/MTU, the CEND analyses of the Yankee Core I data results in an overprediction of U235 depletion by $2.5 \%$ and an underprediction of total plutonium buildup by less than $1 \%$; at 23,500 MWD/MTU, the U235 depletion is overpredicted by $5 \%$ and the plutonium buildup is underpredicted by $7 \%$. 


\section{DESCRIPTION OF BASIC CALCULATIONAL METHODS}

Numerous analytical techniques are available for describing the depletion and buildup of fuel isotopes in operating power reactors. The various techniques vary considerably with regard to complexity and cost of calculations required. The simplest calculation is only concerned with the fuel isotopic composition averaged over the reactor core volume as it varies during the irradiation exposure. For this purpose, the reactor core is effectively treated as a single point with average leakage properties and average absorptive and multiplicative nuclear parameters. The nuclear processes are analyzed using multigroup diffusion theory with the neutron spectra corresponding to an average spectra for the reactor core. For fuel accounting purposes, this approach is generally adequate when the entire core load of exposed fuel is discharged as a single batch. The most complicated calculations are concerned with the detailed spatial variations of the fuel isotopic composition during the irradiation exposure. A basic quantity of interest is the fuel isotopic composition averaged over a cross section of a fuel assembly. Three-dimensional multigroup calculations are used to determine the variations of this basic quantity, i.e., the assemblywise planar-averaged fuel isotopic composition, along the length of each fuel assembly constituting the reactor core. In conjunction with the gross three-dimensional treatment, two-dimensional calculations are used to obtain the fine structure variations in isotopic composition among the individual fuel rods of a fuel assembly. Such calculations require extensive machine computations and are extremely expensive and time consuming to perform. Hence, for general fuel accounting purposes, these detailed calculations are highly impractical to perform.

Various simplifications can be introduced to reduce the costs of the computations. The three-dimensional problem can be reduced to one involving a series of two- and one-dimensional calculations. Two-dimensional fuel-burnup calculations are performed for various axial zones of the reactor; each calculation gives the isotopic distribution, across the reactor core at the axial zone considered, as a function of average fuel exposure in the given axial zone. The results of the various two-dimensional calculations are then stitched together by means of a single one-dimensional calculation performed for each value of core average fuel exposure. This approach, referred to as a synthesis technique, which in this case utilizes a series of two- and one-dimensional calculations, results in loss of accuracy particularly with respect to defining the detailed axial variation of fuel exposure and isotopic composition along the lengths of the individual fuel assemblies. The foregoing synthesis technique reduces the required machine calculations to a more practical level; nevertheless, the machine computations are extensive and the procedures quite elaborate.

Further simplifications of the problem are possible. A simplification which is extremely effective towards reducing complexity of computations is cylindricization of the core cross section. Generally, the core layout, rod patterns, and fuel reloading scheme (e.g., out-in zonal refueling) are such as to permit cylindricization with consequent reduction of the calculations to a two- or onedimensional treatment. Because of the geometrical distortion introduced, the 
comparable locations of the individual fuel assemblies in the cylindricized core can not be identified for the purpose of determining fuel-assembly exposure and isotopic composition. However, the fuel assemblies can be grouped into batches and each batch approximately identified as an annular ring in the cylindricized core. Hence, the cylindricization approximation is most meaningful for fuel accounting purposes when "annular" batches of fuel assemblies are discharged at a time. Control rods must be treated either as discrete concentric annular shells or as equivalent distributed poisons.

With cylindricization of the reactor, various alternate approaches are possible depending on the additional approximations introduced. The cylindrical core can be directly analyzed by two-dimensional R-Z depletion calculations wherein the actual rod positions (say, through simulation with equivalent distributed poisons) are taken into account during the burnup (provided their withdrawal pattern reasonably well preserves azimuthal symmetry, which generally is the case). Another approach is to apply the synthesis technique but utilizing, instead, a one-dimensional burnup analysis for each chosen axial zone of the cylindricized reactor core. The foregoing simplifications to R-Z two-dimensional calculations or to synthesis by a series of one-dimensional calculations considerably reduce the complexity of the problem to the point where it is reasonably manageable of analysis.

The problem can be still further simplified to one purely in the onedimensional domain. Analysis is performed for the reactor cylindricized cross section with no detailed consideration of the variations in the axial direction. Partially-inserted control rods are accounted for by appropriate adjustment in the strength of the equivalent distributed poisons introduced in various annular rings of the core cross section to simulate the control rod absorption processes. This method has the important advantage of simplicity of analysis; however, its use to obtain meaningful results is dependent on whether reasonably appropriate axially-averaged nuclear constants can be developed.

The next order of simplification reduces the problem to a zero-dimensional one, i.e., to one where the reactor core is effectively treated as a single point.

The successive orders of approximation considered above reduce the problem from an actual three-dimensional to a final zero-dimensional problem. It is possible, however, to reduce complexity of treatment by considering fewer neutron energy groups while retaining the three-dimensional geometry. By use of only a single neutron energy group and a coarse mesh description of the three-dimensional geometry layout, the calculations are simple enough to be performed on a routine basis.

A description is presented herein of the various calculational techniques generally used to determine fuel depletion and heavy-isotope buildup in operating power reactors. Various nuclear codes are involved in the performance of these calculations and these are identified in Appendix A. The specific problem analyzed, the approach used, and the assumptions involved are discussed. The various reactor designers often use somewhat different codes to perform the same general type of calculation; these codes were, in many cases, independently developed for the designer's own use and so have different code names. Although differences exist between those codes which perform similar type calculations, the differences are generally on the details of the calculations rather than on the method of approach. Where possible and where considered important, these differences will be noted in Appendix A which is devoted to a straightforward description of the important aspects of each nuclear code of interest herein. 
The following sections describe the basic calculational approaches which have been used; the calculational approaches include: (I) zero-dimensional multigroup; (2) one-dimensional multigroup; (3) two-dimensional multigroup; (4) three-dimensional one-group; (5) three-dimensional multigroup; and (6) multigroup synthesis.

\section{A. Zero-Dimensional Analyses}

Zero-dimensional depletion calculations neglect the spatial effects of burnup; they consider the reactor as a single point. Since every power reactor built to date is heterogeneous in structure and since further non-uniformities arise from the depletion of fuel materials and burnable poisons as well as from the production of fertile and poison materials, the above assumption grossly oversimplifies the actual physical situation. The model is unable to treat accurately the neutron leakage out of the reactor core since, in addition to the size and composition of the core, the leakage depends strongly on the temporarily existing flux shape. While the energy distribution of the neutron spectrum can be approximated through the use of more than one neutron energy group and account can be taken of the time variation of the spectra by recalculating the few-group constants after each time step, the spatial variation of the spectrum has to be ignored. Assuming a flat flux distribution, some of the codes provide means to investigate the effects of regionwise refueling. However, to follow the depletion of an individual fuel assembly alone is impossible.

Zero-dimensional programs function in the following general way. A library of microscopic few-group cross sections, fission yields and self-shielding factors are read into the computer together with a description of the material concentrations existing in the core. Many of the basic constants are usually stored in the program library. The code first computes few-group macroscopic constants from the input data. It is assumed that all materials in the core, including control rods, are homogeneously mixed. The use of self-shielding factors are the only means to take care of the inhomogenities. Then the initial group fluxes are calculated and normalized to the given power level. Usually a buckling model is used to account for the neutron leakage; the buckling is kept constant during the calculations.

The multiplication factor ( $k_{\text {eff }}$ ) is next calculated. In straight lifetime studies the computed multiplication factor is stored and the program proceeds to the next time step (time steps to be used in calculations defined in input). Most of the codes provide an option for criticality search. In zero-dimensional codes either the control poison concentration or the neutron leakage (buckling) is adjusted and the multiplication factor is recalculated. This procedure is repeated within each time step until the multiplication factor attains its predetermined value (for example, 1.00 ) to within a given specified margin $( \pm \boldsymbol{\epsilon})$. The program then proceeds to the isotope-determination portion of the calculations within the time step.

The calculated flux levels and few group constants are assumed to be invariant for each time step. Solutions to the isotopic differential equations based on the constant flux assumption during the time step are programmed in the codes, and are used to obtain the isotopic compositions at the end of the time step. Following this determination, the calculational routine proceeds to the next time step. Many of the codes use an exact analytic solution for determination of the isotopic compositions; some of them take advantage of an approximate solution based on a finite difference approximation to the differential equations. The latter solution is somewhat simpler to obtain, and gives good results as long as the time steps are short. Usually, only solutions for given isotopes are available in the codes. Since most of the power reactors are fueled with slightly enriched uranium, most available depletion codes handle U235 and 
higher uranium isotopes and the plutonium isotopes. Some of the more recently developed codes do not fix the depletion chains; it is left to the user to select the depletion chains. This general treatment has a definite advantage of flexibility; however, in general it requires somewhat longer computing times.

Burnable poisons are often used in reactors to decrease the initial excess reactivity of the core without appreciably shortening core life. These poisons burn out during operation and, in a well-designed reactor, are present only in very small concentration at the end of core life. The time dependence of the poison concentration cannot be ignored. Most of the codes have provisions, that is time-dependent differential equations, available for the treatment of burmable poisons. These equations are solved in a similar manner to that of the isotopic equations. When burnable poisons are applied in high concentrations, it is important to follow the time variation of their effective poison effect through the use of concentration-dependent self-shielding factors which can be inputed into the calculation.

During the operation of a nuclear reactor, both stable and unstable fission products are formed in large numbers. In general, they all capture neutrons and therefore adversely affect the neutron economy of the reactor. A quantitative knowledge of the concentrations of the fission products during core life and a knowledge of the fission product cross sections for each energy group are needed in order to make a realistic prediction of reactor behavior.

Among the many fission products, Xel35 and $\mathrm{Sml} 49$ are produced with relatively large yields and have large absorptive cross sections. Present calculational techniques treat these isotopes individually and lump all other fission products into one or more fission product aggregates. The time variation of the concentration of these aggregates is then described by differential equations and equivalent cross sections are used for these lumped fission product poisons. Since the absorption of a neutron by a primary fission product results in a new nucleus, some of the techniques utilize the assumption that the nuclear properties of these secondary fission products on the average are similar to those of the primary fission products. That is, the fission product aggregate is non-saturating; its concentration continuously builds up in proportion to the production rate.

As more fission-yield and cross-section data become available, besides Xel35 and Sml49, other high cross section fission products like CdI13, Sml51, Eul55, Gd155, and Gdl57 deserve individual treatment. Some of the newer codes have provisions to handle many of the fission product isotopes individually.

At the end of each time step, the code prints out the multiplication factor, the group neutron fluxes, and the concentrations of the fuel isotopes, burnable poisons, fission product isotopes and fission product aggregates. There are other edit options; for example, reaction rates in each energy group, total uranium or plutonium concentration or plutonium to uranium ratio can be printed out if desired. The problem can be terminated at a given time or when multiplication factor is reduced to unity in a straight burnup calculation. If poison search is employed, the problem is often terminated when the reactor becomes sub-critical without poison.

In addition to the standard burnup calculations described above, many of the codes have options to perform additional calculations of interest. GAD and TONG have provisions to simultaneously follow burnup in each of several fuel regions. The flux levels are assumed to be the same in each of the regions, but the initial number densities can differ. It is also possible to change the isotopic composition after each time step to simulate refueling. This arrangement permits studying the effects of different fuel cycles. Some of the codes even provide a subroutine to evaluate fuel cycle costs. 
The burnup and buildup of the various fuel-materials and buildup of fission products as well as the new fuel introduced in a refueling process cause the energy spectrum of the neutron flux to vary during core life. Some of the codes permit the use of new sets of few group cross sections after selected time steps to account for the spectrum change. In TONG and IEOPARD, this is accomplished by automatic stopping of the depletion calculation and recalculating of the few group cross sections using the GAM-THERMOS and the MUFT-SOFOCATE models, respectively; the depletion calculations are then resumed with the new set of cross section data.

Although they have many limitations, the zero-dimensional depletion calculations have the great advantage of simplicity; they are inexpensive to run and are especially useful for relating isotopic composition to the accumulated fuel exposure (MWD/MTU) of a group of fuel assemblies.

\section{B. One-Dimensional Multigroup Analyses}

The basic problem in the use of one-dimensional depletion calculations is in the treatment of the three-dimensional reactor in terms of only a single dimension. It is obvious that gross simplifications have to be introduced. If the main interest is to investigate fuel depletion in zonal batches of fuel assemblies, the computations are best carried out in the radial dimension. In this case, axial variations in the power distribution are neglected; a transverse buckling is used to account for the neutron leakage from the core in the axial direction. The reactor core is cylindricized, the diameter of the equivalent core being usually determined on a volume basis. The cylindricized core cross section is then subdivided into circular radial regions and the fuel assemblies, moderator, coolant and other materials are homogenized within each region; hence, the one-dimension calculational model consists of concentric circular regions, each of uniform initial fuel composition.

To properly account for each individual fuel assembly in this model is not possible. The model is best suited for consideration of the reactor core as a whole or, at best, for consideration of zonal batches of fuel assemblies in the core. Where possible, the circular regions should be selected in a manner so that the major volume of each fuel assembly batch of interest falls into, at most, two regions. A simple volume average, or a weighted average, of the isotopic compositions determined for each region could then be used to estimate the batch isotopic concentration. More complications arise with control rod representation. Here the homogenized-poison treatment is possible wherein the control-rod poisons are distributed in each circular region according to the control-rod strength and depth of insertion in that region. Another possibility is to represent a set of control rods by equivalent control rings; most of the calculations performed use homogenized poisons. Obviously, the control rod locations and groupings used to control the reactor also affect the choice of regions used in the calculations. Difficulties are involved in determining the proper axially-averaged nuclear constants for use in the calculations, particularly for the boiling-water type reactor with its axially dependent steamvoid content.

When the gross axial flux pattern is of interest, one-dimensional calculations can be performed in the $z$-direction. In this case, the $x-y$ variation is neglected and the radial leakage is approximated by a transverse buckling. With appropriate axial zoning, control rod withdrawal patterns can be simulated with reasonable accuracy as long as major groups of control rods are withdrawn as banks. Often, combinations of radial and axial calculations are performed to make the most realistic use of the one-dimensional treatment. 
To calculate the flux distribution, the one-dimensional multigroup diffusion equation is solved in slab or cylindrical geometry (spherical geometry is also available). Each circular region or axial zone is divided into a large number of mesh points and a finite difference approximation to the diffusion equation is applied to each of the mesh points. A variety of boundary conditions are available to suit the user's purpose. Starting from an initial flux guess, the flux distribution is calculated by iterative techniques. Different codes may employ different techniques to accelerate the convergence of the spatial solution.

Spatial variations in the neutron spectrum can partially be taken into account by calculating and using different few-group constants in the various regions. Many of the codes have provisions to permit the use of different parameters for the same material in different regions. The nuclear code CNCR goes one step further; it provides means to calculate the spatial variations in neutron density due to coolant temperature variations. This is accomplished by inputing the total resonance escape probability and the U238 resonance escape probability as a function of coolant density in tabulated form. The variation of the coolant density with local enthalpy rise is also fed into the computer in terms of a polynomial fit. Since the enthalpy rise depends on the power distribution which in turn is related to the coolant density distribution, an additional iteration loop is involved.

There is a larger variety of criticality controls available than in the zero-dimensional case. The poison concentration search can be applied in the same manner as before; more flexibility of choice is possible in that the control poisons can be appropriately distributed in the various regions. Since the neutron leakage, at least in one-dimension, is approximated by a buckling model, a transverse buckling search is possible. Another possibility in the case of the axial calculation is to use poison boundary search. Here, the interface between poisoned and unpoisoned regions is changed until criticality is reached; this is closely equivalent to a control rod position search, assuming rods withdrawn as a bank. Lately, more and more reactor designs call for the use of soluble poison. CNCR has a provision to treat such poisons; their concentration is assumed to be proportional to the coolant density at each point in the core. This code also permits a rod equivalent poison search that compensates for the variation of the reactivity worth of control rods with varying neutron diffusion length in the core because of changes in coolant density.

Once the spatial flux and power distributions have been obtained, the second step in diffusion-depletion programs is to simulate reactor operation during a specified time interval. Using the power normalized flux from the spatial calculation, the differential equations describing the time behavior of the nuclide concentrations are solved for that time interval. The solution yields a new djstribution of nuclide concentrations in the reactor which are used in the generation of few-group macroscopic cross sections for the spatial calculations in the next time step. In the case of mesh point depletion, each small annulus between two mesh points is depleted according to the mean of the flux values at the mesh points. For regionwise depletion, the average flux is computed for each region and is used to calculate the new isotopic compositions in the region. Burnable poisons and fission products are handled in the same way as in zero-dimensional calculations. Their concentration is computed either for each mesh point or for each region.

\section{Two-Dimensional Multigroup Analyses}

In depletion calculations for fuel accounting purposes, it is desirable to obtain accurate estimates of the relative assemblywise power outputs as a function of time. As long as it can be reasonably assumed that the neutron flux is separable into an axial and a radial component, a two-dimensional $\mathrm{x}-\mathrm{y}$ power 
distribution calculation can be expected to yield reasonable estimates of the assemblywise power outputs. Unfortunately, disturbances in the overall flux shape, introduced mainly by the presence and movement of control rods, adversely affect the validity of assuming separability of the solution and thereby introduce uncertainties in the results obtained. The axially non-uniform steam-void content in boiling-water reactors introduce further complications, particularly with respect to defining appropriate axially-averaged nuclear constants for use in the $x-y$ calculations. Two-dimensional depletion calculations are, nevertheless, still very valuable and, in many cases, represent the most accurate and yet practical techniques which can be used. A two-dimensional $\mathrm{x}-\mathrm{y}$ setup provides means for the individual representation of fuel assemblies and control rods, thus permitting fuel cycle calculations even in the case of scattered refueling. Where the main interest is in zonal batches of fuel assemblies, the twodimensional $\mathrm{R}-\mathrm{Z}$ representation is appropriate; in this case, the subregions are appropriately defined so as to give best representation of the zonal fuelassembly batches and of the control-rod groupings used.

The flux distribution is calculated in a similar manner as in the onedimensional case. An iterative technique is employed to obtain a numerical solution to the two-dimensional neutron diffusion equations. Solutions in either of three geometries ( $X-Y, R-Z$ and $R-\theta$ ) are usually available. Two-dimensional depletion calculations are expensive; they run in the order of two-thirds of an hour per time step on the fastest available computers. Inasmuch as the most time consuming part of the computations is the power distribution calculation, it is important to take advantage of symmetry conditions; in most cases, a half- or a quarter-core calculation will suffice.

When depletion of individual fuel rods is of interest, in addition to the depletion calculation performed for the entire core, an independent twodimensional calculation of a single fuel assembly (with associated water channel with or without adjacent control rod) can be made. This calculation would give, for example, exposure received by a fuel rod near a water channel or control rod relative to that received by a fuel rod in the middle of a fuel assembly.

Because of the complexity of the two-dimensional calculations, most codes limit the number of neutron energy groups to four or five. ASSAULT is probably the only current two-dimensional code that permits the use of fifty energy groups. HARMONY provides for two thermal energy groups. By approximating the thermal neutron spectrum at each point as a linear combination of an overlapping hard and soft spectrum, the spatial dependence of the thermal spectrum can be described.

The costly power distribution calculations limit the usefulness of criticality search. In fuel-accounting calculations performed during and following reactor operation, the actual control rod positions recorded during operation are simulated and the multiplication factor is computed only to verify the accuracy of the calculations. A region-dependent poison search is usually available in both $\mathrm{X}-\mathrm{Y}$ and $\mathrm{R}-\mathrm{Z}$ geometries. In $\mathrm{X}-\mathrm{Y}$ geometry, the poison concentration of the controlling rods can be changed to attain criticality. In $\mathrm{R}-\mathrm{Z}$ studies, the criticality search is equivalent to a control rod position search with some restrictions since the control rods cannot be represented explicitly in the cylindricized geometry.

The isotopic number densities are calculated in a similar fashion as in the one-dimensional case. To reduce expense, relatively large time steps are usually chosen. The accuracy of the calculations is improved if the time interval between successive power distribution calculations is further divided into subintervals. At the end of each subinterval, the group fluxes are renormalized to the given power level, but the flux shape is assumed to be constant during the 
time interval. Further improvements can be realized by dividing the subintervals into even smaller units. At the end of each of these smallex subintervals, the cross section data can be altered to account for the concentration dependence of the effective cross sections. Some codes even permit the use of different time, intervals at different locations in the core. In most of the codes, compositions can be replaced at any time during the depletion calculation to investigate the effect of fuel rearrangement.

\section{Three-Dimensional One-Group Analyses}

By means of the nuclear code FLARE it is possible to treat the burnup problem in three dimensional, $x-y-z$, core geometry according to a one-group diffusion-theory formulation. The present version of FLARE handles a maximum array of $14 \times 14 \times 12$ nodes in full-core, half-core, or quarter-core representation. In the use of FLARE, the core is divided axially into up to 12 axial zones with nodal points in each of the planes that are centrally located in the axial zones. In each plane, a nodal point is generally placed at the center of each fuel element (in either the full core, half core, or quarter core, depending on the prevailing symmetry conditions). It is evident that the nodal representation of the three-dimensional core is quite coarse; however, a fast inexpensive calculational tool is achieved for calculating power and burnup distributions.

With the one-group diffusion-theory model used in the FLARE calculations, only the parameters $k_{\infty}$ and $\mathrm{M}^{2}$ are involved, where $\mathrm{k}_{\infty}$ is the infinite multiplication factor and $\mathrm{M}^{2}$ is the migration area. An additional simplification involves the replacement of the reflector by an albedo, $\alpha$, at the core surface so that only mesh points within the active fuel region are actively considered in the calculations. Several options are available on the type of transport kernel to be used in the calculations, where the transport kernel represents the probability that a neutron born at a given node is absorbed in the various nodes used for the core representation. For each transport kernel formulation, variations can be introduced in the transport kemel through specification of the mixing parameter $g$, where $0 \leq g \leq 1$. Generally, the type of transport kernel and the values of $\mathrm{g}$ and $\alpha$ are chosen to give best agreement with available experimental data or with the results of more detailed and precise calculations. For this purpose, the more precise calculations are generally performed for zero exposure in twodimensional geometry (with, possibly, several important control-rod patterns). The reason for this is that the more precise three-dimensional multigroup calculations require considerable effort and an exorbitant expenditure of computer time so that it is not practical to utilize them for FLARE parameter-fitting purposes. It should be noted that FIARE can also handle two-dimensional geometry problems.

The complete FLARE calculation, which is iterative in nature, presently consists of essentially three levels of iteration; namely, (1) source or power iteration, (2) void iteration for the case of the boiling-water reactor, and (3) fuel burnup iteration. In the void calculation, the average steam quality at each node is based on the inlet water velocity, inlet enthalpy, and the power distribution integrated from the bottom of the fuel assembly to the given node. The voids are then calculated by a numerical fit to a void-quality correlation curve.

Fuel burnup is calculated at the end of each time (or exposure) step to correspond to the control-rod program (as specified in the FLARE input for each time step). The effects of loss of reactivity resulting from fuel burnup are included in the calculations by a simple fit of $\mathrm{k}_{\infty}$ to exposure, exposureweighted voids, and exposure-weighted local control. The data from which these fits are generated must come from separate calculations which relate $k_{\infty}$ to fuel exposure in MWD/MIU for the various important neutron-spectrum conditions. From 
these independent calculations, the isotopic composition is also related to fuel. exposure for the pertinent neutron-spectrum conditions; hence, once the exposure at a given node is calculated' with F'ARE the isotopic content at that node is also knôwn. FLARE can hardle cores containing up to 13 different types of fuel assemblies each with its own unique nuclear characteristics ( $k_{\infty}$ and $M^{2}$ and their particular variations with burnup, void, etc.). FLARE permits refueling and fuel switching at any of the specified time steps.

The FLARE output includes the assemblywise power output and exposure at the end of each time step. As previously indicated, the assemblywise isotopic content is obtained from the results of independent calculations to correspond to the assemblywise accumulated exposure.

It is evident that severe approximations are inherent in the calculational model for the FLARE code. For this reason, FLARE provides for the use of adjustable parameters which are chosen to give best fit to experimental data or to the results of more precise calculations. Normally, this is accomplished at beginning-of-life (zero exposure) conditions; the adjustable parameters thus chosen are then used throughout the burnup.

\section{E. Three-Dimensional Multigroup Analyses}

The accurate design of a reactor basically demands a calculational model which has the capability to treat the reactor three-dimensionally and to predict in any stage in life the critical control-rod configuration and the detailed three-dimensional flux distribution. A direct approach to this problem involves: (a) finding a solution to the three-dimensional multigroup neutron diffusion equation at the beginning of a time step through an iteration technique; and (b) depleting the fuel while assuming constant power (or flux) distribution during the time step. At the end of the time step, the power distribution is recalculated by the same technique so as to obtain the initial conditions for the next time step and the process is repeated until the end of core life.

One of the first three-dimensional depletion codes, DRACO (Reference 4), developed at Bettis Laboratory, employed this direct approach. DRACO is essentially a three-dimensional version of TURBO; it handles two or four neutron energy groups. A modified version of the time independent program TKO-I (Reference 5) provides the solution to the neutron diffusion equations; an iterative method is used to obtain a flux value at each interior point of the mesh. The maximum number of mesh points is limited to 4750 . It was found that the limited number of mesh points did not provide a good representation of the heterogenities of the core; at the same time, the three-dimensional iterations at every time step required appreciable amounts of computer time. Consequently, the program has not been used often.

A revision of DRACO, called TNT-1 (Reference 6), allows depletion of up to about 100,000 mesh points. However, this amount of detail has not been used in any calculations because of the large expense in computing time. A power distribution problem of 50,000 mesh points has been found to require almost a full day of computation on the Philco-2000. When time dependence is added, as in depletion studies, the situation becomes much worse. To reduce expenses, it has been proposed that the determination of the three-dimensional nuclear characteristics of reactors as a function of time be accomplished by combining one- and two-dimensional calculations. These methods, known as synthesis techniques, are discussed in the next section. 


\section{F. Multigroup Synthesis}

Synthesis methods permit the construction of approximate solutions to the three-dimensional few-group neutron diffusion equations using only the solutions of one- and two-dimensional problems. Since two-dimensional solutions require much shorter computing times than three-dimensional calculations, the result is a sharp reduction in costs; this permits an increase in the details of the calculations through the use of a larger number of total effective mesh points.

Some of the synthesis techniques use the assumption that the neutron distribution is spatially separable, or nearly so. One of the most commonly used techniques of this type is the TURBO-ZIP system which synthesize a threedimensional solution from a series of two-dimensional solutions and a onedimensional axial solution. Other methods based on the same assumption may synthesize radial and axial solutions into a two-dimensional $R-Z$ solution. However, all these methods share the disadvantage that there are discontinuities at the interfaces between separate axial zones, and also they are not suited to perform partial refueling studies. For highly heterogeneous reactors, the assumption that the neutron distribution in a reactor is separable does not apply; consequently, this method is not expected to yield good results.

Advanced synthesis techniques do not assume separability. Instead, they try to find a set of axial functions, which if combined with a preselected set of radial or $\mathrm{x}-\mathrm{y}$ solutions, give the sought three-dimensional results. The radial solutions usually represent asymptotic cases (like unrodded and full-rodded cases) from which it appears reasonable to attempt to construct a solution for each intermediate case. There have been many different techniques proposed to determine the axial functions (Reference 7). Some techniques only aid in the selection of a set of axial functions, which together with the radial functions satisfy the three-dimensional neutron diffusion equation, while others also guarantee that the constructed solution is optimal in some sense. For example, a given set of radial functions may lead to that solution which gives the smallest possible mean square error relative to the exact solution. It is clear that in order to obtain good results one must make a good choice of trial functions. Serious numerical difficulties may arise if the set of trial functions is close to being linearly dependent. Unfortunately, as of today, there is no way to estimate the magnitude of the error relative to the exact solution.

Two depletion calculational methods, based on synthesis techniques, are discussed in the following. One of them, the TURBO-ZIP model, employs conventional synthesis while the other, TNTO2, is based on the advanced synthesis method. Both are typical of their class, and TNTO2 is perhaps the only available code of its type today.

\section{TURBO-ZIP System}

The TURBO-ZIP depletion calculational method (References 8 and 9) is based on the assumption that the solution to the neutron diffusion equation can be approximated by the product of a simple axial function and several two-dimensional radial shapes (Reference 10). The reactor core is divided into a number of axial zones, and these zones are individually depleted throughout life using the $\mathrm{x}-\mathrm{y}$ option of the TURBO code. Then by means of flux weighting, average diffusionequation coefficients are calculated from the TURBO results for each axial zone. In contrast to the TURBO program, specific isotopic densities are not directly included in the ZIP calculations; instead, the TURBO data on isotopic densities and average nuclear parameters for each axial zone are related to its fuel fraction, i.e., the relative amount of fuel remaining in the slice. The TURBO data is then supplied as input to the ZIP calculations either in the form of (1) polynomials, usually least square fitted, relating the flux-weighted average 
diffusion-equation coefficients to the average fuel fraction for the axial zone, or preferably, (2) data directly from TURBO, which the ZIP program uses to set up an interpolation table. The latter feature is available in the ZIP-03 program. In addition, the control rod withdrawal sequence is provided to ZIP.

After the diffusion-equation coefficients have been prepared for each axial point in ZIP, a critical rod position search is made. The calculated power distribution thus obtained is then assumed to be constant for a time interval, and each axial point in the ZIP layout is depleted accordingly. Two chains of fission products (usually the xenon and samarium chain) can be treated explicitly. The above cycle is repeated until the end of core life is reached. The threedimensional flux and power distributions are then constructed by combining the appropriate $\mathrm{x}-\mathrm{y}$ and $\mathrm{z}$ solutions.

One of the most severe problems associated with the use of the TURBO-ZIP system, and for that matter all conventional depletion synthesis systems, is that of the xenon treatment. If xenon is included in the $x-y$ solutions, the TURBO data then depend on the power level assumed in the TURBO solution. On the other hand, if the xenon effect is suppressed from the radial solution, then the radial bucklings derived from TURBO are inappropriate for the ZIP description with xenon. Usually, xenon is included in the axial solutions, and artificial weighting factors are used to modify the macroscopic absorption cross section of xenon.

Predicted and experimental control rod group positions are compared throughout core life in Reference 1l. The flux wej.ghted synthesis technique was applied to a typical, highly enriched, pressurized water reactor. The agreement between the predicted and measured rod positions is very good; the discrepancy was always less than $5 \%$ of rod travel.

Measurcd flux distribulions in a seed-blanket slab reactor are compared to the predictions of calculations based on the flux-weighted synthesis technique in Reference 12. The agreement is good; the difference between the calculated and experimental thermal flux peak-to-average ratios is within $3 \%$.

\section{TNTO2 System}

The TNTO2 depletion calculations (Reference 13) are based on the assumption that the three-dimensional flux is well approximated by a linear combination of two-dimensional radial components. In general, a spatial solution of the form

$$
\begin{aligned}
& \phi^{i}(x, y, z)=\sum_{k=1}^{n} z_{k}^{i}(z) H_{k}^{i}(x, y) \\
& \text { where } z_{k}^{i}=\text { mixing functions } \\
& { }_{H}^{i}=\text { trial functions } \\
& k=
\end{aligned}
$$$$
\text { i refers to the energy group }
$$

is assumed. The trial functions are chosen intuitively, such that an expression of the form (1) could be expected to be a good approximation to the true solution. 
The simplest trial functions consist of radial flux shapes from the various axial zones of the core. Both, intuitive reasoning and experiment, indicate that all asymptotic functions should be included. In doing depletion analyses, it is advantageous to consider using trial functions which reflect changes in neutron flux shapes due solely to depletion. Intermediate stages of depletion may be well approximated by using, as trial functions, flux shapes from early and late depletion stages of the core. Difficulty may arise if the trial functions are close to being linearly dependent.

The method of weighted residuals is used to determine the mixing functions. The assumed form of the solution is substituted into the three-dimensional equation; both sides are multiplied by a weighting function and integrated with respect to $\mathrm{x}$ and $\mathrm{y}$. The result is a set of ordinary differential equations that can be solved by standard techniques for the mixing functions, $\mathrm{Z}_{\mathrm{k}}$. There is an option in the code to select one of two sets of weighting functions. The first option calculates the adjoints of the trial functions and employs them as weighting functions. This corresponds to a solution by variational method. The second approach follows Galerkin's technique and uses the trial functions as weighting functions. The second approach is simpler, but the first one should produce better results.

The depletion calculations performed in TNIO2 consist of solving thirteen time dependent equations. They include the uranium-plutonium chain, samarium and xenon, two fission product aggregates and a burnable poison. There is no provision made for the treatment of the thorium chain. Since potentially it could be very expensive to perform depletion calculations using the same mesh representation employed in the spatial solution, provision is made for depleting the materials inventory using a coarser mesh description. Fluxes averaged over three-dimensional blocks, each of which contain many mesh points, are used for the depletion calculations. There may be as many as 135,000 of these blocks. The flux distribution is available at as many as three million spatial points.

The accuracy of power distributions calculated by this method is demonstrated in Reference 14. Three-dimensional depletion calculations were performed at Bettis Laboratory for the Shippingport reactor using the TIT-I program. As a test of the method, the calculations were repeated using the synthesis approximation. Eigenvalues, power sharing between seed and blanket, and power distributions were compared; excellent agreement was obtained. A simplified model of the core with control rods represented as homogenized poison was chosen, because for this case an exact solution was available. In this case, the synthesized solution required one-third of the computer time used for the exact solution. However, the time required for the synthesis increases roughly linearly with the number of mesh points, whereas the time for an exact solution increases roughly as the square of the number of points. Consequently, the time advantage of the synthesis is greater for larger problems. Furthermore, with the synthesis methods it is possible to search for critical rod positions at essentially no additional cost, whereas it is very costly by the exact method. 


\section{UTILIZATION OF IN-CORE AND OUT-OF-CORE MEASUREMENTS}

The promising measurement techniques used in operating power reactors to obtain fuel assembly relative power outputs and, in some cases, also axial power distributions are discussed. The techniques utilize measurements of coolant enthalpy rise, of in-core neutron and gamma fluxes, and out-of-core gross gamma fluxes and gamma emissions of certain fission-product chains. In general, the experience with these techniques is rather limited since they have only recently been put into practice in operating power reactors.

As indicated in Section III, the problem of calculating the average fuel isotopic composition in the individual fuel assemblies of an operating power reactor is extremely complex. The complexity and time-consuming aspects of the problem arise from the necessity of obtaining the history of the three-dimensional spatial power distribution over the volume of the reactor core, taking into account the detailed geometry of the reactor lattice, control-rod patterns, etc. The amount of effort and computing time required is reduced by utilization of synthesis techniques, which use a combination of one- and two-dimensional calculations to represent the actual three-dimensional configurations; however, for the purpose of checking the isotopic content of individual discharged fuel assemblies, or groups of assemblies, even such techniques are too complicated so that, where possible, it is preferable to circumvent or minimize their use. This can be accomplished for fuel accounting purposes by using approximate but vastly simpler analytical approaches such as embodied in the nuclear code FLARE. An alternate approach is to utilize the results of in-core or out-of-core measurements which are interpretable in terms of the relative power output and relative energy-production of the individual fuel assemblies constituting the reactor core.

In Section VI, results are given of simplified calculations performed at Combustion Engineering, Inc. (CEND) of the U235 depletion and Pu isotopic buildup in Yankee Core I. These calculations were performed for a unit cell of the reactor core. The calculated results of isotopic concentration versus MWD/MIU fuel exposure agree reasonably well with the available experimental data; similar simplified approaches can be used for the various reactor types to relate average heavy-isotope content of a fuel assembly to the assembly integrated exposure. With this possibility as a premise, the problem of obtaining isotopic content reduces to one of determining the integrated exposure of the fuel assembly or group of assemblies under consideration.

\section{A. Coolant Enthalpy Rise Measurements in Individual Fuel Assemblies}

In several power reactors, the fuel assemblies are housed in individual flow channels or process tubes which confine the coolant flow to the fuel assembly. Measurements are taken during power operation of the coolant flow through each assembly and of the coolant-inlet and individual coolant-outlet temperatures. Hence, the measurement results directly give the individual assembly power outputs and integrated exposures. Three power reactors in which such individual fuel-assembly measurements are possible and are continually being performed are the Carolinas-Virginia, Hallam and Piqua. The accuracy with which the individual 
exposure values can be determined depends on the individual measurement accuracies and on the relative magnitude and accuracy of estimation of the net heat losses from the coolant (including the power directly deposited into the moderator by gamma and neutron radiation). With all or a sufficient number of representative channels monitored, the individual channel outputs can be normalized to the measured total power output, which value can be determined with much greater accuracy.

In the Carolinas-Virginia reactor (CVTR), the reactor core is comprised of a lattice array of U-tubes, each of which contains two fuel assemblies (one in each leg of a U-tube). The channel measurements give the U-tube power rather than the individual fuel-assembly power; in this case, the results of PDQ calculations are used to separate the measured U-tube power into its two components appropriate to each assembly in the U-tube. The procedures utilizing the individual channel measurements in CVTR are further discussed in Appendix B.

In the Hallam reactor, each fuel assembly is enclosed within a process tube and measurements are taken of coolant-inlet and -outlet temperatures and of the settings of the individual fuel channel orifices, which are adjustable under power operation. The channel coolant flow is calibrated versus channel orifice setting as a function of the reactor total coolant flow, which is separately measured. From records of these continual measurements, the relative energy output of each fuel channel is obtained; from the measurements of the history of reactor total power output, the individual fuel assembly burnups (MWD/MIU) are found. The overall accuracy is crucially dependent on the accuracy of the orifice-position indication and of the orifice flow calibration curves. The average coolant temperature rise across the Hallam reactor core is $4500 \mathrm{~F}$ so that errors of as much as $\pm 5^{\circ} \mathrm{F}$ in the individual channel coolant temperature measurements result in only $1 \%$ uncertainty. The main discrepancy is introduced through the flow measurements. It is estimated that the measured relative power factors are good to $\pm 10 \%$. Appendix $B$ further describes the procedures used to determine individual fuel assembly burnups in the Hallam reactor.

In the Piqua reactor, each fuel assembly is contained in an annular stainless steel coolant duct of full core length which is provided with a flow orifice at its upper end. Temperatures are measured continually by thermocouples located in the outlet coolant stream of each fuel assembly. Individual relative fuelassembly powers are found by ratioing the individual flow-weighted coolanttemperature rises. For the Piqua reactor, the average coolant temperature rise across the core is only on the order of $46^{\circ} \mathrm{F}$. There is only a single thermocouple at the outlet of each fuel channel and the estimated accuracy of the individual temperature measurements is $\pm 4^{\circ} \mathrm{F}$. Hence, the uncertainty in the relative power factors associated with the temperature measurements is $\pm 9 \%$. The flow rate is determined on the basis of the channel orifice setting and is believed known to about $\pm 10 \%$. When statistically combined, the sum of the errors due to the individual temperature and flow-rate measurements amounts to $\pm 14 \%$. The heat loss to the moderator is relatively small so that the error introduced by uncertainties in the heat-loss estimation is negligible. The procedures for the Piqua reactor are further described in Appendix B.

\section{B. In-Core Flux-Wire and Ion-Chamber Measurements}

When a full-core-length boundary is not used to confine the flow through each fuel assembly, it is not possible to monitor the individual assembly powers through enthalpy-rise measurements. However, indirect indications of assemblywise power outputs are obtainable by use of in-core flux wires or miniature ion chambers. Preferably, the flux wires should run axially along the axis of each fuel assembly or each representative of symmetrically placed assemblies (symmetrical not only with respect to core position but also with respect to the 
control-rod patterns used throughout operation). More convenient and, possibly, more practical locations for installation of miniature ion chambers can be found by limiting the required flux indications to be representative of individual supracells rather than of individual fuel assemblies. A supracell could, for example, be defined as a $2 \times 2$ array of fuel assemblies which may or may not include a central cruciform control rod; in this case, ion chambers could be located at the four corners of the supracell. Such a supracell would generally be used as the basic unit of the reactor core when flux measurements are made with miniature ion chambers because of the space limitations on placement of the ion chambers within the reactor core.

If the flux mapping is sufficiently extensive, e.g., each representative of symmetrically disposed fuel assemblies contains at least one flux wire, the fluxwire activity readings are susceptible to interpretation in terms of relative assemblywise power output. Accurate interpretation requires establishment of the relationship between relative activity and relative average power density at the fuel-assembly cross section under consideration. This relationship can be obtained by performance of $\mathrm{X}-\mathrm{Y}$, $\mathrm{PDQ}$ or TURBO calculations for a relatively simple unit cell representation of the fuel assembly with its associated channel water (with and/or without a cruciform control rod or follower in the water channel). The calculations give the correction factors for converting the axial activity variations and relative integral activity readings of the flux wires into the fuel assembly axial power density variations and relative assemblywise power ratios. The capabilities of such an approach are amply demonstrated by results of this type of an analysis on Yankee Core I (Reference 15). As described in Appendix B, a similar approach is used in CVTR (Reference 16). This approach is simpler than the use of direct calculations alone and undoubtedly leads to better accuracy of overall results. Appendix $B$ gives more details on the Yankee in-core instrumentation system and procedures used to interpret the flux-wire readings in terms of relative assembly power outputs. Appendix $B$ also describes some fluxwire measurements performed as part of a study of long-term reactivity characteristics of fuels irradiated in the Vallecitos Boiling Water Reactor (Reference 17).

An in-core ion chamber system is provided in the Humboldt Bay reactor which makes it possible to monitor neutron flux at 24 discrete points in the core. These in-core readings are presently used to hand calculate the relative power of each fuel assembly in the core. The procedure basically involves interpolations between in-core locations to obtain fuel assembly-average neutron fluxes. It takes into account the various core variables which influence the flux distributions, including control rod position, steam voids, and reflector and leakage effects at the edge of the core. The relative power of each individual fuel assembly is then obtained from these fluxes. Another experimental technique employed at Humboldt Bay utilized in-core miniature ion chambers at the sides of the fuel assemblies to measure the fission product gamma fluxes. The results of the in-core gamma flux measurements were in good agreement with the results of the in-core neutron flux measurements. Further investigations are underway at Humboldt Bay on in-core monitoring systems; additional discussion is presented in Appendix B including the Dresden and Big Rock Point reactors.

\section{Out-of-Core Gamma-Flux Scanning Measurements}

For reactors in which no provisions have been made to perform in-core measurements, the only recourse is to employ out-of-core measurements. Promising experimental techniques, based on gamma activity measurements of various fission product chains, are under development (for example, Reference 18). If sufficiently developed, these techniques could be used in gamma scans of the individual fuel assemblies in out-of-core measurements. 
For measurement of the mid-life power distribution in the Indian Point Reactor, a technique has been developed by Babcock and Wilcox to measure the characteristic gamma-ray activities emitted by the 12.8 day Ba-La fission product chain (Reference 19). The fission product distribution was measured on 26 fuel elements to provide a complete mapping of an octant of the core and to obtain an indication of the degree of symmetry throughout the core. Because of the relatively short half-Iife of the fission products measured, the relative assembly activity is essentially proportional to the relative assembly power just prior to reactor shutdown. The experimentally-inferred relative power distributions (both assemblywise and axially along the length of the assemblies) agree well with analytically-derived distributions, thus providing a check on the accuracy of the measurements (Reference 20). Further details of the Babcock and Wilcox technique are described in Appendix B.

In the Yankee Core Evaluation Program, gross gamma scans of individual fuel assembilies (Reference 21) were made to determine the degree of correlation existing between relative gross gamma activity and relative burnup (as obtained from in-core data and calculations). Variations in cobalt content of the fuel rod clad introduced a variable activity source which is not correlated with burnup and, hence; which interfered with straightforward interpretation of the measurements. 'The relative gamma activity values generally agreed with the relative burnup values to within. $\pm 16 \%$. This accuracy of indication may be sufficiently adequate for checking purposes j.f other methods of determination are not possible or practical for convenient use. Some more detailed results obtained by Westinghouse are presented in Appendix B. 


\section{ASSEMBLYWISE POWER OUTPUTS AND FUEL EXPOSURES}

A variety of power reactors of various types have been in operation for a number of years, some of which have completed at least one refueling cycle. As a consequence, a fund of reactor operating data is being gradually accumulated to make possible comparisons between observed and predicted performances. Such comparisons provide the opportunity of checking the validity of the nuclear design methods used to calculate reactor nuclear characteristics. Of special interest herein are the measurements of assemblywise power distributions and, in a few cases, of exposure distributions made in several operating power reactors, notably, Yankee Core I, Indian Point, Dresden, Humboldt Bay and RWE-Kahl. For comparison with the measured results, calculations have been performed by the reactor designers; both calculated and measured results are presented herein to provide an indication of the reliability of the calculational techniques used. As part of the contract study, extensive calculations were also performed at CEND for Yankee Core I for which considerable data are available; the results of these calculations are included in the comparison with measurements.

In several cases where experimental data on power distributions are lacking, comparisons have been made for zero exposure between the results of the nuclear code FLARE, which is relatively simple and inexpensive to run, and the results of more precise and detailed PDQ calculations. The purpose is to provide additional evaluation of FTARE for fuel accounting purposes.

\section{A. Yarikee Core I Pressurized Water Reactor}

An extensive in-core instrumentation system was installed by Westinghouse in Yankee Core I to measure, in fairly complete detail, the power density and exposure distributions throughout life. The details of the experimental measurements made during Core I operation are described in Reference 15; the instrumentation system and data reduction techniques are briefly outlined in Appendix $B$. Analytical determinations were also made by Westinghouse and CEND for comparison with the measurement results to determine accuracy of predictions.

In the analytical studies, it was possible to use experimental power densities and control-rod configurations from the actual operating history of the reactor. The analyses were made for: (1) an axial slab of the core perpendicular to the axis of the reactor; and (2) the full reactor core. The axial slab is 14.2 inches thick and is centered 21.3 inches above the bottom of the active section of the core. The power output of the slab relative to the core total power output was obtained from the flux-wire data as a function of equivalent full power hour of reactor operation.

The analyses performed by Westinghouse were confined to the axial slab of the core (Reference 15). The primary analytical tool used by Westinghouse was the TURBO diffusion-theory depletion code which was run with two neutron groups in $\mathrm{X}-\mathrm{Y}$ geometry; the nuclear code, FLARE, which utilizes only a single neutron energy group, was run in $X-Y$ and $X-Y-Z$ geometries at CEND. By using a fine mesh description in one, quadrant of Yankee Core I (which possessed quarter-core symmetry), it 
was possible to represent the core quite accurately in the TURBO study. The control rods, water slots, core baffle and reflector were represented explicitly in the calculations. A coarse mesh description with nodal points placed only at the centers of the individual fuel assemblies was used in the FLARE studies.

The analytical and experimental power distributions for the axial zone are compared in Figures 9 through 13 at values of MWD/MIU ranging from 1385 to 7755 . The experimental uncertainties make it difficult to pinpoint the source of any discrepancies obtained between calculation and measurement. In particular, symmetrically located control rod groups were periodically interchanged during operation of Yankee Core I whereas in the TURBO and FLARE problems no interchanges were made. Also, the library of microscopic cross sections input to TURBO was not changed with burnup so that the neutron energy spectrum in the fast and thermal energy groups was assumed to be invariant.

The agreement between calculated and experimental values of relative assembly power outputs is generally good throughout the entire control rod withdrawal program. Some of the differences between the analytical and experimental values are attributable to scatter in the experimental data. Another source of discrepancies may be found in the difference in control rod interchange programs.

The burnup distributions in the axial zone at the end of $7755 \mathrm{MND} / \mathrm{MIU}$ average exposure are compared in Figure 14. For this comparison, the exposures of fuel assemblies located in symmetrical octant positions within the core quadrant are averaged to approximately account for the control rod interchanges which actually took place; this averaging was performed separately for the experimental and calculated results so that the exposure values listed for comparison are made as consistent as possible. The agreement between analytical and experimental assemblywise burnups is excellent for both methods of calculation; the maximum deviation is only $8.7 \%$ for the FLARE calculation and $11.5 \%$ for the TURBO calculation. The discrepancies are well within the range of interchange effects and estimated experimental error ( $5 \%$ to $10 \%$ ). The experimental burnups were found by a time integration of discrete power distribution measurements; this integration smooths out the data scatter in the power distributions. The good agreement obtained demonstrates the validity of both the TURBO and FLARE burnup results.

Figures 15 and 16 compare the TURBO and FTARE results on relative assemblywise exposures at several intermediate exposure values ( 4133 and $5694 \mathrm{MWD} / \mathrm{MIU}$ ). The agreement between the two analytical approaches is remarkably close.

Data are presented in Reference 2 on axially-integrated assemblywise exposure distribution at end of Yankee Core I life (corresponding to an average core exposure of $8,470 \mathrm{MWD} / \mathrm{MIU}$ ) as inferred from flux-wire measurements, isotopiccomposition measurements, and Cs137 measurements. For comparison with the experimental data, FTARE calculations of axially-integrated assemblywise exposures were performed at CEND by following the detailed control-rod programming used during reactor operation to end of core life. The comparison results are presented in Figures 17 and 18. It is evident that the differences between calculation and the average of the measurements are of the same order of magnitude as the differences between any individual measurement and the average of the three measurements. The maximum deviation between calculation and the average of the measurements is only 10.1\%. The standard deviation of the differences between the calculated values of assemblywise exposure and the average values obtained from the three different types of measurements is $4.7 \%$. The agreement obtained is as good as can be expected even with the most sophisticated types of calculations.

In Reference 21, comparisons are presented of the axial burnup distributions in several Yankee Core I fuel assemblies, as inferred from gross gamma activity measurements and from the flux-wire, isotopic, and Csl37 data. These axial 
distributions are reproduced in Figures 19,20 and 21 where, in addition, FLAREcalculated results are also shown for comparison. The calculated gross axial variations in exposure along the individual fuel assemblies agree with the experimental data to within the scatter of the data points obtained by the different types of measurements.

\section{B. Dresden, Humboldt Bay and RWE-Kahl Boiling Water Reactors}

Gamma probe measurements have been made by General Electric as part of the startup test programs on the Dresden, Humboldt Bay and RWE-Kahl boiling-water reactors (References 22 and 23). These measurements, which were performed at reactor shutdown, permit very detailed power distribution determinations which are not possible during reactor operation.

Comparisons made by General Electric between measured and calculated power distributions are shown in Figures 22 and 23 for the Dresden and Humboldt Bay Reactors, respectively, at essentially zero exposure conditions. The calculations were performed with the coarse mesh, three-dimensional, one-group nuclear code, FLARE. The data are tabulated in terms of the radial power distribution (axially integrated fuel assembly power outputs). The calculated results are in reasonably good agreement with the experimental values.

During the first $21 / 2$ years of power operation, the RWE-Kahl reactor was shut down three times; each time the individual fuel assemblies were gamma probed to obtain a measure of the core power distribution. For comparison purposes, calculations were performed by General Electric for each of the three: core exposure conditions utilizing FIARE. Figure 24 gives a comparison of calculated and measured fuel assembly relative power outputs. The agreement between calculated and experimental results remains good over the short range of fuel exposures investigated.

Some statistics on the comparisons between calculated and experimental data are given in the following table:

RWE-Kahi

\begin{tabular}{|c|c|c|c|c|c|}
\hline & Dresden & Humboldt & $\sim 0 \mathrm{MWD} / \mathrm{MTU}$ & $\sim 2,000 \mathrm{MWD} / \mathrm{MTU}$ & $\sim 4,000 \mathrm{MWD} / \mathrm{MTU}$ \\
\hline$|\bar{\Delta}|$ & 8.0 & 4.7 & 4.8 & 2.7 & 2.9 \\
\hline$\sigma$ & 9.6 & 5.7 & 6.5 & 3.2 & 3.7 \\
\hline
\end{tabular}

where $|\bar{\Delta}|$ is the average percentage value of the absolute difference between individual calculated and measured values, and $\sigma$ is the standard deviation (\%) of the differences between calculated and measured values.

The estimated standard deviation of the experimental data from Dresden and Humboldt is $7 \%$; hence, the standard deviation of the error between calculations and measurements is nearly the same as the standard deviation of the experimental measurements.

\section{Indian Point Pressurized Water Reactor}

Gamma scan tests were performed by Babcock and Wilcox on Core A of the Indian Point Reactor just prior to core mid-life (References 19, 20 and 24). 
The primary purpose was to measure the relative elementwise power outputs and the axial power-density variations just prior to scheduled removal of fixed shims. The gamma scan was performed by a technique which measured the distribution of the characteristic gamma rays of the barium-lanthanum fission product chain along the length of individual fuel elements.

In order to check the adequacy of the calculational methods in predicting power distributions (in particular, for subsequent reactor operation after removal of the fixed shims), calculations were performed by Babcock and Wilcox for comparison with the experimentally-derived power distributions (References 20 and 24). The calculational method used is basically of the synthesis type in that it combines the results of two-dimensional X-Y calculations by means of onedimensional axial calculations. The specific calculational approach is briefly outlined herein.

(1) The power distribution of interest was that prevailing at the end of the first 189 equivalent full-power days (EFPD) of operation. During this period of operation, a single group of control rods (referred to as the Group A rods) was withdrawn.

(2) The gross axial power shapes were first determined as a function of position of the Group A rods by means of a one-dimensional axial depletion calculation. The absorption of the Group A rods was simulated by introduction of a uniform poison smeared over the core cross sectional area for the axial extent of the Group A rods. The control rod motion, as a function of EFPD, was made to correspond to the reactor operating history. From the reactor power history and the gross axial power shapes thus generated, the total energy production occurring in any given axial zone (or slice) of the core is obtained for the operation during the first 189 equivalent fullpower days.

(3) Two characteristic radial (X-Y) power distributions were used for each axial zone, one for the case where the Group A rods penetrated the given axial zone and the other for the case where the Group A rods were out of the axial zone; the radial power distributions chosen were those measured for these two basic rod configurations at beginning of core life. The elementwise burnup accumulated in each axial zone during the first 189 EFPD of power operation was then determined by weighting each radial power distribution according to the zonal total energy production incurred with the corresponding basic rod configuration prevailing in the zone.

(4) A zero-dimensional depletion model was then used to determine isotopic concentrations as a function of fuel burnup. From these results, detailed isotopic concentrations were obtained for each axial-zone of each fuel element. Four-group diffusion constants were generated using the calculated isotopic concentrations and X-Y PDQ spatial calculations were run for each axial zone. The calculated radial power distributions were then normalized by the same factors required to bring into agreement the measured and calculated beginning-of-life power distributions.

(5) The foregoing procedure generated the following results:

(a) Gross axial power shape at the end of 189 EFPD of power operation. 
(b) Elementwise power output of each axial zone, às normalized to unity value for the axial zone.

Results (a) and (b) were simply combined to give the elementwise power output of each axial zone, as normalized to unity value for the entire core.

For comparison purposes, the experimental and calculated results have been presented by Babcock and Wilcox in two ways (Reference 24). First, the results are shown for a series of slices (or axial zones) through an octant of the core. Eighteen such slices were considered in the analysis so as to correspond to the eighteen measurement points along each fuel element. The results for typical axial slices No. 2, 7, 12 and 18 are reproduced in Figures 25 through 28, respectively. The second method of presentation is in the form of plots comparing calculated and measured power distributions as a function of distance from the bottom of the active fuel for an individual fuel element. Typical plots for fuel elements No. 21, 28, 57 and 62 are reproduced in Figures 29 through 32 , respectively. Figure 33 gives the average power output of each element normalized to the average of unity in the core. The greatest deviation between calculated and measured elementwise power output is $15.2 \%$. Some statistics on the comparisons between calculated and experimental data are as follows:

$$
\begin{aligned}
|\bar{\Delta}| & =7.7 \% \\
\sigma & =8.7 \%
\end{aligned}
$$

\section{Comparison of FLARE and PDQ Power Distributions}

A BONUS-Boiler configuration was chosen which consists of an $8 \times 8$ array of boiler assemblies with the four corner assemblies missing. Since PDQ handles only two-dimensional geometries, an average steam void content was used and the control rod configurations chosen were those amenable to two-dimensional analyses. The cases considered are: (1) all control rods out; (2) center control rod full in; and (3) center control rod and corner rod bank full in.

FLARE involves the use of adjustable parameters which are normally chosen to give best fit to the assemblywise power distributions at beginning-of-life conditions. The adjustable parameters thus chosen are used throughout the burnup, during which time various control rod configurations are encountered. Hence, in consideration of FLARE for following the burnup, it is also important to determine whether the initially chosen adjustable parameters give best, or nearly best, results for the various control rod configurations used during operation.

Three neutron groups (fast, epithermal, and thermal) were used to represent the neutron processes in the PDQ calculations. The individual fuel-rod lattice cells, water channels, water holes, and control regions were discretely represented. The control-rod absorptions were included by application of appropriate logarithmic boundary conditions for the epithermal and thermal fluxes at the control-rod surface. Hence, the PDQ calculations performed are quite detailed and give rod-by-rod power distributions in addition to the relative assembly power outputs.

The basic nuclear constants utilized in the one-group analysis of FLARE are the infinite multiplication constant, $\mathrm{k}_{\infty}$, and the migration area, $\mathrm{M}^{2}$. The value $\mathrm{M}^{2}$ is specified for each fuel type and can, if necessary, be inputed as a function of local void content. The value of $k_{\infty}$ can be specified for each axial node of each fuel assembly according to whether the axial portion of the fuel 
assembly is adjacent to control rods or not. The values of $k_{\infty}$ for input into FLARE were obtained by cell-type three-group PDQ calculations performed for an entire fuel assembly which included the adjacent water channels (fuel assembly cell was defined to the centerlines of the water channels which border the fuel assembly). The uncontrolled $k_{\infty}$ was obtained from a PDQ run for a fuel assembly cell with no adjacent control rods; the full-controlled $k_{\infty}$ was obtained for a fuel assembly cell with a cruciform control rod at one of its corners. The value of $\mathrm{M}^{2}$ is only slightly affected by the presence of control rods and so was obtained from the PDQ uncontrolled-cell calculation.

Once the constants $k_{\infty}$ and $M^{2}$ were obtained from the PDQ fuel-assembly cell calculations, a nodal network representing the chosen BONUS-Boiler array was selected for the FLARE calculations; each nodal point in the network was chosen to be at the center of a fuel assembly. A range of values of the adjustable parameters ( $\mathrm{g}$ and $\alpha$ ) was investigated for each control rod configuration. Running times for these problems were about $.02 \mathrm{hr} / \mathrm{problem}$.

The FLARE calculations indicate that, for each control-rod configuration, best fit is consistently obtained by use of $g=0$ and $\alpha=0.4,0.9$. The albedo $\alpha=0.4$ is applied to those peripheral fuel assemblies (i.e., bordering the reflector) lying along the flat side of the core, and $\alpha=0.9$ is applied to corner peripheral fuel assemblies. Comparisons of the assemblywise power outputs indicated by FLARE and PDQ are presented in Figures 34 through 36 for the three control-rod configurations. The percentage differences in assemblywise power outputs between FTARE and PDQ are also given.

For all control rods out, the maximum deviation between FLARE and PDQ assemblywise power outputs is only $7.6 \%$. The average absolute difference, $|\bar{\Delta}|$, is $3.0 \%$ and the standard deviation, $\sigma$, is $3.9 \%$. For the case of center rod in, the maximum deviation is $9.5 \%$ while $\mid \frac{1}{\Delta} /$ and $\sigma$ are $3.8 \%$ and $4.6 \%$, respectively. The poorest agreement between FLARE and PDQ is obtained for the case of center rod in with corner rod bank fully inserted. Here the power output for a fuel assembly near the reflector and alongside the inserted corner rod is extremely low (amounting to only 0.463 of the average value) so that the difference obtained between FLARE and PDQ values is magnified as a relatively large percentage deviation. In this case, the maximum deviation amounts to $32.1 \%$; the next largest difference is only $11.8 \%$. The values of $/ \bar{\Delta} /$ and $\sigma$ are $6.5 \%$ and $10.3 \%$, respectively.

The large percentage difference obtained for a fuel assembly whose output is very low due to proximity of control rods is not of itself significant. During the time that this condition prevails, the accumulated burnup of the fuel assembly will be relatively low. A much larger fraction of the burmup will instead be accumulated later on in life when the control rod is withdrawn for which the percentage deviation in the FLARE-derived power output is greatly reduced. Hence, the deviations in overall exposure values will be closer to those determined for control-rod-out than for control-rod-in conditions.

A comparison of FTARE and PDQ calculational results obtained by General Electric for a control rod pattern in Big Rock Point is presented in Figure 37 (Reference 25). The FLARE parameter values used are $g=0, \alpha=0.3,0.6$. It is not known whether this set of parameter values gives best fit to the PDQ results. The maximum deviation between FLARE and PDQ results occur for two corner assemblies, amounting to $28.4 \%$ and $24.4 \%$. The next largest deviation is $13.6 \%$ with the remaining deviations averaging well under $10 \%$. The average absolute difference for all assemblies is $7.7 \%$ and the standard deviation is $10 \%$. It should be noted that the power output in fuel assemblies adjacent to inserted control rods is not severely depressed as was the case in the BoNus boiler array. In BONUS, presence of a control rod results in a $35 \%$ loss in reactivity of 
adjacent fuel elements; the control rod effects in Big Rock Point are much smaller, as judged by the depression in power output of fuel assemblies located adjacent to the control rods.

It should be further pointed out that the BONUS calculations represent extremely severe cases with regard to the local changes in $\mathrm{k}_{\infty}$ obtained. In general, fuel burnup effects will produce local variations of $k_{\infty}$ of less than $10 \%$, which are small compared to the control rod effects herein considered. 


\section{CALCUIAATED AND MEASURED HEAVY-ISOTOPIC COMPOSITIONS IN OPERATING FUEL ELEMENTS}

Experimental data on heavy-isotopic compositions in operating power reactors are quite limited. The data obtained are for reactors which have been in operation for some time, such as the boiling-water and pressurized-water types. At present, the bulk of the data is generally limited to exposure values of less than about $16,000 \mathrm{MWD} / \mathrm{MIU}$ with some data points from Yankee extending into the 16,000 to 25,000 MWD/MIU range. Several measurement programs underway include the analysis of high burnup fuel samples (20,000 - 30,000 MWD/MTU).

The measurement of the isotopic content of irradiated fuels provides an excellent means of evaluating the analytical techniques used to predict reactor nuclear characteristics throughout fuel life. Basic work is being performed in this area, which includes: (I) development of reliable measurement techniques for making significant experimental measurements of fuel exposure and isotopic composition in order to obtain statistically accurate data; (2) more accurate and detailed measurements of the basic cross sections and resonance parameters of heavy isotopes and of the individually important fission product species; and (3) development of more sophisticated physical calculational models that permit representation of the reactor geometry in considerably more detail and that utilize the much more detailed and precise nuclear data. Considerable progress has been made during the past several years and efforts are continuing to obtain further improvements.

Heavy-isotope measurement programs are being carried out on the Shippingport, Yankee and Dresden reactors. Measurements have been conducted in the Vallecitos reactor. The available data and comparisons with calculated results are presented herein.

\section{A. Shippingport Pressurized Water Reactor}

Isotopic analyses were made of the fuel material in 30 individual fuel rods removed from the natural-uranium blanket region of the core at the end of the first and second seed lives (Reference 26). The isotopic analyses gave the average concentration in each fuel rod of the uranium and plutonium isotopes. Radiochemical separation and gamma spectrometry were used to determine the mass of the fission product Cesium-137 (used as the exposure indicator) present in each fuel rod. The exposure ranged from 2500 to $16,000 \mathrm{MWD} / \mathrm{MIJ}$.

The experimental results for each fuel rod were compared directly with the isotopic concentrations obtained by calculation. The calculational technique employed involves: (a) a three-dimensional, three-group diffusion-theory calculation of the gross flux variations over the core volume; (b) a two-dimensional three-group diffusion-theory calculation of the fine structure of the flux variations over the fuel assemblies; (c) a superposition of the gross and finestructure fluxes; and (d) a one-point depletion calculation utilizing the derived three-group fluxes and the best available isotopic constants and cross sections. The nuclear code TNT was used for the three-dimensional calculations, PDQ for 
the two-dimensional calculations and CINDER for the one-point depletion calculations. The calculational technique is a highly sophisticated one which provides for considerable detail both in geometrical representation and in nuclear data utilization. Hence, the comparison results should give an indication of the best probable accuracy of calculational results obtainable at the present time.

The comparison results are presented in Reference 26 as plots of experimental versus calculated value for the various quantities of interest. The comparison plots are reproduced as Figures 38 through 45 . The precision (95\% confidence level) of the experimental data is of the order of $1 \%$, which is roughly the size of the circles in the figures. Two different sets of calculations were performed; one set corresponds to the original plutonium cross sections which had been in use at Bettis Atomic Power Laboratory and the other set corresponds to plutonium cross sections which had been revised at the time of the investigation in order to take into account all of the latest cross section measurements. Points plotted as circles correspond to the original cross sectional data and points plotted as crosses represent the revised data. If no crosses appear on a figure for a given quantity, it is because changing the plutonium cross sections has a negligible effect on that quantity. The comparison results in Figures 38 through 45 are summarized as follows:

(1) Figure 38 shows that the maximum discrepancy in U235 depletion is approximately $10 \%$ and the average discrepancy is about $3 \%$. There was a consistent overestimation of U235 depletion in the calculations. A correlation is noted (although not evident in Figure 38 because the plotted points are not identified) between magnitude of the discrepancy and physical location of the fuel rod within the fuel assembly (which consisted of an $11 \times 11$ array of fuel rods).. Those rods located at the centers of the asscmblies exhibit the largest overestimation in U235 depletion while those rods located at or near the corners are represented by points lying close to the $45^{\circ}$ line. A possible explanation of this effect is that the superposition technique used in the calculations gives a thermal flux shape which is too flat thereby resulting. in overdepletion at the center and underdepletion at the edge of the fuel assemblies.

(2) Figure 39 shows that the maximum discrepancy in Pu buildup is approximately 10\%, and the average discrepancy is about $4 \%$. As in the case of U235 depletion, there appears to be a slight overestimation of the amount of plutonium. Use of the revised cross sections has only a small effect.

(3) Figures 40 through 43 indicate that the calculated distribution of plutonium isotopes is shifted towards the isotopes of higher mass number relative to experiment. The Pu239 content is underestimated by as much as $12 \%$, although most of the calculated values fall within a $\pm 6 \%$ band of the measured values; use of the revised cross section data gives slightly better overall agreement. The Pu240, Pu24l and Pu242 contents are consistently overestimated. Use of the revised cross sections results in: (a) little change in calculated Pu240 content; (b) large reduction in discrepancies for Pu241 (from discrepancies ranging up to $70 \%$ to discrepancies which are within $20 \%$ for most fuel rods); and (c) pronounced reduction in discrepancies for Pu242 (from discrepancies of more than a factor of two to discrepancies which are generally well within 50\%).

(4) Figure 44 compares the calculated and measured values of the ratio of total fissions to U235 fissions. Calculations tend to overestimate 
this quantity although agreement is within $3 \%$ on the average.

(5) Figure 45 compares the calculated and measured values of integrated exposure. The calculations generally overestimate the integrated exposure (average deviation of about $7 \%$ ) which is consistent with the overdepletion of U235. Some small consistent exror may be present in the experimental values, as introduced by inaccuracies in the known values of half-life and fission yield for Csl37.

Inasmuch as detailed sophisticated methods with up-to-date nuclear constants were used for the calculations, the average discrepancies listed above probably represent the present-day limits of prediction of average heavy-isotopic composition in fuel elements.

\section{B. Vallecitos and Dresden Boiling Water Reactors}

Isotopic composition measurements of slightly enriched $\mathrm{UO}_{2}$ fuel irradiated in the Vallecitos Boiling Water Reactor (VBWR) have been performed and are reported in Reference 17. The fuel exposures ranged from 100 to $3200 \mathrm{MWD} / \mathrm{Ton}$. Reference 27 also reports these data and, in addition, presents data on one fuel sample which had attained an exposure of $7000 \mathrm{MWD} /$ Ton. Irradiated fuel samples from Dresden in the exposure range of 100 to $3200 \mathrm{MWD} / T$ Ton were also analyzed using the same techniques as for the Vallecitos fuel samples, and these data are included in Reference 27 . The fuel pellets analyzed were taken from several positions within the reactor cores, $i . e$. , from several axial positions along a fuel rod so as to span the void range from $0 \%$ to $30 \%$, from fuel assemblies with different histories in terms of control rod position during irradiation, and from different fuel rods within a fuel assembly.

The fuel exposure was determined by measuring the concentration of four fission products ( $\mathrm{Cs} 137, \mathrm{Ce} 144, \mathrm{Zr} 95$ and Bal40). The uranium content was determined by isotopic dilution mass spectrometry using U233 as the spike and the isotopic composition was simultaneously determined. The Pu239/U238 atom ratio was determined by a combination of gross alpha counting, alpha spectroscopic and mass spectrometric analyses. The higher plutonium isotope concentrations were obtained from the mass spectrometric analysis. The experimental uncertainties (one standard deviation) associated with these measurements are as follows:

$\begin{array}{ll}\text { Ratios of Pu isotopic concentrations } & \pm 1 \text { to } 1-1 / 2 \% \\ \text { Ratios of isotopes of } U & \pm 1 \text { to } 1-1 / 2 \% \\ \text { Pu/U ratio } & \pm 2 . \text { to } 5 \% \\ \text { Concentration of Csl37 burnup indicator } & \pm 6 \%\end{array}$

Comparisons are presented in References 17 and 27 of the measured data with calculated values in order to test the adequacy of the analytical model and basic cross section data. A multiregion fuel depletion code was utilized at General Electric for calculating the depletion and production of the heavy-isotopes corresponding to the measured burnup. Details of the method are outlined in Reference 27.

The comparisons presented in Reference 17 for the Vallecitos fuel samples irradiated in the 100 to $3200 \mathrm{MND} / \mathrm{Ton}$ exposure range are summarized:

(1) The measured and computed U235 and U236 atom fractions are compared in Figures 46 and 47, respectively. The differences for U235 are generally less than about $1 \%$ as compared to an estimated measurement accuracy of somewhat better than $1 \%$. The computed data for U236 are generally lower than those measured by $4 \%$ to $5 \%$, as compared to an estimated measurement accuracy of about $2 \%$. 
(2) Figures 48 through 51 compare the measured and computed Pu239/U238, Pu240/Pu239, Pu241/Pu240 and Pu242/Pu24I ratios, respectively. These isotope concentration ratios are significant in that an error in any one ratio may be associated with errors in the effective values of particular cross sections of the plutonium isotopes and U238. With the exception of the Pu242/Pu241 ratio, the computed data are consistently lower than measured. These results imply that the effective capture cross sections of U238, Pu239 and Pu240 are too low and the effective capture cross section of Pu24l is too high. The average error, $\bar{\Delta}$, and standard deviation, $\sigma$, of the differences between calculated and measured isotopic concentrations were obtained for the Pu239, Pu240 and Pu241 isotopes and are as follows:

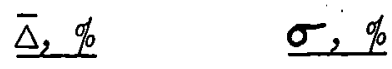

Pu239

Pu240

Pu241
7
9
17

\section{9 \\ I1 \\ 22}

Figure 52 compares the measured and calculated quantities of total plutonium production.

(3) It was assumed that all discrepancies are due to uncertainties in the cross sections. When $\sigma_{c} 28$ and $\sigma_{c} 40$ are increased by $10 \%$ and $\sigma_{c} 41$ is decreased by $10 \%$, the corresponding values of $\bar{\Delta}$ and $\sigma$ are:

$\begin{array}{lrc} & \bar{\Delta}, \% & \underline{\sigma, \%} \\ \text { Pu239 } & 0.7 & 6 \\ \text { Pu240 } & 0.1 & 7 \\ \text { Pu241 } & -0.3 & 15\end{array}$

Prior to changing the cross sections, all computed Pu atom concentrations (excepting Pu242) were too low. After changing the cross sections, about one-half of the data points are higher and one-half are lower than computed.

(4) It is instead assumed that all discrepancies are due to an underestimate of the fuel exposure. When the fuel exposure is increased by $6 \%$, the corresponding values of $\vec{\Delta}$ and $\sigma$ are:

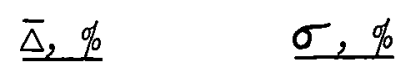

$\begin{array}{rrr}\text { Pu239 } & -1 & 5 \\ \text { Pu240 } & +3 & 8 \\ \text { Pu241 } & +0.8 & 16\end{array}$

After the fuel exposure increase, the Pu239 is very slightly low, the Pu240 is slightly high, and the Pu24l is generally half high and half low.

(5) Uncertainties are present in the computed void fractions which affect the magnitude of the cross sections. To investigate this void effect, a void distribution was redetermined along the length of each fuel rod analyzed so as to force agreement with the measured Pu239 concentrations. A uniformly greater void fraction than used in the original calculations is indicated; later flow measurements support the evidence that the void fractions used in the original calculations are too low. The values of $\bar{\Delta}$ and $\sigma$ obtained from the comparison results 
for one fuel rod with the revised void fraction distribution are:

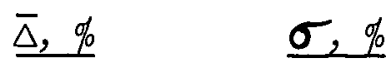

$\begin{array}{lcl}\text { Pu239 } & 0 & 0 \\ \text { Pu240 } & +0.7 & 6 \\ \text { Pu241 } & -4.7 & 9\end{array}$

The comparisons presented in Reference 27 include the foregoing data and, in addition, data for: (1) a Vallecitos fuel sample irradiated to $7000 \mathrm{MWD} /$ Ton exposure; and (2) Dresden fuel samples irradiated in the 100 to $3200 \mathrm{MWD} / \mathrm{Ton}$ exposure range. The comparison results from Reference 27 are reproduced herein as Figures 53 through 57 . These results show:

(1) For the high-exposure fuel sample irradiated in Vallecitos (isotope ratio indicated in each figure by a circle), the relative isotope ratios (as measured and as calculated) exhibit the same general trend as obtained for the 100 to $3200 \mathrm{MWD} / T$ Ton irradiated fuel samples of Vallecitos.

(2) The discrepancies between measured and calculated isotope ratios for the Dresden irradiated fuel samples are somewhat larger than obtained. for the Vallecitos samples. The major source of error in the Pu239/U238 atom ratio is a systematic offset of about $10 \%$ between the computed and measured ratios. The error is greater near the water gaps than at the center of the fuel bundle. This bias in the error is partially explained by the softening of the thermal flux energy spectrum near the water gaps, which was not accounted for in the calculations. With respect to the Pu240/Pu239 atom ratio, the Dresden data show a mean relative difference of $15 \%$, the calculations being higher than the measured data. The calculations tend to underpredict the Pu241/Pu240 atom ratio by about $35 \%$ and tend to overpredict the Pu242/Pu241 atom ratio by $20 \%$ to $25 \%$. The U236/U235 atom ratio data are in agreement within the limits of experimental error.

Measurements of isotopic content of fuel samples irradiated in VBWR and Dresden, when compared with calculations, indicate that: (1) the amount of Pu239 may be underpredicted by as much as 5\%; (2) the amount of Pu240 may be overpredicted by as much as $15 \%$; and (3) considerably greater uncertainties are involved in the prediction of the concentrations of the higher plutonium isotopes due to the larger uncertainties associated with their basic cross section values.

\section{Yankee Core I Pressurized Water Reactor}

Following removal of fuel assemblies from Yankee Core I, a program was initiated at Westinghouse to evaluate the characteristics of the spent fuel by destructive analysis and to compare them with calculations (References 1 and 28 through 36). Fuel burnup distribution, uranium depletion, and plutonium buildup were among the parameters studied; altogether, more than 200 fuel samples were analyzed. The destructive analyses permitted determination of:

(1) Fuel isotopic composition as a function of burnup for fuel rods located near the center of the fuel assemblies (i.e., located in the asymptotic reactor spectrum) and for fuel rods located near the edges of the fuel assemblies adjacent to the water slots (i.e., located in the perturbed reactor spectrum).

(2) Distribution of fuel isotopes in the core. 
(3) Total isotopic content of the depleted core.

(4) Burnup distribution in the core as determined from fission product concentrations.

Pellets were carefully selected from about 60 rods of 17 fuel assemblies which were taken mainly from one quadrant, the instrumented quadrant. Usually 4 pellets per rod, selected from 4 axial regions, were taken for examination. In the case of 3 rods, 6 pellets were studied from each so as to obtain more detailed information about the axial distribution.

Fuel samples were prepared from the individual pellets and were analyzed by Tracerlab, General Electric and the New Brunswick Laboratory for isotopic abundance of each of the uranium and plutonium isotopes; measurements were also made of the plutonium to uranium ratio. Data obtained from each of the three laboratories, including those on identical fuel samples, were compared; measurement accuracies quoted by each laboratory are given in Table C-2 of Appendix C. After initial disagreements, the sources of which were eventually resolved, good agreement of the finally reported isotopic compositions of the fuel samples was obtained among the laboratories. As an additional check of the accuracy of the uranium isotopic abundances reported, a solution of the National Bureau of Standards uranium isotopic standard was analyzed at General Electric and at Tracerlab. Significant discrepancies were obtained only in the U234 and U236 abundances; the General Electric data were $31 \%$ and $10 \%$ higher, respectively, than the certified values.

Radiochemical analyses were performed on most of the samples to determine burnup from fission product concentration. Cs137, Sr89 and Y90 activities were counted. The measurements have a $\pm 5 \%$ to $a \pm 8 \%$ error. Combined with the uncertainties in the physical constants used, this leads to approximately a $\pm 10 \%$ error in the burnup values reported. Burnup was also determined from the measured isotopic composition of the spent fuel. No error evaluation was performed on the burnups inferred from isotopic data, but the errors are estimated to be no more than $\pm 8 \%$. Values of fuel-pellet burnup obtained from isotopic and radiochemical data were compared. At relatively high burnups, there is a $5 \%$ to $10 \%$ discrepancy between the burnup inferred from isotopic and Cs137 analyses. Because of the relatively low temperature gradient in the fuel rods, it is believed that the error is not caused by cesium migration. Using newer values for capture-to-fission ratios, $\alpha^{49}$ and $\alpha^{41}$, the agreement is slightly improved.

The experimental data reduction was done at Westinghouse by a computer code, REBUF (Reference 31). The code calculates the isotopic concentrations and burnups from the results of the mass spectrometric, radiochemical and $X$-ray spectrographic measurements. A computer code, MASTER, generates a three-dimensional matrix of the inventories of uranium and plutonium isotopes for the entire core from the measured data (References 35 and 36). The code computes the average assembly burnups and inventories as well as the total core burnup and inventory.

In order to ascertain the accuracies of predicting isotopic concentrations, Westinghouse performed four-group TURBO calculations in a manner consistent with the Yankee Core design methods (Reference 35). Simplified four-group calculations were also performed at CEND to provide an indication of the feasibility of introducing fairly gross simplifications in the calculations of isotopic fuel composition. The procedure used at CEND was briefly as follows:

(1) A homogenized core composition was assumed with criticality maintained during fuel burnup by variation of homogeneous core poisons. Fourgroup core constants were derived for the central fuel-rod lattice cell of the Yankee Core I fuel assemblies so as to provide direct comparisons 
with the isotopic composition data obtained for fuel rods in the asymptotic neutron spectrum. FORM was used to obtain the lattice cell constants for the above-thermal energy groups; except for U238 and Pu240, the above-thermal self-shielding L-factors for all isotopes were taken as unity. The L-factor for U238 was determined by use of the nuclear code QUERY (Reference 37) which utilizes tables by Adler, Hinman, and Nordheim for calculation of resonance-escape probability. Lattice-interaction effects were included through use of G. I. Bell's concept of the effective average-chord-length of the fuel lump (Reference 38). The self-shielding for Pu240 was based on the infinite mass approximation of the effective resonance integral (at $1.054 \mathrm{ev}$ ) and was taken to be concentration dependent (Reference 17). For the thermal group, TEMPEST was used to determine the Wigner-Wilkins spectrum for the volume-weighted composition of the homogenized unit cell; the thermal disadvantage factor was obtained from a cylindrical-geometry P-3 calculation of the heterogeneous unit cell using thermal-neutron constants appropriate to the Wigner-Wilkins spectrum.

(2) The zero-dimensional burnup code, CRUMB, was used to determine U235 depletion and Pu isotopic buildup as a function of average fuel exposure. The neutron spectral changes occurring with fuel burnup were neglected. Also, the thermal disadvantage factor was assumed constant during the burnup. With the single point treatment, all detailed spatial effects of fuel burnup are disregarded.

Plots of measured data points on plutonium isotopic composition and Pu/U mass ratio versus U235 atom depletion are presented in Figures 58 and 59, respectively. The data correspond to exposure values up to about 24,000 MWD/MrU. Included in each figure for comparison purposes are two sets of calculated curves, namely, (1) the results of the four-group TURBO calculation performed by Westinghouse up to about 14,000 MND/MTU exposure; and (2) the results of the zero-dimensional calculation performed at CEND up to about 24,000 MWD/MTU exposure. The data scatter is due to experimental uncertainties in both the plutonium and U235 concentration measurements. Over the range investigated, the TURBO results agree quite well with the data, the major discrepancy occurring for Pu242. Over this limited range (up to 14,000 $\mathrm{MWD} / \mathrm{MIU}$ ), the agreement with the zero-dimensional results is almost equally good. However, the zero-dimensional results show increasing departure from the data points with increasing exposure above 14,000 MWD/MIU. The measured and CEND-calculated compositions at 14,000 and 23,500 MWD/MIU are compared in Table III. At 14,000 MWD/MIU, the U235 depletion is overpredicted by $2.5 \%$ and the plutonium buildup is underpredicted by less than $1 \%$; however, at 23,500 $\mathrm{MWD} / \mathrm{MHU}$, the U235 depletion is overpredicted by $5 \%$ and the plutonium buildup is underpredicted by $7 \%$.

The average burnup of the first Yankee core was determined from the pellet burnups as inferred from both the mass spectrometric and radiochemical (Csl37) analyses (Reference 2). The average core burnup was also determined from calorimetric data obtained at the Yankee site during reactor operation. The results agree within $1 \%$ of the average value, which is well within the accuracy limits of the methods used.

The total core isotopic inventory has been calculated from the mass spectrometric data of approximately 170 pellet samples (Reference 2). The experimentally-derived results, together with predictions based on the original $R-Z$ TURBO calculations used in the Yankee Core I design and on more recent $X-Y$ TURBO* calculations, are given in Table IV. The original design method predicts higher Pu239 inventory by $2.3 \%$ and higher Pu241 inventory by $11.8 \%$. At the same time, the calculated U235 inventory is $1.1 \%$ lower than the measured inventory for a calculated U235 overdepletion of $3.5 \%$ 
TABLE III

MEASURED AND CEND-CALCULATED(a) ISOTOPIC COMPOSITIONS IN YANKEE CORE I

\begin{tabular}{|c|c|c|c|c|}
\hline & \multicolumn{4}{|c|}{ MWD/MTU } \\
\hline & \multicolumn{2}{|c|}{14,000} & \multicolumn{2}{|c|}{23,500} \\
\hline & $\begin{array}{c}\text { AVERAGE OF } \\
\text { MEASUREMENTS }\end{array}$ & CALCULATED & $\begin{array}{c}\text { AVERAGE OF } \\
\text { MEASUREMENTS }\end{array}$ & CALCULATED \\
\hline $\begin{array}{l}\text { U-235 ATOM } \\
\text { DEPLETION, \% }\end{array}$ & 37.5 & 38.5 & 53.5 & 56.0 \\
\hline $\begin{array}{l}\text { PU/U MASS } \\
\text { RATIO, \% }\end{array}$ & 0.76 & 0.75 & 1.12 & 1.04 \\
\hline $\begin{array}{l}\text { Pu ISOTOPIC } \\
\text { COMPOSITION } \\
\text { (ATOM \%) } \\
\text { Pu-239 } \\
\text { Pu-240 } \\
\text { Pu-241 } \\
\text { Pu-242 }\end{array}$ & $\begin{array}{r}78.0 \\
14.0 \\
7.2 \\
0.8\end{array}$ & $\begin{array}{r}75.3 \\
16.2 \\
7.4 \\
1.1\end{array}$ & $\begin{array}{r}69.5 \\
16.2 \\
12.3 \\
2.0\end{array}$ & $\begin{array}{r}64.1 \\
21.5 \\
11.3 \\
3.1\end{array}$ \\
\hline
\end{tabular}

(a) ZERO-DIMENSIONAL CALCULATIONS FOR FUEL RODS IN THE ASYMPTOTIC NEUTRON FLUX OF THE VARIOUS FUEL ASSEMBLIES 
TABLE IV

PREDICTED VERSUS EXPERIMENTAL ISOTOPIC INVENTORY FOR SPENT YANKEE CORE I (FROM REFERENCE 2)

\begin{tabular}{|c|c|c|c|c|c|}
\hline Isotope & Measured $(M) *$ & $\mathrm{R}-\mathrm{Z}$ TURBO $\left(\mathrm{C}_{1}\right)^{* *}$ & $X-Y$ TURBO* $\left(C_{2}\right)^{* * *}$ & $\frac{C_{1}-M}{M}$ & $\frac{c_{2}-M}{M}$ \\
\hline$U-234$ & 3.78 & 3.5 & 3.5 & & 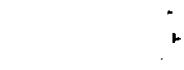 \\
\hline$U-235$ & 539 . & 533. & 537. & -1.1 & -0.4 \\
\hline$U-236$ & 36.7 & 42.1 & 37.9 & +12.8 & +3.2 \\
\hline$U-238$ & 20,040 & 20,030 & 20,052 & -0.05 & +0.06 \\
\hline Total U & $20,620 . \quad \mathrm{kg}$ & $20,608 . \mathrm{kg}$ & $20,630 . \mathrm{kg}$ & $-0.06 \%$ & $+0.05 \%$ \\
\hline Pu-239 & 81.3 & 83.2 & 80.0 & +2.3 & $\therefore 1.6$ \\
\hline Pu-240 & 10.3 & 10.1 & 10.3 & -2.0 & 0.0 \\
\hline Pu-241 & 4.94 & 5.6 & 4.4 & +11.8 & -12.3 \\
\hline$P u-242$ & 0.435 & $\sim 0.4$ & $>0.33$ & & \\
\hline Total Pu & $97.0 \mathrm{~kg}$ & $99.3 \mathrm{~kg}$ & $95.0 \mathrm{~kg}$ & $+2.3 \%$ & $-2.1 \%$ \\
\hline
\end{tabular}

* Initial U-235 and U-236 inventories are 711 and $4.2 \mathrm{~kg}$, respectively.

** Original design calculations (1960).

*** Preliminary calculations being performed to check accuracy of predictions (1965). 
D. Heavy-Isotope Cross Section Data

Data on heavy-isotope cross sections averaged over standard neutron energy spectra were obtained from the various reactor designers. This form of data collection was chosen due to the proprietary nature and extensiveness of the basic cross section data, i.e., of individual neutron cross section and parameter values as a function of neutron energy. The datia obtained are:

(1) Maxwellian-averaged microscopic cross sections of the pertinent isotopes at neutron temperatures of $68^{\circ} \mathrm{F}, 500^{\circ} \mathrm{F}, 900^{\circ} \mathrm{F}$ and $1300^{\circ} \mathrm{F}$.

(2) Infinitely-dilute resonance integrals of the pertinent isotopes for a $1 / E$ spectrum in the neutron energy range of $0.625 \mathrm{ev}$ to $10 \mathrm{Mev}$,

$$
\text { i.e., } \quad \int_{0.625 \mathrm{ev}}^{10 \mathrm{Mev}} \sigma^{\mathrm{dE}}
$$

The cross sections are $\sigma_{a}, \sigma_{F}$, and $\nu \sigma_{F}$. The isotopes are Th232, Pa233, U233, U234, U235, U236, U238, Pu239, Pu240, Pu241 and Pu242.

These data have been compared to obtain an indication of the consistency of the basic nuclear constants presently used by the various reactor designers to calculate heavy-isotope concentration in the various power reactors. The results of the comparison are presented in Table V. The results given for each isotope cross section or parameter are: (1) the average of the specific values quoted by the various designers; and (2) the percent deviation of the value used by each designer from the average. The reactor designers are not identified but, instead, are simply indicated as Designers A through F. Table VI gives, for each pertinent nuclear constant of each heavy isotope, the standard deviation, $\sigma$, of the differences between the individual values and the average of the values used by the various reactor designers.

The reactor designers are in reasonably good agreement as to the values of the pertinent nuclear constants for the more abundant heavy isotopes encountered in present reactor cores. The differences among the values used by the designers increase with the higher isotopes, particularly for the case of the resonance integrals. These comparison results point up the differences in the interpretation by the various reactor designers of the available data rather than the basic uncertainties existing in the present data. 
TABLE $\vee$

HEAVY-ISOTOPE MAXWELLIAN-AVERAGED CROSS SECTIONS AND INFINITELYDILUTE RESONANCE INTEGRALS USED BY REACTOR DESIGNERS

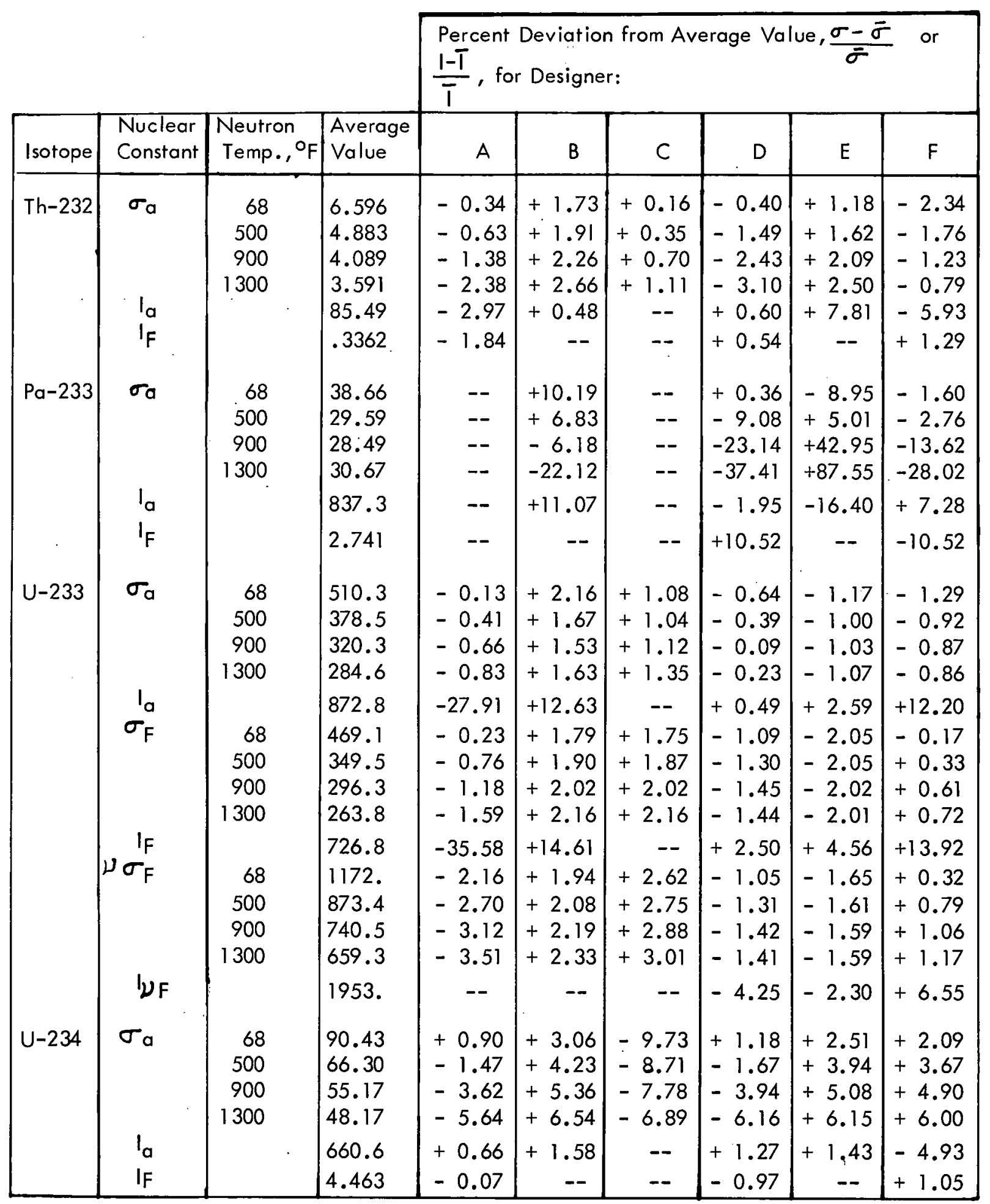


TABLE $\vee$ (cont.)

HEAWY-ISOTOPE MAXWELLIAN-AVERAGED CROSS SECTIONS AND INFINITELYDILUTE RESONANCE INTEGRALS USED BY REACTOR DESIGNERS

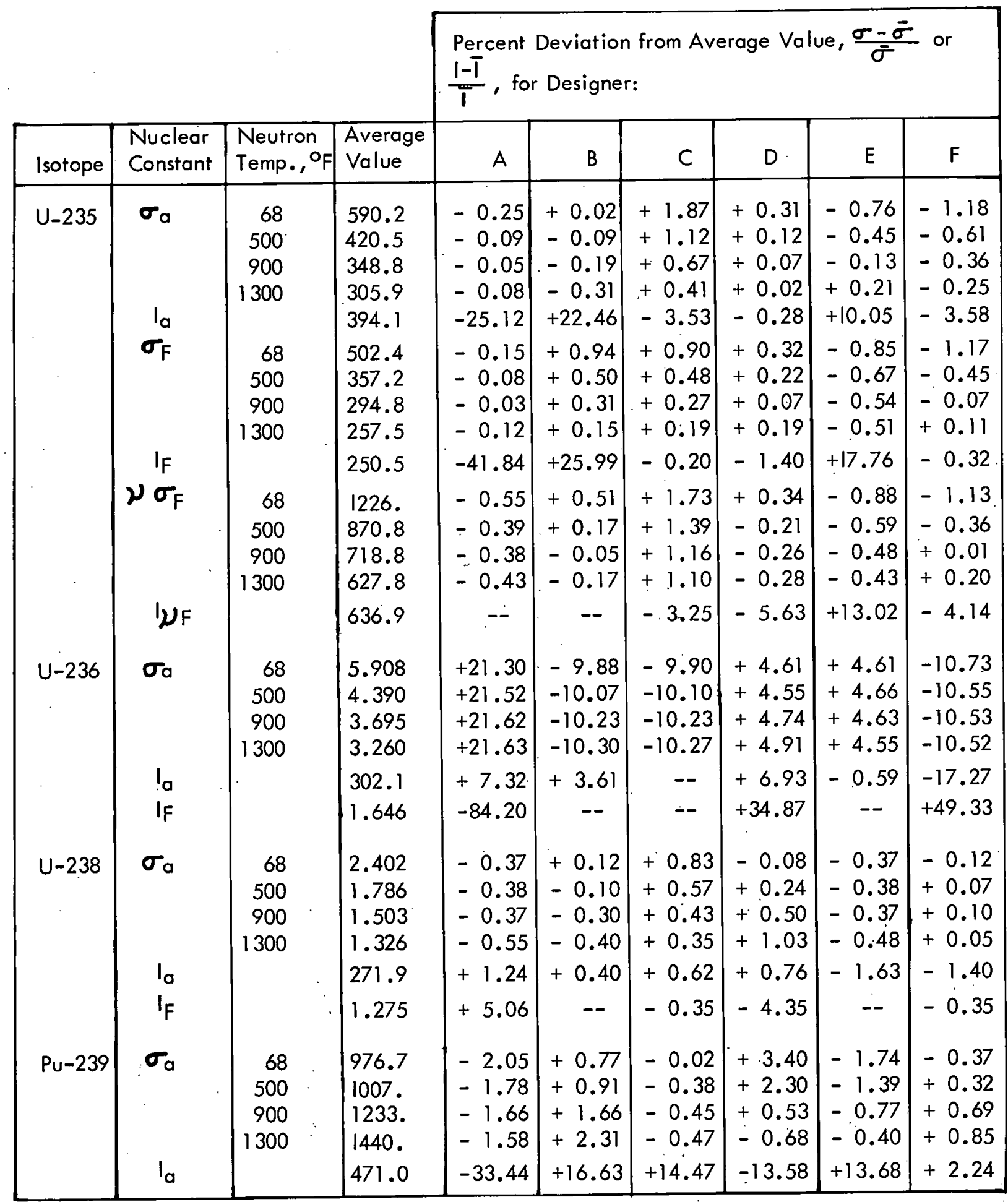


TABLE V (cont.)

HEAW-ISOTOPE MAXWELLIAN-AVERAGED CROSS SECTIONS AND INFINITELYDILUTE RESONANCE INTEGRALS USED BY REACTOR DESIGNERS

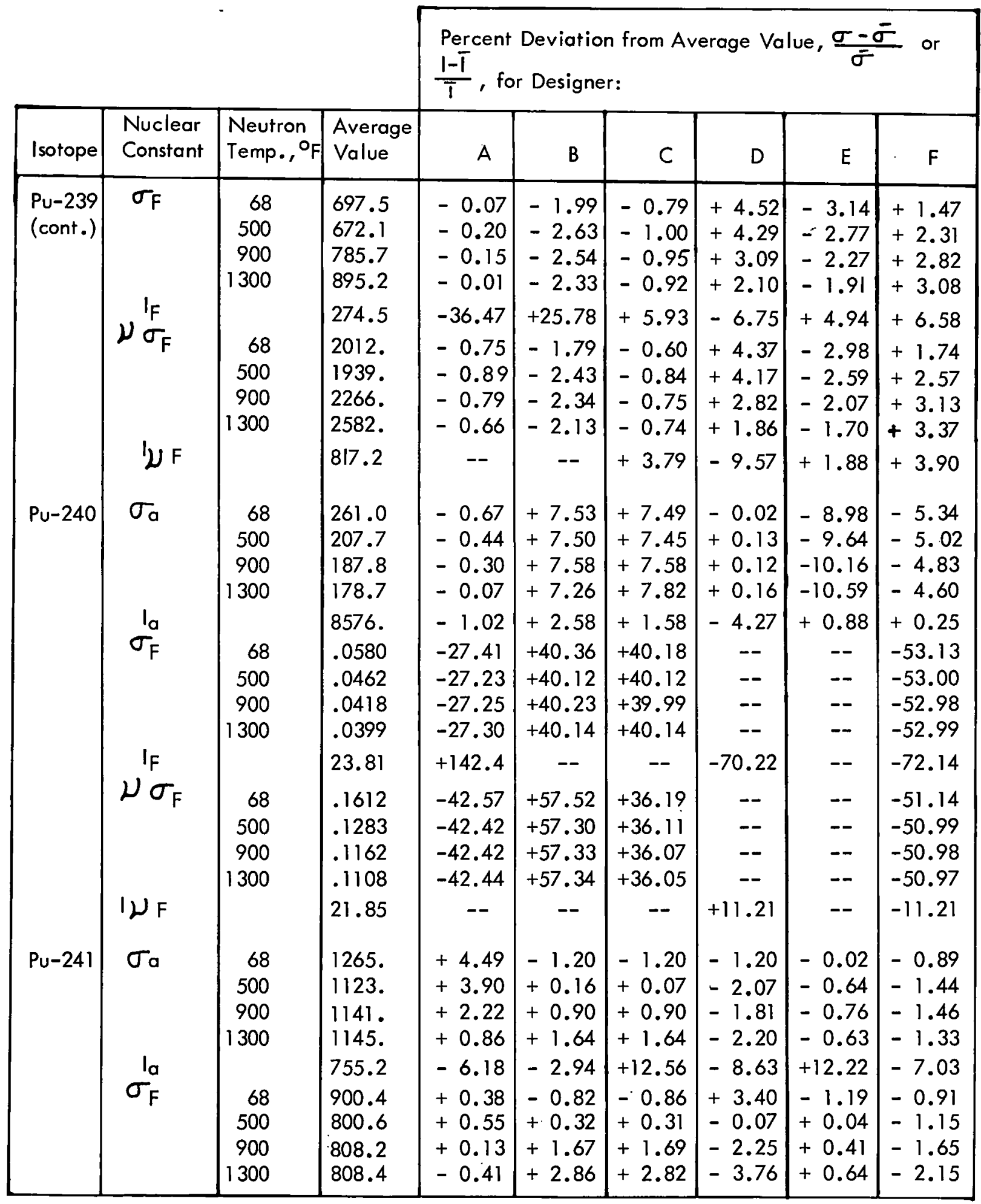


TABLE. $V(\text { cont : })^{\prime}$

HEAWY-ISOTOPE MAXWELLIAN-AVERAAGD CROSS SECTIONS AND INFINITELYDILUTE RESONANCE INTEGRALS USED BY REACTOR DESIGNERS

\begin{tabular}{|c|c|c|c|c|c|c|c|c|c|}
\hline \multicolumn{4}{|c|}{+} & \multicolumn{6}{|c|}{$\begin{array}{l}\text { Percent Deviation from Average Value, } \frac{\sigma-\bar{\sigma}}{\bar{\sigma}} \text { or } \\
\frac{1-\bar{T}}{T} \text {, for Designer: }\end{array}$} \\
\hline Isotope & $\begin{array}{l}\text { Nuclear } \\
\text { Constant }\end{array}$ & $\begin{array}{l}\text { Neutron } \\
\text { Temp. , }{ }^{\mathrm{F}}\end{array}$ & $\begin{array}{l}\text { Average } \\
\text { Value }\end{array}$ & A & B & C & D & $E$ & $F$ \\
\hline \multirow{3}{*}{$\begin{array}{l}\text { Pu-24l } \\
\text { (cont.) }\end{array}$} & $\mathrm{I}_{\mathrm{F}}$ & & 525.2 & +1.25 & +12.52 & -10.52 & +1.29 & -10.77 & +6.24 \\
\hline & $\mathcal{\nu} \sigma_{F}$ & $\begin{array}{r}68 \\
500 \\
900 \\
1300\end{array}$ & $\begin{array}{l}2726 . \\
2426 . \\
2453 . \\
2464\end{array}$ & $\begin{array}{l}+1.09 \\
+1.19 \\
+0.60 \\
-0.32\end{array}$ & $\begin{array}{l}+0.25 \\
+1.39 \\
+3.57 \\
+6.86\end{array}$ & $\begin{array}{l}-0.12 \\
+0.94 \\
+2.15 \\
+2.88\end{array}$ & $\begin{array}{l}+1.61 \\
-1.49 \\
-3.80 \\
-5.84\end{array}$ & $\begin{array}{l}-1.77 \\
-0.63 \\
-0.42 \\
-0.61\end{array}$ & $\begin{array}{l}-1.07 \\
-1.41 \\
-2.09 \\
-2.96\end{array}$ \\
\hline & ${ }^{1} \nu \mathrm{F}$ & & 1542. & -- & -- & -6.86 & +5.72 & -8.48 & +9.61 \\
\hline \multirow[t]{3}{*}{ Pu-242 } & $\sigma_{a}$ & $\begin{array}{r}68 \\
500 \\
900 \\
1300\end{array}$ & $\begin{array}{l}21.45 \\
16.08 \\
13.68 \\
12.22\end{array}$ & $\begin{array}{l}-- \\
-- \\
--\end{array}$ & $\begin{array}{l}+24.07 \\
+22.81 \\
+22.17 \\
+22.16\end{array}$ & $\begin{array}{l}-- \\
-- \\
-- \\
--\end{array}$ & $\begin{array}{l}-24.49 \\
-23.52 \\
-22.50 \\
-21.62\end{array}$ & $\begin{array}{l}+23.47 \\
+22.44 \\
+21.14 \\
+19.54\end{array}$ & $\begin{array}{l}-23.05 \\
-21.71 \\
-20.82 \\
-20.06\end{array}$ \\
\hline & $I_{a}$ & & 1435. & -- & -25.02 & -- & -22.65 & +68.92 & -21.25 \\
\hline & ${ }^{\mathrm{I}} \mathrm{F}$ & & 4.546 & -- & -- & -- & -1.23 & -- & +1.23 \\
\hline
\end{tabular}


STATISTICS ON VARIATIONS IN VALUES OF HEAWY-ISOTOPE NUCLEAR CONSTANTS USED BY VARIOUS REACTOR DESIGNERS

\begin{tabular}{|c|c|c|c|c|c|}
\hline Cross & Section* & $\sigma, \%^{* *}$ & Cross & Section* & $\underline{\sigma, \%^{* *}}$ \\
\hline$\sigma_{a}$ & (Th232) & 1.7 & $\sigma_{a}$ & (Pu239) & 1.4 \\
\hline$\sigma_{a}$ & (U233) & 1.1 & $\sigma_{F}$ & (Pu239) & 2.3 \\
\hline$\sigma_{F}$ & (U233) & 1.6 & $\nu \sigma_{F}$ & (Pu239) & 2.3 \\
\hline$\nu \sigma_{F}$ & (U233) & 2.1 & $\sigma_{a}$ & $(P \cup 240)$ & 6.3 \\
\hline$\sigma_{a}$ & (U234) & 5.2 & $\sigma_{a}$ & (Pu241) & 1.7 \\
\hline$\sigma_{a}$ & (U235) & 0.6 & $\sigma_{F}$ & (Pu241) & 1.7 \\
\hline$\sigma_{F}$ & (U235) & 0.5 & $\nu \sigma_{F}$ & (Pu24l) & 2.5 \\
\hline $\mathcal{\nu} \sigma_{F}$ & (U235) & 0.9 & $\sigma_{a}$ & (Pu242) & 22.3 \\
\hline$\sigma_{a}$ & (U236) & 11.7 & $\sigma_{a}$ & (Pa233) & 28.8 \\
\hline$\sigma_{a}$ & (U238) & 0.4 & & & \\
\hline Resono & lance Integral ${ }^{* * *}$ & $\underline{\sigma}, \%^{* * * *}$ & \multicolumn{2}{|c|}{ Resonance Integral $^{* * *}$} & $\underline{\sigma, \% * * * *}$ \\
\hline$I_{a}$ & (Th232) & 4.6 & $I_{a}$ & (U238) & 1.1 \\
\hline$I_{F}$ & (Th232) & 1.3 & $I_{F}$ & (U238) & 4.0 \\
\hline $\mathrm{I} a$ & (U233) & 14.8 & $I_{a}$ & (Pu239) & 18.2 \\
\hline$I_{F}$ & (U233) & 18.4 & $I_{F}$ & (Pu239) & 18.9 \\
\hline $\mathfrak{L}_{\mathrm{F}}$ & (U233) & 4.7 & ${ }^{\prime} \nu_{F}$ & (Pu239) & 5.6 \\
\hline$I_{a}$ & (U234) & 2.5 & $I_{a}$ & (Pu240) & 2.2 \\
\hline$I_{F}$ & (U234) & 0.8 & $I_{a}$ & (Pu24l) & 8.9 \\
\hline$I_{a}$ & (U235) & 14.5 & $I_{F}$ & (Pu241) & 8.4 \\
\hline$I_{F}$ & (U235) & 21.4 & ${ }^{I}{ } F$ & (Pu241) & 7.8 \\
\hline
\end{tabular}


TABLE VI (cont.)

STATISTICS ON VARIATIONS IN VALUES OF HEAVY-ISOTOPE

NUCLEAR CONSTANTS USED BY VARIOUS REACTOR DESIGNERS

\begin{tabular}{|c|c|c|c|c|c|}
\hline \multicolumn{2}{|c|}{ Resonance Integral*** } & \multirow{2}{*}{$\frac{\sigma, \%^{* * * *}}{7.6}$} & \multicolumn{2}{|c|}{ Resonance Integral $^{* * *}$} & \multirow{2}{*}{$\underline{\sigma ., \% * * *}^{* 0.0}$} \\
\hline${ }^{\prime} \nu \mathrm{F}$ & (U235) & & Ia & (Pu242) & \\
\hline Ia & (U236) & 9.1 & $I_{F}$ & (Pu242) & 1.2 \\
\hline \multirow[t]{2}{*}{$I_{F}$} & (U236) & 59.8 & Ia & (Pa233) & 10.6. \\
\hline & & & $I_{F}$ & (Pa233) & 10.5 \\
\hline * & \multicolumn{5}{|c|}{ Maxwellian-averaged values } \\
\hline$* *$ & \multicolumn{5}{|c|}{$\begin{array}{l}\text { Standard deviation of the differences between the individual values and the } \\
\text { average of the values used by the various reactor designers at neutron temperatures } \\
\text { of } 68^{\circ}, 500^{\circ}, 900^{\circ} \text { and } 1300^{\circ} \mathrm{F} \text {. }\end{array}$} \\
\hline$* * *$ & \multicolumn{5}{|c|}{ Infinitely dilute values } \\
\hline$\star * * *$ & \multicolumn{5}{|c|}{$\begin{array}{l}\text { Standard deviation of the differences between the individual integral values and } \\
\text { the average of the values used by the various reactor designers. }\end{array}$} \\
\hline
\end{tabular}




\begin{tabular}{c|c|c|c} 
SYMBOL & $\begin{array}{c}\text { SOURCE OF } \\
\text { MEASUREMENT }\end{array}$ & $\begin{array}{c}\text { SOURCE OF } \\
\text { CALCULATION }\end{array}$ & $\begin{array}{c}\text { STANDARD DEVIATION (\%) } \\
\text { BETWEEN TALC AND MEAS }\end{array}$ \\
\hline 0 & VBWR & GE & 12.7 \\
\hline$\square$ & SHIPPINGPORT & METIS & 5.3 \\
\hline$\diamond$ & YANKEE I & $\begin{array}{c}\text { CEN } \\
\text { (0-DIMENS CRUMB) }\end{array}$ & 8.2
\end{tabular}

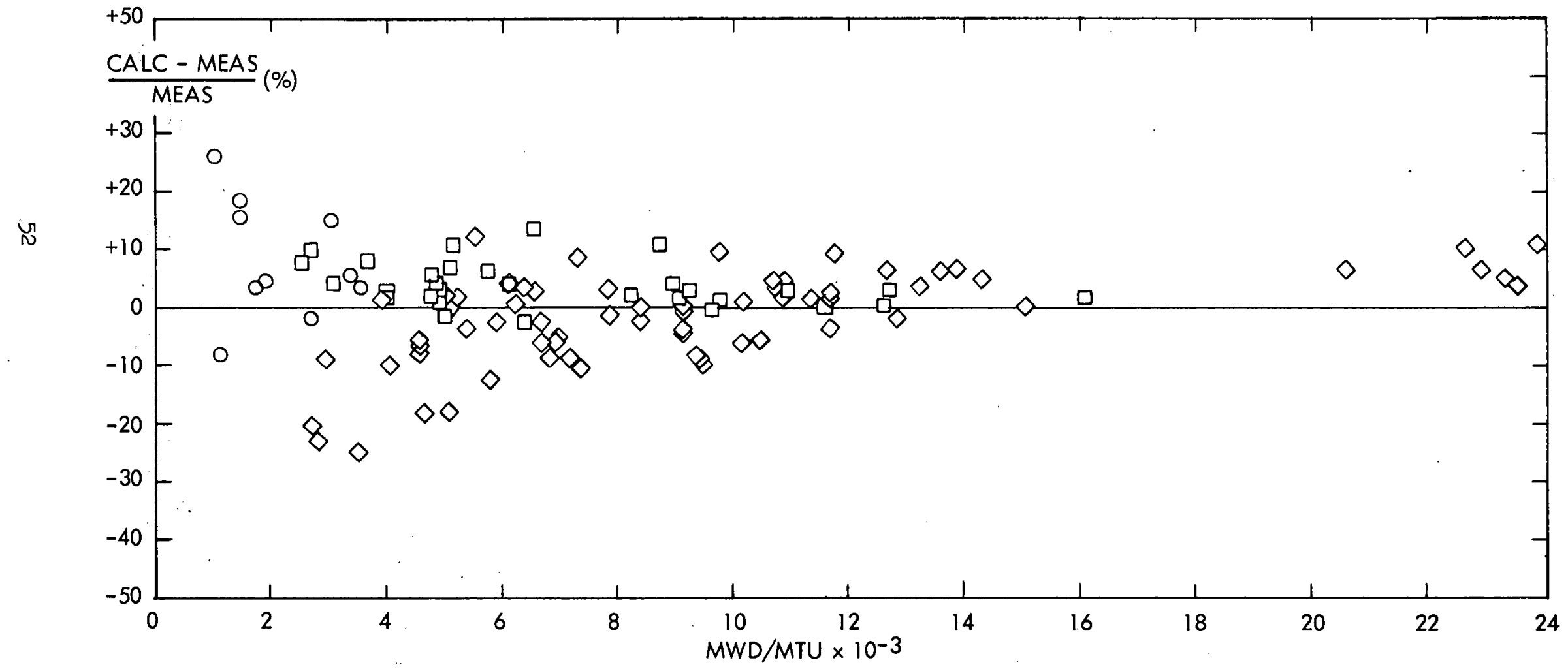

FIG $i$ COMPARISON OF MEASURED AND CALCULATED U-235 DEPLETION IN ANALYZED FUEL SAMPLES 


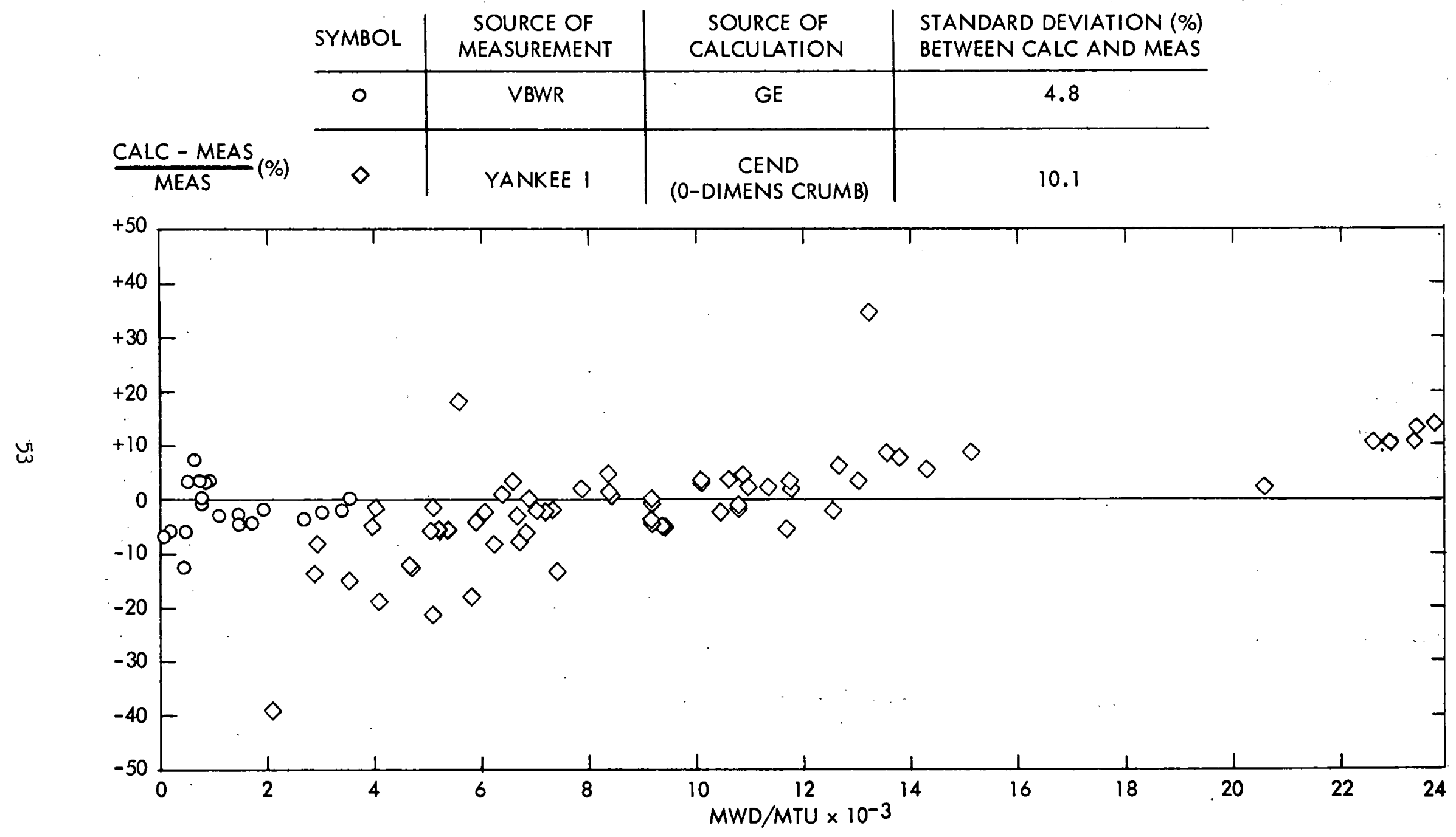

FIG 2 COMPARISON OF MEASURED AND CALCULATED U-236 CONTENT IN ANALYZED FUEL SAMPLES 


\begin{tabular}{c|c|c|c} 
SYMBOL & $\begin{array}{c}\text { SOURCE OF } \\
\text { MEASUREMENT }\end{array}$ & $\begin{array}{c}\text { SOURCE OF } \\
\text { CALCULATION }\end{array}$ & $\begin{array}{c}\text { STANDARD DEVIATION (\%) } \\
\text { BETWEEN CALC AND MEAS }\end{array}$ \\
\hline 0 & VBWR & GE & 9.1 \\
\hline$\square$ & SHIPPINGPORT & BETTIS & 5.7 \\
\hline$\Delta$ & DRESDEN & GE & 6.0 \\
\hline$X$ & YANKEE I & $\begin{array}{c}\text { WESTINGHOUSE } \\
\text { (2-DIMENS TURBO) }\end{array}$ & 5.2 \\
\hline$\diamond$ & YANKEE I & $\begin{array}{c}\text { CEND } \\
\text { (0-DIMENS CRUMB) }\end{array}$ & 8.7
\end{tabular}

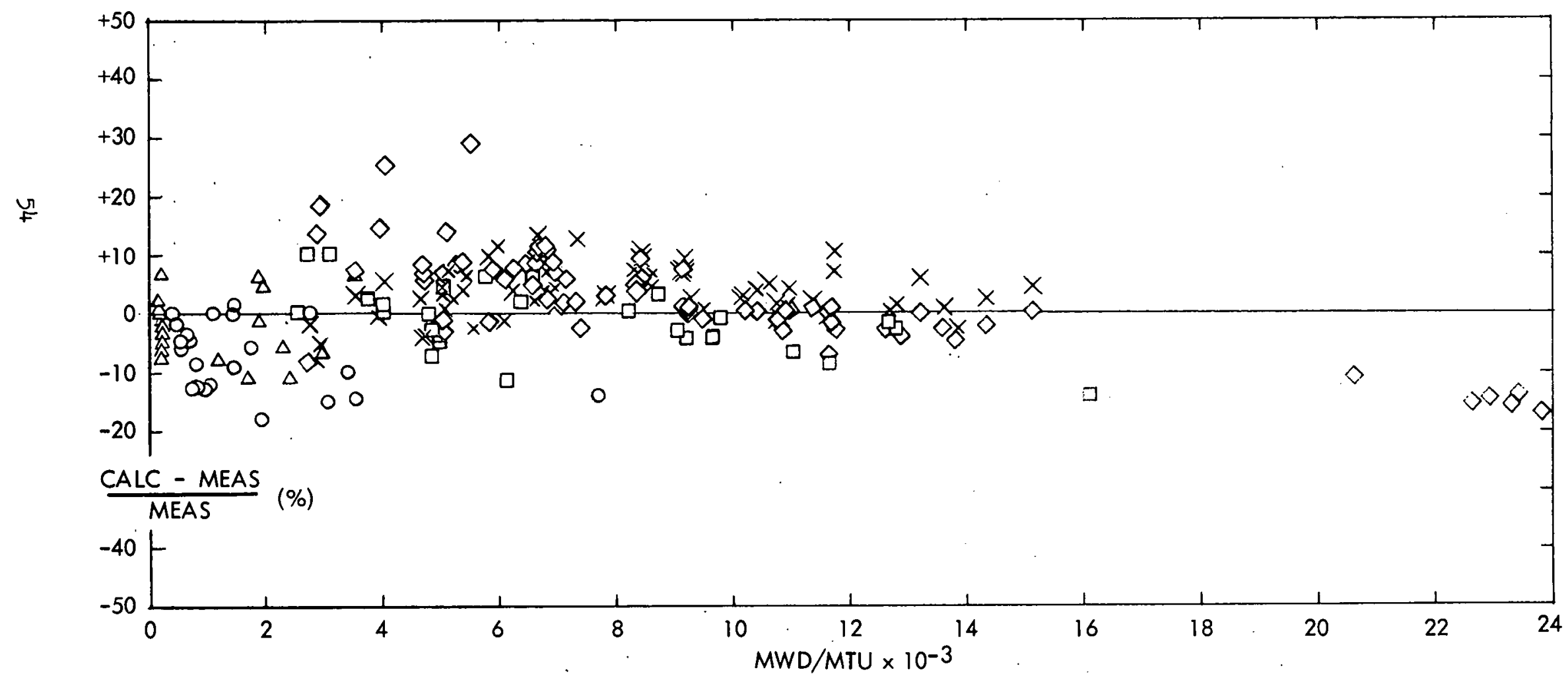

FIG 3 COMPARISON OF MEASURED AND CALCULATED PU-239 CONTENT IN ANALYZED FUEL SAMPLES 


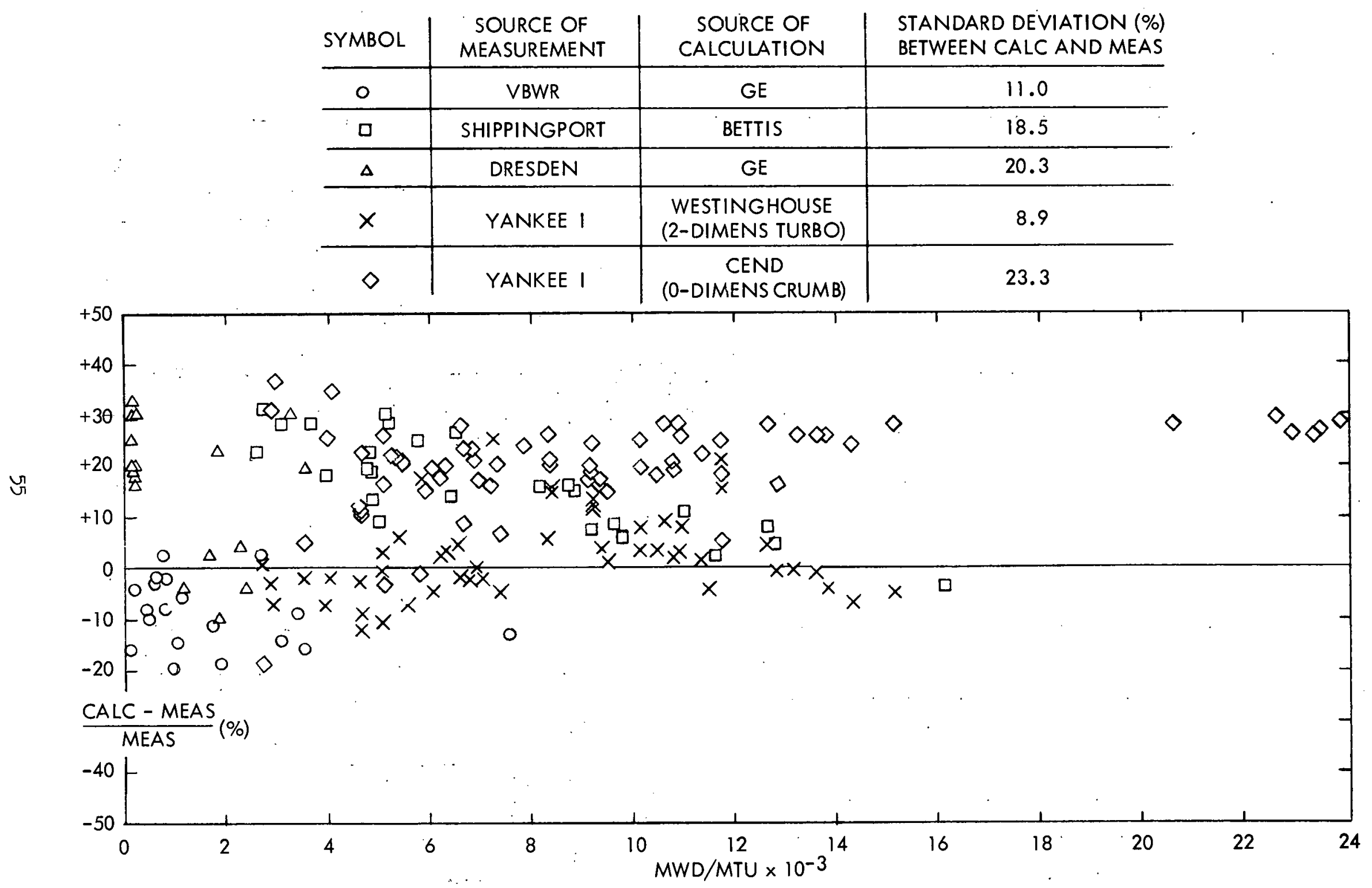

FIG 4 COMPARISON OF MEASURED AND CALCULATED Pu-240 CONTENT IN ANALYZED FUEL SAMPLES 


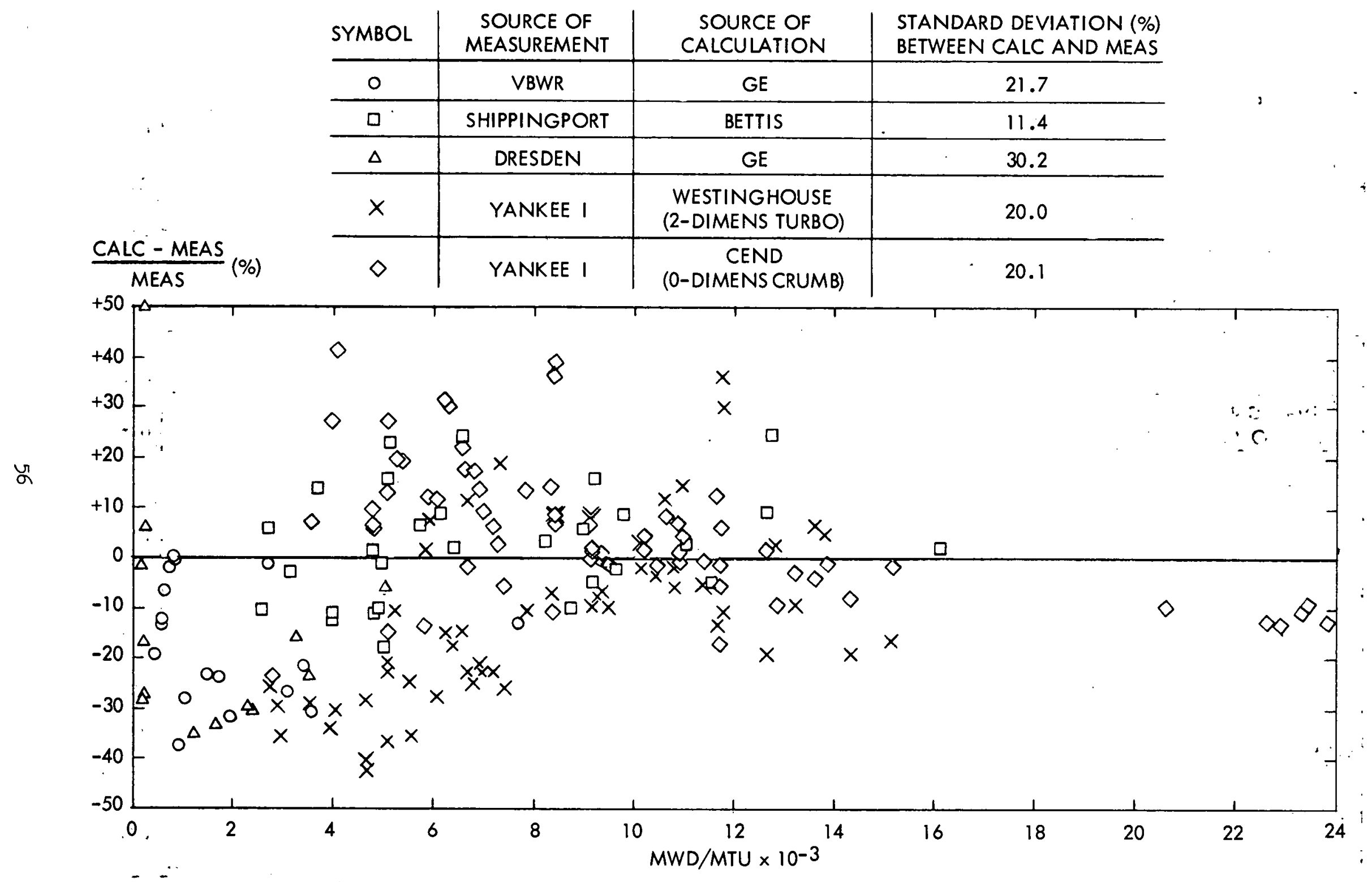

FIG 5 COMPARISON OF MEASURED AND CALCULATED PU-24I CONTENT IN ANALYZED FUEL SAMPLES 


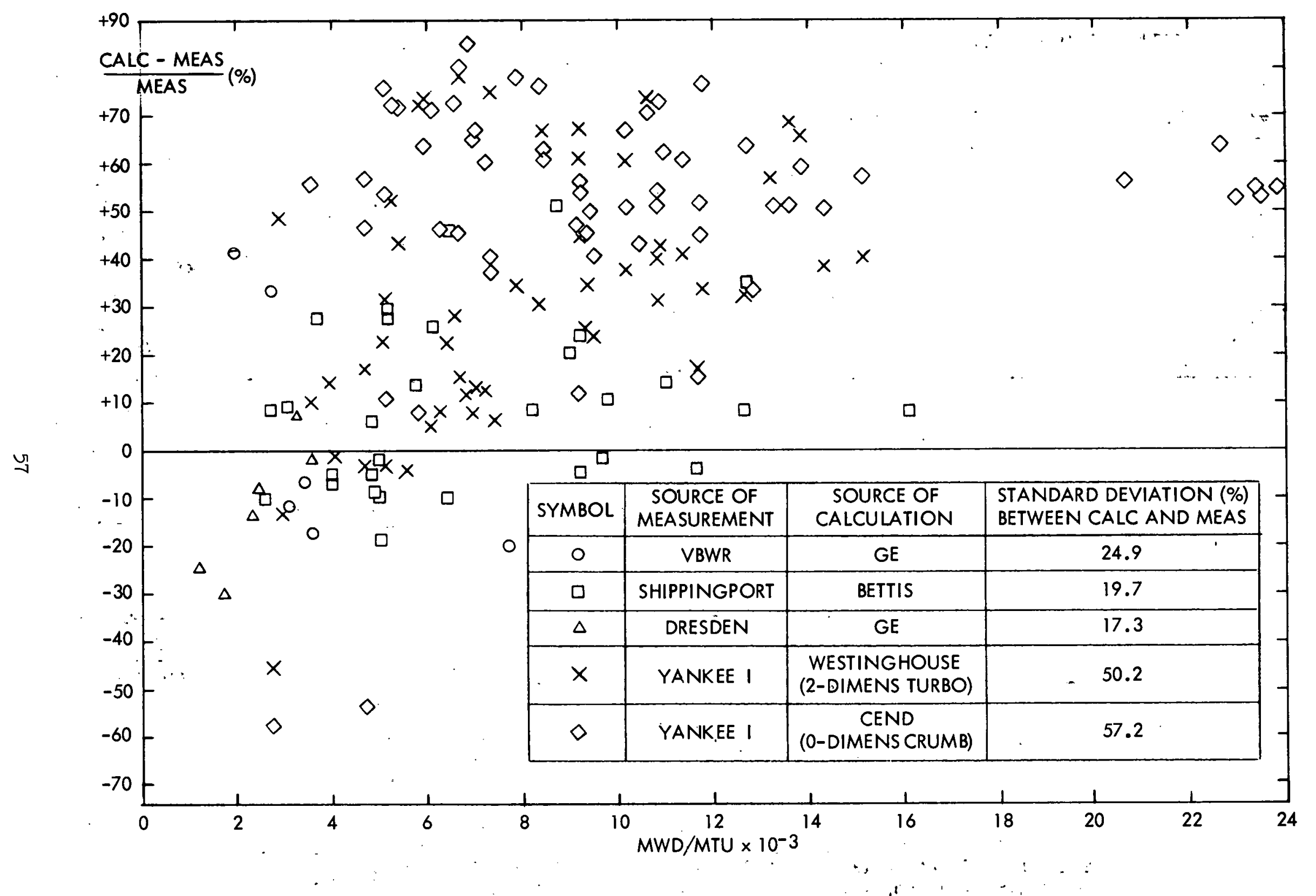

FIG 6 COMPARISON OF MEASURED AND CALCULATED PU-242 CONTENT IN ANALYZED FUEL SAMPLES 


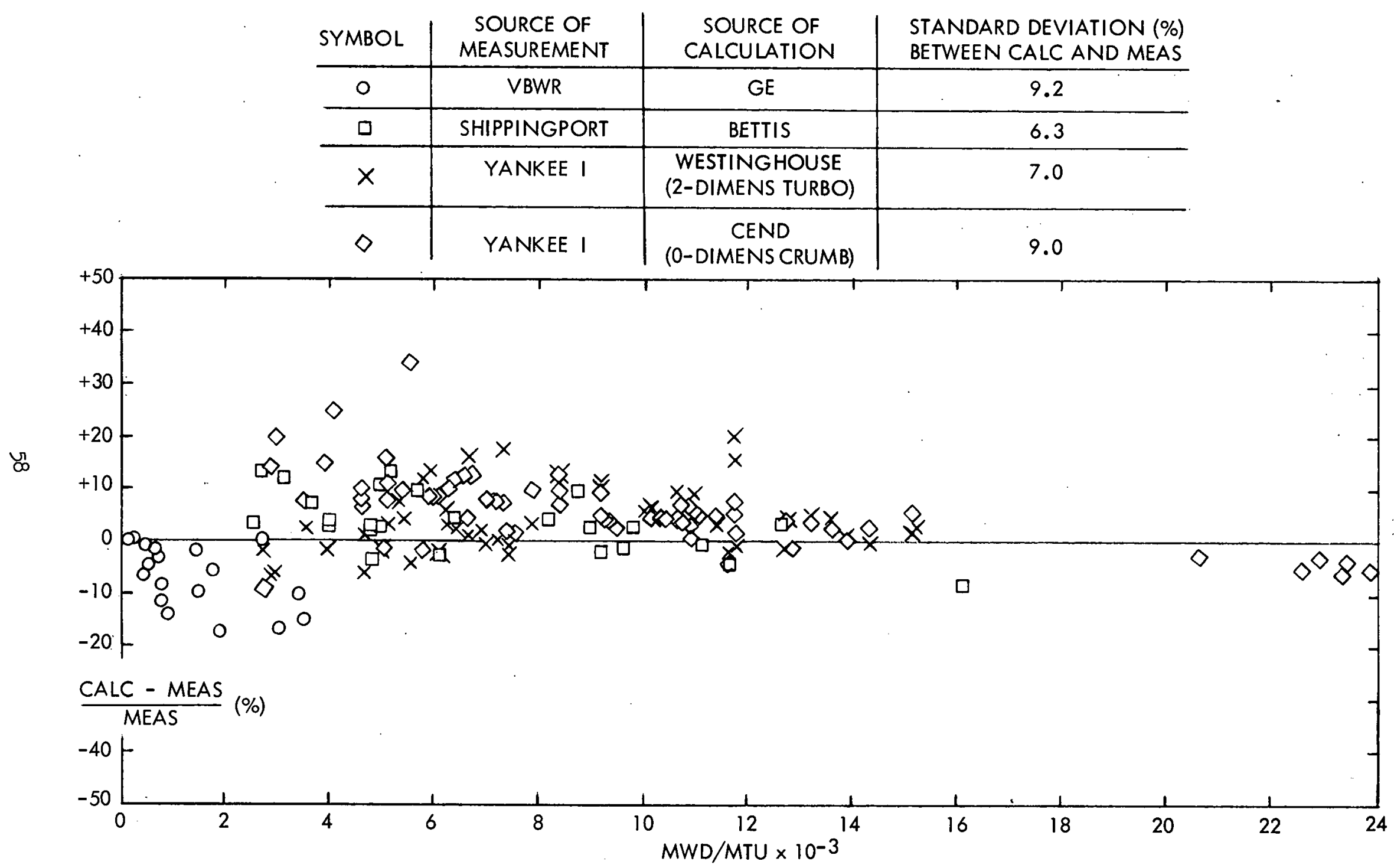

FIG 7 COMPARISON OF MEASURED AND CALCULATED TOTAL PLUTONIUM IN ANALYZED FUEL SAMPLES 


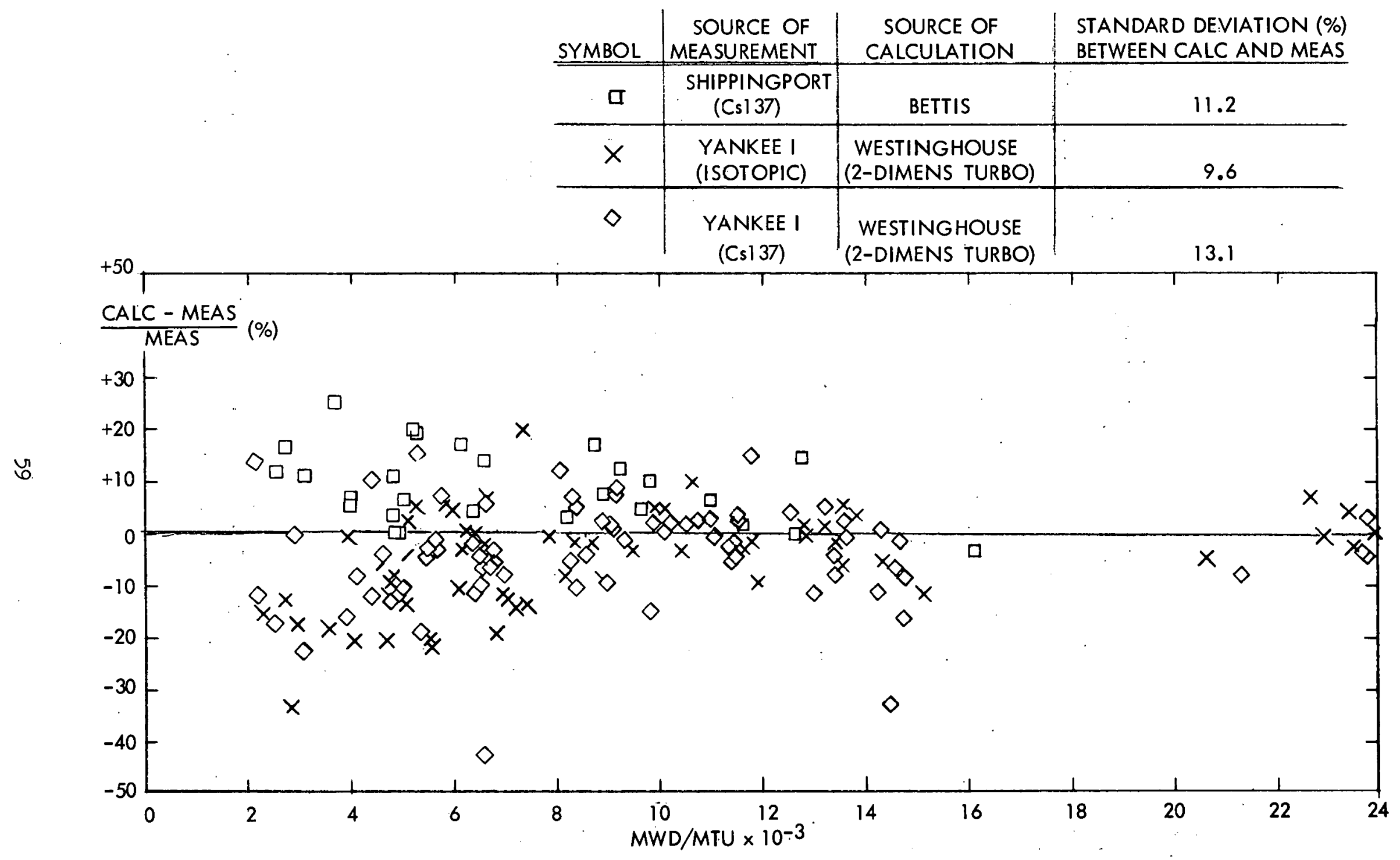

FIG 8 COMPARISON OF MEASURED AND CALCULATED INTEGRATED EXPOSURE OF ANALYZED FUEL SAMPLES 


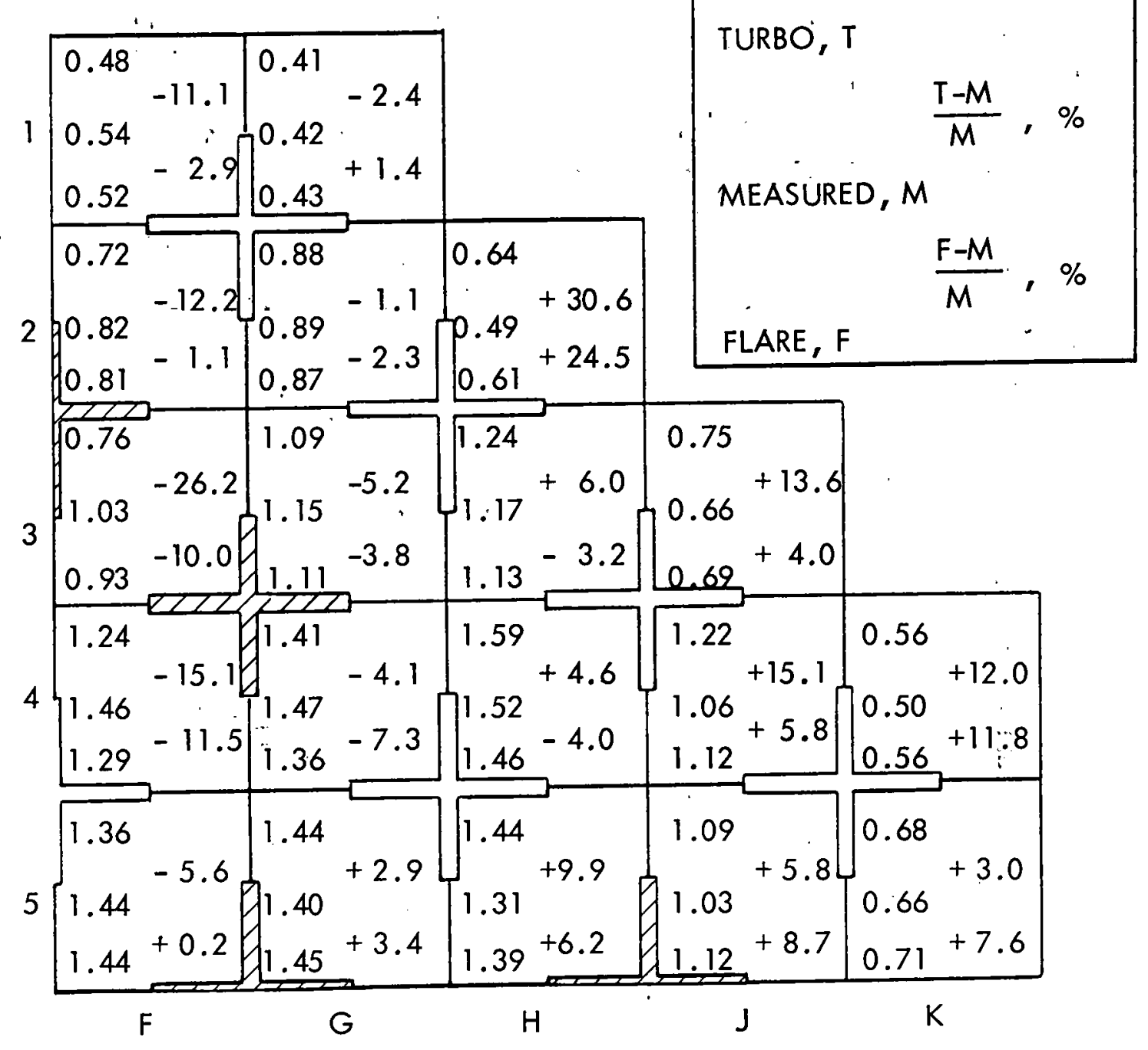

FIG 9 ANALYTICAL AND EXPERIMENTAL POWER DISTRIBUTIONS FOR AXIAL ZONE OF YANKEE CORE I AT 1385 MWD/MTU AVERAGE EXPOSURE 


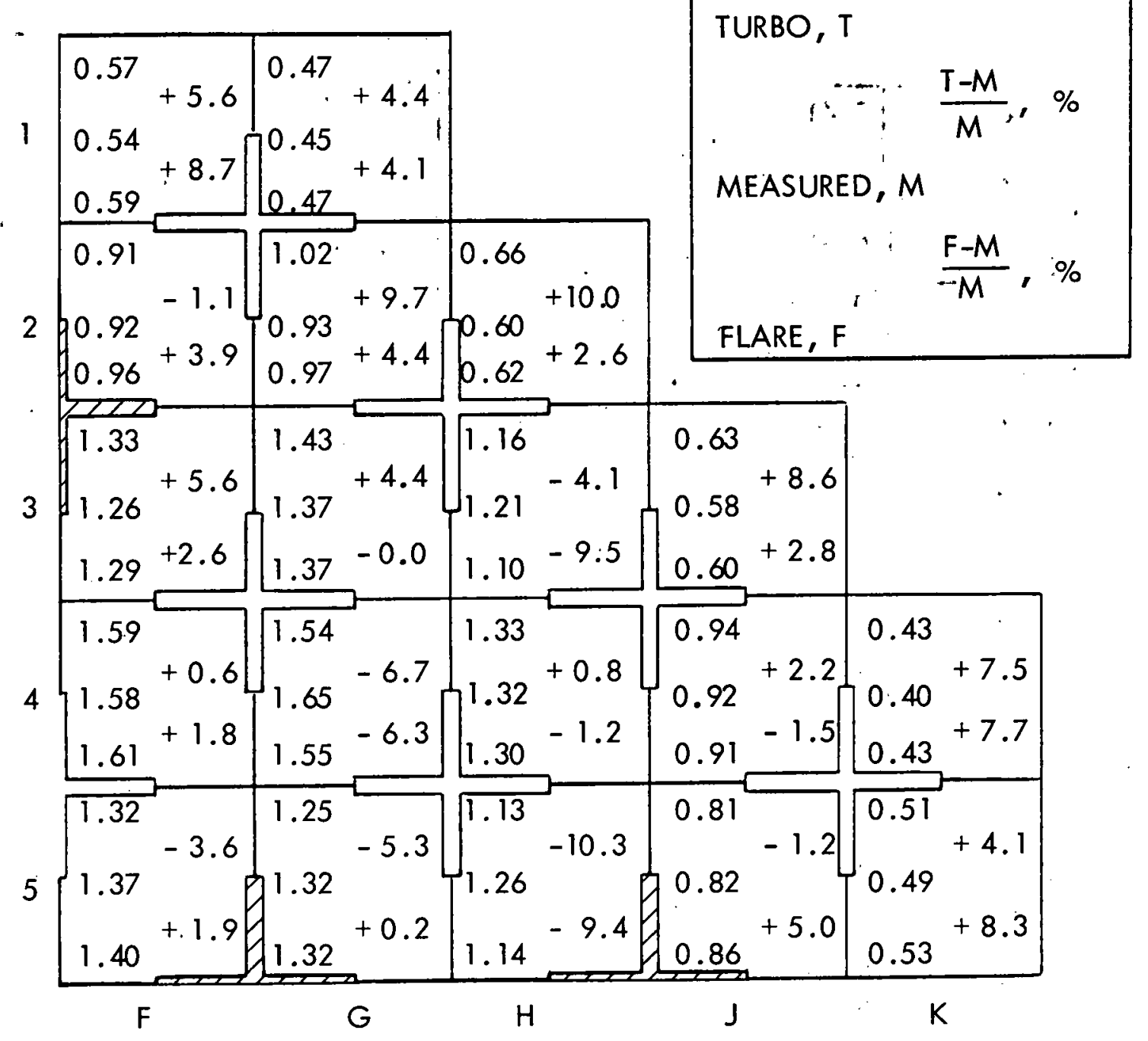

FIG 10 ANALYTICAL AND EXPERIMENTAL POWER DISTRIBUTIONS FOR AXIAL ZONE OF YANKEE CORE I AT 4133 MWD/MTU AVERAGE EXPOSURE 


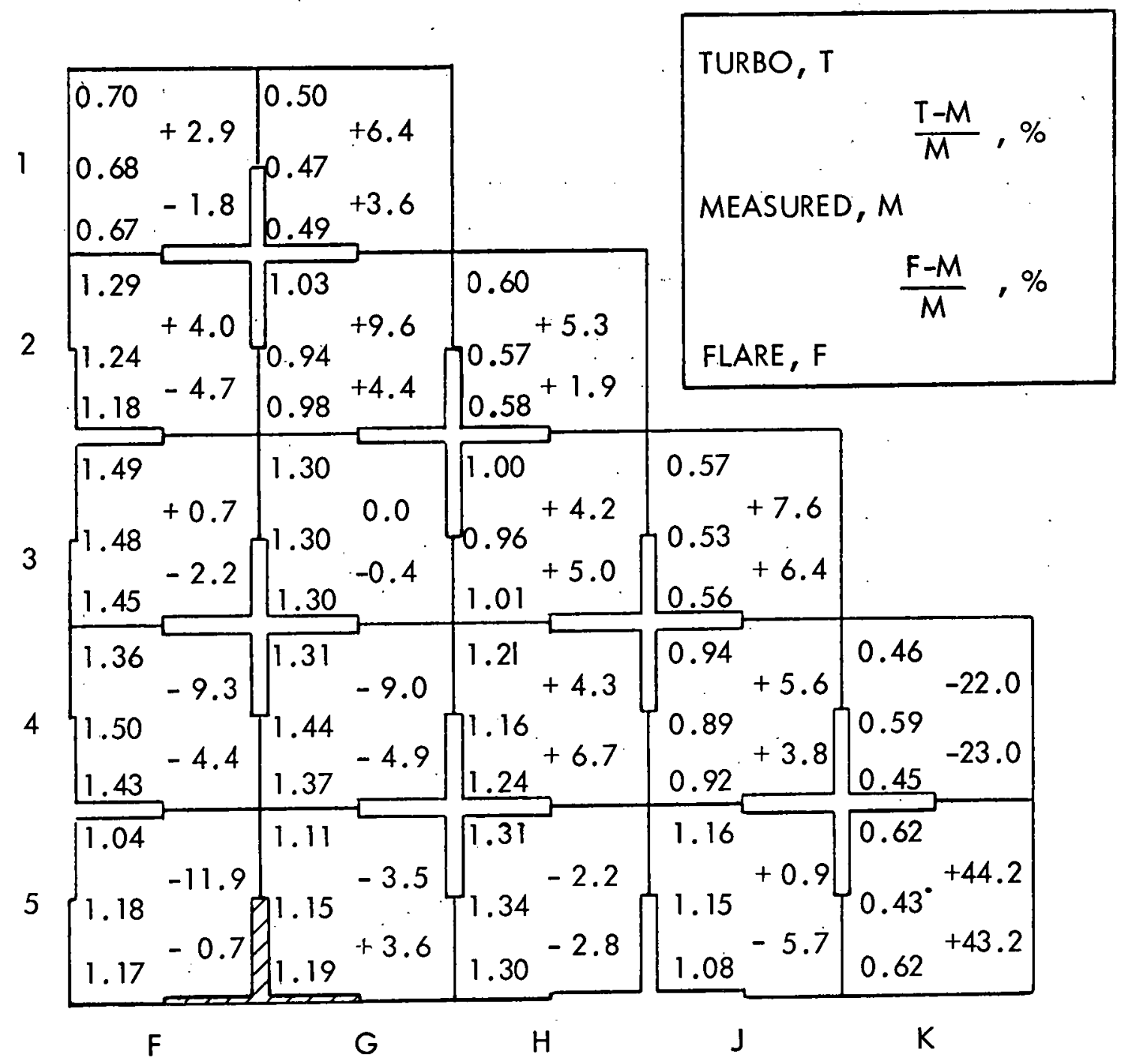

FIG $I 1$ ANALYTICAL AND EXPERIMENTAL POWER DISTRIBUTIONS FOR AXIAL ZONE OF YANKEE CORE I AT 5694 MWD/MTU AVERAGE EXPOSURE 


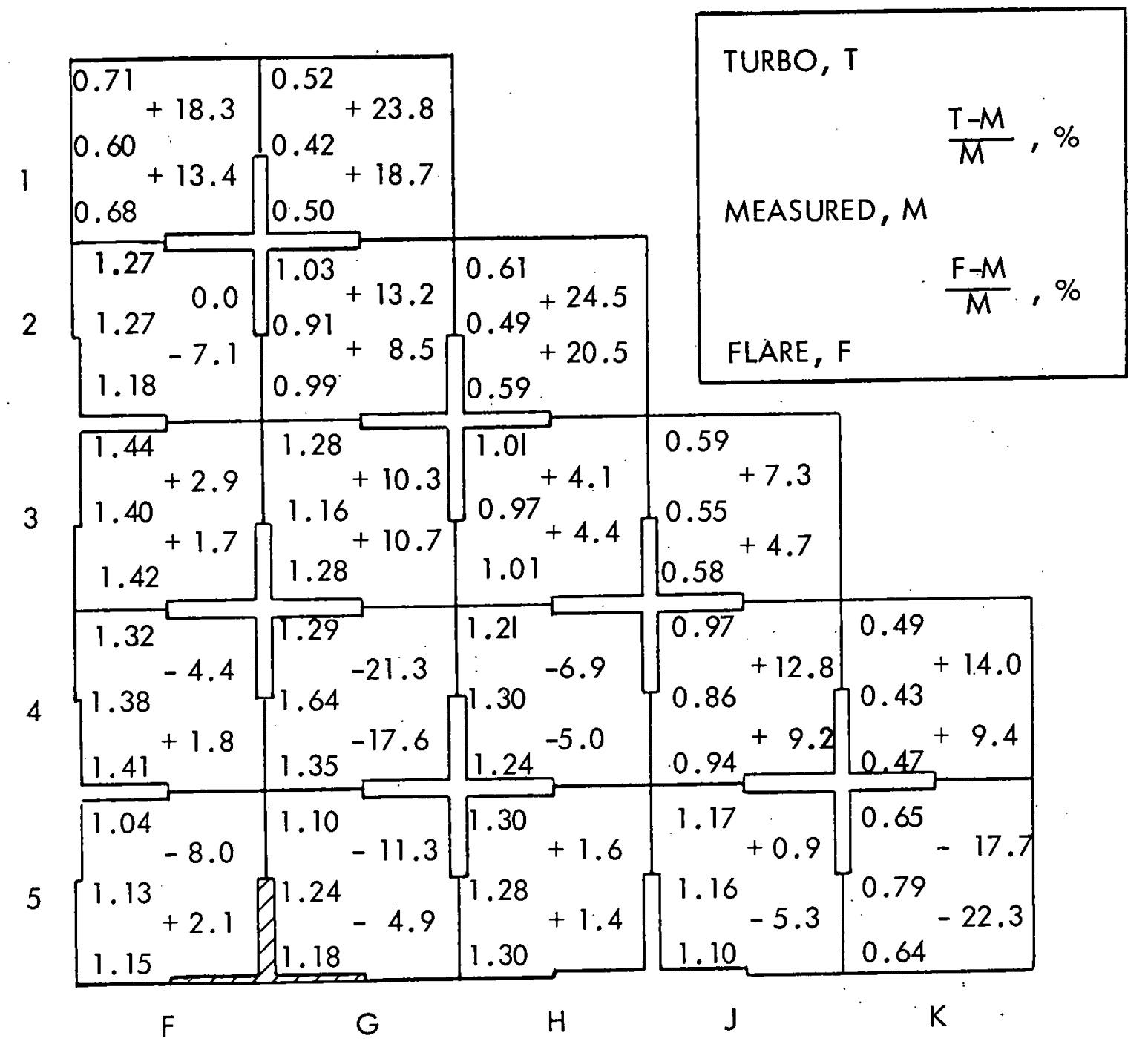

FIG 12 ANALYTICAL AND EXPERIMENTAL POWER DISTRIBUTIONS FOR AXIAL ZONE OF YANKEE CORE I AT 7034 MWD/MTU AVERAGE EXPOSURE 


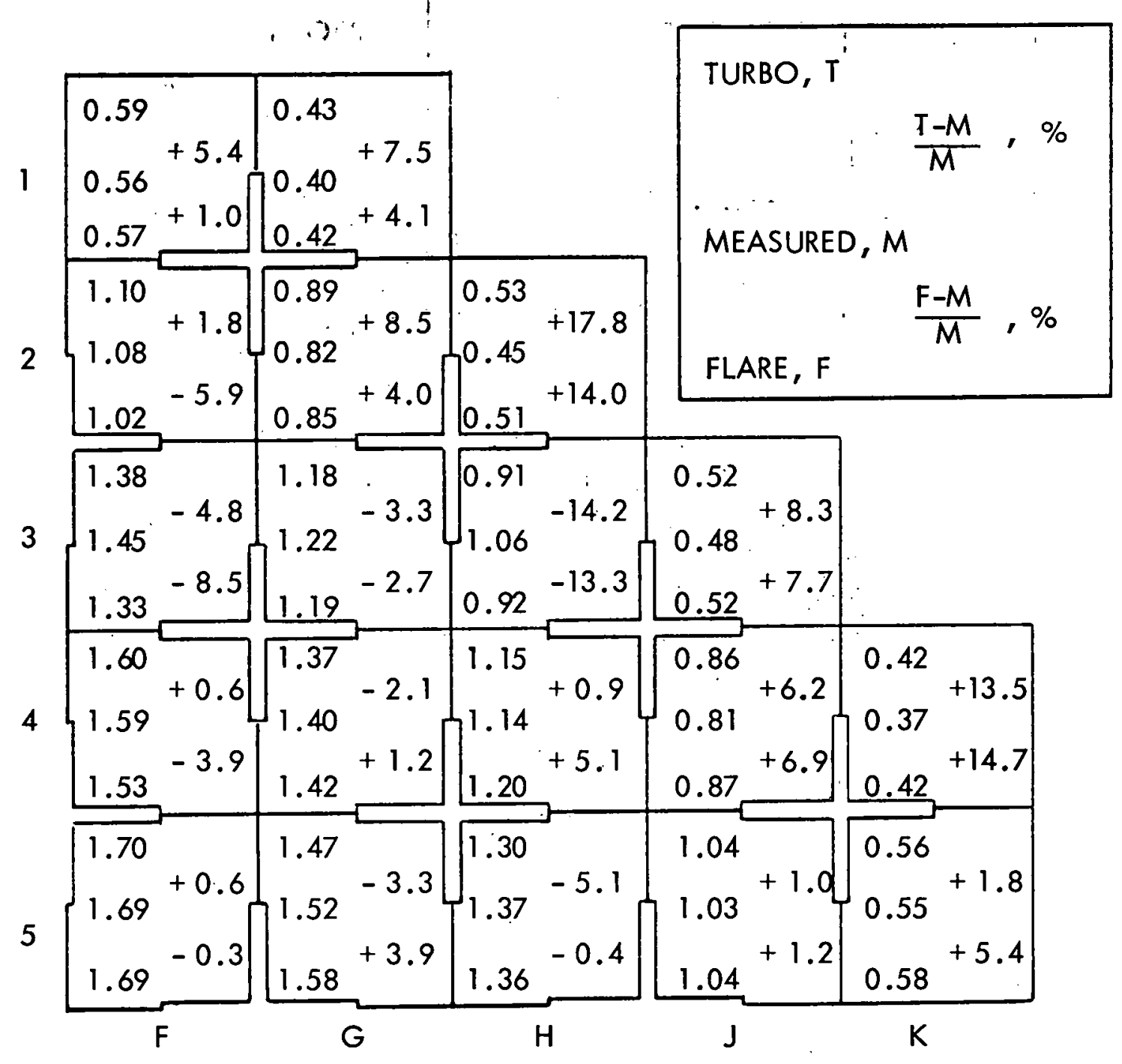

FIG 13 ANALYTICAL AND EXPERIMENTAL POWER DISTRIBUTIONS FOR AXIAL ZONE OF YANKEE CORE I AT 7755 MWD/MTU AVERAGE EXPOSURE 


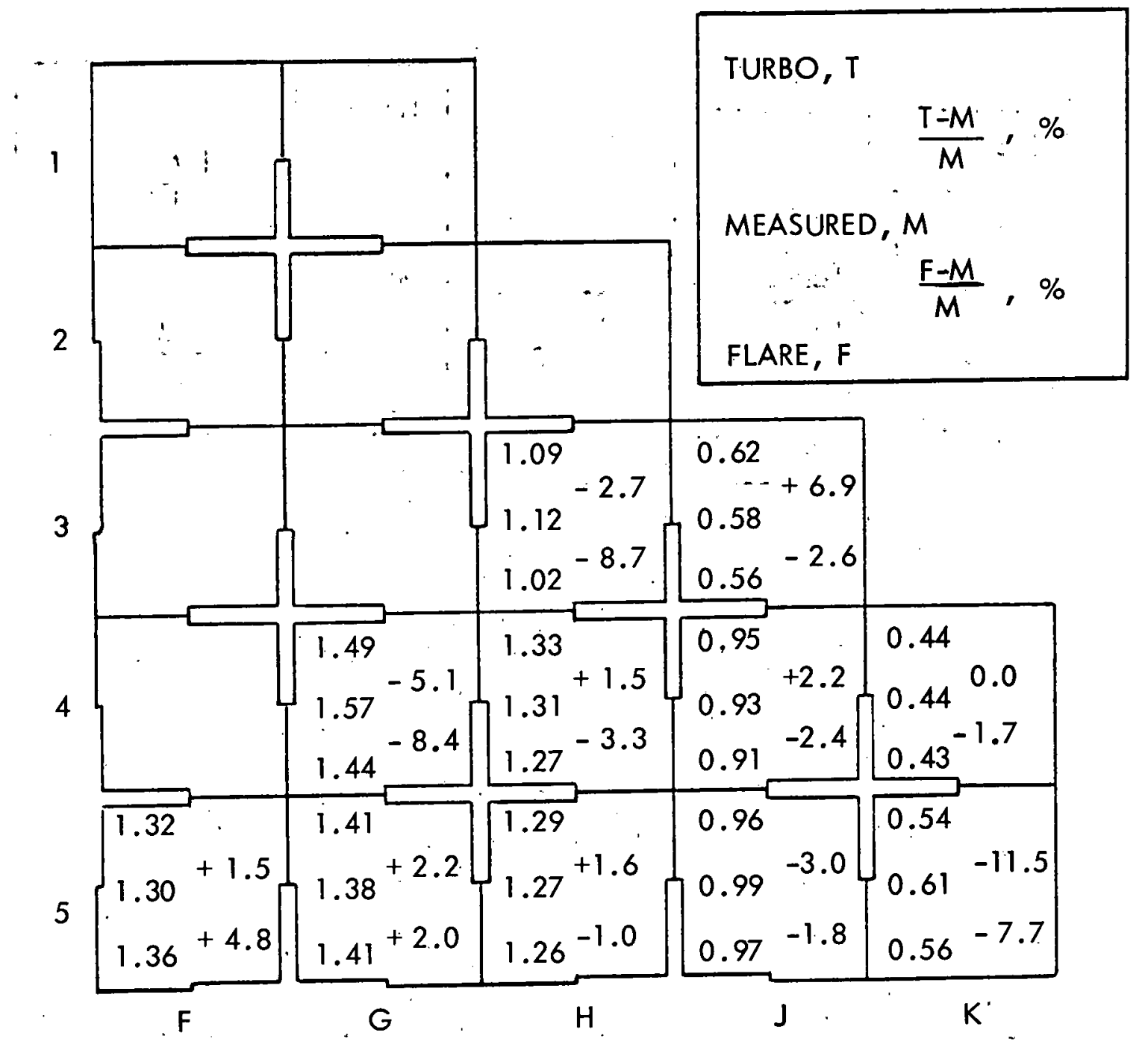

FIG 14 ANALYTICAL AND EXPERIMENTAL EXPOSURE DISTRIBUTIONS FOR AXIAL ZONE OF YANKEE CORE I AT 7755 MWD/MTU AVERAGE EXPOSURE 


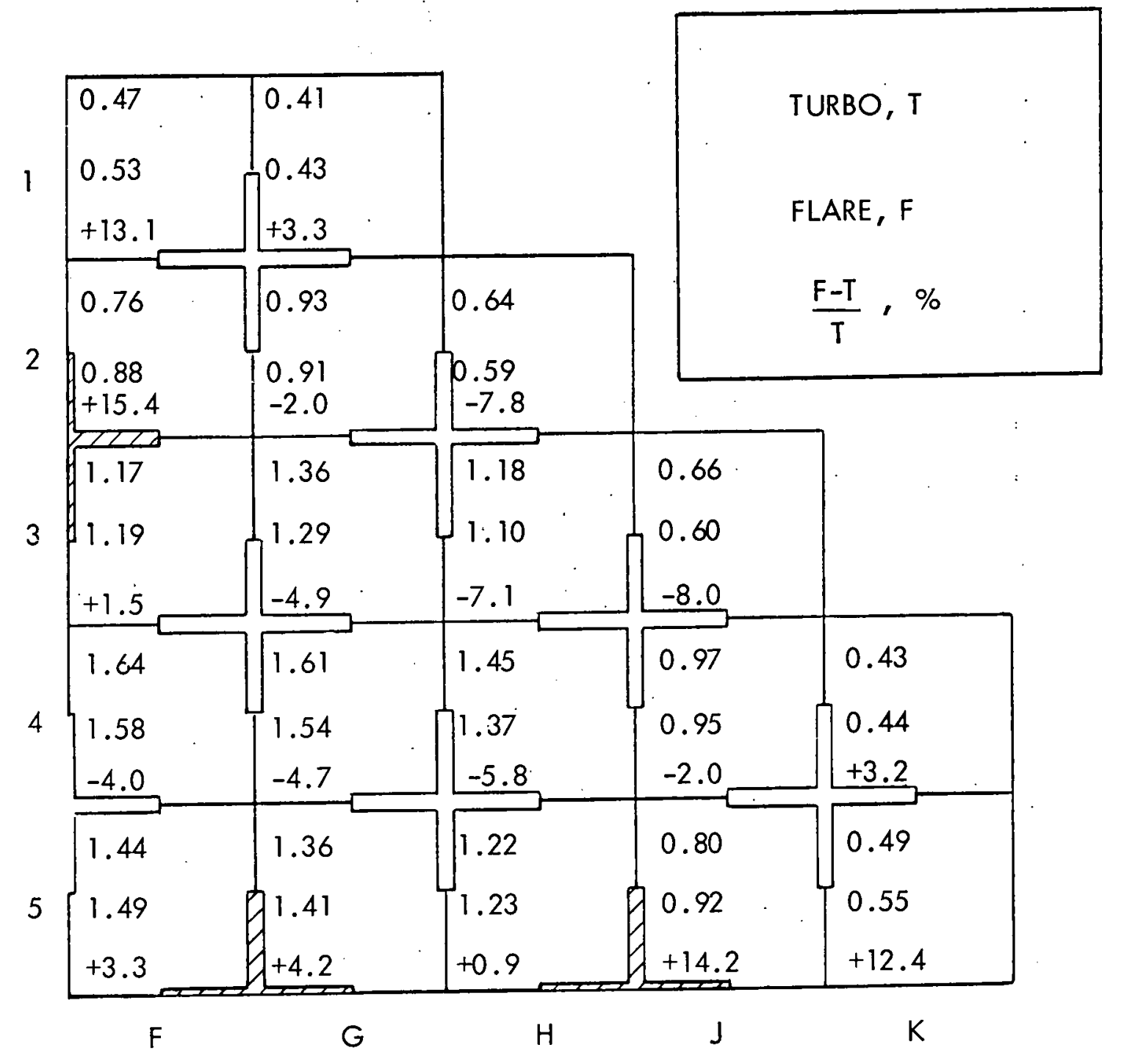

FIG 15 TURBO AND FLARE ANALYTICAL EXPOSURE DISTRIBUTIONS FOR AXIAL ZONE OF YANKEE CORE I AT 4133 MWD/MTU AVERAGE EXPOSURE 


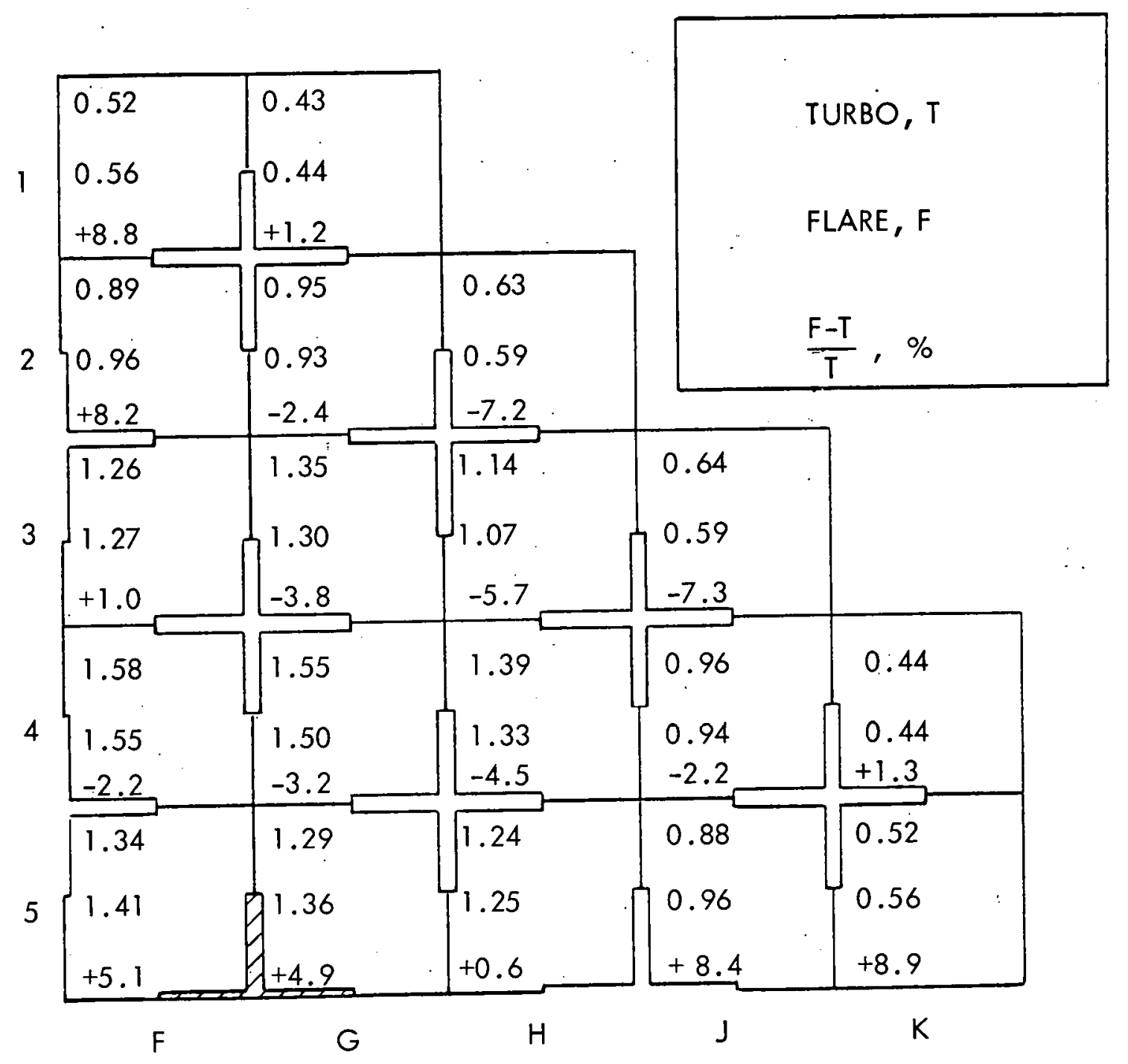

FIG 16 TURBO AND FLARE ANALYTICAL EXPOSURE DISTRIBUTIONS FOR AXIAL ZONE OF YANKEE CORE I AT 5694 MWD/MTU AVERAGE EXPOSURE 

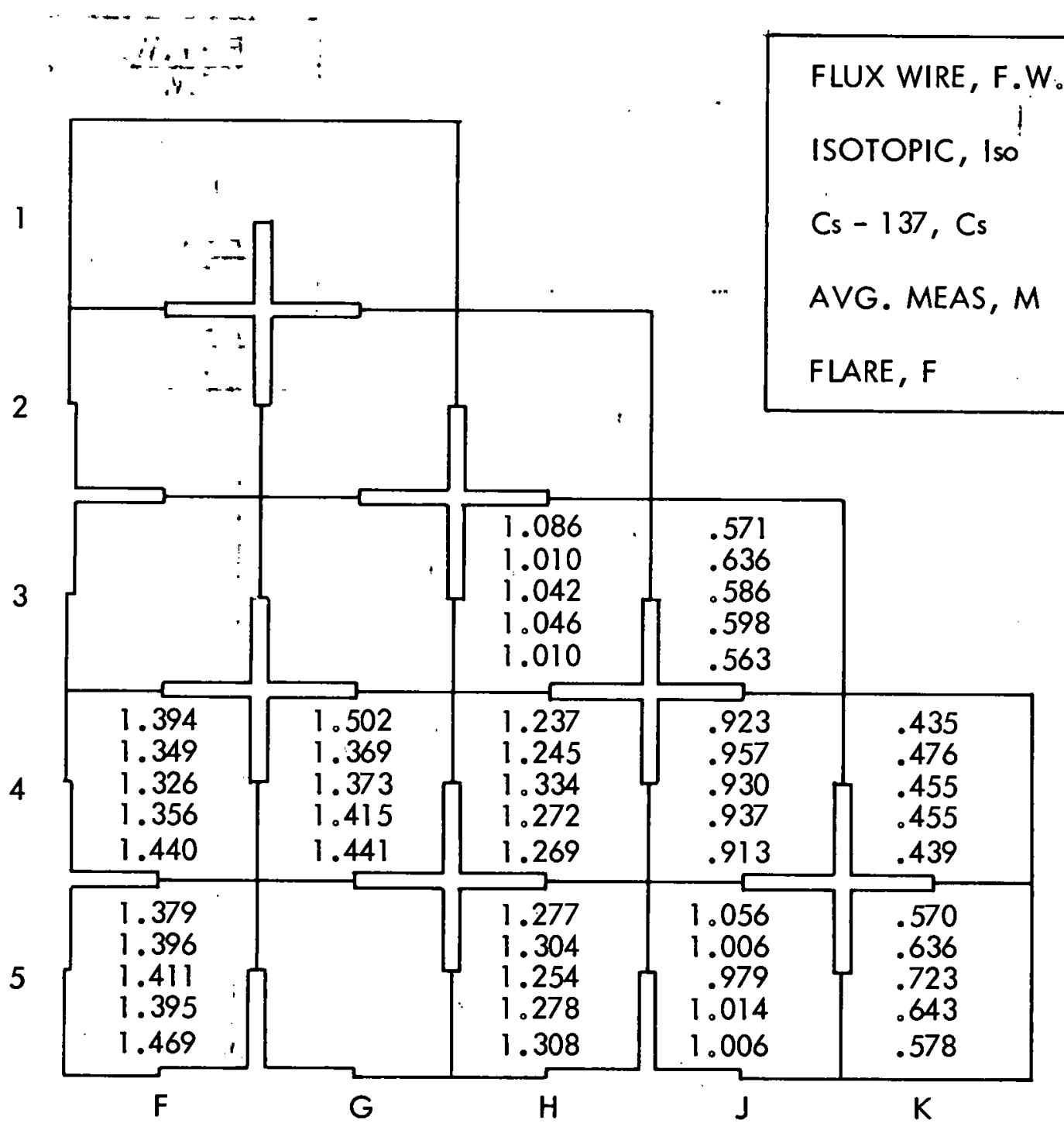

FIG 17 COMPARISON OF CALCULATED AND MEASURED AXIALLY-AVERAGED RELATIVE EXPOSURES ACCUMULATED BY INDIVIDUAL FUEL ELEMENTS IN YANKEE CORE I AT END OF LIFE (CORE AVERAGE EXPOSURE OF $8,470 \mathrm{MWD} / \mathrm{MTU})$ 


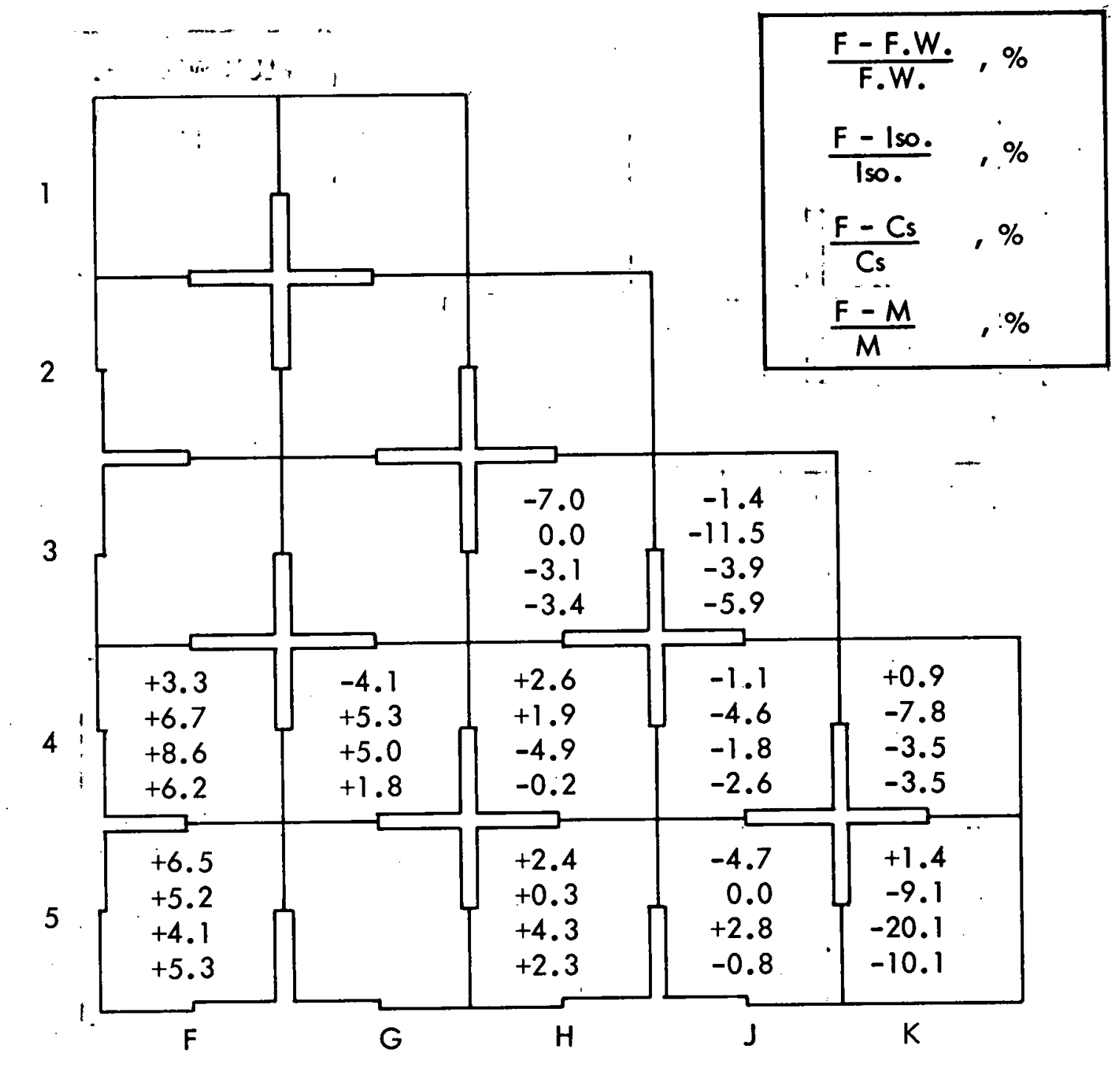

FIG 18 PERCENTAGE DIFFERENCES BETWEEN CALCULATED AND MEASURED AXIALLY-AVERAGED EXPOSURES OF INDIVIDUAL FUEL ELEMENTS IN YANKEE CORE I AT END OF LIFE (CORE AVERAGE EXPOSURE. OF 8,470 MWD/MTU) 


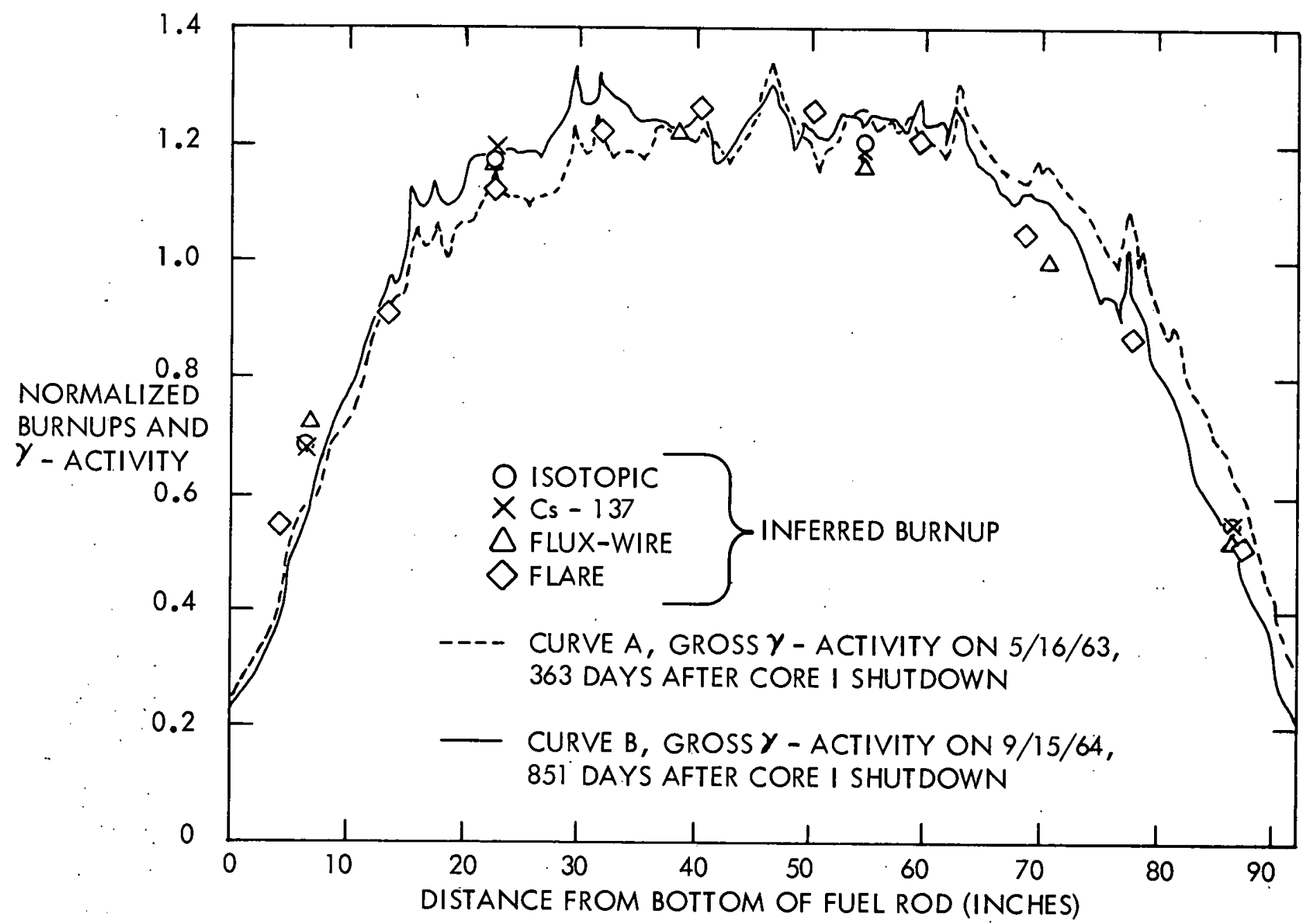

FIG 19 COMPARISON OF AXIAL DISTRIBUTION OF GROSS GAMMA ACTIVITY AND CALCULATED AND MEASURED BURNUPS IN YANKEE CORE I ASYMPTOTIC CORE POSITION H3-C-f6 


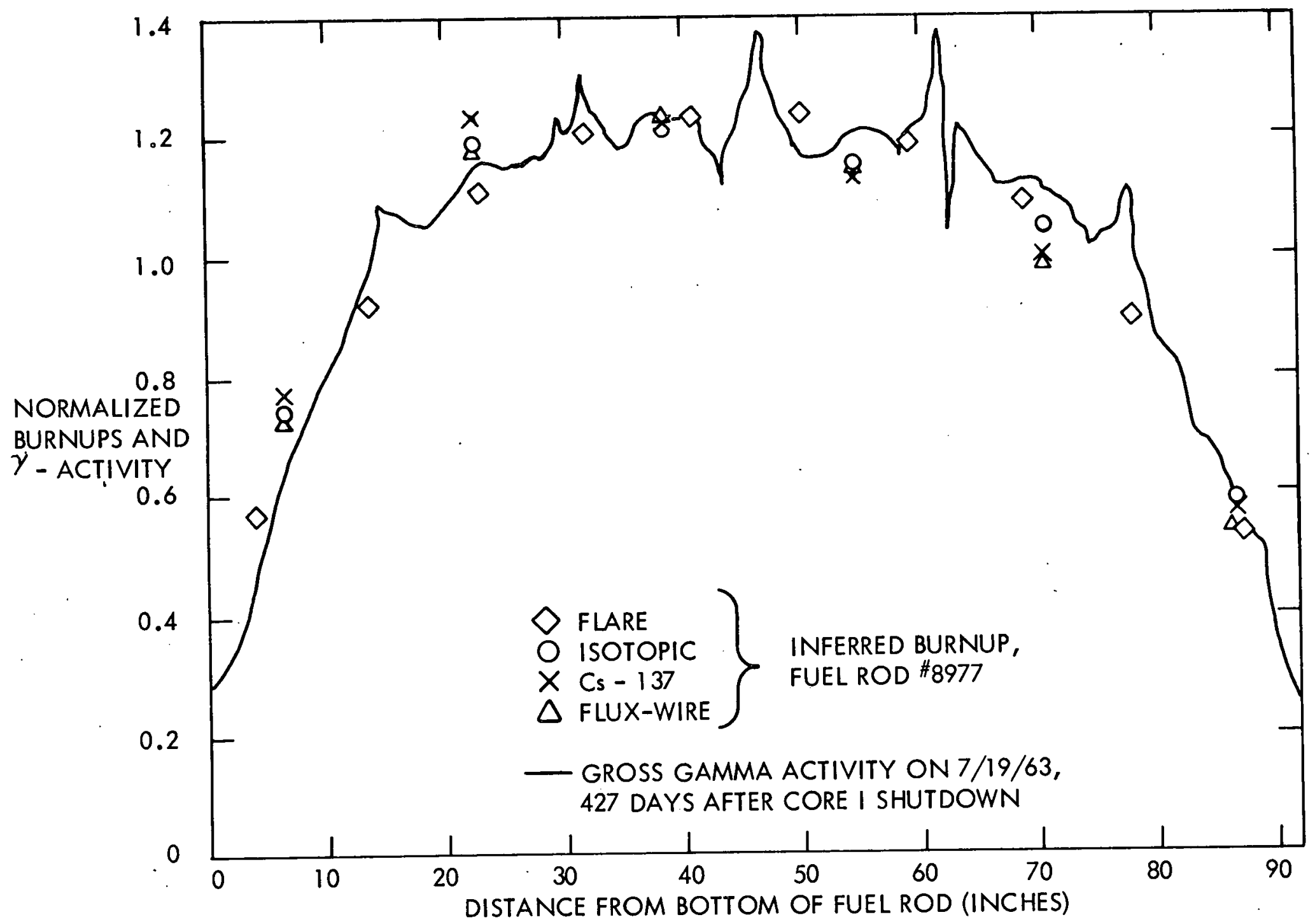

FIG 20 COMPARISON OF AXIAL DISTRIBUTION OF GROSS GAMMA ACTIVITY AND CALCULATED AND MEASURED BURNUPS IN YANKEE CORE I ASYMPTOTIC CORE POSITION F4-C-fI 


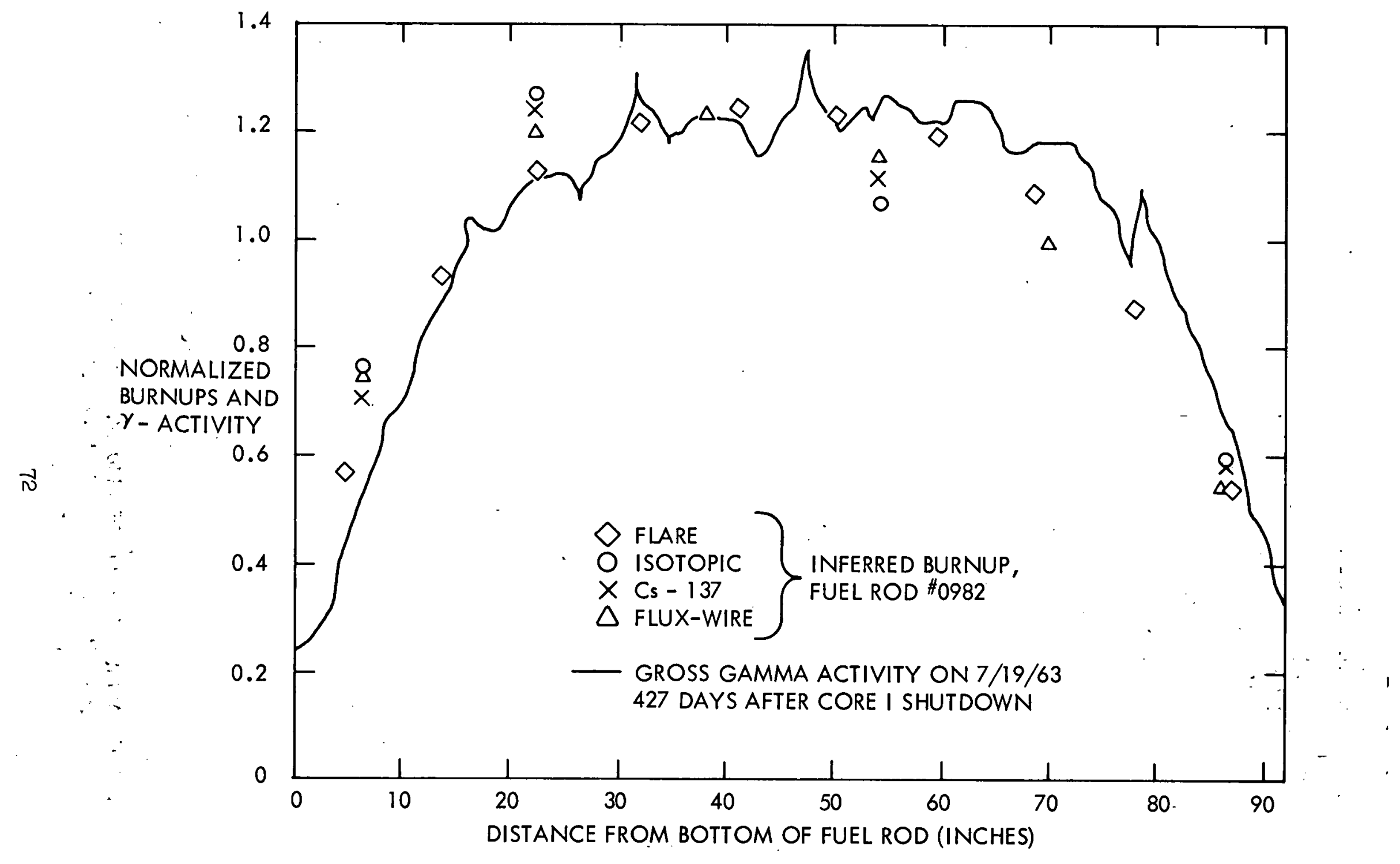

FIG 21 COMPARISON OF AXIAL DISTRIBUTION OF GROSS GAMMA ACTIVITY AND CALCULATED AND MEASURED BURNUPS IN YANKEE CORE I ASYMPTOTIC CORE POSITION G4-C-f6 


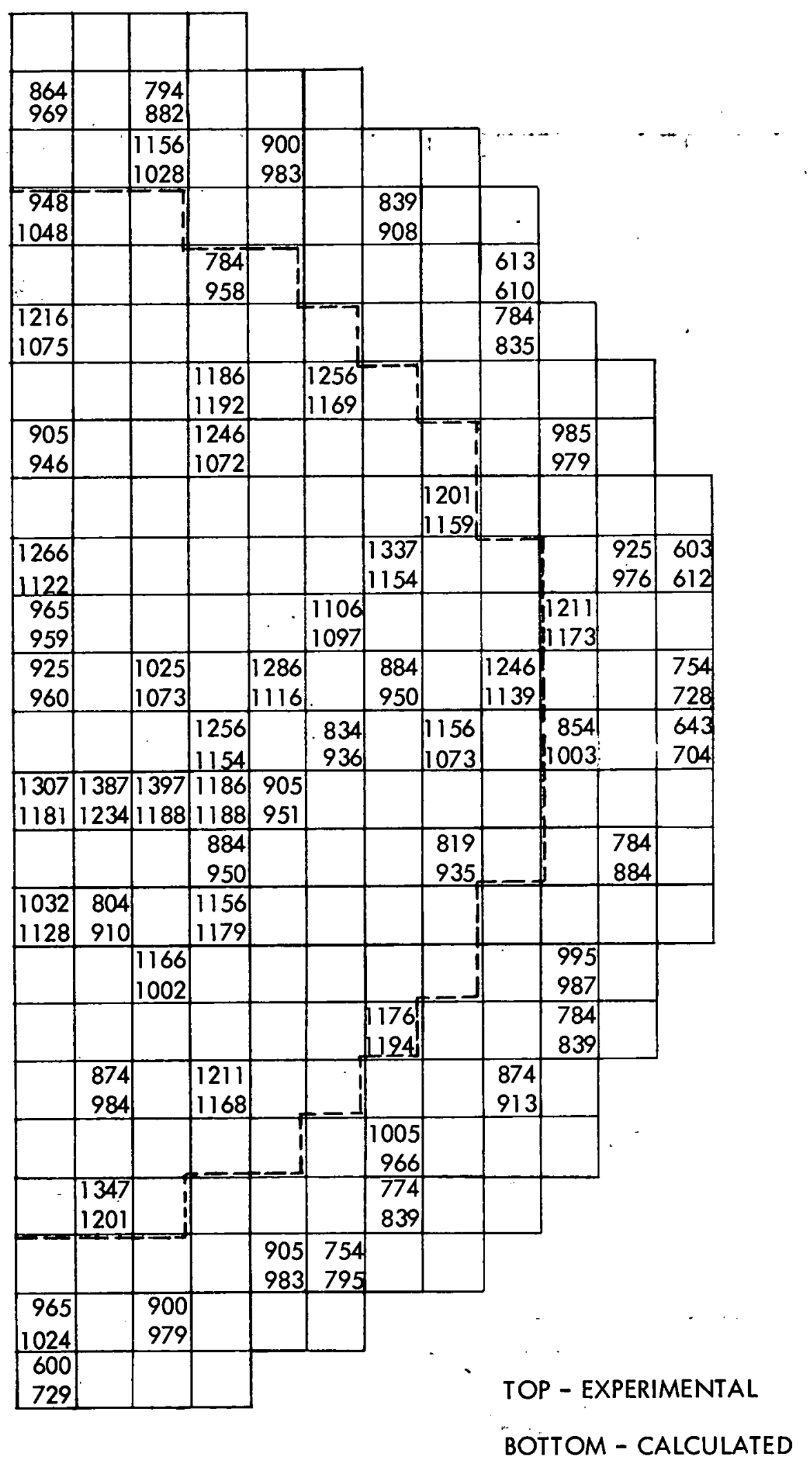

FIG 22 ANALYTICAL (FLARE) AND EXPERIMENTAL POWER DISTRIBUTIONS FOR DRESDEN (FROM REF 22); CLEAN CORE - 1/2 POWER 


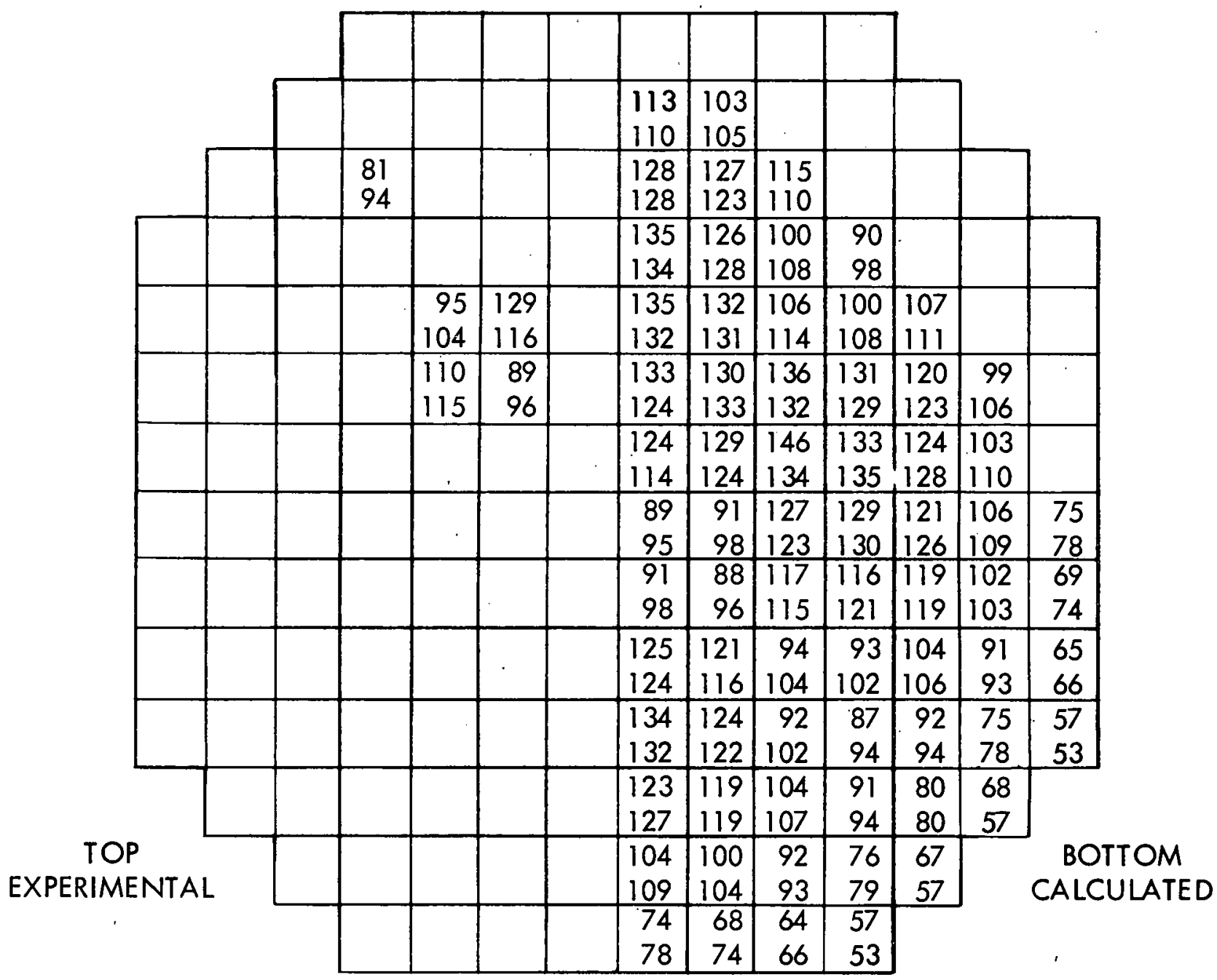

FIG 23 ANALYTICAL (FLARE) AND EMPERIMENTAL POWER DISTRIBUTIONS FOR HUMBOLDT BAY (FROM REF. 22 ); CLEAN CORE, FULL POWER 


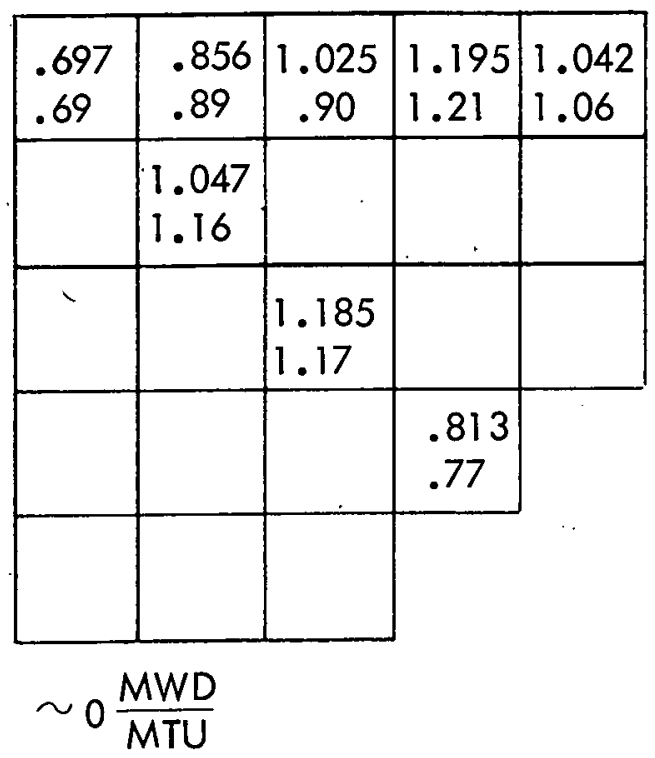

\begin{tabular}{|c|c|c|c|c|}
\hline $\begin{array}{l}.958 \\
.941\end{array}$ & $\begin{array}{l}1.049 \\
1.043\end{array}$ & $\begin{array}{l}1.121 \\
1.066\end{array}$ & $\begin{array}{l}1.140 \\
1.098\end{array}$ & $\begin{array}{l}.918 \\
.943 \\
\end{array}$ \\
\hline & $\begin{array}{l}1.159 \\
1.205\end{array}$ & & & \\
\hline & & $\begin{array}{l}1.154 \\
1.193 \\
\end{array}$ & & \\
\hline & & & $\begin{array}{l}.732 \\
.737\end{array}$ & \\
\hline & & & & \\
\hline
\end{tabular}

\begin{tabular}{|c|c|c|c|c|}
\hline $\begin{array}{l}.918 \\
.960\end{array}$ & $\begin{array}{l}.976 \\
.960\end{array}$ & $\begin{array}{r}1.069 \\
.993\end{array}$ & $\begin{array}{l}1.158 \\
1.122\end{array}$ & $\begin{array}{l}.970 \\
.975\end{array}$ \\
\hline & $\begin{array}{l}1.119 \\
1.163\end{array}$ & & & \\
\hline & & $\begin{array}{l}1.171 \\
1.159\end{array}$ & & \\
\hline & & & $\begin{array}{l}.765 \\
.772\end{array}$ & \\
\hline & & & & \\
\hline
\end{tabular}

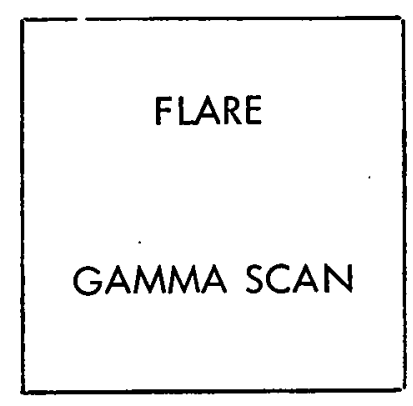

$\sim 4,000 \frac{M W D}{M T U}$ 


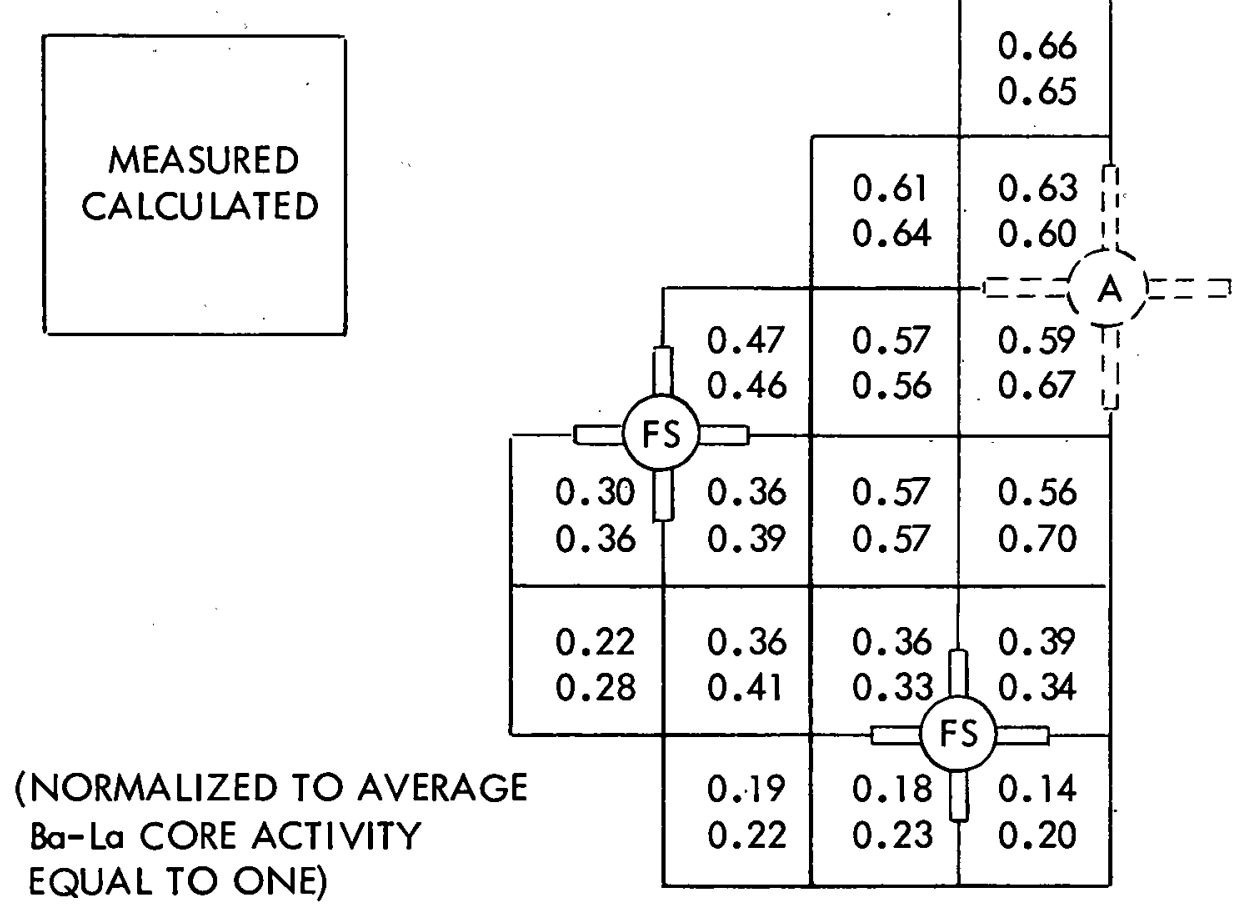

FIG 25 COMPARISON OF CALCULATED AND MEASURED Ba-La ACTIVITIES AT AXIAL SCAN POSITION 2 IN OCTANT OF INDIAN POINT REACTOR

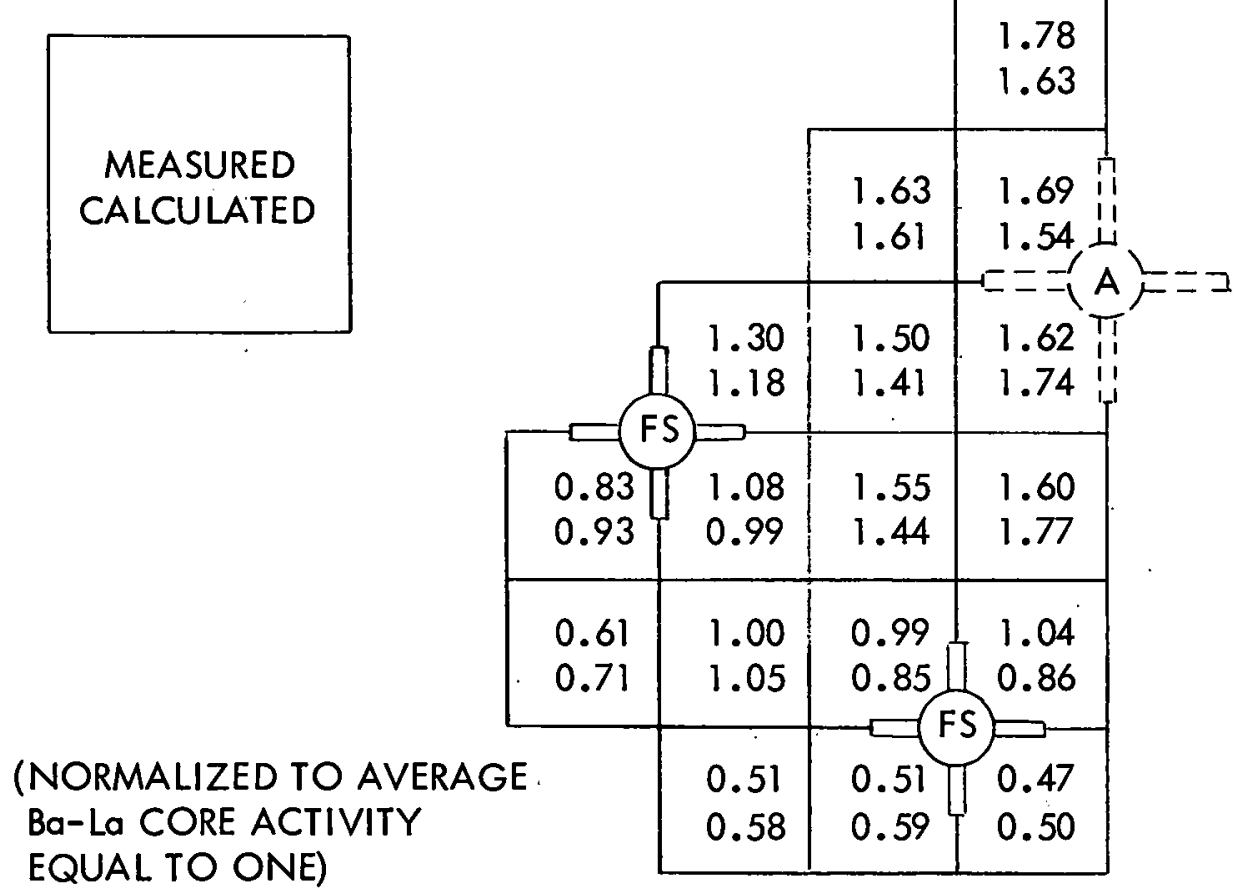

FIG 26. COMPARISON OF CALCULATED AND MEASURED Ba-Lo ACTIVITIES AT AXIAL SCAN POSITION 7 IN OCTANT OF INDIAN POINT REACTOR 

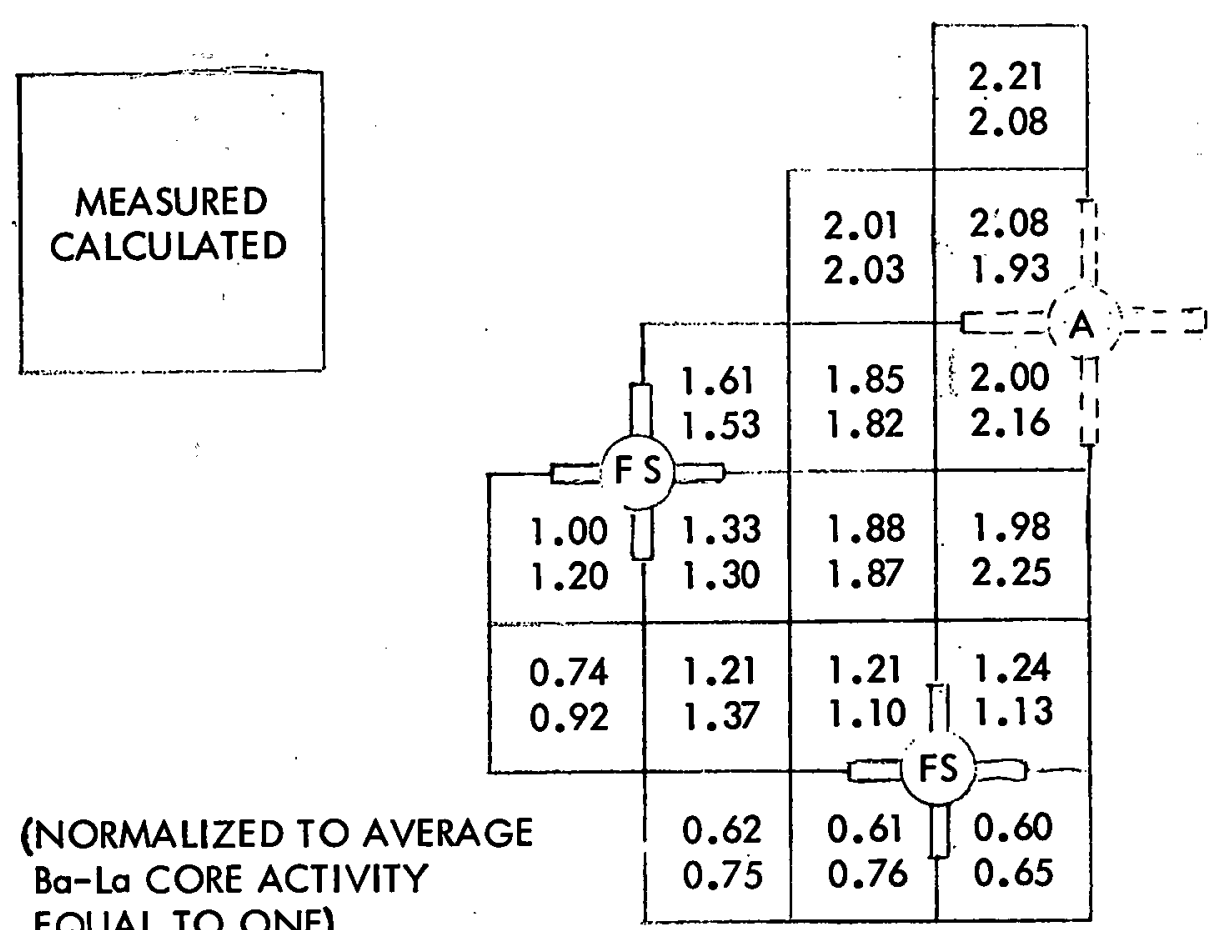

(NORMALIZED TO AVERAGE Ba-La CORE ACTIVITY EQUAL TO ONE)

FIG 27 COMPARISON OF CALCULATED AND MEASURED Ba-La ACTIVITIES AT AXIAL SCAN POSITION 12 IN OCTANT OF INDIAN POINT REACTOR

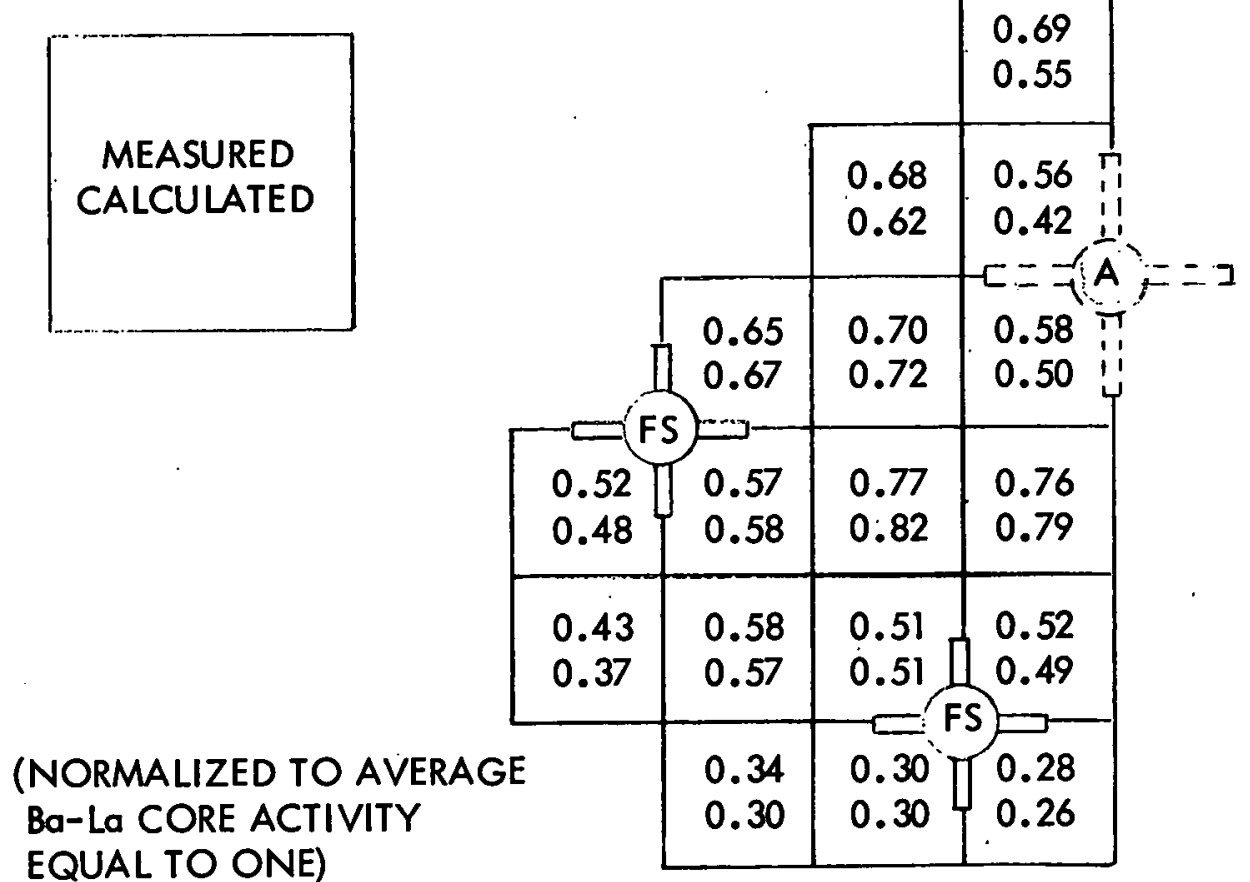

FIG 28 COMPARISON OF CALCULATED AND MEASURED Ba-La ACTIVITIES AT AXIAL SCAN POSITION 18 IN OCTANT OF INDIAN POINT REACTOR 


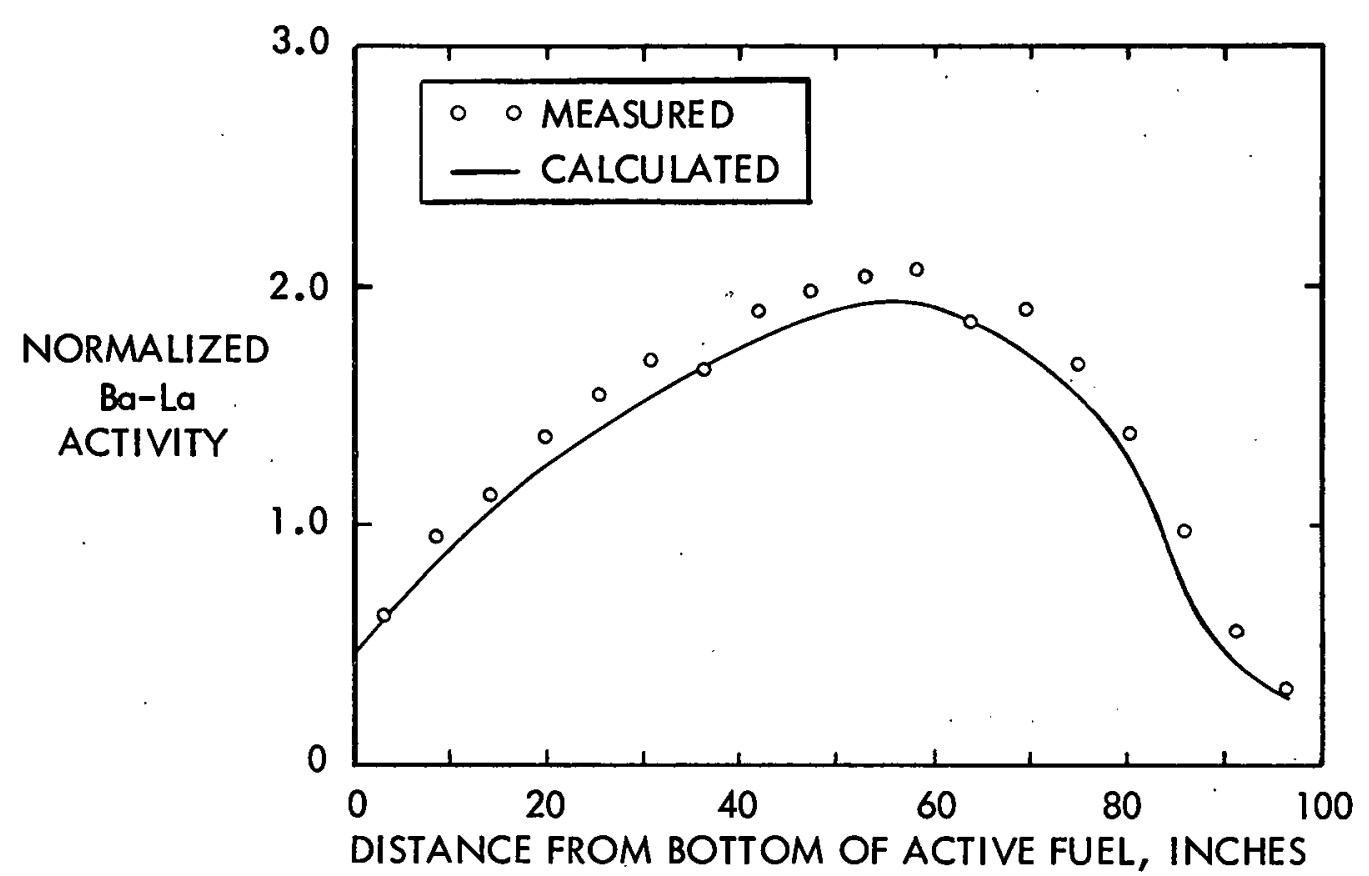

FIG 29 COMPARISON OF MEASURED AND CALCULATED Ba-La ACTIVITIES ALONG FUEL ELEMENT NO. 21 OF INDIAN POINT REACTOR.

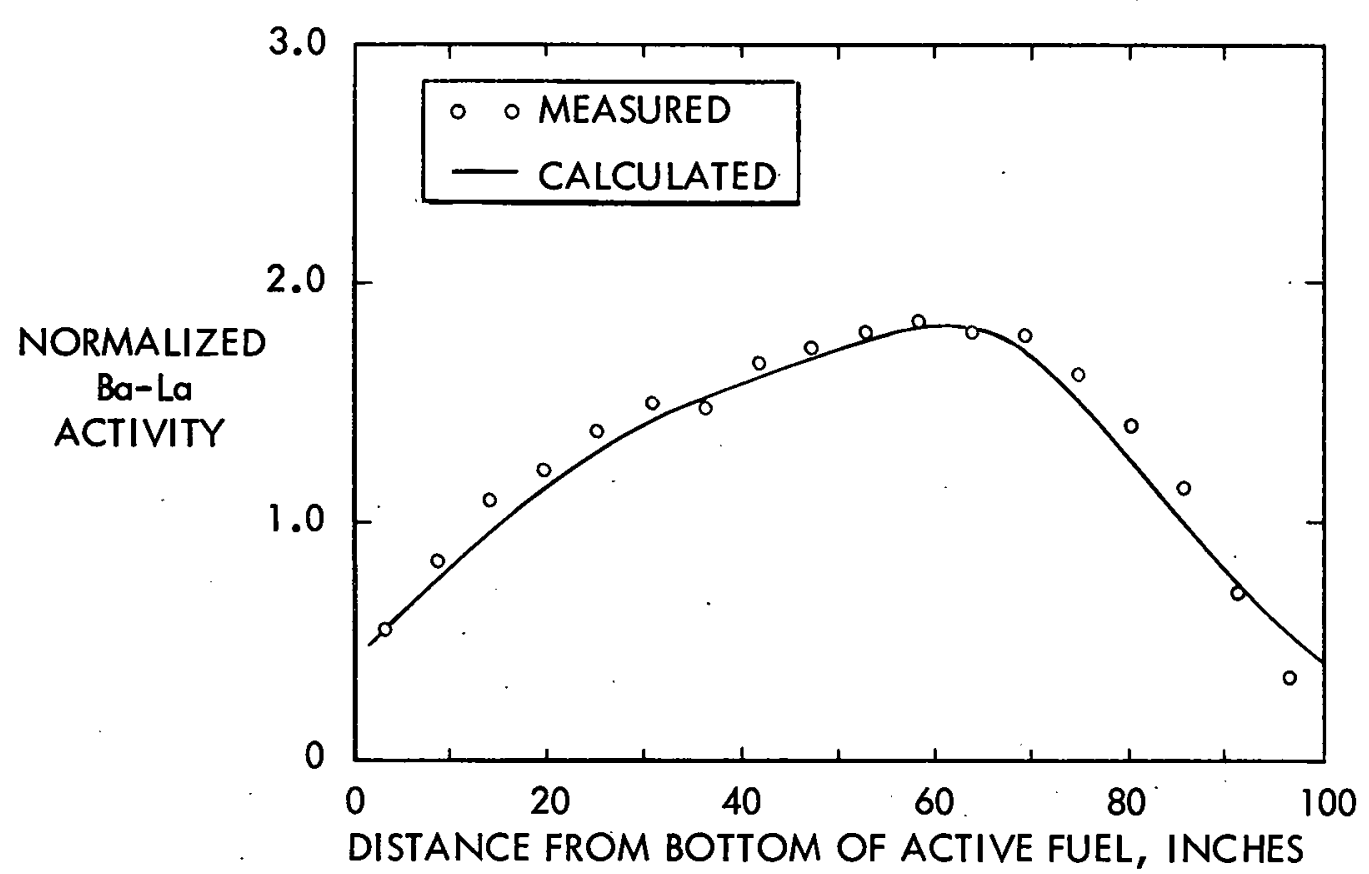

FIG 30 COMPARISON OF MEASURED AND CALCULATED Ba-La ACTIVITIES ALONG FUEL ELEMENT NO. 28 OF INDIAN POINT REACTOR 


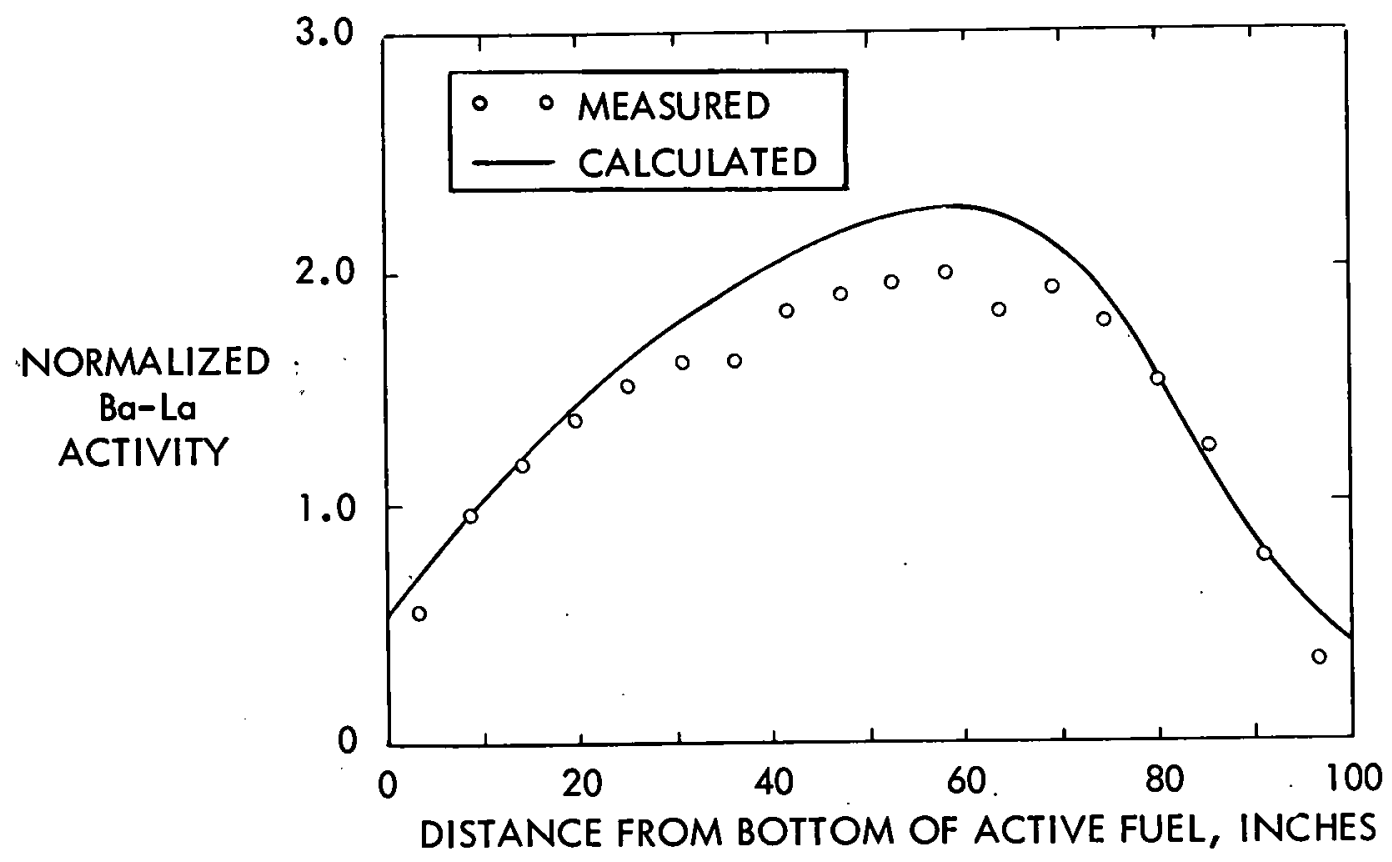

FIG 31 COMPARISON OF MEASURED AND CALCULATED Ba-La ACTIVITIES ALONG FUEL ELEMENT NO. 57 OF INDIAN POINT REACTOR

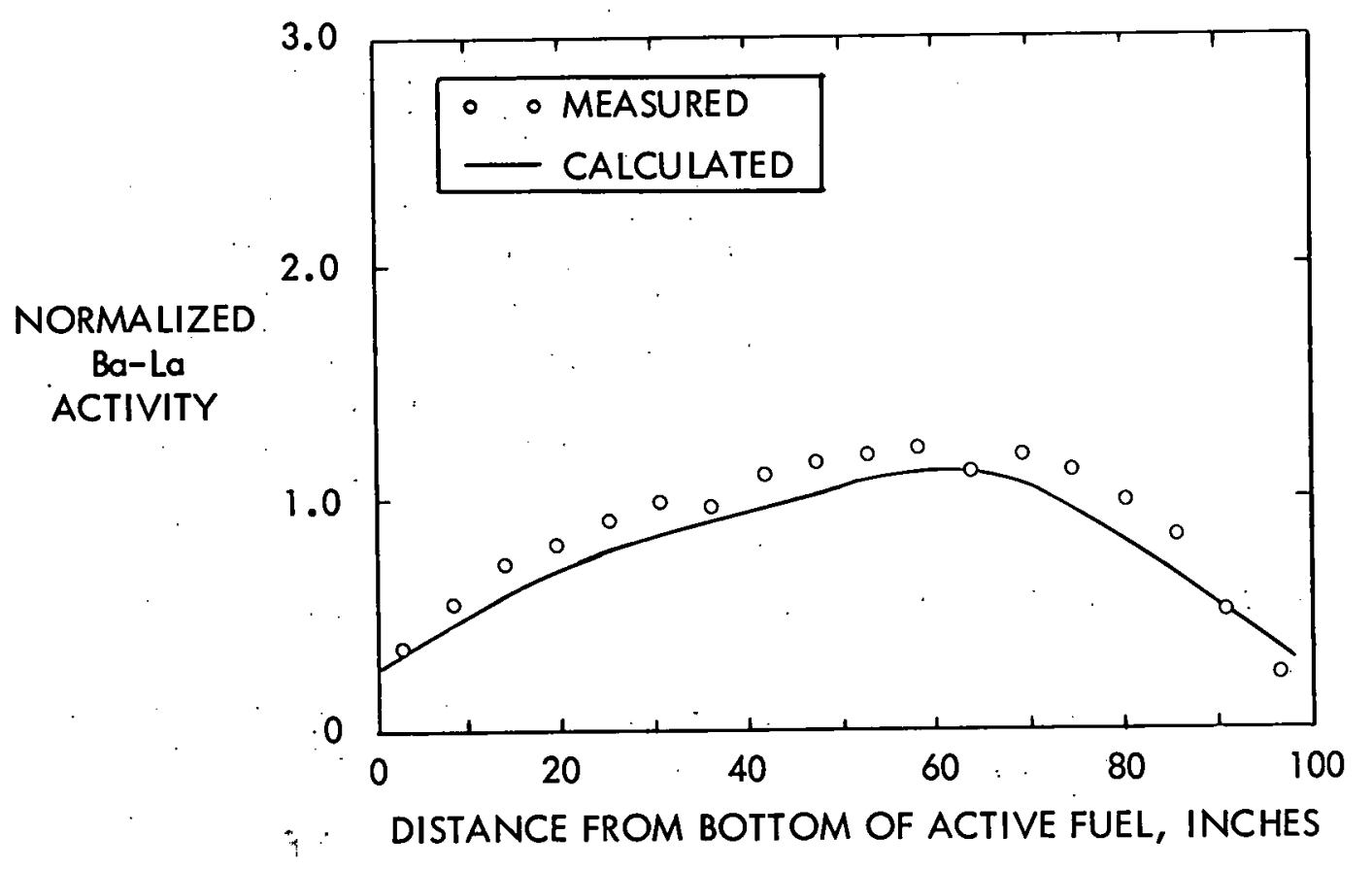

FIG 32 COMPARISON OF MEASURED AND CALCULATED Ba-La ACTIVITIES ALONG FUEL ELEMENT NO. 62 OF INDIAN POINT REACTOR 

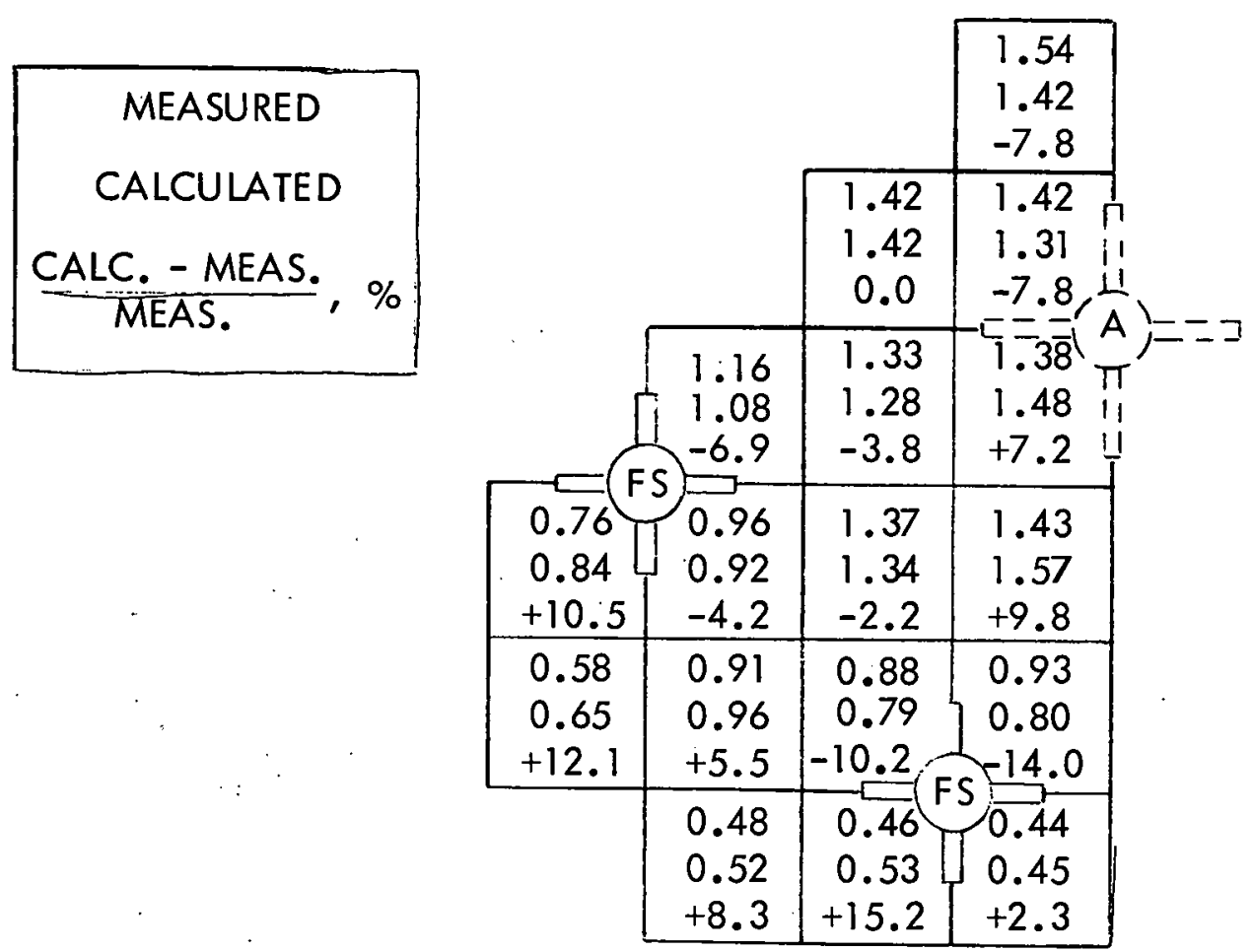

(NORMALIZED TO AVERAGE Ba-La CORE ACTIVITY EQUAL TO ONE)

FIG 33 COMPARISON OF CALCULATED AND MEASURED INTEGRATED Ba-La ACTIVITIES OF INDIAN POINT REACTOR 

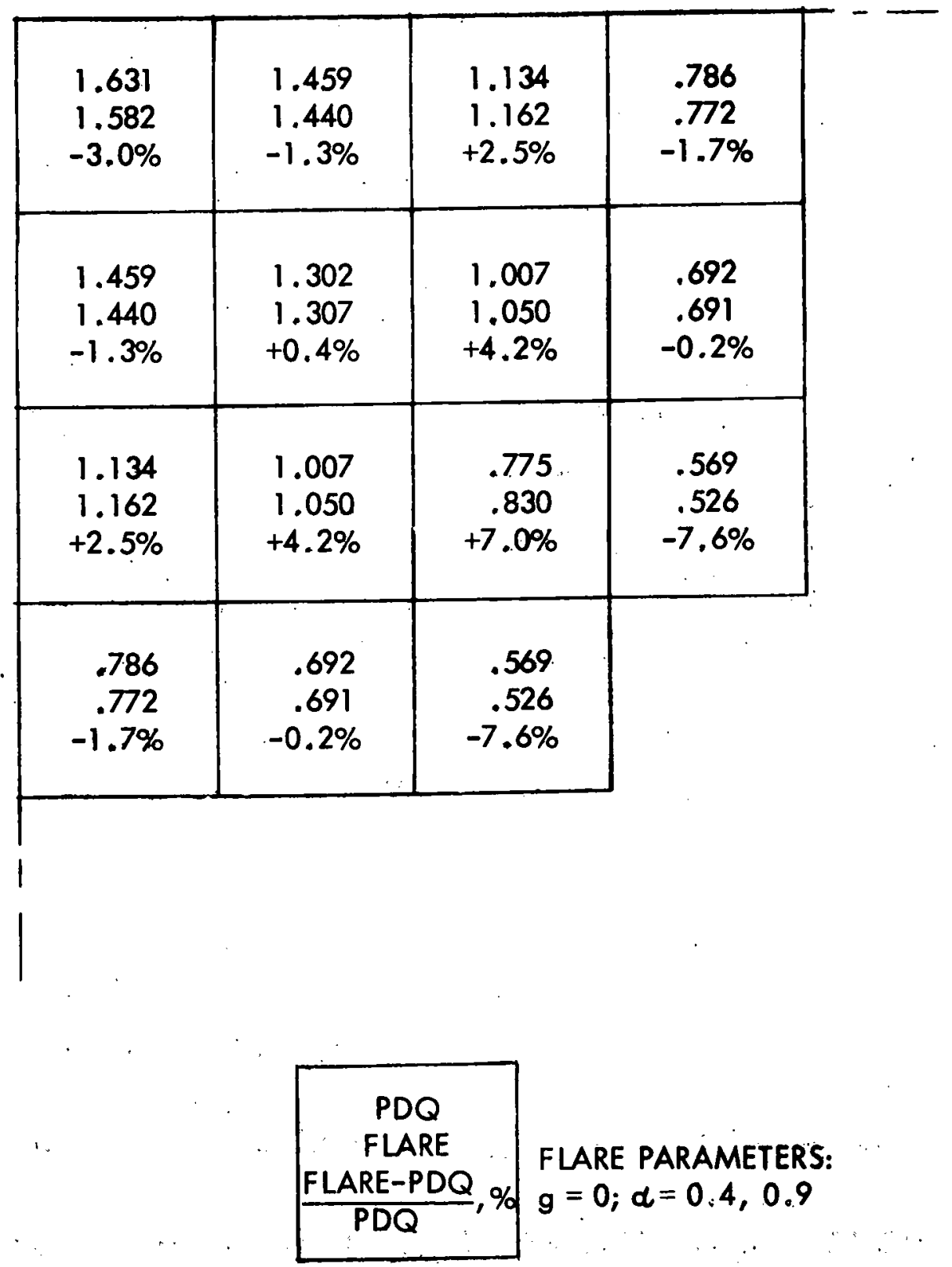

FIG. 34 COMPARISON OF FLARE AND DETAILED PDQ CALCULATIONS ON ASSEMBLYWISE POWER DISTRIBUTION FOR A BONUS BOILER CONFIGURATION. ALL CONTROL RODS OUT. 

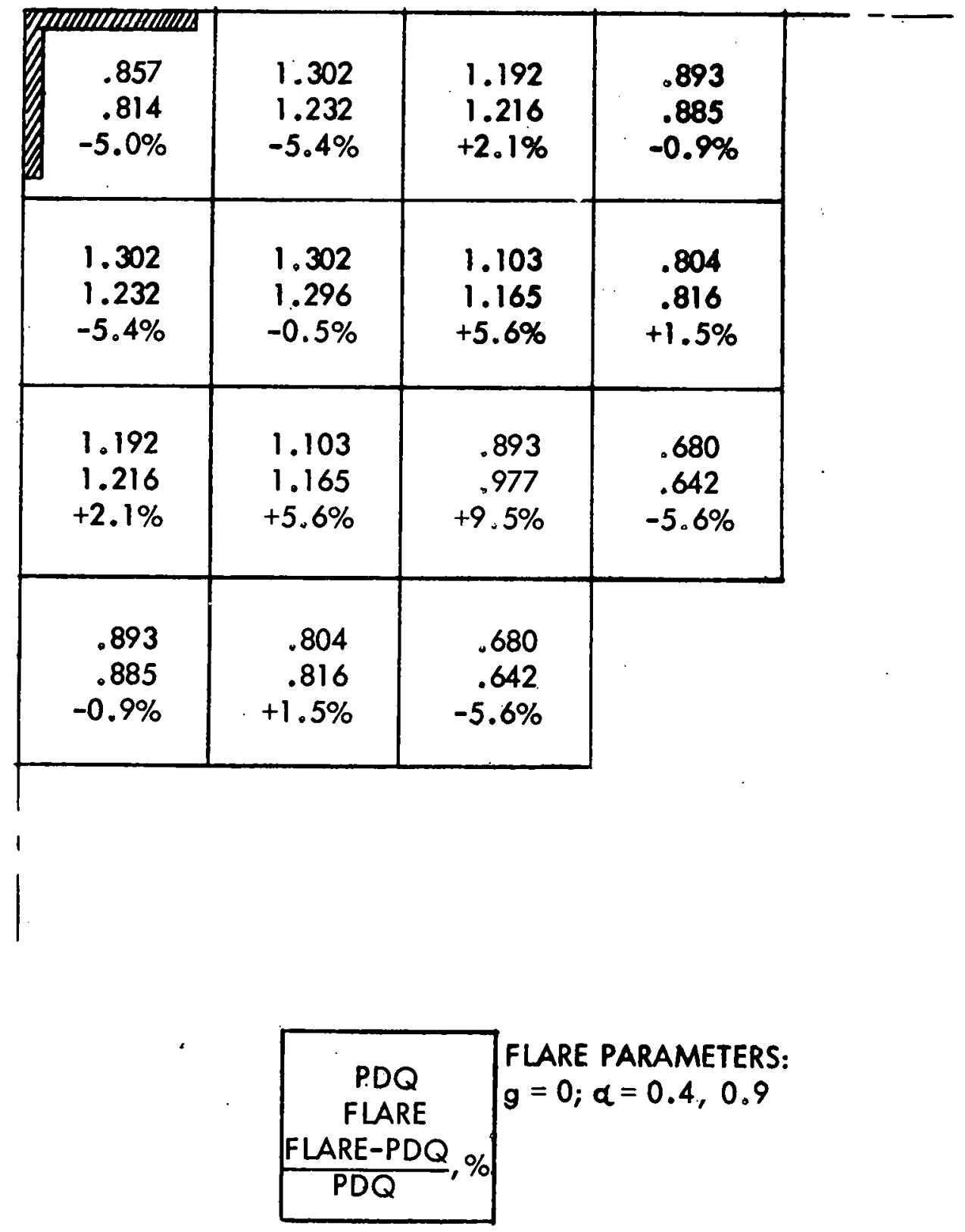

FIG. 35 COMPARISON OF FLARE AND DETAILED PDQ CALCULATIONS ON ASSEMBLYWISE POWER DISTRIBUTION FOR A BONUS BOILER CONFIGURATION. CENTER ROD IN. 

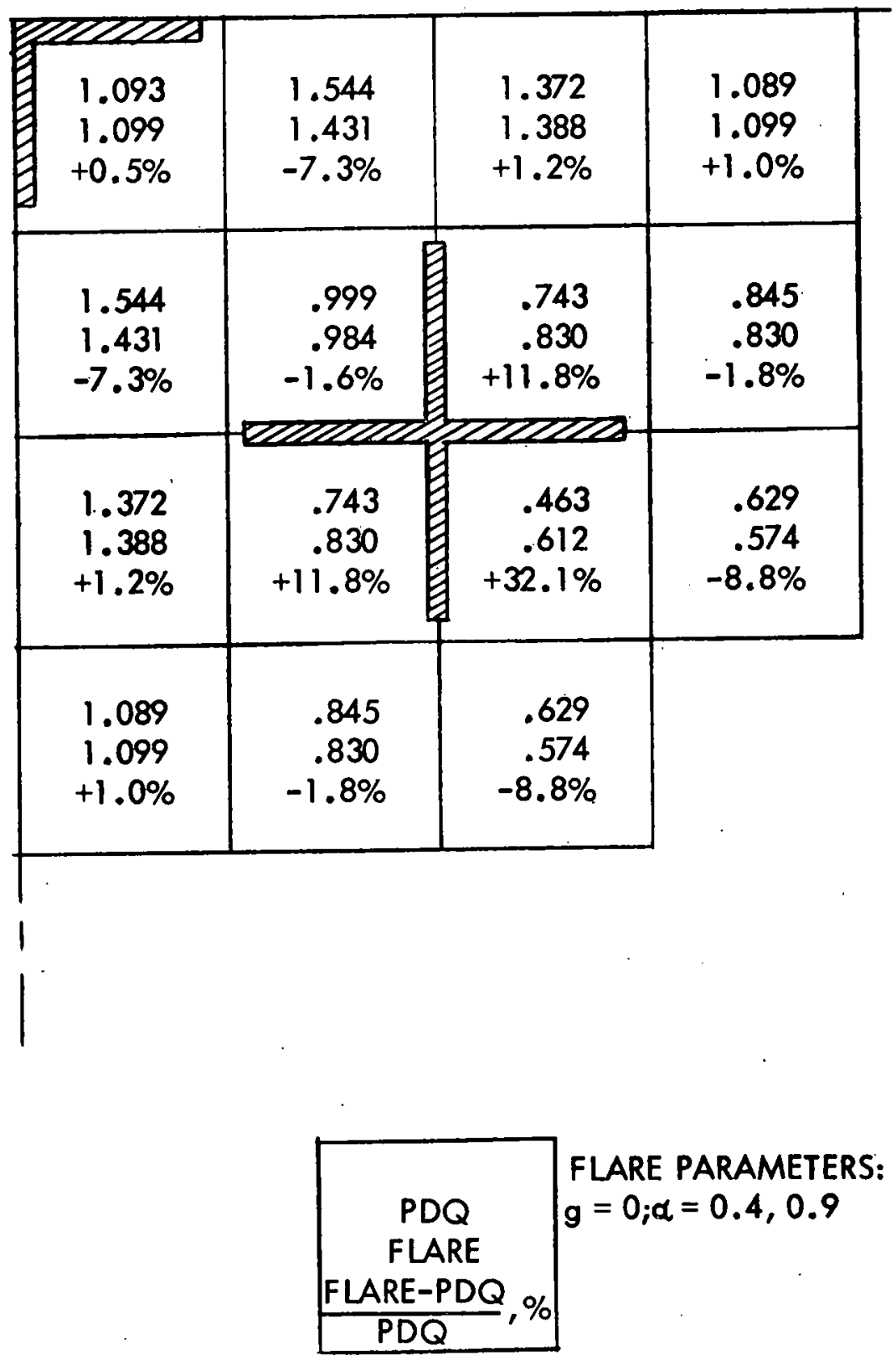

FIG. 36 COMPARISON OF FLARE AND DETAILED PDQ CALCULATIONS ON ASSEMBLYWISE POWER DISTRIBUTION FOR A BONUS BOILER CONFIGURATION. CENTER ROD PLUS CORNER RODS IN. 


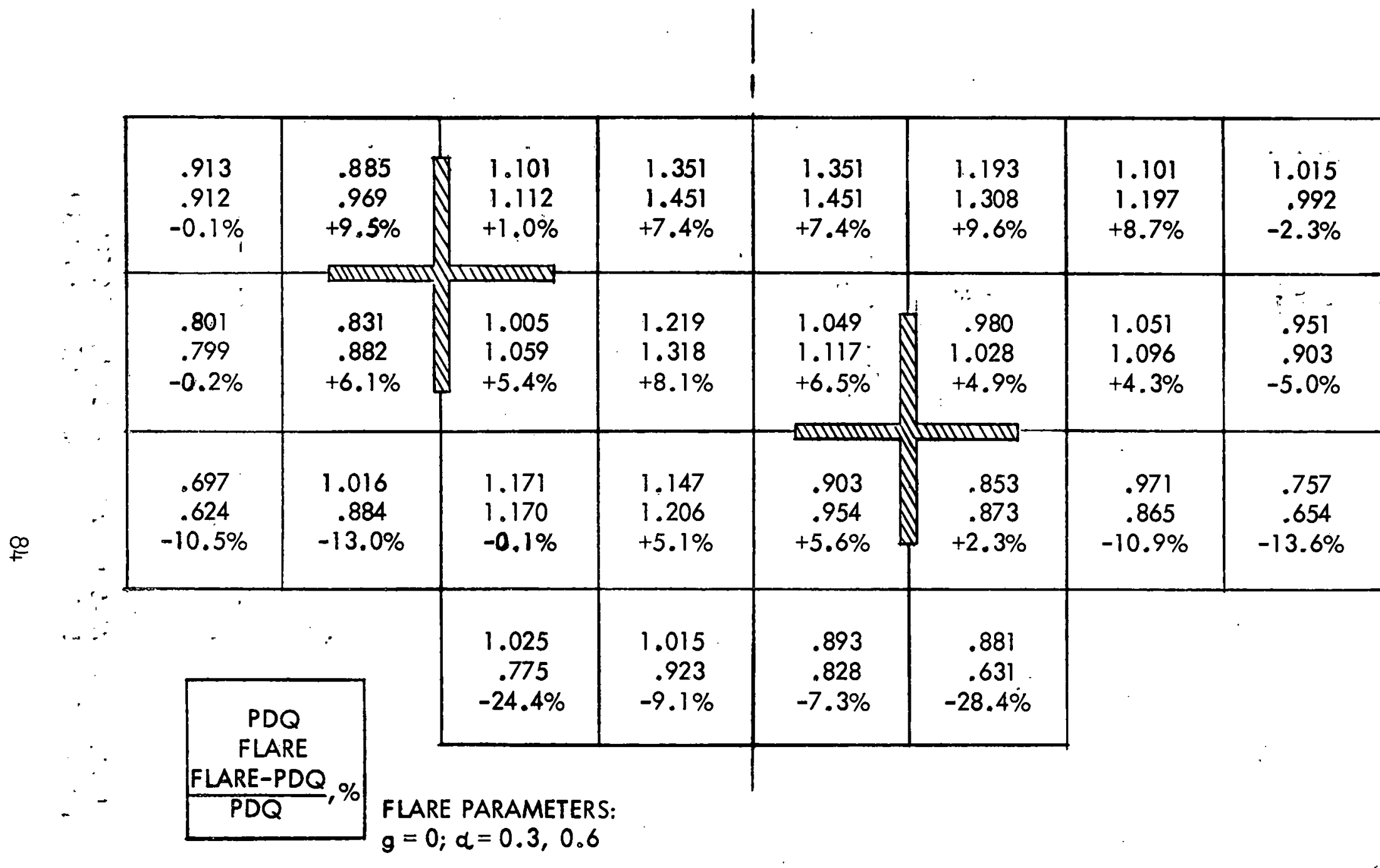

FIG. 37 COMPARISON OF FLARE AND DETAILED PDQ CALCULATIONS ON ASSEMBLYWISE POWER DISTRIBUTION FOR BIG ROCK POINT (CALCULATIONS BY GENERAL ELECTRIC) 


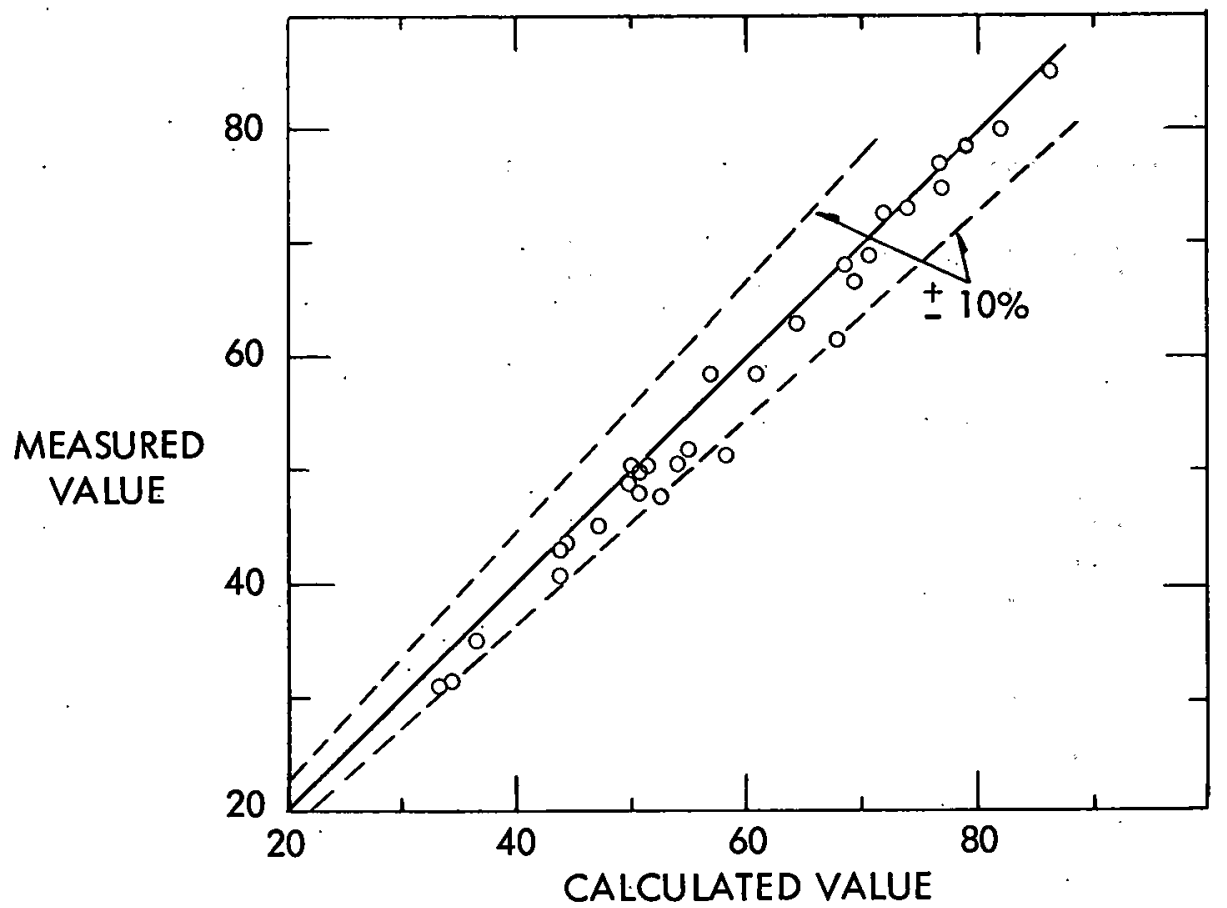

FIG 38 COMPARISON OF MEASURED AND CALCULATED PERCENTAGE DEPLETION OF U-235 IN PWR BLANKET FUEL RODS (FROM REF 26)

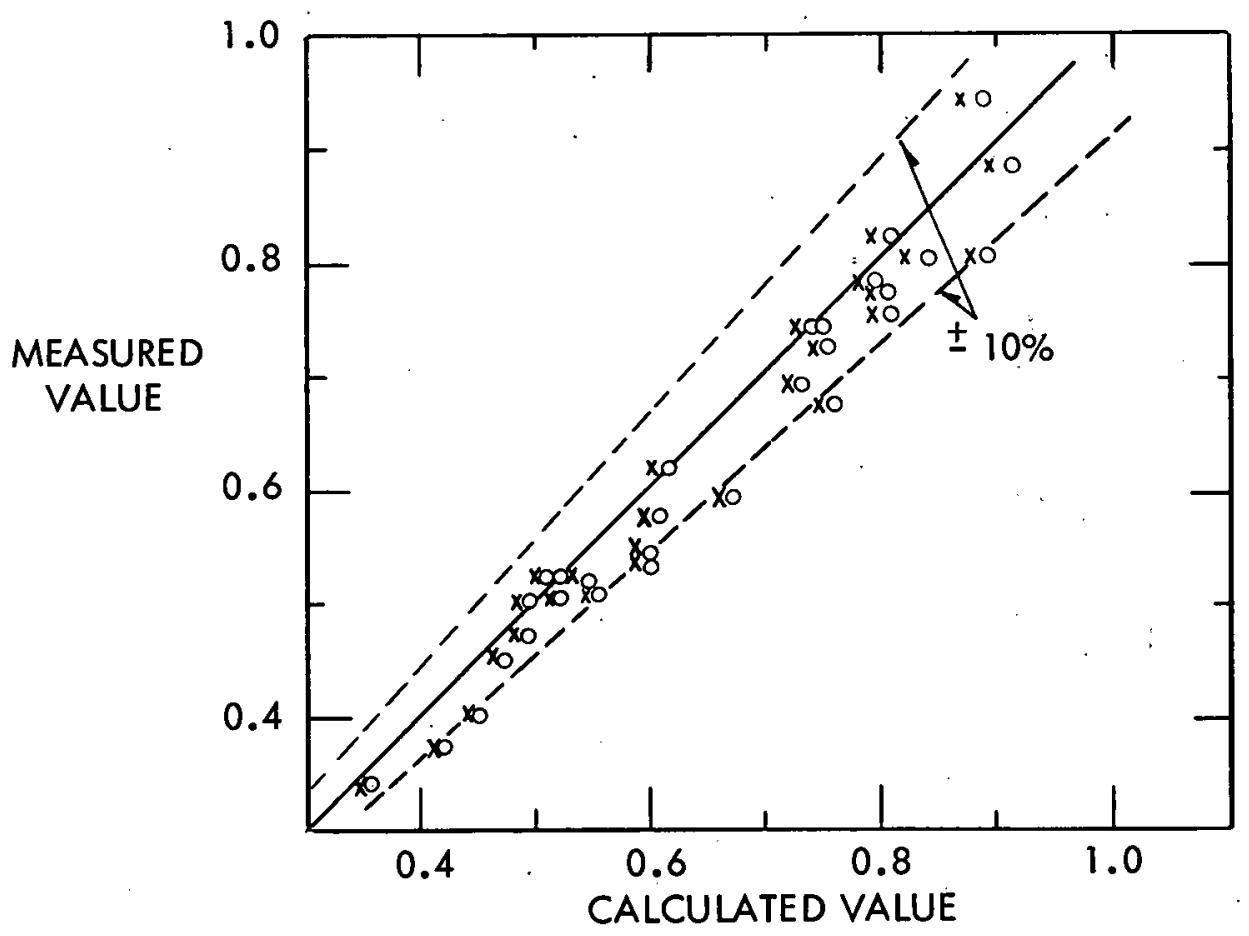

FIG 39 COMPARISON OF MEASURED AND CALCULATED TOTAL PLUTONIUM CONTENT IN PWR BLANKET FUEL RODS (FROM REF 26 ) 


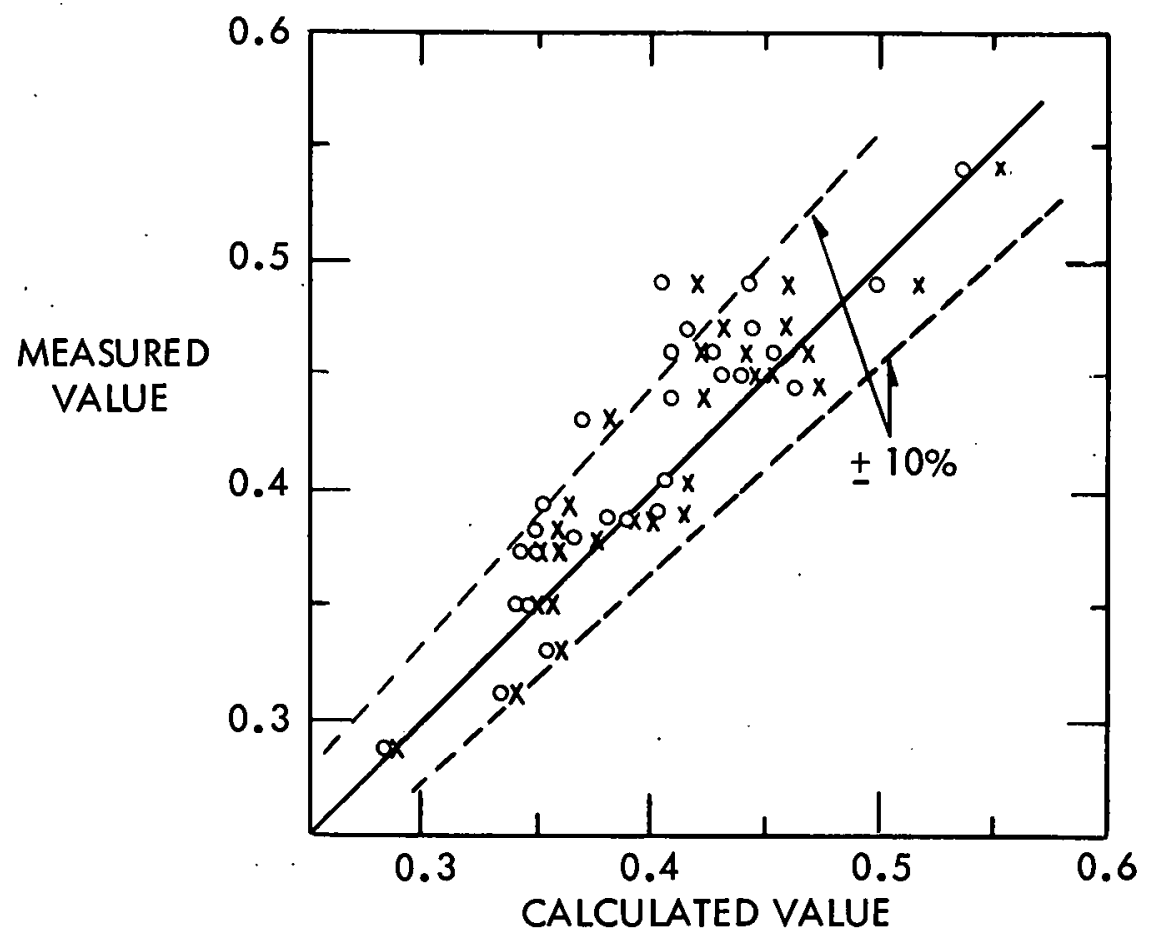

FIG 40 COMPARISON OF MEASURED AND CALCULATED PU-239 CONTENT IN PWR BLANKET FUEL RODS (FROM REF 26 )

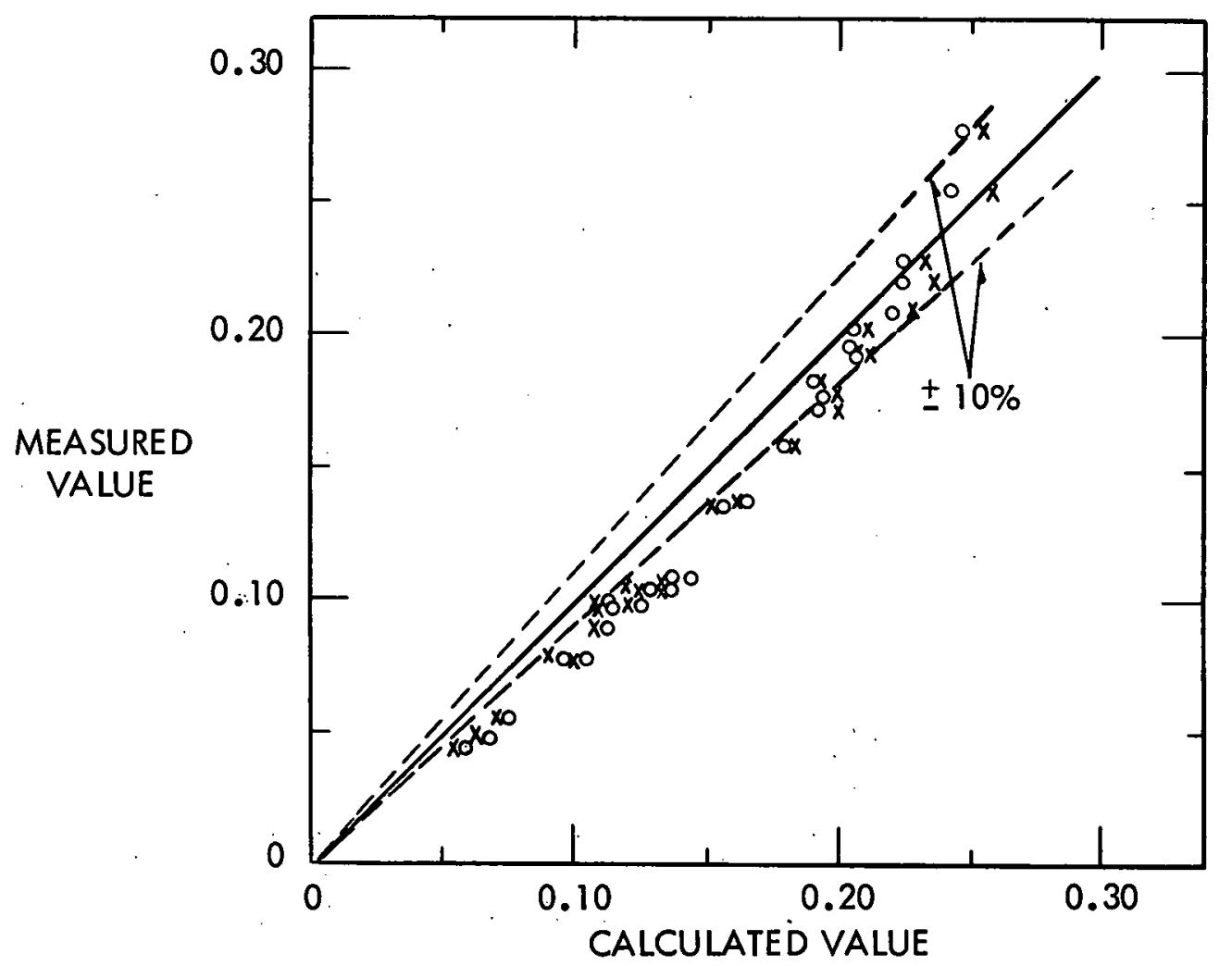

FIG 41 COMPARISON OF MEASURED AND CALCULATED PU-240 CONTENT IN PWR BLANKET FUEL RODS. (FROM REF 26) 


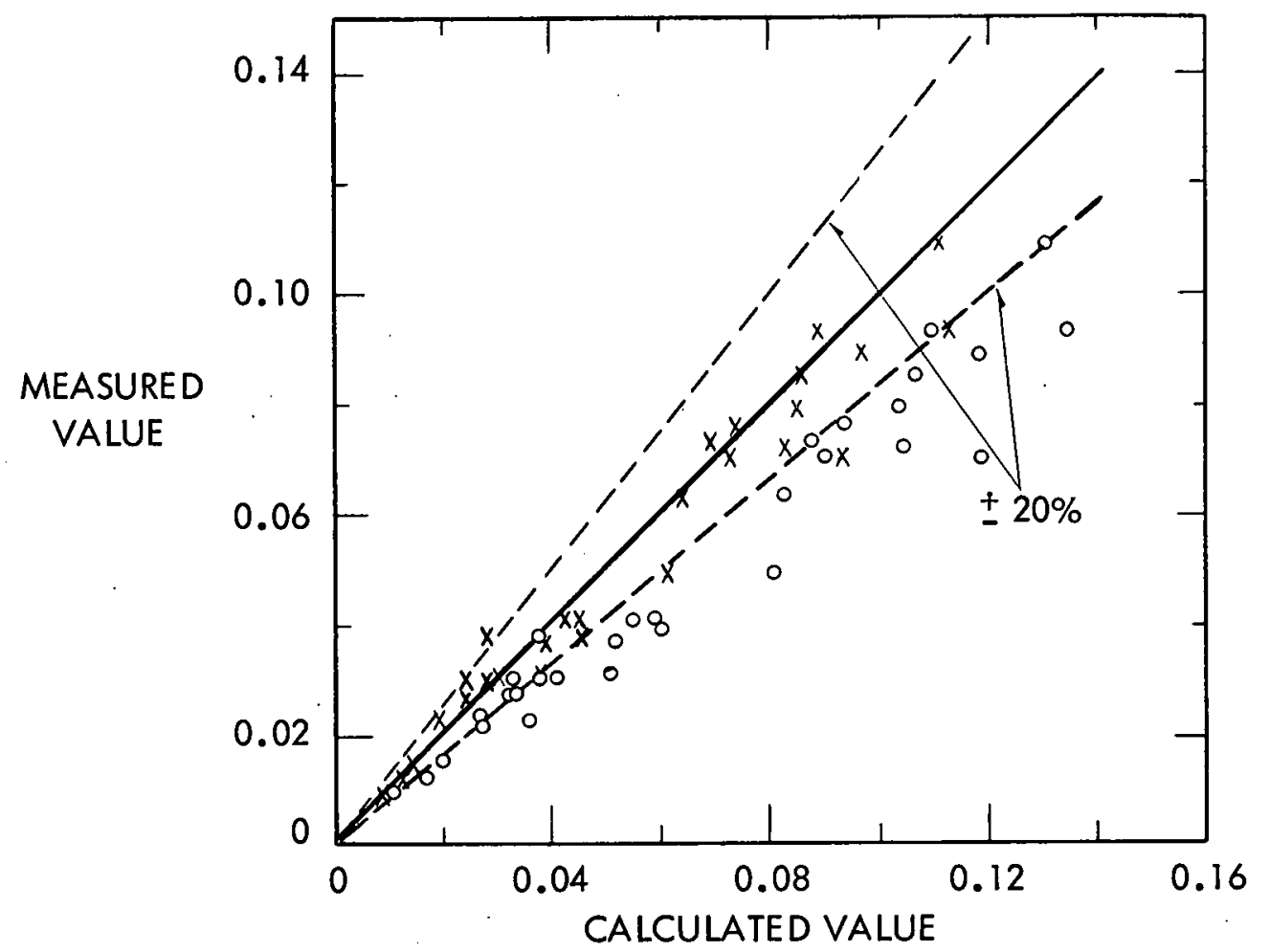

FIG 42 COMPARISON OF MEASURED AND CALCULATED PU-241 CONTENT IN PWR BLANKET FUEL RODS (FROM REF 26 )

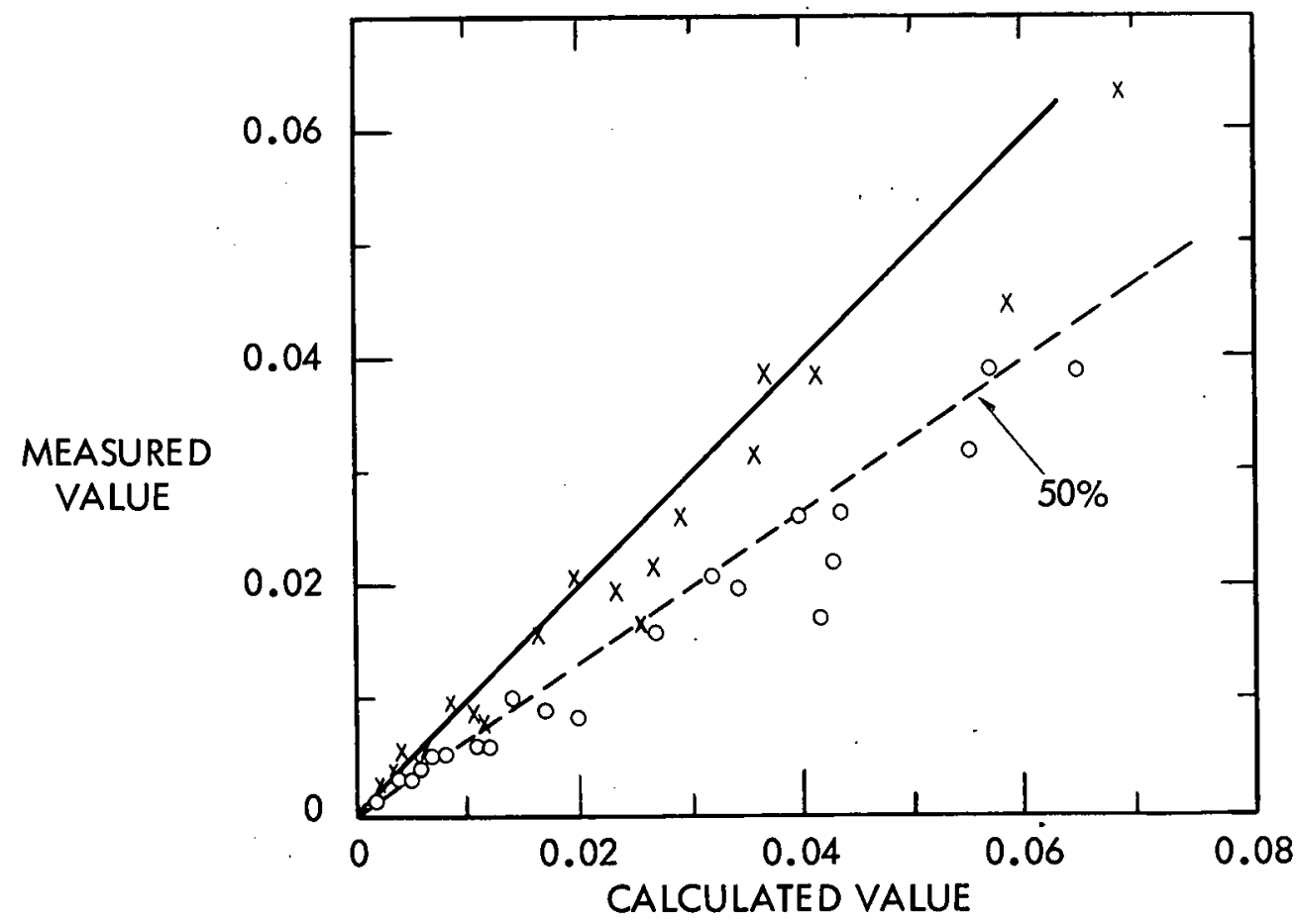

FIG 43 COMPARISON OF MEASURED AND CALCULATED PU-242 CONTENT IN PWR BLANKET FUEL RODS (FROM REF 26) 


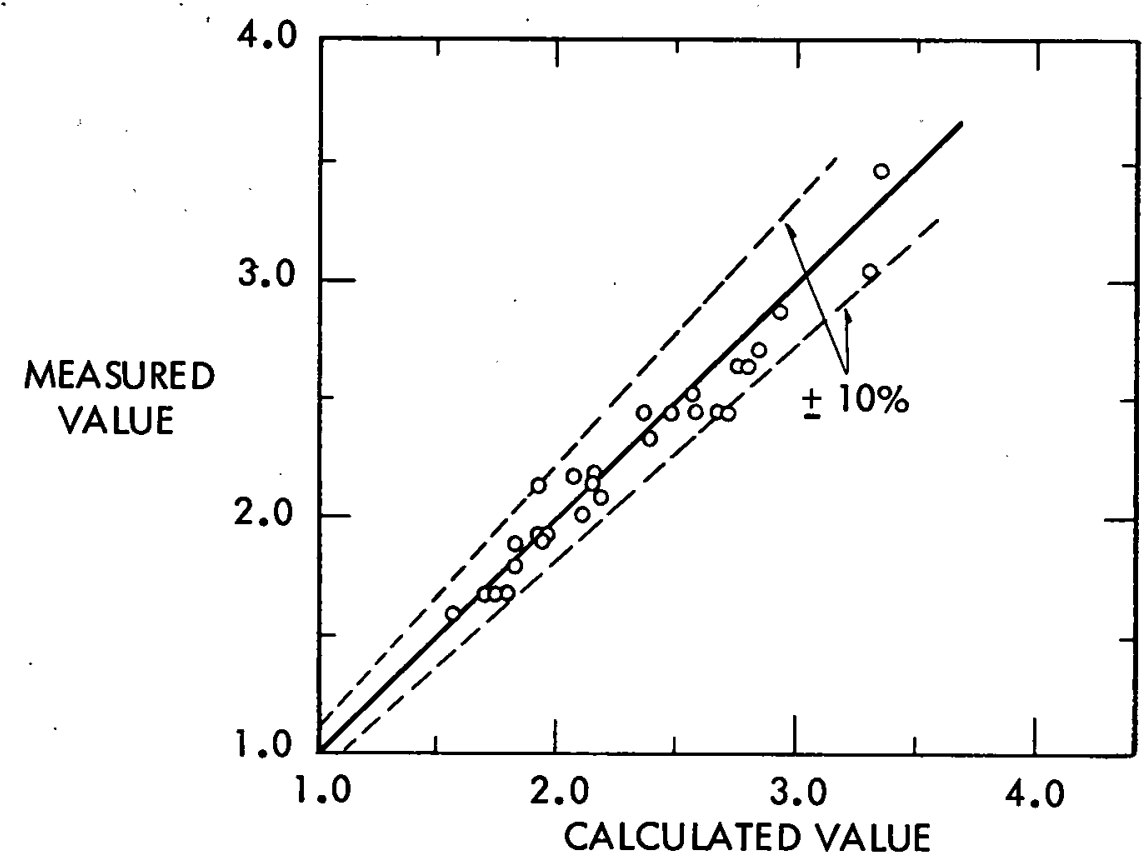

FIG 44 COMPARISON OF MEASURED AND CALCULATED TOTAL

FISSIONS/U-235 FISSIONS IN PWR BLANKET FUEL RODS (FROM REF 26)

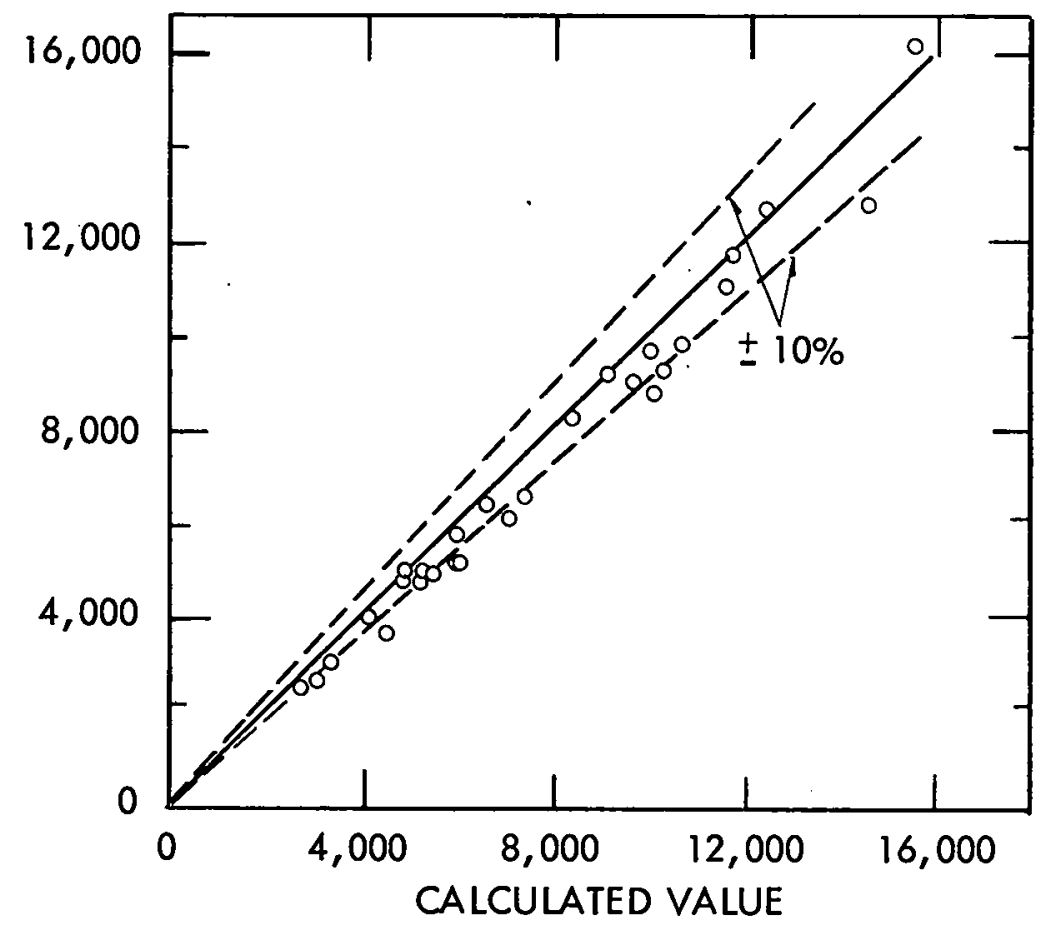

FIG 45 COMPARISON OF MEASURED AND CALCULATED BURNUP IN MEGAWATT DAYS/METRIC TON URANIUM IN PWR BLANKET FUEL RODS (FROM REF 26) 


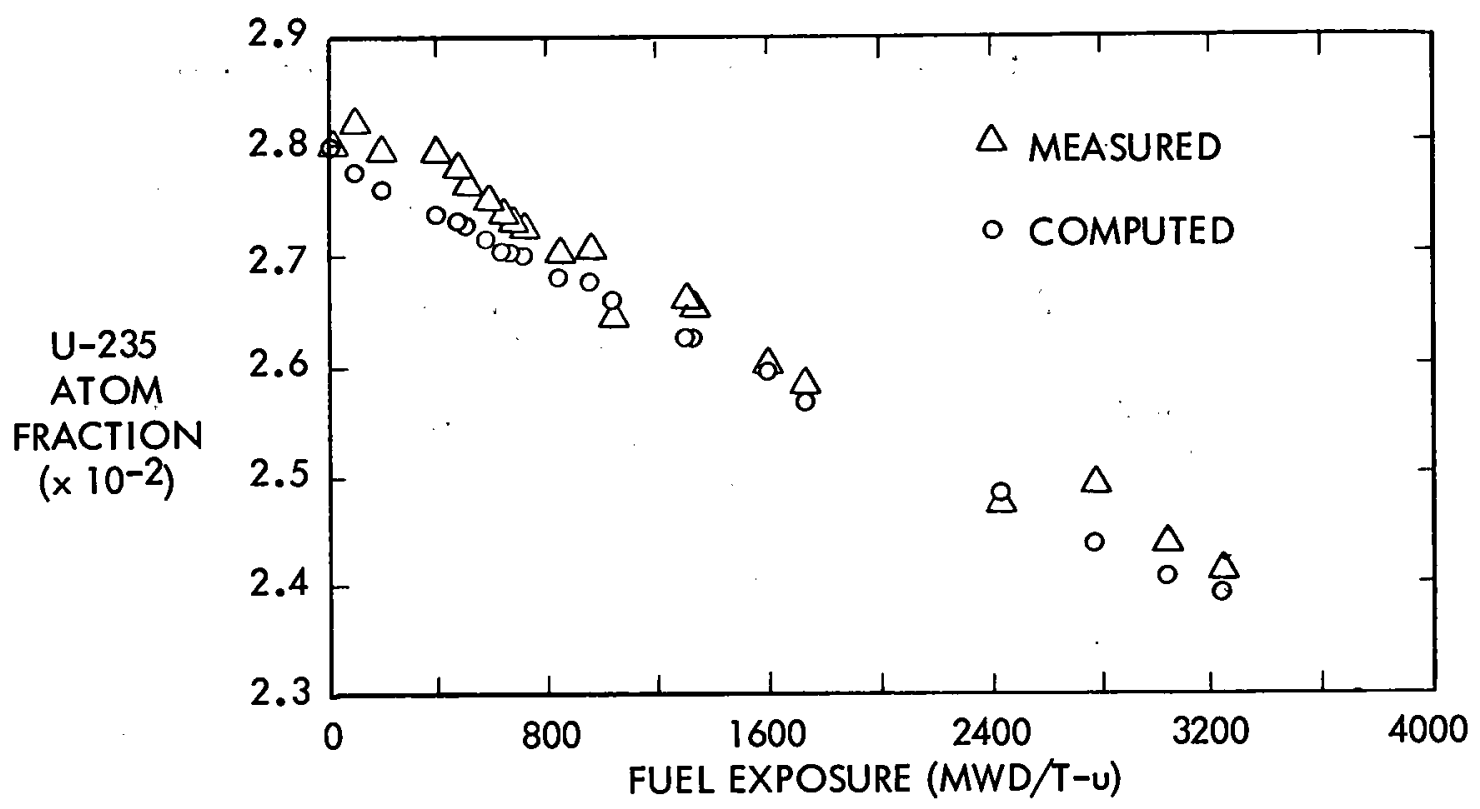

FIG $46 \quad U$-235 ATOM FRACTION AS A FUNCTION OF FUEL EXPOSURE IN VBWR (FROM REF 17.)

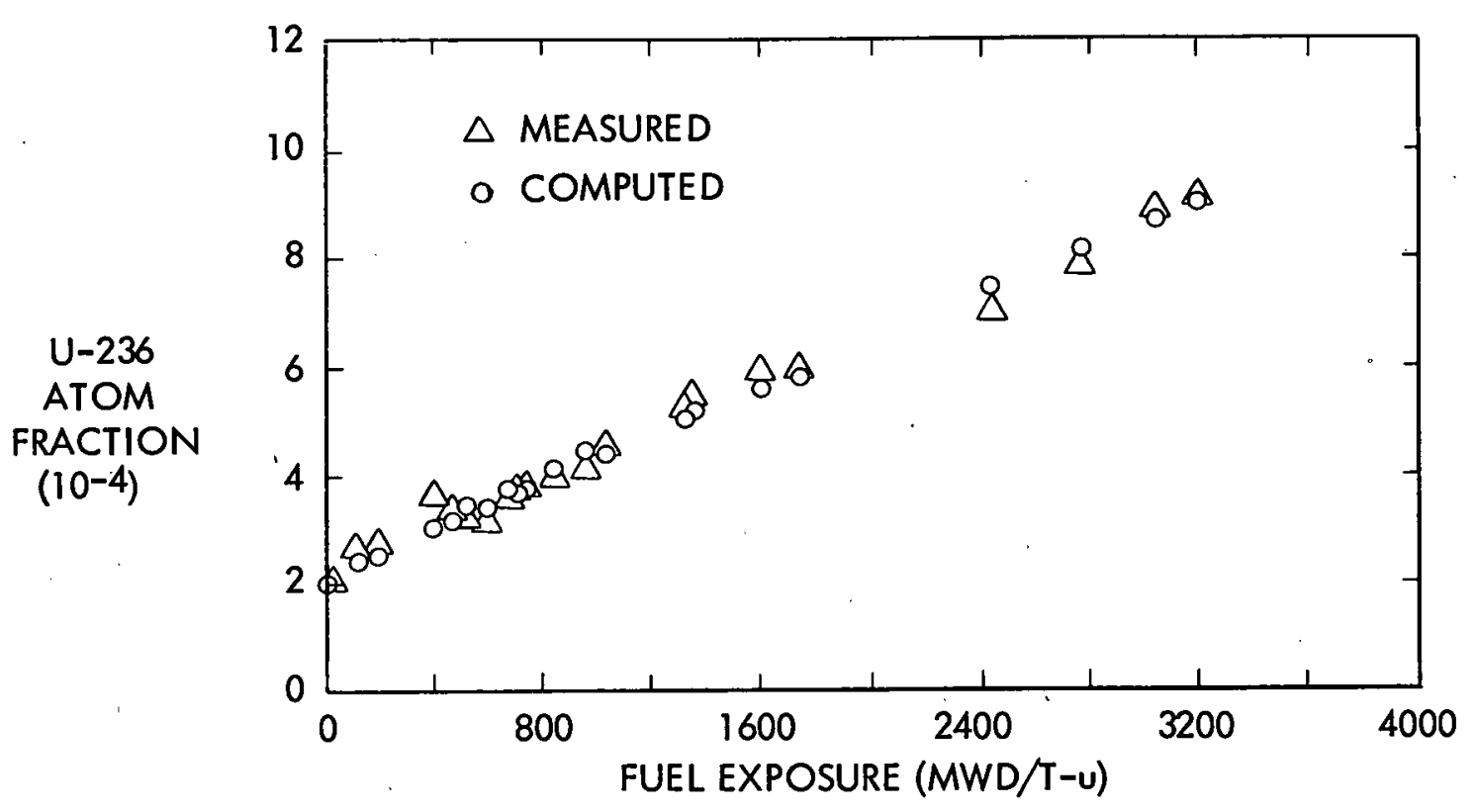

FIG 47 U-236 ATOM FRACTION AS A FUNCTION OF FUEL EXPOSURE IN VBWR (FROM REF 17) 

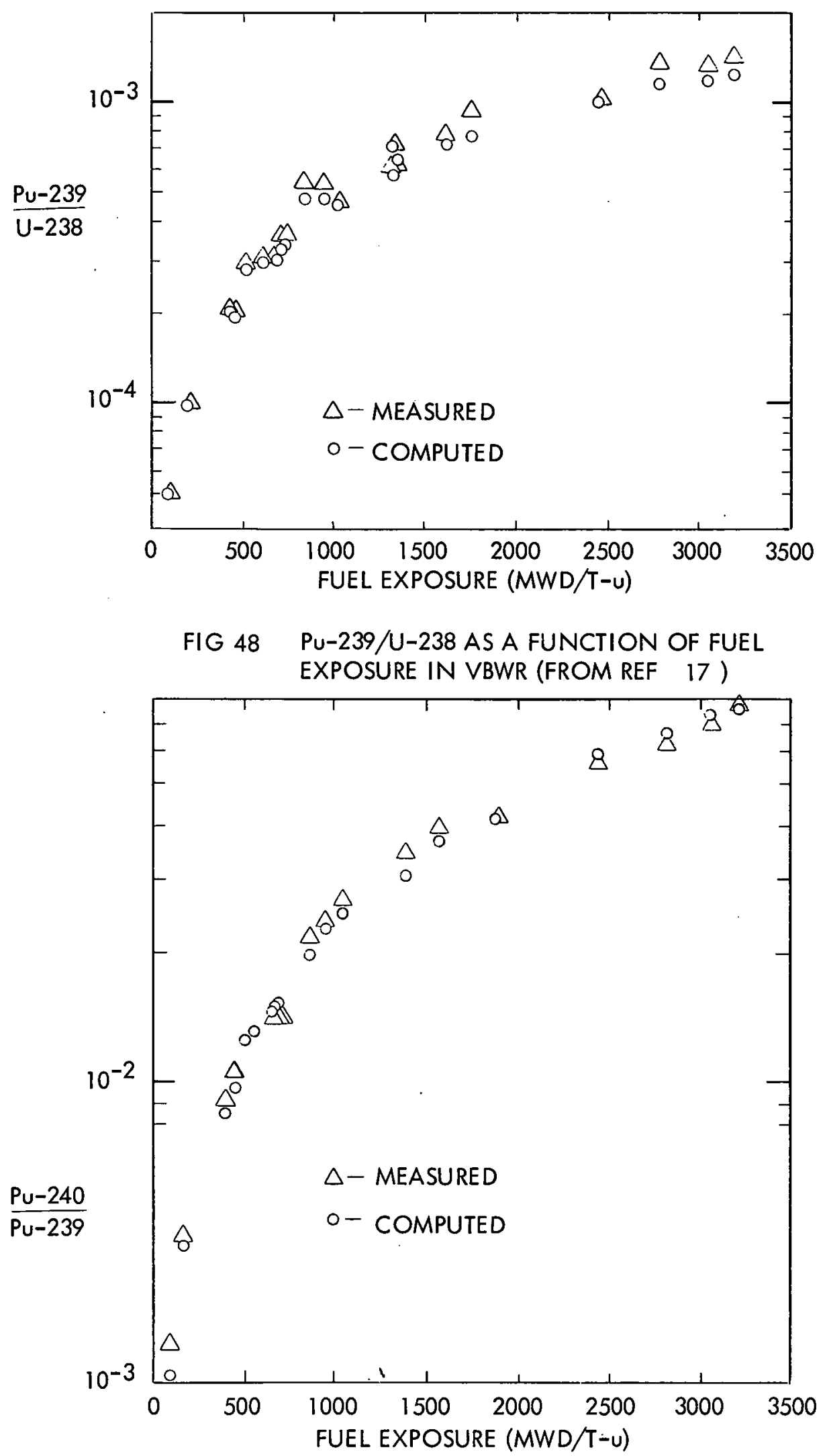

FIG 49 Pu-240/Pu-239 AS A FUNCTION OF FUEL EXPOSURE IN VBWR (FROM REF I7) 


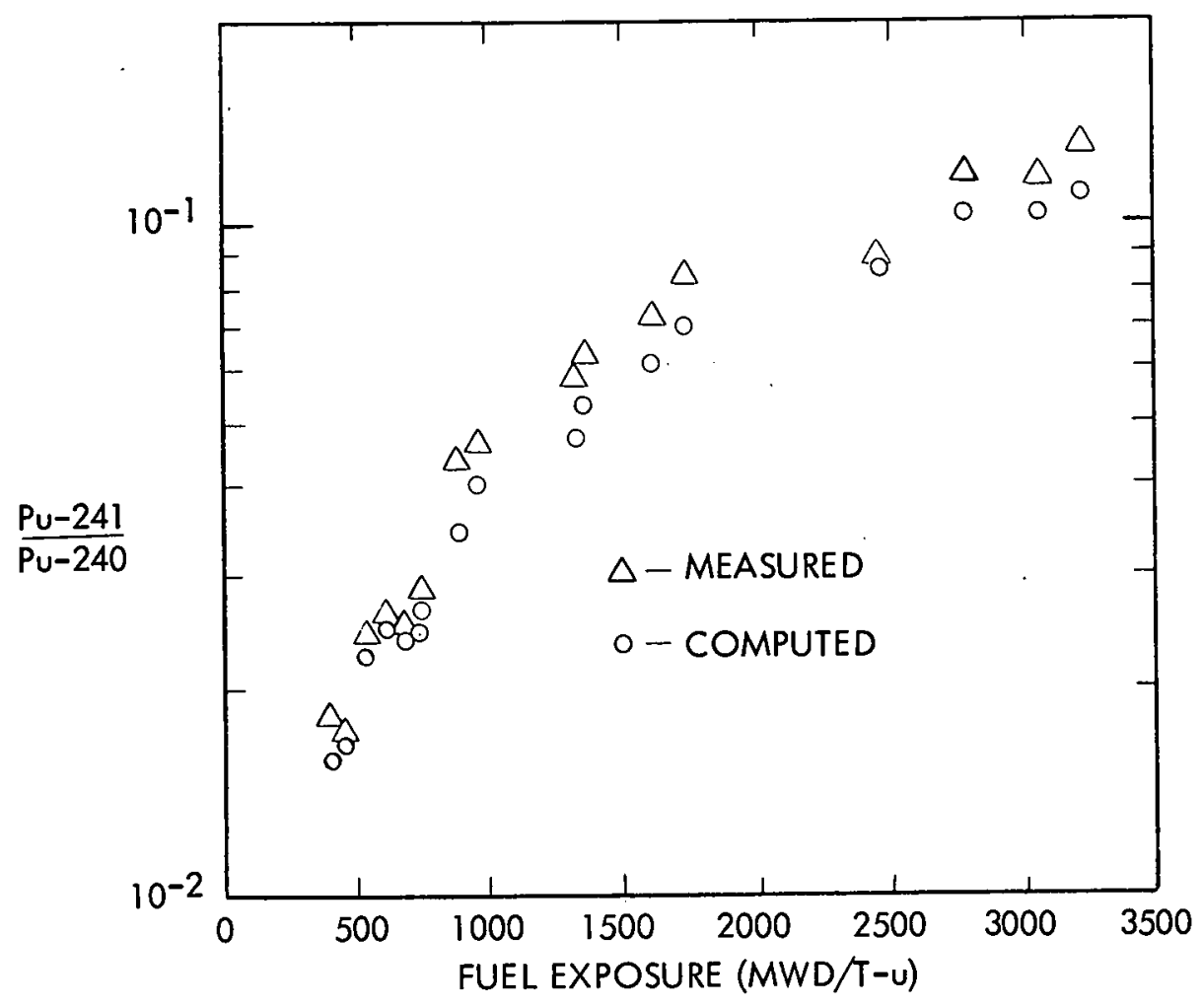

FIG $50 \quad \mathrm{Pu}-241 / \mathrm{Pu}-240$ AS A FUNCTION OF FUEL EXPOSURE IN VBWR (FROM REF 17 )

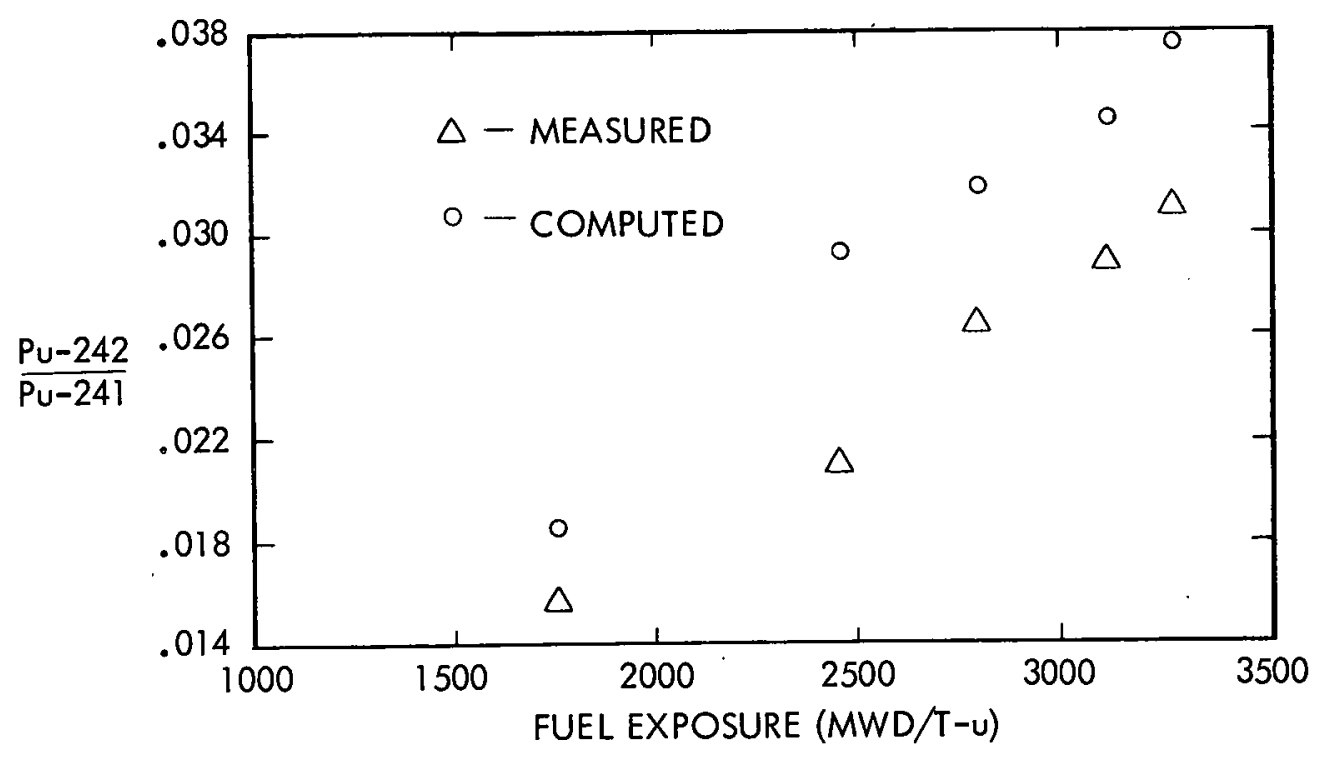

FIG 51 Pu-242/Pu-241 AS A FUNCTION OF FUEL EXPOSURE IN VBWR (FROM REF 17 ) 


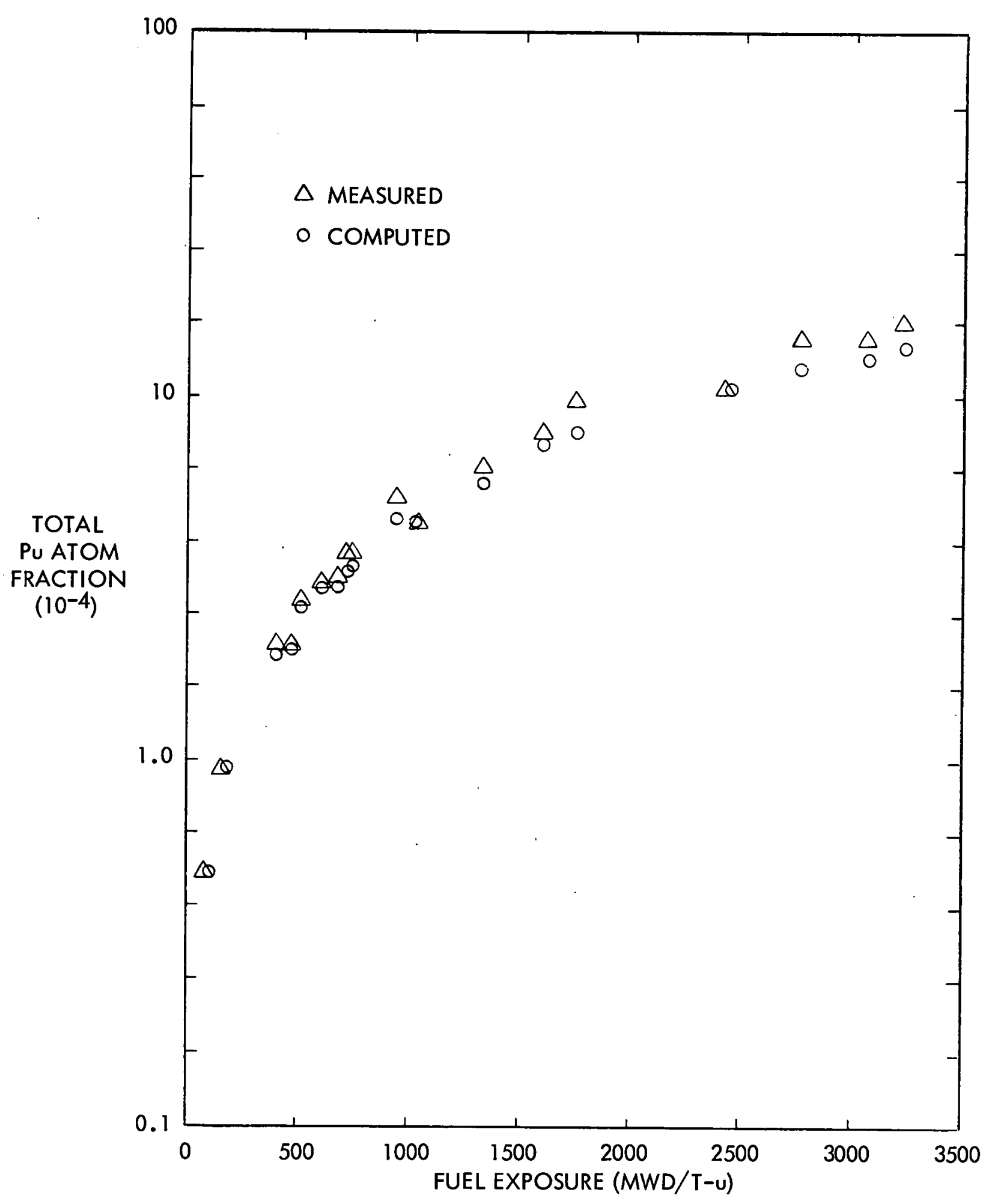

FIG 52 TOTAL PU AS A FUNCTION OF FUEL EXPOSURE IN VBWR (FROM REF 17) 


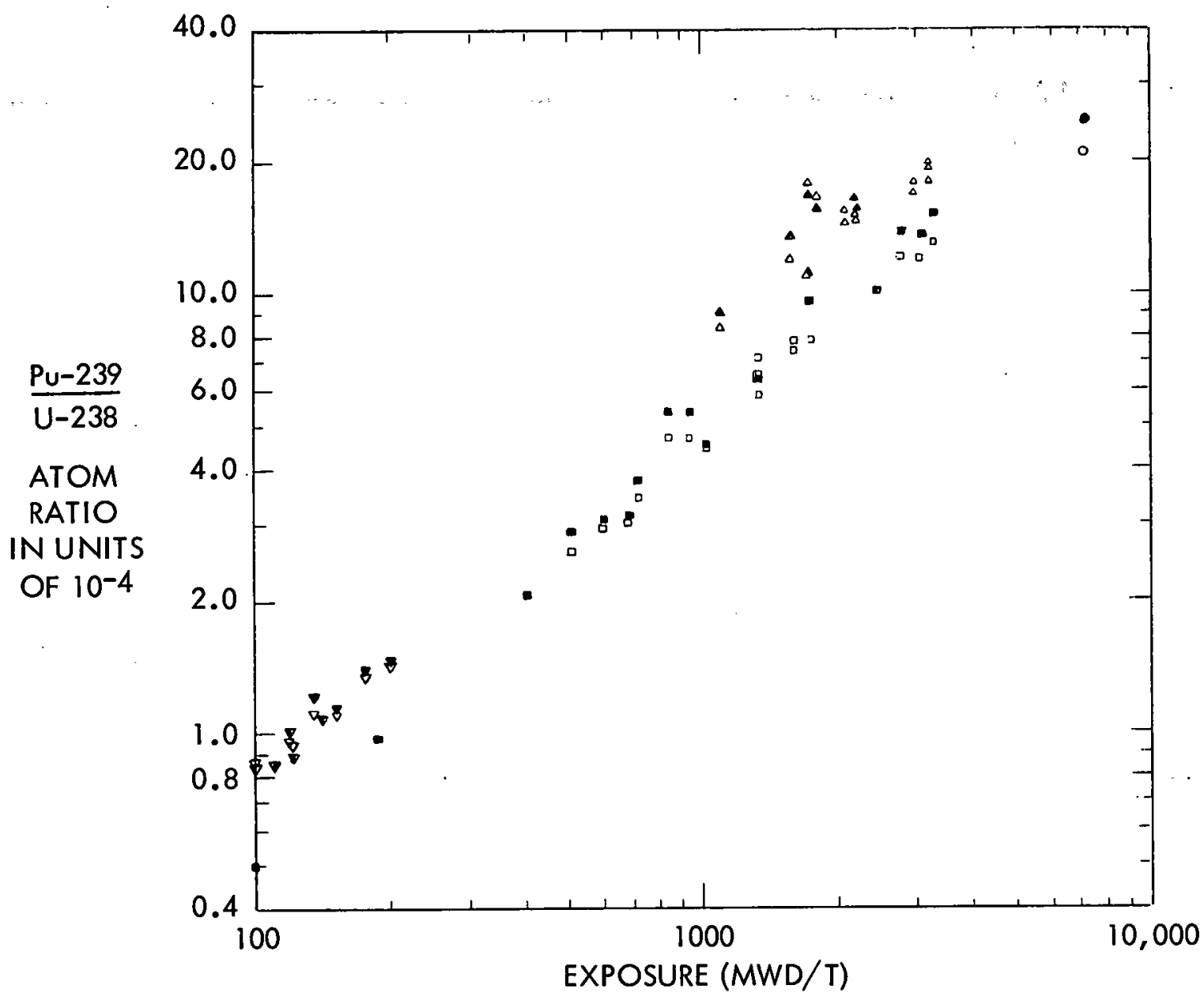

- $2.3 \%$ ENRICHMENT VBWR FUEL

$-2.7 \%$ ENRICHMENT VBWR FUEL

$\triangle \nabla-$ DRESDEN FUEL

SOLID SYMBOLS - MEASURED DATA

OPEN SYMBOLS - COMPUTED DATA 


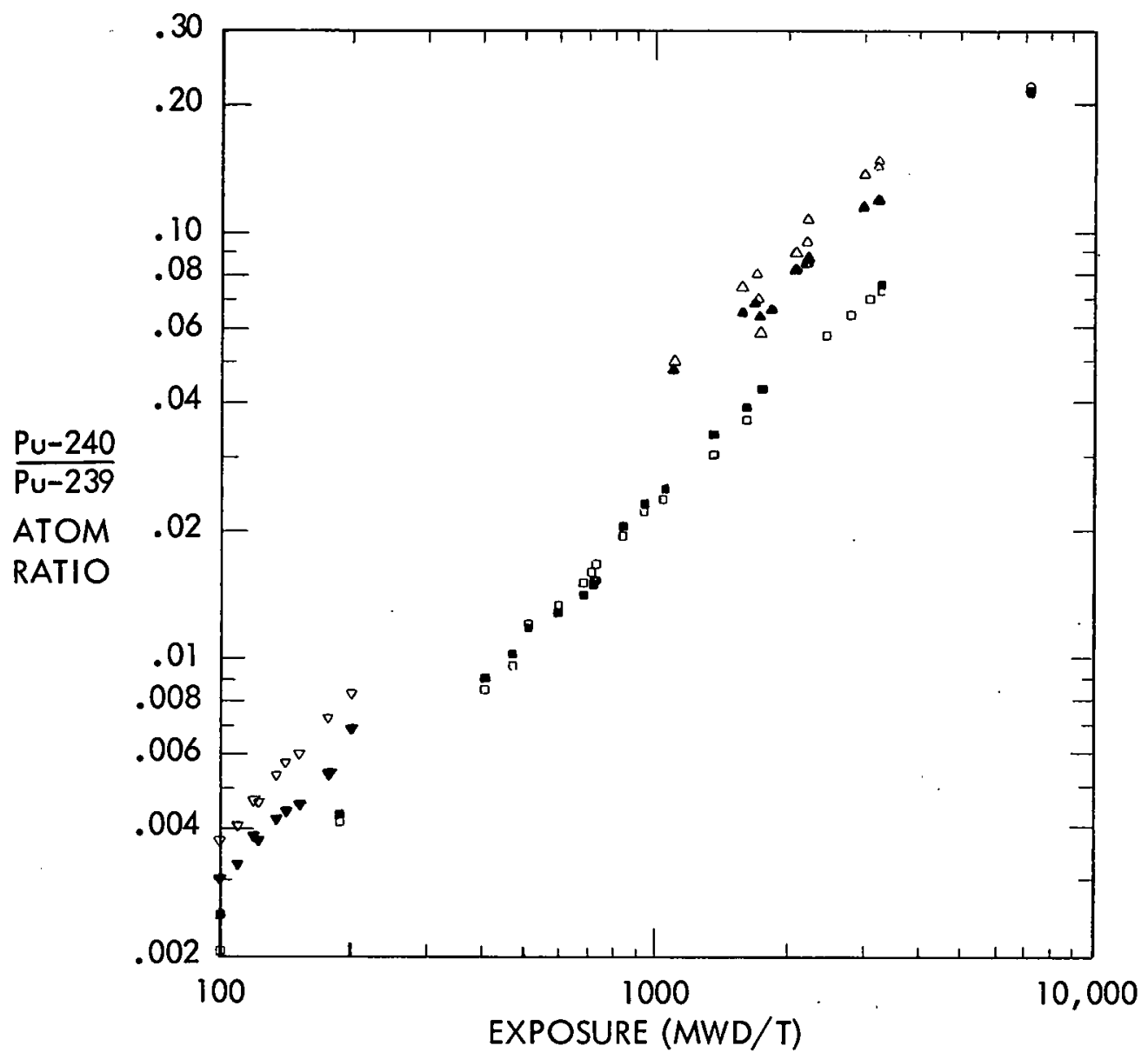

$\circ-2.3 \%$ ENRICHMENT VBWR FUEL

$-2.7 \%$ ENRICHMENT VBWR FUEL

$\triangle \nabla-$ DRESDEN FUEL

SOLID SYMBOLS - MEASURED DATA

OPEN SYMBOLS - COMPUTED DATA

FIG 54 MEASURED AND COMPUTED ATOM RATIOS OF Pu-240/Pu-239 IN VBWR AND DRESDEN REACTORS (FROM REF 27) 


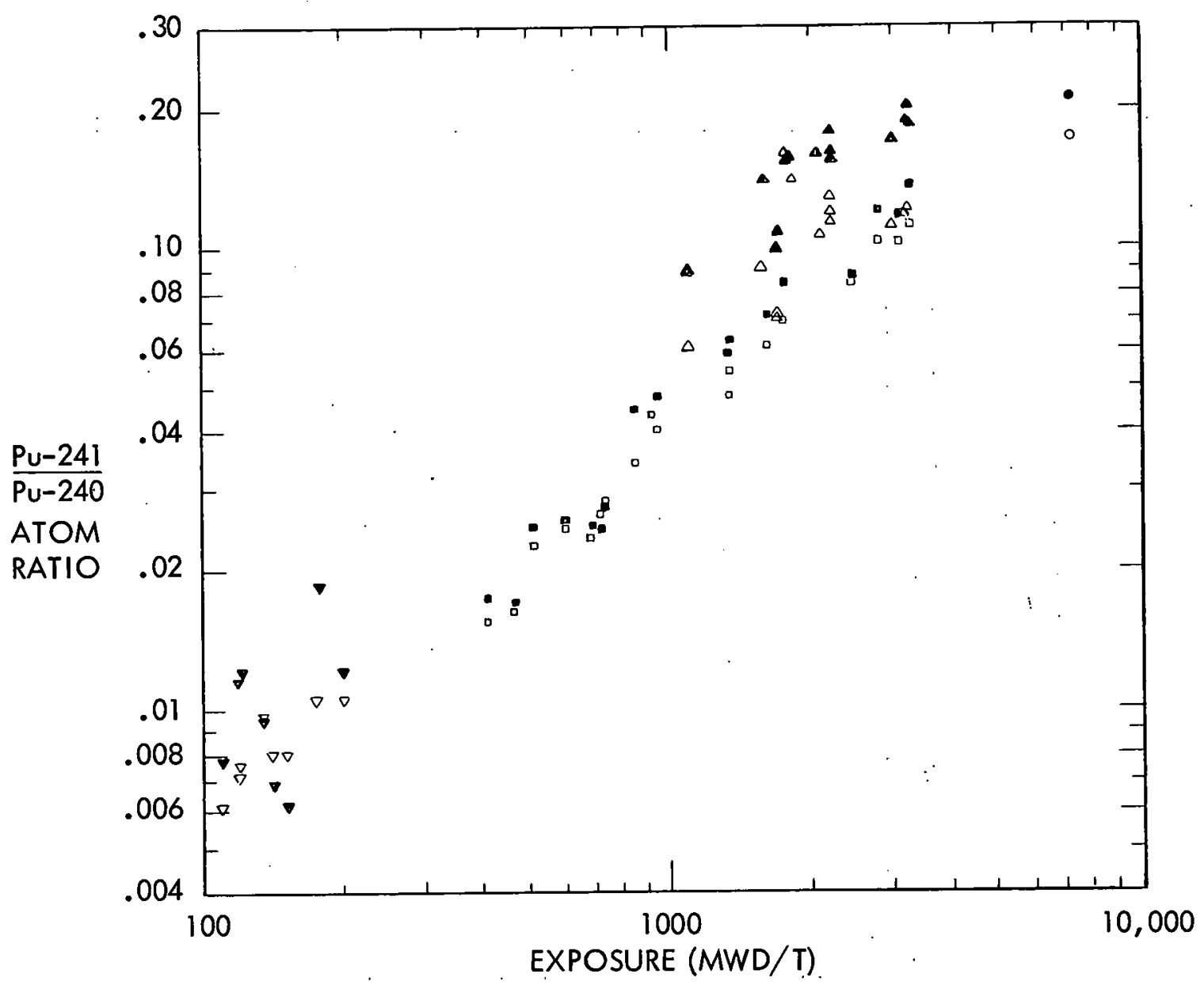

- $2.3 \%$ ENRICHMENT VBWR FUEL

- $2.7 \%$ ENRICHMENT VBWR FUEL

$\triangle \nabla$ DRESDEN FUEL

SOLID SYMBOLS - MEASURED DATA

OPEN SYMBOLS - COMPUTED DATA

FIG 55 MEASURED AND COMPUTED ATOM RATIOS OF Pu-24I/Pu-240 IN VBWR AND DRESDEN REACTORS (FROM REF 27 ) 


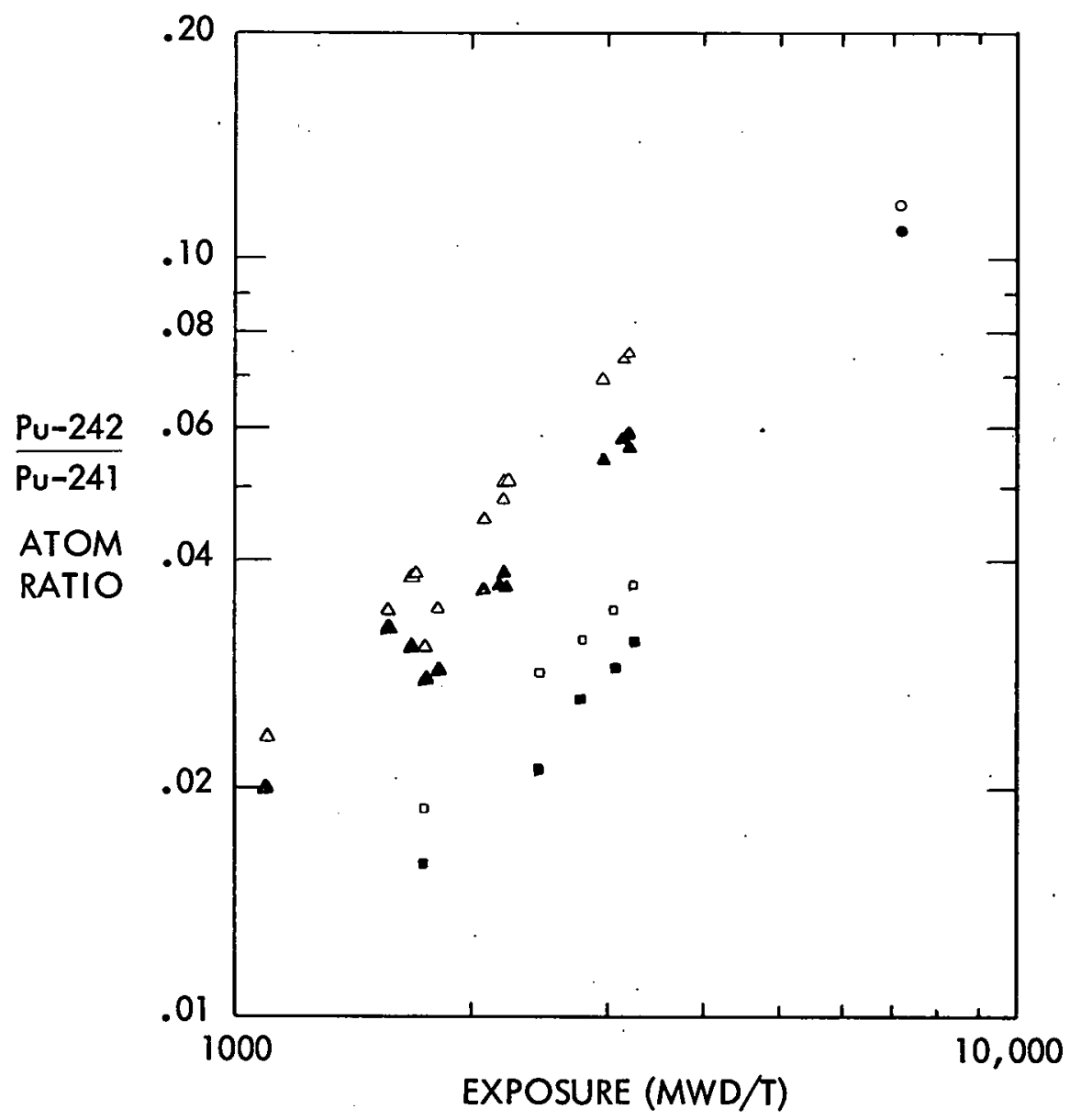

$0-2.3 \%$ ENRICHMENT VBWR FUEL

- $-2.7 \%$ ENRICHMENT VBWR FUEL

$\triangle$-DRESDEN FUEL

SOLID SYMBOLS - MEASURED DATA

OPEN SYMBOLS - COMPUTED DATA 


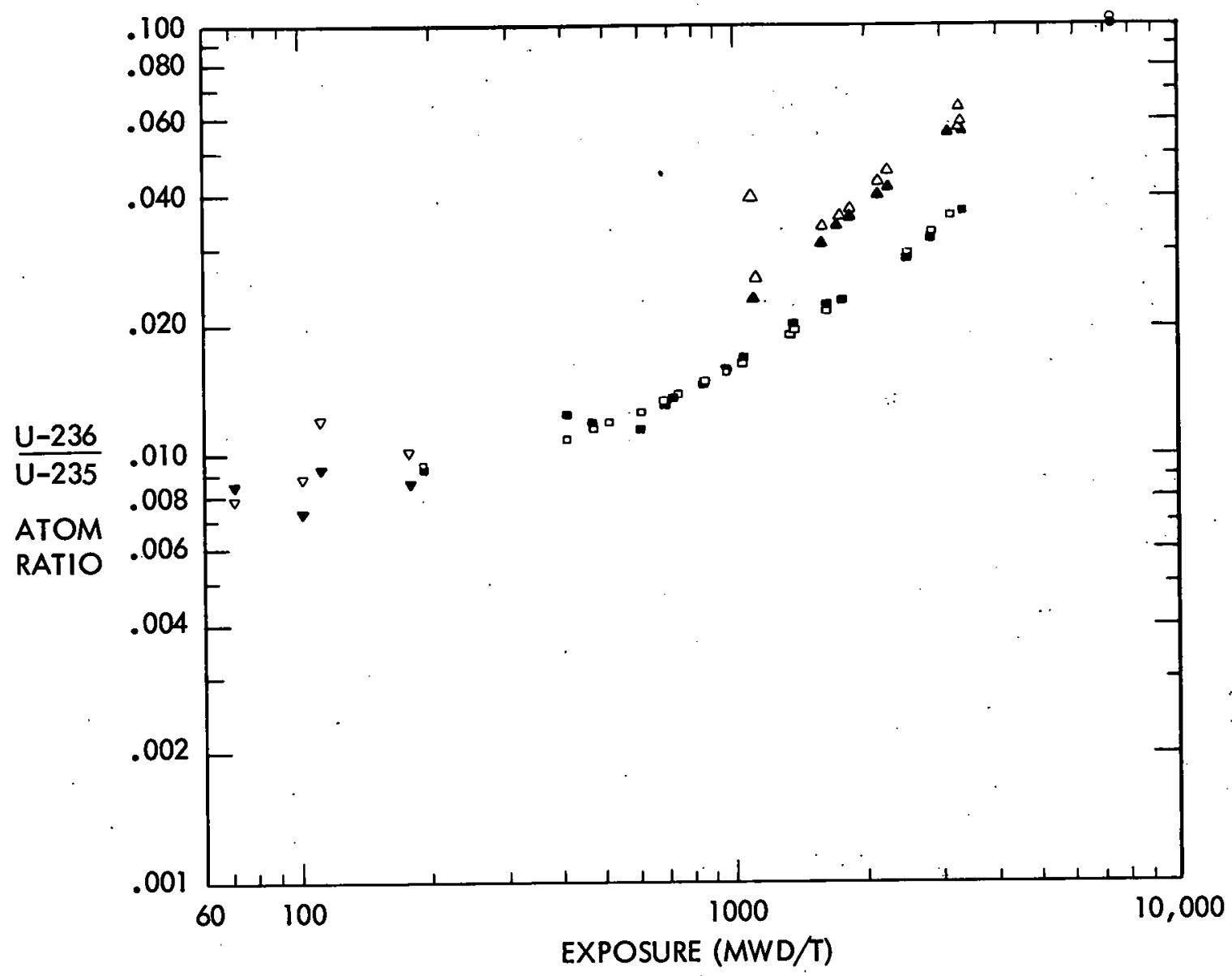

$\circ-2.3 \%$ ENRICHMENT VBWR FUEL

$-2.7 \%$ ENRICHMENT VBWR FUEL

$\triangle \nabla-$ DRESDEN FUEL

SOLID SYMBOLS - MEASURED DATA

OPEN SYMBOLS - COMPUTED DATA

FIG 57 MEASURED AND COMPUTED ATOM RATIOS OF U-236/U-235 IN VBWR AND DRESDEN REACTORS (FROM REF 27 ) 


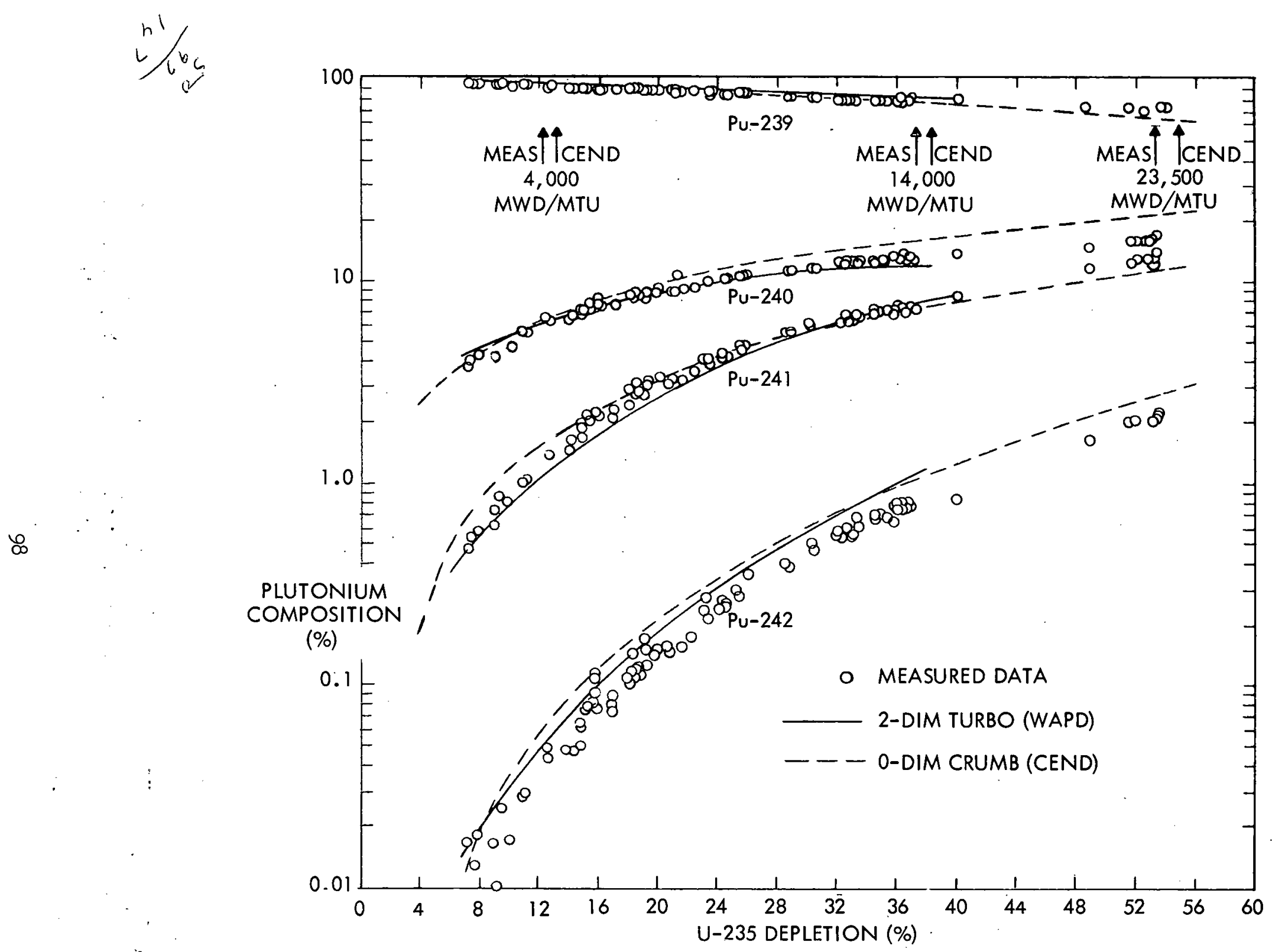

FIG 58 PLUTONIUM COMPOSITION IN THE ASYMPTOTIC NEUTRON SPECTRUM OF YANKEE CORE I 


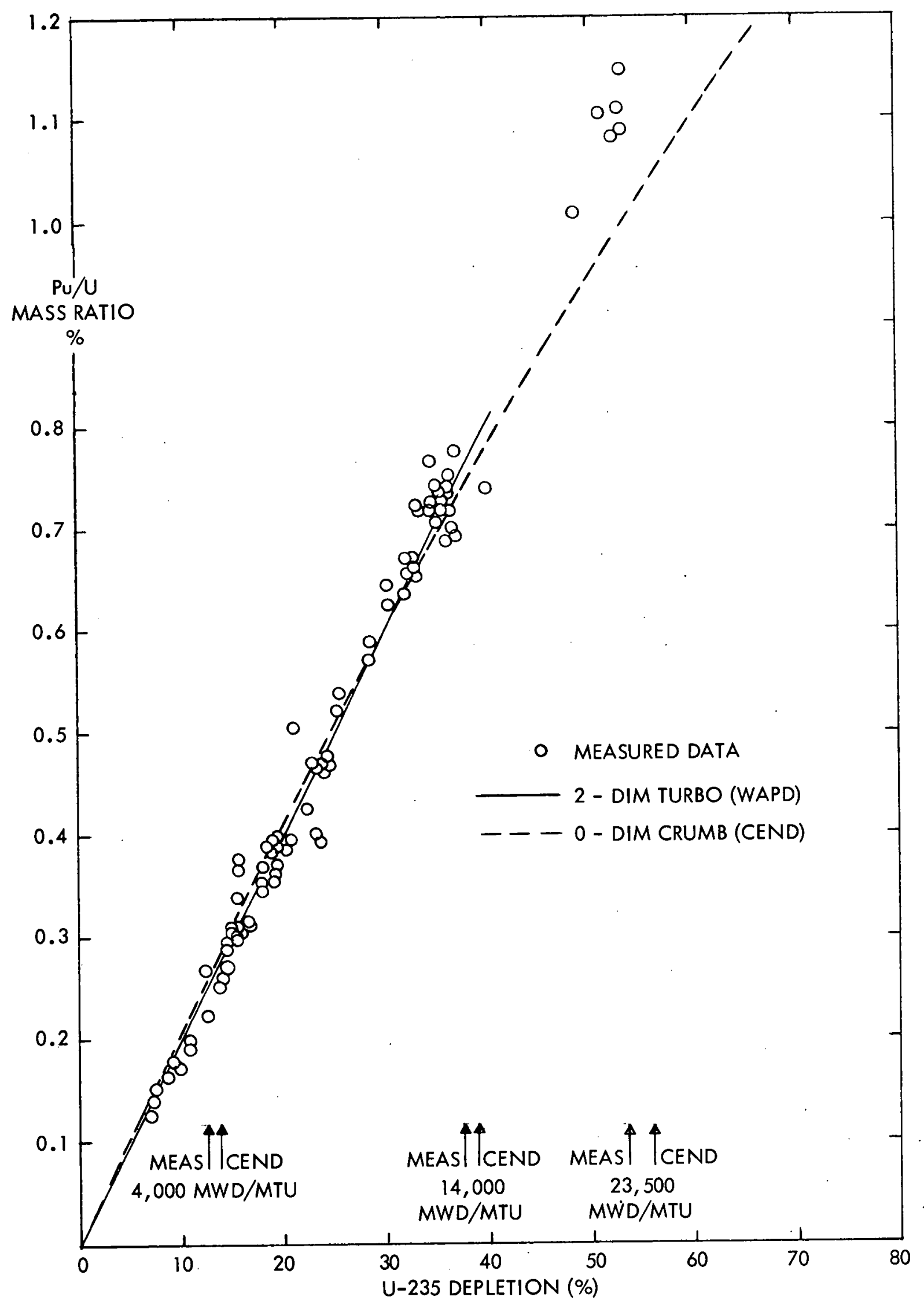

FIG 59 PU/U MASS RATIOS IN THE ASYMPTOTIC NEUTRON SPECTRUM OF YANKEE CORE I 
VII. REFERENCES

1. L. Chajson, Project Manager, Yankee Core Evaluation Program, Quarterly Progress Report. for the Period Ending March 31, 1965, USAEC Report WCAP6075, Westinghouse Electric Corp., Atomic Power Division.

2. J. Jedruch and R. J. Nodvik, Experimentally Determined Burnup and Spent Fuel Composition of Yankee Core I, USAEC Report WCAP-6071, Westinghouse Electric Corp., Atomic Power Division, July 1965.

3. C. E. Foreman and G. R. Parkos, Commonwealth Edison Company Dresden Cycle I Discharged Fuel Exposure and Isotopic Compositions Calculations, GECR-4299, General Electric Company, Atomic Power Equipment Department, June 20, 1963.

4. D. S. McCarty, et al, DRACO - A Three-Dimensional Few-Group Depletion Code for the IBM-704, USAEC Report WAPD-TM-137, Westinghouse Electric Corp., Bettis Atomic Power Division, December 1958.

5. W. R. Cadwell, TKO - A Three-Dimensional Neutron-Diffusion Code for the IBM-704, USAEC Report WAPD-TM-143, Westinghouse Electric Corp., Bettis Atomic Power Laboratory, October 1959.

6. O. J. Marlowe, et al, Nuclear Reactor Depletion Programs for the Philco2000 Computer, USAEC Report WAPD-TM-221, Westinghouse Electric Corp., Bettis Atomic Power Laboratory, January 1961.

7. Martin Becker, The Principles and Applications of Variational Methods, The M.I.T. Press, Cambridge, Massachusetts, 1964.

8. S. M. Hendley and R. A. Mangan, TURBO* - A Two-Dimensional Few-Group Depletion Code for the IBM-7090, USAEC Report WCAP-6059, Westinghouse Electric Corp., Atomic Power Division, March 1964.

9. C. J. Pfeifer and F. R. Urbanus, ZIP-2 - A One-Dimensional Few-Group Synthes is Nuclear Reactor Depletion Program for the Philco-2000 Computer, USAEC Report WAPD-TM-228, Westinghouse Electric Corp., Bettis Atomic Power Laboratory, November 1961.

10. J. E. Meyer, Synthesis of Three-Dimensional Power Shapes - Flux-Weighting Technique, Bettis Technical Review, USAEC Report WAPD-BT-4, Westinghouse Electric Corp., Bettis Plant, October 1957.

11. W. N. Lorentz, Synthesis of Three-Dimensional Power Shapes - Application of Flux-Weighted Synthesis Technique, Bettis Technical Review, USAEC Report WAPD-BT-8, Westinghouse Electric Corp., Bettis Plant, June 1958.

12. D. H. Jones, Calculations and Measurements of Xenon Transients in the PWR, Bettis Technical Review, USAEC Report WAPD-BT-17, Westinghouse Electric Corp., Bettis Atomic Power Laboratory, February 1960.

13. C. A. Flanagan, et al, TNTO2: A Three-Dimensional Neutron Flux Synthesis and Depletion Calculation Computer Program, USAEC Report WAPD-TM-468, Westinghouse Electric Corp., Bettis Atomic Power Laboratory, August 1964. 
14. S. Kaplan, O. J. Marlowe and J. Bewick, Application of Synthesis Techniques to Problems Involving Time Dependence, Nuclear Science and Engineering, 18 (2): 163-176 (February 1964).

15. J. D. McGaugh and R. H. Chastain, Power Density and Burnup Distributions in Yankee Core I, USAEC Report WCAP-6051, Westinghouse Electric Corp., Atomic Power Division, January 1963.

16. Raymond J. Nath, CAVIAR (Carolinas-Virginia Analysis and Data Reduction Code), CVNA-223, Westinghouse Electric Corp., Atomic Power Division, March 1965,

17. M. R. Hackney and C. P. Ruiz, Heavy Element Isotopic Analys is of $\mathrm{UO}_{2} \mathrm{Fuel}$ Irradiated in the VBWR, USAEC Report GEAP-4107, General Electric Company, Atomic Power Equipment Department, December 28, 1962.

18. M. J. Higatsberger, H. Hick and P. Weinzierl, Burn-up Determination of Nuclear Fuel by High-Resolution Gamma-Spectroscopy, Presented at the Third United Nations International Conference on the Peaceful Uses of Atomic Energy, Geneva, 1964, Paper A/Conf. 28/P/399.

19. M. L. Batch, et al, Mid-Iife Power Distribution in the Indian Point Reactor, Presented at the Annual Meeting of the American Nuclear Society, San Francisco, California, December 1964.

20. D. R. Hostetler, Prediction of Mid-Life Power Distribution in the Indian Point Reactor, Presented at the Annual Meeting of the American Nuclear Society, San Francisco, California, December 1964.

21. R. J. Nodvik, Evaluation of Gamma Activity Distributions in Yankee Core I and Core II Spent Fuel, USAEC Report WCAP-6067, Westinghouse Electric Corp., Atomic Power Division, June 1965.

22. R. J. McWhorter and R. G. Parkos, Nuclear Performance of Boiling Water Reactors - An Evaluation of Reactor Operating Data and Reactor Calculations, Presented at American Nuclear Society Topical Meeting on Nuclear Performance of Power-Reactor Cores, TID-7672, p. 71, September 1963.

23. D. I. Fischer and J. M. Harriman, Simplified Analytical Model for Simulation of Boiler Water Reactors, Presented at American Nuclear Society Topical Meeting on Nuclear Performance of Power-Reactor Cores, TID-7672, p. 193, September 1963.

24. R. M. Ball, et al, Consolidated Edison Indian Point Reactor - Core "A" Garma Scan Results, USAEC Docket No. 50-3, July 1964.

25. D. L. Delp, et al, FLARE - A Three-Dimensional Boiling Water Reactor Simulator, USAEC Report GEAP-4598, General Electric Company, Atomic Power Equipment Department, July 16, 1964.

26. C. D. Sphar, Isotopic Composition of PWR Core I Blanket Irradiated tc 16,000 MWD/MIU: Theory vs Experiment, Presented at American Nuclear Society Topical Meeting on Nuclear Performance of Power-Reactor Cores, TID-7672, p. 303, September 1963.

27. M. R. Hackney, D. I. West, and R. Protsik, Isotopic Composition Experiments with Boiling Water Reactor Fuel, Presented at American Nuclear Society Topical Meeting on Nuclear Performance of Power-Reactor Cores, TID-7672, p. 288, September 1963. 
28. L. Chajson, Project Manager, Yankee Core Evaluation Program Quarterly Progress Report for the Period June 20, 1962 to September 30, 1962, USAEC Report WCAP-6052, Westinghouse Electric Corp., Atomic Power Division, October 1962.

29. L. Chajson, Project Manager, Yankee Core Evaluation Program Quarterly Progress Report for the Period Ending December 31, 1962, USAEC Report WCAP-6053, Westinghouse Electric Corp., Atomic Power Division.

30. L. Chajson, Project Manager, Yankee Core Evaluation Program Quarterly Progess Report for the Period Ending March 31, 1963, USAEC Report WCAP6054, Westinghouse Electric Corp., Atomic Power Division, May 1963.

31. L. Chajson, Project Manager, Yankee Core Evaluation Program Quarterly Progress Report for the Period Ending June 30, 1963, USAEC Report WCAP6055, Westinghouse Electric Corp., Atomic Power Division, July 1963.

32. L. Chajson, Project Manager, Yankee Core Evaluation Program Quarterly Progress Report for the Period Ending September 30, 1963, USAEC Report WCAP-6056, Westinghouse Electric Corp., Atomic Power Division.

33. L. Chajson, Project Manager, Yankee Core Evaluation Program Semi-Annual Progress Report for the Period Ending March 31, 1964, USAEC Report WCAP6061, Westinghouse Electric Corp., Atomic Power Division, April 1964.

34. L. Chajson, Project Manager, Yankee Core Evaluation Program Quarterly Progress Report for the Period Ending June 30, 1964, USAEC Report WCAP6063, Westinghouse Electric Corp., Atomic Power Division, July 1964.

35. L. Chajson, Project Manager, Yankee Core Evaluation Program Quarterly Progress Report for the Period Ending September 30, 1964, USAEC Report WCAP-6064, Westinghouse Electric Corp., Atomic Power Division, October 1964.

36. I. Chajson, Project Manager, Yankee Core Evaluation Program Quarterly Progress Report for the Period Ending December 31, 1964, USAEC Report WCAP-6070, Westinghouse Electric Corp., Atomic Power Division, January 1965.

37. Combustion Engineering, Inc., Nuclear Division, An IBM-704 Program for Calculating Effective Resonance Absorption Cross Sections by the Narrow Resonance or Narrow-Resonance Infinite Mass Approximation, USAEC Report CEND-94, 1960.

38. G. I. Bell, A Simple Treatment for Effective Resonance Absorption Cross Sections in Dense Lattices, Nuclear Science and Engineering, 5 (2): 138 (1959).

39. General Electric Company, Atomic Power Equipment Department, Fuel Cycle Program: A Boiling Water Reactor Research and Development Program Sixth Quarterly Progress Report, USAEC Report GEAP-3898, January 1962.

40. B. F. Rider, C. P. Ruiz and H. W. Alter, Measurements of Burnup and Heavy Element Isotopic Composition in Irradiated Power Reactor Fuels, Presented at American Nuclear Society Topical Meeting on Nuclear Performance of Power-Reactor Cores, TID-7672, p. 275, September 1963. 
41. B. F. Rider, et al, Accurate Nuclear Fuel Burnup Analysis XII, USAEC Report GEAP-4776, General Electric Company, Atomic Power Equipment Department, December 1964.

42. R. P. Larsen, Determination of Burnup on EBR-II Fuel, Transactions American Nuclear Society, 8 (1): 8 (June 1965).

43. B. F. Rider, et al, BURNUP - A Code for Calculation of Nuclear Fuel Burnup from U, Pu, and Nd Mass Spectrometric Measurements, USAEC Report GEAP-4811, General Electric Company, Atomic Power Equipment Department, June 1965.

44. M. C. Edlund, et al, Consolidated Edison Thorium Reactor - Determination of Power Distribution in the CETR by Measurement of Lanthanum-140 Activity, USAEC Docket 50-3 Exhibit K-5A6B, or BAW-164, The Babcock and Wilcox Company, September 1961.

45. D. L. West and W. R. Morgan, Power-Distribution Measurements at Dresden, Transactions American Nuclear Society, 8 (1): 104. 


\section{APPENDIX A}

DESCRIPTION OF NUCLEAR CODES

This section presents a short description of presently used nuclear reactor fuel depletion codes. Only codes widely used in the power reactor industry and recently developed codes offering improvements relative to the old ones are included. No effort has been made to collect information on all existing depletion codes. European programs like MELE II (solves the diffusion equation using a series expansion method), MAFIA II (similar to the General Atomic depletion codes) or METHUSELAH are not included.

The descriptions are short indicating only the major purpose of the codes and the limitations of the codes. For further details, the references, given after each code description., should be consulted. It should be recognized that most of the codes are continually changing; new routines are added to them to permit additional calculations (continuous refueling, fuel cycle economics) and new methods are incorporated to shorten computing times. Many of them have different versions, some of which is applicable only for a given computer. While computers (on which, to the author's knowledge, the code has been run) are given, this list is not considered to be complete. For example, new versions like recent adaptations to Control Data Corporation machines are not mentioned.

The following nuclear codes are described:

Zero-dimensional multigroup depletion codes: CINDER . LEOPARD CRUMB TONG

GAD

One-dimensional multigroup depletion codes: CANDLE

CNCR FEVER

GROM

SIZZLE

ZIP

Two-dimensional multigroup depletion codes: ASSAULT TURBO DDB

Three-dimensional one-group codes: FLARE

Three-dimensional multigroup depletion codes: DRACO TNTO2 TNT-1

Depletion systems: DEPLETION 
CINDER

Developed by: Westinghouse Electric Corporation

Written in: $\quad$ FORTRAN

Has been run on: Philco-2000 computer

Description of code:

Zero-dimensional few-group depletion code. Number of energy groups $\leq 4$; total number of nuclides $\leq 250$; number of fissile nuclides $\leq 10$. Self-shielding factors can be provided for the thermal group. Group 3 shielding factor can be specified for up to 10 nuclides. It is inexpensive to run; a calculation of 64 chains containing 218 nuclides required 2.3 minutes total running time for nine time steps on the Philco-2000 computer.

\section{Depletion calculations:}

The code allows the user to formulate his own depletion program, to specify the depletion chains of interest to him. Up to 40 depletion and 99 fission product chains are permitted, but the total number of nuclides is restricted to 250. The number of nuclides per chain cannot exceed 15. The exact solution to the differential equations is programmed in the code. The maximum number of time steps is 100.

Types of control:

Straight burnup

Reference:

$$
\text { H. }
$$

T. R. England: "CINDER: A One-Point Depletion and Fišsion Product Program." WAPD-TM-334, August 1962

$$
\begin{aligned}
& \cdots \\
& \therefore \quad I D E
\end{aligned}
$$


CRUMB

Developed by:

Written in:

Has been run on:
Combustion Engineering, Inc.

FORTRAN II

IBM-7070, IBM-7094 computers

Description of code:

Zero-dimensional four-group depletion code. The code can handle a maximum of 40 elements. Concentration dependent self-shielding factors are available for each nuclide in the fourth energy group, also for Pu2 40 in the third energy group. In-program library of fast microscopic constants is provided for use if desired. Macroscopic constants generation follows the CANDLE scheme. Geometric effects are approximated by variable bucklings and average distributed poison cross sections. It is very inexpensive to run the code.

Depletion calculations:

The solution to the depletion equations is based on the finite difference approximation. Both the Th232 and U238 chains are included in the depletion calculation. Besides the samarium and xenon chains, time dependent equations are solved for two fission product aggregates (one non-saturating and one saturating) of each of three fissile materials (U235, U233 and Pu) and for B1O and one more burnable poison. There are a maximum of 50 time points permitted.

Types of control:

Straight burnup

Energy dependent poison search

Energy dependent buckling search

References:

C. J. Hansen: "CRUMB-2: A One-Point, Four-Group Reactor Burnup Code for the IBM-7070." CEND-130, May 1961

D. F. Kreidler: "CRUMB-3: A One-Point, Four-Group Reactor Burnup Code." To be published. 
GAD

Developed by:

Written in:

Has been run on:

Reactor used for:
General Atomic and Empire State Atomic Development Associates, Inc.

FORTRAN II

IBM-7090 computer

Peach Bottom

Description of code:

Zero-dimensional multigroup depletion code for fuel cycle analysis. Number of fuel zones $\leqslant 8$; number of energy groups $\leqslant 20$; number of fast energy groups $\leqslant 10$; number of thermal groups $\leqslant 19$; up-scattering is allowed for each of 3 moderator nuclides. It is assumed that the fluxes in all zones are identical. Concentration dependent selfshielding factors may, be applied to any nuclide whose concentration varies with exposure. Irradiated fuel may be removed and fresh fuel reloaded in one or more zones as often as desired. Irradiated fuel may also be recycled. A fuel cycle cost calculation is included which calculates costs for each zone at the time the zone is refueled. Computing time on the IBM-7090 is approximately $1.5 \times 10^{-5}$ hours per group per region per small time step. The code was developed by private funds and it is proprietary.

Depletion calculations :

Nuclide concentrations are computed separately for each fuel zone. Finite difference approximation is used to obtain the solution to the differential equation of the Th232 and U238 chains. Xel35 and Sml49 concentrations are computed using the equilibrium equations. One non-saturating fission product is included and there is option for 20 other burnable materials and one lumped poison. A special option is available for calculating the concentration of tritium and He 3 when beryllium is used as moderator. The shape of the flux spectrum is recalculated for each large time step, which consists of one or more small time steps.

Types of control:

Straight burnup

Control poison search

Reference:

F. W. Todt: "GAD: An Infinite Medium Multigroup Burnup Code for Fuel Cycle Analysis." GA-4150, April 1963 
LEOPARD

Developed by:

Written in:

Has been run on:
Westinghouse Electric Corporation

FORTRAN II and FAP for a 32,000 word computer with 12 tape units

IBM-7094

Description of code:

Zero-dimensional few-group spectrum dependent depletion code. Number of energy groups $\leq 4$. The code determines fast and thermal spectra, using only basic geometry and temperature data, based on a modified MUFT-SOFOCATE model. It optionally computes fuel depletion for a dimensionless reactor and recomputes the spectra before each discrete burnup step. It is assumed that the reactor contains a large array of unit fuel cells arranged in either a square lattice or a hexagonal lattice. Each unit cell contains one cylindrical fuel rod, a metallic clad around the fuel rod, and a moderator. Running time for LEOPARD on the IBM-7094 computer is about one minute per complete spectra calculation.

Depletion calculations:

The exact solution to the differential equations of the Th232 and U238 nuclide chains is programed in the code. Xenon and samarium are treated individually; the rest of the fission products are grouped into one fission product aggregate. There is provision made to use B1O as burnable or changeable poison. The number of time steps is limited to a maximum of 100 steps.

Types of control:

Straight burnup

Reference:

R. F. Barry: "LEOPARD: A Spectrum Dependent Non-Spatial Depletion Code for the IBM-7094." WCAP-3269-26, September 1963 
Developed by:

Written in:

Has been run on:
Oak Ridge National Laboratory

FORTRAN II for a 32,000 word computer with 14 tape units

IBM-7090

Description of code:

Zero-dimensional multigroup depletion code. Number of fast groups $\leqslant 30$; number of thermal groups $\leqslant 10$; maximum number of energy groups for depletion $=36$; number of fissile nuclei $\leq 10$. The code is designed to calculate microscopic multigroup cross sections and to solve the zero-dimensional reactor depletion problem. The 68 fast group GAM code and the 30 group thermal code THERMOS are used in modified form to produce a set of few-group microscopic cross sections. Up and down transfer probabilities and nuclide dependent fission source spectrums may be specified. Fuel cycle costs may be determined; intermittent, once-through fuel movement or scatter-refueling can be considered. Typical running times are 5 minutes for GAM, 10 minutes for THERMOS, 5 minutes for a depletion calculation and 25 minutes for a complex fuel rearrangement depletion calculation with economics.

Depletion calculations:

An explicit solution is used to determine nuclide concentrations at the end of a time step with reaction rates fixed during this period. Nuclide chains are specified by the user; there is provision to consider interlocked chains. Depletion history may be followed for each of several fuel zones. At the end of each large time step the concentrations are averaged, and the point eigenvalue problem is solved to establish the fluxes. The number of eigenvalue calculations cannot exceed 24 .

Types of control:

Straight burnup

Control poison search

\section{Reference:}

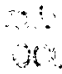

D. R. Vondy and T. B. Fowler: "Computer Code TONG for Zero-Dimensional Reactor Depletion Calculations." (ORNL-TM report to be issued) 
CANDLE

Developed by:

Written in:

Has been run on:

Reactors used for:
Westinghouse Electric Corporation

FORTRAN for a 32,000 word computer with 16 tape units

IBM-704 and Philco-2000 computers

Saxton, Shippingport, Indian Point, Carolinas-Virginia, Piqua and Hallam

Description of code:

One-dimensional, few-group diffusion theory depletion code. Number of mesh points $\leqslant 500$; number of regions $\leqslant 50$; number of energy groups $\leq 4$. The elements are uniformly distributed within a region. As burnup progresses the distribution of fuel becomes non-uniform within a region. A library of fast microscopic cross sections is available in the code. In the thermal group, constant selfshielding factors can be specified for each isotope. Variable self-shielding factors are allowed for U235 in the thermal group and for BlO, both in the thermal and in the epithermal group.

Depletion calculations:

A finite difference solution to the isotopic equations is used. Depletion is calclilated for each mesh point. A total of thirteen time dependent isotopes are allowed; Th232, U233, U234, and Pu242 are not included. Xenon and samarium are treated individually; the rest of the fission products are grouped into two fission product aggregates.

Types of control:

Straight burnup Poison concentration search Variable transverse buckling search Moving the interface between poisoned and unpoisoned regions

Reference:

O. J. Marlowe, et al: "Nuclear Reactor Depletion Programs for the Philco-2000 Computer." WAPD-TM-221, January 1961 
CNCR

Developed by:

Written in:

Has been run on:
Westinghouse Electric Corporation

FORTRAN for a 32,768. word computer with 4 tape units

IBM-7090 and IBM-7094 computers

Description of code:

One-dimensional few-group diffusion theory depletion code. Number of mesh points $\leq 251$; number of regions $\leq 11$; number of energy groups: 2 or 4 . CNCR is a modified version of the CANDLE code; the effects of spatial variations of water density due to coolant heating are included. The code can be used for boiling water reactors also. In this case, the only effect considered is the resulting decrease in water density; hydrodynamic effects are ignored. Variable self-shielding factors are allowed only for U235 and BIO.

Depletion calculations:

The same time dependent equations are used as in CANDLE. A finite difference approximation is employed and depletion is calculated for each mesh point. A total of thirteen time dependent isotopes are allowed; Th232, U233, U234 and Pu242 are not included. Xenon and samarium are treated individually; the rest of the fission products are grouped into two fission product aggregates.

Types of control:

Straight burnup

Varlable transverse buckling search

Variable poison concentration search

Water soluble poison search

Rod equivalent poison search

Axial poison boundary search

Reference :

S. M. Hendley and R. A. Mangan: "CNCR-2: A One-Dimensional Few-Group Depletion Code for the IBM-7094, Which Includes the Effects of Water Density Variations on Neutron Moderation." WCAP-6058, January 1964 


\section{GROM}

Developed by:

Written in:

Has been run on:
University of California Lawrence Radiation Laboratory *

SAP language for a 32,000 word computer with 6 tape units

IBM-7094 computer

Description of code:

One-dimensional multigroup diffusion theory depletion code. Number of energy groups $\leq 18$; number of zones $\leq 40$. Non-fission product nuclides are allowed to have individual fission spectra, yields and fast fission factors together with concentration dependent group cross sections. Energy dependent capture cross sections, decay constants and fission yields are allowed for fission products. The number of non-fission product nuclides is limited to 14 and the number of fission products is limited to 100.

Depletion calculations:

All nuclide concentrations may be time dependent. The analytical solutions of the generalized burnup differential equations are used. The maximum number of time steps is 99 . There is no limitation imposed on the number of decay chains as long as the total number of non-fission product nuclides do not exceed 14 and the number of fission products do not exceed 100.

Types of control:

Straight burnup

Control poison search

Reference:

G. M. Benson and E. T. Collins: "GROM: A Time-Dependent, OneDimensional, Multigroup Neutron Diffusion Theory Reactor Burnup Code for the IBM-7094." UCRL-6801, June 1962 


\section{FEVER}

Developed by:

Written in:

Has been mun on:

Reactor used for:
General Atomic

FORTRAN II for a 32,000 word computer

IBM-7090 cormuter

Peach Bottom

Description of code:

One-dimensional few-group diffusion theory depletion code. Number of mesh points $\leq 150$; number of regions $\leq 20$; number of energy groups $\leq 4$. Slowing down may occur only to the next adjacent group, and the fission source may be in the highest energy group only. The code allows for the representation of self-shielded burnable poisons. The magnitude of the shielding factor is determined from a polynominal function of poison concentration. The coefficients of this polynominal are supplied as input data to the code: The code also permits the use of different microscopic cross sections for a given material in different zones.

Depletion calculations:

Time-dependent equations are solved for 25 isotopes; the first six equations are for the Th232 chain, the next six are for the U238 chain. One non-saturating fission product aggregate and two rapidly saturating fission products (Xel35 and Sml49) are included. The remaining ten isotopes can be selected freely. Region average nuclide concentrations rather than mesh-point values are used. The solutions programmed in the code are based on the finite difference approximation.

Types of control:

Straight burnup

Burnup with control poison search

Reference:

F. Todt, et al: "FEVER: A One-Dimensional Few-Group Depletion Program for Reactor Analysis." GA-2749, November 1962 
Developed by:

Written in:

Has been run on:

Reactors used for:
Atomics International

FORTRAN for a 32,000 word computer

IBM-704, IBM-709, and IBM-7094 computers

Piqua, Hallam

Description of code:

One-dimensional multigroup diffusion theory depletion code. Number of mesh points $\leqslant 100$; number of regions $\leqslant 20$; number of energy groups 4 18; maximum number of elements: 20. The code was designed for intermediate to fast reactor systems. The diffusion calculations are based on the AIM- 6 code. Slowing down may occur to any of five energy groups; there is no provision for up-scattering. The code accepts either microscopic or macroscopic cross section libraries. A built-in microscopic cross section library is available.

Burnup calculations:

Both the Th232 and U238 chains are treated; the exact solutions to the isotopic equations are programmed in the code. All fission products are included in one saturating type equation. However, the fission products of each fissile isotope are treated in separate terms, permitting the use of different fission yields for each is otope. A modified version of the code provides for the individual treatment of the Xe and Sm chains. The number of burnup steps used in the calculations may vary from four to twenty-five. The first three intervals must total 21 days.

Types of control:

Straight burmup

Poison concentration search

References:

D. P. Satkus and H. P. Flatt: "SIZZLE: NAA Program Description," February 1961, Internal Memorandum

H. P. Flatt and D. C. Baller: "The AIM-6 Code," January 1961, Internal Memorandum 
Developed by:

Written in:

Has been run on:
Westinghouse Electric Corporation

FORTRAN for a 32,768 word computer with 7 tape units

Philco-2000 computer

Description of code:

One-dimensional few-group diffusion theory depletion code used for the synthesis of three-dimensional solutions from a set of twodimensional calculations. Number of energy groups $\leq 4$; number of mesh points $\leq 400$; number of compositions $\leq 50$; number of control rod configurations $\leqslant 50$. Flux-weighted average diffusion-equation constants as function of burnup are calculated from the $x-y$ solutions for input to the ZIP program. Specific isotopic densities are not specifically included in the ZIP calculations; instead each axial zone is described by its fuel fraction. The relationships between isotopic densities and fuel fraction are given by the results of the two-dimensional calculations performed for each axial zone of the reactor.

Depletion calculations :

Heavy-isotope concentrations given in terms of fuel fractions by the corresponding two-dimensional calculations; individual fuel isotopes are not explicitly considered in the ZIP calculation. Two, chains of fission products (usually the xenon and samarian chain) can be treated explicitly.

Types of control:

Straight burnup

Control poison boundary search

Reference:

C. J. Pfeifer and F..R. Urbanus: "ZIP-2: A One-Dimensional FewGroup Synthesis Nuclear Reactor Depletion Program for the Philco-2000 Conputer." WAPD-TM-228, November 1961 
ASSAULT

Developed by:

Written in:

Has been run on:
Oak Ridge National Laboratory

FORTRAN II for a 32,000 word computer with 14 tape units

IBM-7090

Description of code:

Two-dimensional few-group diffusion theory depletion code. Number of mesh points $\leq 20,000$; number of mesh points in one direction $\leq 250$; number of regions for depletion $\leqslant 200$; number of energy groups $\leqslant 50$. It is essentially a combination of the diffusion theory code EXTERMINATOR and the depletion part of the TONG code. The EQUIPOISE iterative technique is used to solve the neutron diffusion equation. $\mathrm{R}-\mathrm{Z}, \mathrm{X}-\mathrm{Y}$ and $\mathrm{R}-\theta$ geometry may be considered. Scattering from any group to any other group is allowed. A typical 8 group, 648 mesh point problem requires 37 minutes running time on the IBM-7090 for the first time step and an average of 20 minutes for each additional eigenvalue problem.

Depletion calculations :

Nuclide chains are specified by the user; the nuclide chain equations are solved explicitly. Nuclide concentrations may be changed, material added and removed at any time. Any of the 200 nuclides permitted in the code can be depleted.

Types of control:

Straight burnup Group and region dependent poison search. Specifled material interchanges

\section{Reference:}

D. R. Vondy, et al: "Reactor Depletion Code ASSAUTT (Two-Dimensional, Multi-Neutron Group)" ORNL-TM report to be issued. 
DDB

Developed by:

Written in:

Has been run on:

Reactor used for:
General Atomic

FORTRAN for a 32,768 word computer

IBM-7090 corputer

Peach Bottom

Description of code:

Two-dimensional few-group reactor diffusion code with burnup option. Number of mesh points $\leq 4,000$; number of regions $\leqslant 300$; number of energy groups $\leq 5$; number of isotopic species $\leq 80$. Down-scattering two groups from the third group and up-scattering one group from the fifth group is allowed. The diffusion portion of DDB is basically a translation into FORTRAN of the UCRI program ANGIE. It is written in $\mathrm{R}-\mathrm{Z}$ geometry and each region is assigned to one of ten sets each of which can have its own cross section library. The fission source spectrum is independent of incident energy and fissioning isotope. A full size problem requires about one minute per diffusion iteration and about 8 hours for a 50 time step burnup calculation.

Depletion calculations:

A finite difference approximation (Adam's Method) is used to solve the time-dependent equations. Only regionwise burnup is calculated. Each material occurring in the reactor can be depleted.

Types of control:

Straight burnup

Control rod configuration search (regionwise)

Reference:

C. Cyl - Champlin, et al: "DDB: A Two-Dimensional Reactor Diffusion Code with Criticality Search and Burnout Options." GAMD-2797, March 1962

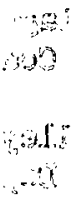


TURBO

Developed by:

Written in:

Has been run on:

Reactor used for:
Westinghouse Electric Corporation

FORTRAN for a 32,768 word computer with 13 tape units

IBM-704, IBM-7090 and Philco-2000 computers

Yankee, Shippingport

Description of code:

Two-dimensional few-group diffusion theory depletion code. Number of mesh points $\leq 7500$; number of compositions $\leq 35$; number of energy groups: 2 or 4 . A microscopic fast cross section library is furnished as a part of the code. If this library is not desired, all or part of it may be modified as part of the input data. Direct input of macroscopic cross sections is permitted. Constant self-shielding factors can be specified for each isotope; variable self-shielding factors are allowed for U235 and for B10. The above limitations apply to the TURBO* version of the code. Earlier versions might be more flexible in some sense.

Depletion calculations:

A finite difference solution to the isotopic equations is used. Depletion is calculated for each mesh point. A total of thirteen time dependent isotopes are allowed; Th232, U233, U234 and Pu242 are not included. Xenon and samarium are treated individually; the rest of the fission products are grouped into two fission product aggregates. Power level, microscopic cross sections, self-shielding factors and transverse buckling can be adjusted after each time step. It is also possible to change isotopic densities at a particular time step; hence, to study the effects of fuel rearrangements.

Types of control:

Straight burnup

References :

0. J. Marlowe, et al: "Nuclear Reactor Depletion Programs for the Philco-2000 Computer." WAPD-TM-221, January 1961

J. B. Callaghan, et al: "TURBO -- A Two-Dimensional Few-Gro up Depletion Code for the IBM-704." WAPD-TM-95, November 1957

S. M. Hendley and R. A. Mangan: "TURBO*: A Two-Dimensional Few Group Depletion Code for the IBM-7090." WCAP-6059, March 1964 
FLARE

Developed by:

Written in:

Has been mun on:

Reactor used for:
General Electric Corporation

FORTRAN II for a 32,000 word computer

Philco-2000, IBM-7094 and CDC-3600 computers

Dresden, Humboldt Bay, Big Rock Point, Elk River, Pathfinder, La Crosse

Description of code:

Three-dimensional, one-group power distribution and fuel exposure code. The present version of the code will handle a maximum array of $14 \times 14 \times 12$ nodes. It is based on a modification to one-group diffusion theory in which only the parameters $k_{0}$ and $\mathrm{M}^{2}$ (migration area) are involved. The variations of $k_{\infty}$ and $M^{2}$ with exposure are inputed as analytical fits. The code was developed for boiling water reactors, but is applicable to other reactor types; the coupled effects of flow, power and void are included in the calculations. The reflector is replaced by an albedo at the core surface. Each control rod is independently represented. The code is simple and it is inexpensive to run. Typical running times on the Philco-2000 are 0.001 hour per source iteration or 0.03 hour for a solution with converged power and voids but fixed control rod position and burnup. A number of approximations are built in the code to simplify the reactor model. The validity of these approximations must be checked by comparison to more exact models at least at the beginning of core life.

Depletion calculations:

There are no depletion calculations programed in the code; only fuel exposure is computed for each node and for each fuel assembly so that the isotopic concentrations must be obtained from independent calculations.

Types of control:

Straight burnup

Control rod position search (presently not in the code)

Reference:

D. L. Delp, et al: "FLARE: A Three-Dimensional Boiling Water Reactor Simulator." GEAP-4598, July 1964 
DRACO and TNT-1

Developed by:

Written in:

Has been run on:
Westinghouse Electric Corporation

FORTRAN for a 16,384 or 32,768 word computer with 9 tape units

IBM-704 and Philco-2000 computers

Description of code:

Three-dimensional few-group diffusion theory depletion code. Number of mesh points $\leq 4750$; number of compositions $\leq 50$; number of elements $\leq 30$; number of energy groups: 2 or 4 . Fast microscopic cross section library is available on the program tape. For each time step, a maximum of four sets of thermal cross sections may be specified. A modified version of the code extended to the Philco-2000 computer is known as TNT-1. The major improvement is in the size of the problem that the program can handle. TNT-1 is restricted to 3600 points in a plane and to about 100,000 total mesh points.

Depletion calculations:

A finite difference solution to the isotopic equations is used. Depletion is calculated for each mesh point. A total of thirteen time dependent isotopes are allowed; Th232, U233, U234 and Pu242 are not included. Xenon and samarium are treated individually; the rest of the fission products are grouped. into two fission product aggregates.

Types of control:

Straight burnup

References :

D. S. McCarty, et al: "DRACO: A Three-Dimensional Few-Group Depletion Code for the IBM-704." WAPD-TM-137, December 1958

O. J. Marlowe, et al: "Nuclear Reactor Depletion Programs for the Philco-2000 Computer." WAPD-TM-221, January 1961 
TNTO2

Developed by:

Westinghouse Electric Corporation

Written in:

FORTRAN

Has been run on:

Philco-2000 computer

Description of code:

Few-group diffusion theory depletion program to synthesize threedimensional solutions. Number of energy groups $\epsilon 4$; number of radial mesh points $\leq 20,000$; number of axial mesh points $\leq 150$; number of depletion blocks $\leq 135,000$.

The three-dimensional flux distribution is approximated by a linear combination of two-dimensional radial components. These radial flux shapes (trial functions) are obtained using two-dimensional programs. The code determines, using these trial functions, the axial mixing coefficients which combine the two-dimensional trial functions to produce the desired approximation to the three-dimensional flux. The code requires less computing time than three-dimensional depletion programs; the time advantage is greater for larger problems.

Depletion calculations:

Thirteen time dependent equations may be solved to obtain the change in nuclide concentrations. There is no provision to treat $T h 232$, U233, U234 and Pu242. Xenon and samarium are considered individually; the rest of the fission products are grouped into two fission product aggregates. The depletion equations are solved for each depletion block. A depletion block contains one or more spatial mesh cubes. There are plans to implement in this program the model-independent depletion system of the HARMONY code.

Types of control:

Straight burnup

Control poison boundary search

Control rod position search

Reference:

C. A. Flanagan, et al: "TNTO2: A Three-Dimensional Neutron Flux Synthesis and Depletion Calculation Computer Program." WAPD-TM-468, August 1964 
DEPLETION

Developed by:

General Electric Corporation

Written in:

FORTRAN for a 32,000 word computer

Has been run on:

Philco-2000 computer

Description of code:

DEPLETION is the KARE System's burnup code. It can be used in conjunction with any of the one, two and synthesized threedimensional diffusion programs of the system. It depends on the other programs of the system and will not function alone. The code was developed for highly enriched U235 reactor cores, and seems to have some disadvantages if applied to power reactors. The KARE system is presently being adopted to the CDC-6600 computer; the new system is called NOVA. Within NOVA each program functions as a separate entity.

Depletion calculations:

The code considers two basic types of isotopes: those with precursors, which include Hfl77, Hfl78, Hfl79 and Hfl80 and those without precursors, i.e., U235, B1O, $\mathrm{Hfl} 74$ and Hfl76. No other fuel isotope is treated explicitly. Constant xenon poisoning is assumed during depletion. Isotopes are depleted by regions rather than on the basis of mesh points. Concentration dependent self-shielding factors are available for $\mathrm{U} 235$ and BIO.

Types of control:

Determined by the selected diffusion program.

Reference:

D. E. Goodman, et al: "KARE: A System of Diffusion Theory Programs for the Philco-2000, Volume II Group Constant and Depletion Calculations." KAPL-2165-2, June 1964 
HARMONY

Developed by:

Written in:

Has been run on:
Westinghouse Electric Corporation

FORTRAN II

Philco-2000 Computer

Description of code:

One-, two- or three-dimensional few-group diffusion theory depletion system. Number of energy groups $\leq 5$. There is no limit on the number of nuclides that may be present. The initial application has been with two-dimensional spatial programs for $x-y$ and $r-z$ geometries in PDQ-5 and hexagonal geometries in PDQ-6. The last two energy groups can be used to describe spatially dependent thermal neutron spectrum by approximating the thermal spectrum as a linear combination of an overlapping hard and soft spectrum. Any of the cross sections or shielding factors used in the spatial or depletion calculations may be represented as time dependent. Treating hydrogen as a depletable isotope, survey calculations as a function of metal to water ratio can be performed.

Depletion calculations:

The depletion equations to be solved by the program are specified by the user and are patterned after those used in the CINDER program. The number of depletable isotopes is limited only by the total amount of storage required. In order to approximate more closely constant power operation, provision has been made to adjust the thermal flux level at specific times within the basic interval. To account for the time dependence of cross sections each renormalization interval may be divided into subintervals. The number of subintervals may vary from point to point. Compositions can be replaced at any time in a depletion study to investigate the effects of fuel rearrangements.

Types of control:

Determined by the selected diffusion program.

Reference:

R. J. Breen, et al: "HARMONY: System for Nuclear Reactor Depletion Computation.". WAPD-TM-478, January 1965 


\title{
APPENDIX B
}

\author{
METHODS USED IN OPERATING POWER REACTORS \\ TO MEASURE POWER AND EXPOSURE DISTRIBUTIONS
}

In-core measuréments have been and are being continually made during the operation of some U.S.power reactors which enable determination of assemblywise power outputs and exposures. For several power-reactor cores, out-of-core measurements of assemblywise power outputs were performed utilizing gamma-scan techniques. The experimental techniques employed and methods used to interpret the measurement results are briefly outlined.

\section{Carolinas-Virginia Tube Reactor, CVTR}

CVTR instrumentation is provided to measure the coolant flow rate and temperature rise across the individual U-type pressure tubes containing the fuel assemblies of the reactor core. These data are recorded and analyzed at frequent intervals so as to insure safe operation of the plant; hence, these data also provide a continuing indication of the relative power output and total energy production from each U-tube. Each U-tube contains two fuel assemblies, one in each leg of the U-tube. The division of measured U-tube thermal power between the two fuel assemblies in the U-tube is obtained by means of $\mathrm{PDQ}$ calculations.

The foregoing dalid, when combined with the normal plant measurements of reactor total thermal power output (including experimental measurement of the total heat losses to the CVTR moderator), permit determination of assemblywise power outputs and integrated exposures.

Flux wires are used in CVTR to determine the axial flux distribution at various times in core life so as to obtain a close estimate of the safety margin to DNB and bulk boiling. The in-core flux wire system consists of 6 carbon steel wires containing 0.5 percent $\mathrm{Mn} 56$. These wires are connected to drive motors which insert and withdraw the flux wires into thimbles located in the reactor core midway between the various U-tube legs. Irradiation in all thimble locations (24 in number) is accomplished by irradiating each of the six flux wires four times. Three dimensional wire-activation distributions are obtained by counting the activity level at successive intervals in the axial direction of the flux wires for different radial positions of these wires. The wire activation data is reduced by use of the nuclear code, CAVIAR, to obtain the three-dimensional flux distributions, power distributions, and fuel-assembly power outputs (Reference 16). CAVIAR interprets the saturated activity values in terms of relative power densities by means of input nuclear factors which are obtained theoretically from two-dimensional few-group diffusion theory (PDQ) calculations. The nuclear factor is simply the ratio of the fission density in a leg of a U-tube divided by the Mn activation between the legs of the U-tube (i.e., at the wire location during irradiation). The nuclear factors for a particular control rod configuration are taken from one or more PDQ problems corresponding to the actual reactor geometry, including discrete representation of the individual U-tube. legs. These PDQ calculations are the same ones used in the interpretation of the U-tube thermal output measurements previously discussed. No indication of the accuracies involved in determining U-tube leg relative power outputs is available at this time. 


\section{Piqua and Hallam Reactors}

The fuel assemblies in the Piqua and Hallam Reactors are housed in individual flow process tubes, thereby permitting determination of the individual coolant flows and outlet temperatures. Fixed orifices are used in the flow process tubes in Piqua, whereas the orifices in Hallam are individually adjustable during power operation. The relative flows through the fuel assemblies are obtained on the basis of hydraulic determinations. In Hallam, the relative channel flow is related to the fuel channel variable-orifice setting, for which calibration curves are available. In Piqua, the variations in flow were checked by hydraulic measurements performed for 21 fuel assemblies and were found to be less than 5 percent. Thermocouples are located at the outlet of each flow channel (1/channel in Piqua, 2/channel in Hallam) and 3 thermocouples are located in the inlet plenums of the Piqua and Hallam cores. From the relative flow and temperature-rise determinations, the relative power outputs of the fuel assemblies are directly obtained. The reactor total coolant flow and power output are measured separately (with corrections included for the heat losses) and are combined with the relative flow and power-output information to obtain the actual flows and power outputs for each flow channel. A computer code, which accepts operating data, is used to obtain the power outputs and integrated exposures of the fuel assemblies. These calculations are performed once a week so as to obtain a continual record of the power and exposure distributions. Contour maps of the accumulated exposure are prepared on a monthly basis.

\section{Yankee Core I}

Westinghouse Electric Corporation, under U.S.AEC Contract, conducted an intensive study of measured and calculated power and burnup distributions in Yankee Core I ( e.g., References 2,15, and 2l). In-core flux-wire measurements performed periodically during Core I operation were utilized. Gross fissionproduct gamma scans of individual fuel assemblies were also taken in out-of-core measurements.

\section{(a) In-Core Measurements}

The in-core instrumentation system consisted of eight flux-wire drive mechanisms to allow the insertion and withdrawal of flux wires in 22 different locations within the core. Flux-wire measurements were made at a central position in each fuel assembly located in one quadrant of the core and in one fuel assembly of each of the other quadrants. Manganese wires we re used for detection, taking advantage of the $\mathrm{Mn} 55(\mathrm{n}, \gamma) \mathrm{Mn} 56$ reaction. The $\mathrm{Mn} 56$ activity is essentially proportional to the fission power density at the center of the fuel assembly.

In order to determine the relative power output of each assembly, it was necessary to obtain: (1) the axially-averaged measured wire activity for each assembly, which is proportional to the power density at the center-line axis of the assembly, and (2) the ratio of the average power density in the assembly to the power density at the center-line axis of the assembly. The latter ratio was determined from the results of X-Y PDQ calculations performed for the various rod configurations that occurred during the normal rod withdrawal program. The PDQ problems contained a fine-mesh description of the Yankee Core in X-Y geometry and used discrete control rod representations. Hence, the power distribution calculated was sufficiently detailed to give the center-to-average power ratios for the individual fuel assemblies. Application of this ratio to the wire activity results permitted interpretation of the wire data in terms of assemblywise, power outputs. Data reduction was done with the aid of a special computer code. Complete mappings of the experimental power distribution were obtained for 14 time steps (i.e., exposure steps) during the life of Core I. 
The accumulated average fuel exposure in the individual fuel assemblies was then determined for the end of each time step by a time integration of the discrete power distributions. The experimental burnup distributions are in reasonably good agreement with the results of an X-Y TURBO analysis performed over the core life (Reference 15). Most discrepancies are within the range of estimated experimental error ( $5 \%$ to $10 \%$ ).

(b) Out-of-Core Gamma Scan Measurements

The gross garma emission along the central axis of Yankee assemblies was measured by scanning within the center hole of each fuel assembly with a miniature ion chamber (Reference 21). Comparisons were made of the relative gamma activity and relative burnup (as obtained from the flux-wire, isotopic and Cs137 measurements) of the individual fuel assemblies (Reference 2). In the use of the flux-wire data, the relative exposure of each assembly was determined by integration with respect to time of the relative assemblywise power output as indicated by the axially-averaged wire activity readings. The integrations were performed over two time intervals; namely, (1) over the entire core life, and (2) over the final $30 \%$ of core life during which all control rods were removed from the core. Some general conclusions draw from the comparisons (References 21 and 3I) are:

(1) In the assemblies along the periphery of the core there appears to be agreement between relative gamma activity and relative predicted burnup to within $\pm 7 \%$. These peripheral assemblies were in that portion of the core which did not contain inserted control rods during very nearly the entire core lifetime.

(2) In the assemblies in the inner core region, the garma activity seem to be more nearly proportional to the power distribution (over final $30 \%$ of core lifetime) or some combination of power and burnup distribution.

Individual fuel rods removed from fuel assemblies were also gamma scanned. The percent difference between fuel rod gamma activity and burnup for fuel rods at the center of the assemblies is generally of the same order of magnitude as the percent difference between assembly gamma activity and burnup (up to $16 \%$ difference). However, larger percentage differences (ranging from $6 \%$ to $36 \%$ ) were obtained for corner fuel rods.

Gamma spectra were taken of 24 fuel samples. The results indicate that most of the activity remaining in the fuel samples is from Cel44, Pr144, Cs134, Cs137, and Zr95. All gamma scans were compensated for fission product decay.

IV. Vallecitos Reactor, VBWR

Numerous and:varied experiments have been conducted in the Vallecitos Boiling Water Reactor and these have utilized instrumentation of various types pertinent to the test setup and program objectives. Briefly described herein are the in-core measurements performed for an experimental study of long-term reactivity characteristics of $\mathrm{UO}_{2}$ irradiated in VBWR (References 17 and 39). In this study, isotopic analyses of uranium depletion and plutonium production were experimentaliy performed and compared to the theoretical predictions; the comparison results are summarized in Section VI of this report.

$$
.^{+}
$$

Two fuel elements of 2.8 atom percent enrichment were used in the experiments. All adjacent fuel locations contained similar fuel elements to provide as homogeneous a region as possible. The experimental fuel elements each con- 
tained five guide tubes for flux-wire insertion. 'The arrangement allowed in-' sertion and withdrawal of the flux wires during reactor operation.

Three types of wires were irradiated which measured separately the following reactions :

$$
\begin{aligned}
& \text { Co59 (n,r) Co6o (Thermal, epithermal fluxes) } \\
& \text { Ni64 (n,r) Ni65 (Thermal flux) } \\
& \text { Ni58 (n,p) Co58 (Fast flux) }
\end{aligned}
$$

When a Ni-Co wire was used, it was counted after a short decay time as a measure of thermal flux $(\mathrm{Ni} 65)$ and after several days as a measure of fast flux (Co58). Attempts were made to relate steam-void fraction to observed fast-to-thermal flux ratio. The ratio was found to vary by about $15 \%$ from no-void to exit-void $(30 \%)$ conditions. No significant use was made of the flux-wire data obtained.

In the same set of experiments, gamma scans were made of irradiated fuel rods from which samples were taken for isotopic analysis. The gamma scans were obtained with a conventional scintillation counting system with the discriminator set to accept pulses from gamma rays having energies in excess of $0.60 \mathrm{Mev}$; i.e., primarily the 65-day Zr-95 activity.

The average power density for each fuel pellet along the fuel rod was determined for each VBWR irradiation run as follows:

(1) A two-dimensional diffusion theory calculation for the entire VBWR core was made to obtain the percent of total core power generated in each of the two experimental fuel elements.

(2) The percent of element power in the fuel rod of interest was then obtained from a two-dimensional diffusion theory calculation wherein each rod in the two experimental fuel elements was specified discretely.

(3) The gamma scan activity distribution for the fuel rod of interest was then utilized to obtain the power density for each pellet along the rod.

Experimental burnup determinations for the individual fuel pellets were also made through radiochemical analysis. The fission products Cs 137 , Cel44, Zr95, and Bal40 were chosen as the burnup indicators. The accuracy of burnup values obtained is estimated to be $\pm 6 \%, \pm 7 \%$, $\pm 8 \%$ and $\pm 10 \%$ for Cs137, Cel44, Zr95 and Bal40, respectively.

Comparisons are presented of the measured burnup and that implied from the gamma scan of the irradiated fuel rod as a function of axial position along the rod for three fuel rods (Reference 17). The standard deviation between the data points (20 measurements with each method) is 10.1 percent. It is concluded that the burnup implied from the gross gamma scans is not sufficiently precise.

\section{Dresden, Humboldt Bay and Big Rock Point Reactors}

These reactor cores employ in-core miniature ion chambers as part of the nuclear instrumentation. The in-core ion chamber system consists of vertical strings of ion chambers which are located within the core to measure the relative average power density in suitably defined supracell regions of the core. 
In Humboldt Bay, eight strings are used which are located at eight of the supracell boundary corners, where a supracell consists of a cruciform control rod and its four surrounding fuel assemblies. Each ion chamber string consists of three miniature fission chambers, one at each of three elevations, and a calibration tube for insertion of flux wires. This system makes it possible to monitor neutron flux at 24 discrete points in the core. From the readings of the in-core system, it is possible to construct the three-dimensional gross power distribution within the core at any time.

In-core ion chamber systems are also incorporated in the Dresden and Big Rock Point cores. Dresden contains 16 ion chamber strings with 4 fission chambers per string. Big Rock Point contains 8 strings with 3 fission chambers per string.

\section{Indian Point Reactor}

Measurements of fission product distribution were made on individual fuel elements from Consolidated Edison's Indian Point Reactor to determine the power distribution just prior to core midlife. All elements within are octant and additional symmetry elements were scanned. The distribution of the characteristic gamma rays of the 12.8 day barium-lanthanum fission product chain along the length of selected fuel elements was used as a measure of the power distribution (Reference 19). The scanning technique utilized the $(\gamma, n)$ threshold reaction in deuterium to detect the $2.58 \mathrm{Mev}$ gamma in the decay chain. After a ten-day cooling period, virtually all gammas with enough energy to cause the reaction come from this chain. The technique thus uses the threshold reaction and gamma insensitive neutron detectors to discriminate the multitude of other gammas. Boron-10 lined detectors were chosen for this application because of their high gamma rejection combined with relatively high thermal-neutron sensitivity. The detectors were located in paraffin blocks which surrounded an aluminum box filled with heavy water. The Ba-La scanners were located in a housing behind a 4-inch thick shadow shield. A fuel element guide was attached to the shield to ensure uniform positioning of each fuel element before the scanner.

As indicated in Section $\mathrm{V}$ of this report, good agreement was obtained between calculated and measured core power distributions for the first period of core operation which was analyzed. The good agreement obtained permitted confident predictions of core power distributions for the remainder of core life. 


\section{APPENDIX C}

MEASUREMENT ACCURACIES IN THE DETERMINATION OF EXPOSURE AND HEAVY-ISOTOPIC COMPOSITION OF IRRADIATED FUEL SAMPLES

\section{Fuel Exposure Measurements}

Three different approaches are used for the experimental determination of fuel exposure. They are:

(1) Measurement of individual $f$ ission product content

(2) Measurement of uranium and plutonium isotopic composition

(3) Gamma Scans

The first of these techniques is the most widely used. It consists of the experimental determination of the content of a selected fission product isotope and the deduction of fuel exposure from this measurement. First the spent fuel is dissolved and the selected burnup monitor is chemically separated from the solution. In the second step, the quantity of the monitor is measured using one of several techniques. Radioactive fission products are usually identified by their characteristic gamma or beta radiation. The most frequently used method to determine nonradioactive fission product content is isotope dilution mass spectrometry.

Fission product burnup indicators are carefully selected. They should satisfy the following requirements:

(1) Fission yield should be independent of the fissile nuclide and the energy of the incoming neutron.

(2) Long half-life and small absorption cross section.

(3) High boiling temperature

(4) Good chemical behavior to suit chemical separation

(5) Well known nuclear constants

The high boiling temperature is important to prevent gas formation; gaseous fission products migrate in the fuel, thus contributing to the inaccuracy of the measurements and may even escape from the fuel elements.

Cs137, Zr95, Sr90 and Ce144 are among the first used fission product burnup indicators (Reference 40). All of these are radioactive, and thus are identified by their characteristic radiation. However, none of these satisfy all of the above requirements. General Electric, in a search among nonradioactive fission products, has selected NdI48 as a promising burnup indicator. They have developed a simple and inexpensive separation technique and have carefully measured the nuclear constants of NdI48 (Reference 4I). Since the effective cross section of a fission product depends on the neutron spectrum of the reactor, a good burnup indicator in a thermal reactor is not necessarily a good one in a fast reactor. For example, Nal48 because of its relatively large cross section at high energies is not suited for fast reactor applications. A recent study (Reference 42) conducted at Argonne National Laboratory indicates that Lal39 and Te99 are the best burnup indicators for fast reactors.

Fuel exposure can also be determined from measured uranium and plutonium concentrations. A computer code recently written for this purpose is described in Reference 43. Since the measurement of heavy isotopic composition is more. 
elaborate than the determination of one fission product content, this method is used only if the fuel composition is also of interest. The techniques used for fuel isotopic content determination are discussed in the second part of this Appendix.

In contrast to the first two methods, gamma scanning is the only nondestructive analysis presently in use to determine fuel exposure distribution. In the simplest case the total gamma activity above a cut-off energy is counted, i.e., gross gamma scanning is utilized. It is assumed that the measured activity is directly proportional to fuel exposure. While this assumption is rough, the present knowledge of fission product parameters and the complicated nature of the many fission product chains does not justify more elaborate calculations. Gross gamma scan is conducted either on a fuel assembly or on an individual fuel rod basis, and is usually performed after appreciable decay of the fission-product radiation. Nonuniformity in the cobalt content of stainless steel clad (due to the use of different batches of steel in the fabrication of the fuel-rod clad) with the resultaint lack of correlation of local co6o activity with local flux irradiation introduce errors in the interpretation of the gamma scan measurements in terms of relative fuel exposure. Another possibility for utilizing gamma radiation measurements to infer relative fuel exposure is to select one or a few characteristic garma radiations for measurement purposes. CsI37 and Cel44 have been proposed for this purpose (Reference 18). Lal40 activity has been used to measure power distribution that existed prior to shutdown. The measurement has to be done within a few days after shutdown since the half-life of Lal40 and its parent nuclide Bal40 is short (40.2 hours and 12.8 days, respectively). Power distribution measurements using Lal40 have been conducted by Babcock and Wilcox on Indian Point spent fuel and by General Electric Corporation on the Dresden reactor (References 44 and 45). General Electric reported an accuracy of $\pm 4 \%$ on a fuel assembly basis.

The uncertainties in fuel exposure measurements are summarized in Table C-1. It is assumed that, with the exception of the gross gamma scan, the analysis is done on single pellet size samples; the fuel assembly and total core burnup values are deduced from this data using calculated weighting factors. The fuel assembly weighting factors are assumed to be known with an accuracy of $\pm 5 \%$, and the individual sample weighting factors are assumed to be known with an accuracy of $\pm 10 \%$. When complete fuel assemblies are dissolved and the solution is sampled, then the single sample accuracy is applicable. Similarly, in the case when a complete spent core is dissolved in one batch, the single sample accuracy should be applied.

It is evident that, at the present time, the most accurate method for single sample analysis is the mass spectrometric determination of Nal 48 . However, when individual sample data is used to infer fuel assembly or total core burnup, the uncertainty in the results is about the same for all methods. An accuracy of about $+4 \%$ for fuel assemblies and an accuracy of $+2 \%$ for total core can be obtained by each method, since the uncertainty in the weighting constants is the limiting factor.

The high value $(+15 \%)$ for the gross garma scan is the direct result of the assumption that the total ganma activity is proportional to burnup. Among other things, a measurement of this sort does depend on the time elapsed since core irradiation. Comparison of data obtained one year after irradiation to that obtained 2.2 years after irradiation indicated that the 2.2 years data approaches the burnup distribution more closely than the earlier data (Reference 2l). At the present, there is not enough information available to calculate accurately the gross gamma activity of spent fuel, thus making possible corrections for the decay of primary fission products and formation of secondary fission products. New developments may drastically improve on 
TABLE C-1

\section{UNCERTAINTIES IN FUEL EXPOSURE MEASUREMENTS}

\begin{tabular}{|c|c|c|c|c|}
\hline Isotope Used & Method Applied & $\begin{array}{c}\text { Single Sample } \\
(\%)\end{array}$ & $\begin{array}{l}\text { Uncertainties for } \\
\text { Fuel Assembly* } \\
(\%) \\
\end{array}$ & $\begin{array}{c}\text { Total Core* } \\
(\%) \\
\end{array}$ \\
\hline Ndi 48 & Mass Spectrometry & \pm 2 & \pm 3.3 & \pm 1.9 \\
\hline Cs137 & Radiochemical Analysis & \pm 6 & \pm 3.7 & \pm 2.0 \\
\hline $\mathrm{Zr} 95$ & Radiochemical Analysis & \pm 8 & \pm 4.0 & \pm 2.0 \\
\hline Sr90 & Radiochemical Analysis & \pm 12 & \pm 4.9 & \pm 2.2 \\
\hline $\mathrm{Bal} 40$ & Radiochemical Analysis & \pm 10 & \pm 4.5 & \pm 2.1 \\
\hline $\operatorname{Lal} 39$ & Mass Spectrometry & \pm 5 & \pm 3.5 & \pm 1.9 \\
\hline Te99 & Spectrophotometry & \pm 5 & \pm 3.5 & \pm 1.9 \\
\hline $\begin{array}{l}\text { U \& Pu } \\
\text { Isotopes }\end{array}$ & Mass Spectrometry & \pm 8 & \pm 4.0 & \pm 2.0 \\
\hline \multicolumn{2}{|c|}{ Gross gamma scan } & --- & \pm 15.0 & -- \\
\hline
\end{tabular}

\section{Notes}

$\mathrm{Ndl} 50$ is used as a spike in isotope dilution

Characteristic gamma radiation; partially gaseous, migrate

Characteristic gamma radiation; short half life

Characteristic beta radiation; fission yield depends on fissile nuclide

Characteristic gamma radiation; very short half life

For fast reactor spectrum only

For fast reactor spectrum only

U233 and Pu242 are used as spikes in isotope dilution

Relative measurement; does not give absolute value

* Assuming 10 samples have been analyzed per fuel assembly and 10 fuel assemblies per core. A $10 \%$ uncertainty in the single sample weighting factors and a $5 \%$ uncertainty in the assembly weighting factors is assumed. 
the accuracy of gross gamma scan measurements.

II. Measurement of Heavy-Isotopic Composition

Uranium and plutonium isotopic content of spent fuel is usually determined by isotopic dilution mass spectrometry (Reference 40). First, uranium and plutonium are chemically separated from the fission products and other materials. Then, a known number of atoms of a uranium isotope and that of a plutonium isotope is combined with the solution and used as a spike. The relative abundance of the other isotopes to that of the spike is measured on a mass spectrometer. U233 and Pu242 are frequently used spikers; Pu236 has also been used.

Quoted accuracies for the mass spectrometric determination of heavy isotopes from three laboratories (General Electric Vallecitos, Tracerlab, and USAEC: New Brunswick Laboratory) are given in Table C-2 (Reference 33). The given values represent the accuracy of measurement of the isotopic composition of uranium and plutonium. The precision of the U238 content determination and that of the plutonium to uranium mass ratios are also given. Inasmuch as the determination of the absolute amount of one plutonium isotope, for example, includes the measurement of the $\mathrm{U} 238$ content, the isotopic composition of uranium, the plutonium to uranium ratio and the plutonium isotopic composition, the precision for this isotope is obtained by appropriately combining all of the individual measurement accuracies.

Recently, as part of the Yankee Core Evaluation Program, Westinghouse resubmitted a single MONITOR sample under different code names seven times to Tracerlab and four times to G.E. Vallecitos for analysis (Reference 2). Observed uncertainties deduced from this MONITOR sample are listed in Table C-3. All values given in Table $\mathrm{C}-3$ are for slightly enriched uranium oxide fuel. The quoted accuracies represent two standard deviations; that is they correspond to a 95\% confidence limit. The values given, however, reflect only the uncertainties which arise during the sample preparation and mass spectrometric analysis at the analyzing laboratory. In no way do the results include the errors which are introduced in the hot cells during the acquisition and preparation of the sample, or in the subsequent analytic treatment of the sample data necessary to obtain inferred quantities.

The last column of Table $\mathrm{C}-3$ shows the author's estimates of how well isotopic analysis can be performed today on slightly enriched spent fuel. These estimates include an additional $\pm 1 \%$ uncertainty to account for sample handling prior to submission for analysis. It is clear that in spent fuel samples all uranium and plutonium isotopes can be measured with an accuracy of $\pm 4 \%$ or less. The only exception in Table $\mathrm{C}-3$ is U234. This is not because of difficulties in the $\mathrm{U} 234$ measurements, but is a consequence of the very low concentration of U234 in slightly enriched or natural uranium fuels. For any fuel material with appreciable U234 content the uncertainty in the U234 content determination should be less than $\pm 4 \%$.

In order to check the mass spectrometric results, Westinghouse developed an independent method for the determination of plutonium in irradiated $\mathrm{UO}_{2}$ fuel pellets (Reference 33). The X-ray spectrographic technique is applicable in the range of $0.2 \%$ to $1.5 \%$ mass ratios of plutonium to uranium, and has an accuracy of $\pm 4 \%$.

Prior to the adoption of the double-spike mass-spectrometric technique, the plutonium to uranium ratio was determined by a combination of alpha counting, alpha spectroscopy and mass spectrometry. This method had an accuracy of $\pm 5 \%$ and is rarely used today. 


\section{TABLE C-2}

PRECISION OF MASS SPECTROMETRIC DATA

$\underline{\text { Isotope }}$

Quoted Accuracies

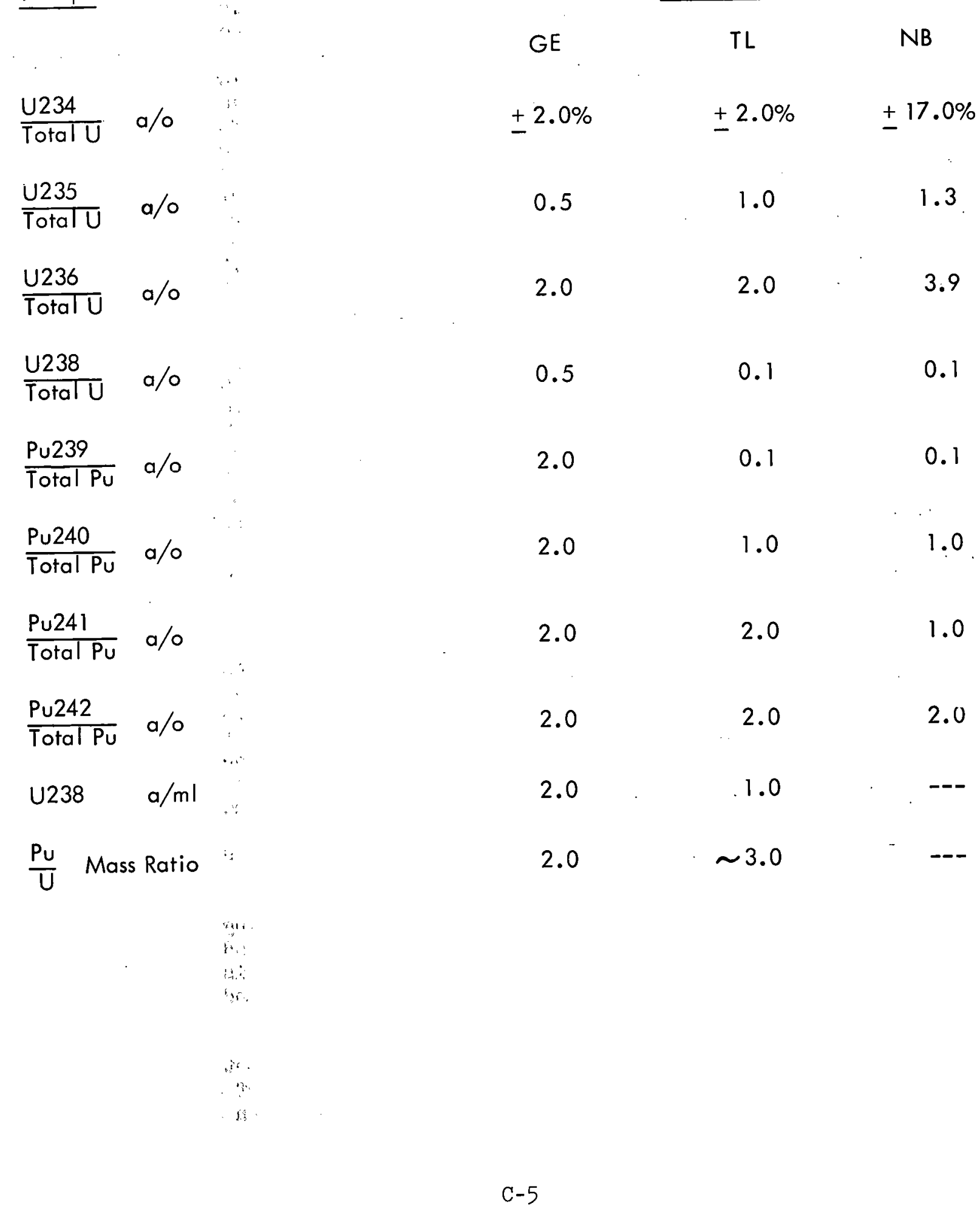


TABLE C-3

\section{ACCURACIES OF ISOTOPIC CONTENT MEASUREMENTS}

Isotope

U234 content

U235 content

U236 content

U238 content

Pu239 content

Pu240 content

Pu24l content

Pu242 content
Observed Accuracies*

\begin{tabular}{|c|c|c|}
\hline General Electric & Tracerlab & Estimated Accuracy** \\
\hline $11.1 \%$ & $4.2 \%$ & $10.0 \%$ \\
\hline 1.7 & 0.8 & 2.0 \\
\hline 3.8 & 1.3 & 4.0 \\
\hline 0.02 & 0.03 & 1.0 \\
\hline
\end{tabular}

1.7

3.7

4.0

3.5

3.6

4.0

2.6

3.9

4.0

2.2

3.3

4.0

* two-standard deviation in the data

** includes a $1 \%$ uncertainty introduced by sample handling 


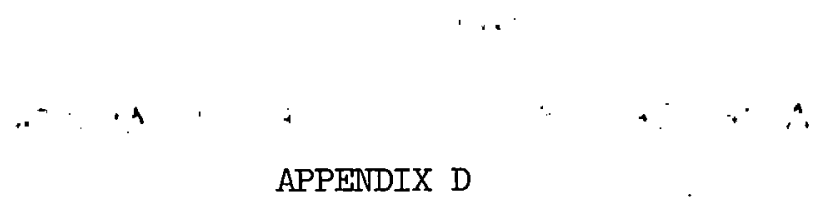

ACCURACY OF PLANT MEASUREMENTS

In operating practice, the thermal output of nuclear fuel must be determined by heat-balance techniques. Determination of the core total thermal output. requires consideration of numerous heat-flow components, each of which must be individually measured or estimated in order to perform the necessary heat balances. Typical heat-flow components include: (1) thermal output to the primary coolant system; (2) thermal output to the steam system where it constitutes the secondary system; (3) thermal losses due to water cleanup and blowdown; (4) nuclear radiation losses and miscellaneous thermal losses such as associated with shield cooling and control-rod seal cooling; and (5) enthalpy inputs associated with electrical pressurizers and pressurizing and circulating pumps. The first two components generally represent over $95 \%$ of the total reactor thermal power. Hence, relatively large uncertainties in the determination of the magnitudes of the remaining heat-flow components have only a small effect on the overall accuracy of the reactor total thermal power determination.

In nuclear power stations, thermal outputs are evaluated in detail on a periodic basis. Generally, the data used in the thermal calculations'are compiled daily from plant station records. By daily data compilation, any abnormal deviations in instrument readings are immediately detected so that corrective action can be taken.

Power range nuclear instrumentation is used to continuously measure power level during normal power operation. The nuclear instmumentation is periodically recalibrated to conform with the heat balance data. Integrated power is generally found by integrating the area under the nuclear power channel recorder trace after the recorder power level is corrected by the heat balance data adjustment.

Standard steam power plant instruments are used for the heat balance measurements. Special instrumentation is often used to meet the particular measurement requirements specified for the plant variables. To preserve accuracy of measurements, systematic recalibration and check programs are generally continually in effect for all instruments involved in the determination of thermal power output. Periodic tests are made to detect any changes in plant cycle performance. For known plant, cycle efficiency, the station electrical power output also provides a continuous monitor of the reactor thermal power output.

The uncertainties involved in those plant measurements pertinent to the determination of the overall accuracy of the reactor total thermal output are indicated herein for a number of nuclear power stations. The uncertainties were arrived at through a consideration by the plant operators of the errors in the physical plant data. 


\section{Indian Point}

The total energy output produced in the reactor is determined once a month. This determination takes the form of a heat balance of the processes within the outer biological shield. These processes are monitored by recording and indicating instrumentation.

The recorded information takes the form of circular charts and strip charts where flows, pressures, and temperatures may be planimetered and averaged hourly as the particular variable requires. Indicators and gages supply information which is logged every two hours. All operating information, pertinent to the heat balance, is either totalled or averaged at the end of the month.

Tests are made two to three times a month to check the accuracy of the operating instruments. Inaccuracies are corrected and adjustments made if necessary. The nuclear instrumentation, which involve 18 power level channels, is calibrated periodically by means of heat balance tests made at specific power levels.

The heat balance of the processes contained within the outer biological shield involves equating the total heat energy leaving the enclosure, which includes the useful as well as the waste heat energies, to the sum of the thermal output of the reactor core and the thermal equivalent of the electrical energy used within the enclosure. From the heat balance equation, the thermal output of the reactor core is determined in terms of the remaining heat-flow components which are evaluated on the basis of the plant measurements. These heat flow components are defined and obtained through measurements as follows:

(1) Electrical power consumption within enclosure

Obtained from kilowatt hours used in pressurizing heaters and by the primary coolant pumps and containment cooling fan.

(2) Heat leaving enclosure (useful and waste heats)

a. Loss to fresh water coolers

Flow determined by pitot tubes connected to manometers; temperatures to and from containment measured by calibrated thermocouples. Cooling water loss determined, by test, two or three times a month.

b. Input to steam of nuclear boilers

Steam flow determined from recorder readings of feedwater flow (calibrated flow nozzles in feedwater lines) by subtracting amount of logged secondary system blowdown. Feedwater temperature and pressure are read from a recorder and gage, respectively. Steam quality measured calorimetrically.

c. Loss to ventilating air

i=

it

J

Air flow estimated from fan design characterističcs. Air temperature and pressure readings (of atmosphere and in containment) logged. Relative humidities... logge d. 
d. Loss in secondary steam blowdown

Blowdown controlled by fixed orifices and control valves. Blowdown periods logged for use in determining blowdown quantities. Drum pressure recorded.

e. Loss in control rod seal water

Seal water return flow recorded on chart, and temperature logged from indicator. Enthalpy of supply water determined from recorded clean-water storage-tank temperature and seal water and makeup pump discharge pressure.

f. Loss in excess makeup and primary blowdown

Excess makeup flow is calculated; primary blowdown flow is recorded. Appropriate temperatures are recorded on charts and pressures are logged.

g. Loss from outer biological shield surface

Based on shield surface area exposed to atmosphere and on a calculated overall heat-transfer coefficient. Temperature of air on containment (near inner shield surface) and in atmosphere (near outer shield surface) are indicated and logged.

Table D-I presents the results of a detailed analysis of the probable accuracy involved in the evaluation of the individual factors used for the determination of nuclear thermal output. The evaluation indicates an overall probable error of $\pm 1.2 \%$ at plant full-power conditions. This error increases with decreased nuclear output, reaching a value of $\pm 4.0 \%$ at $25 \%$ power conditions.

\section{Big Rock Point}

The heat balances performed at Big Rock Point consider a system enclosure basically consisting of the reactor vessel itself. The heat-balance equation hence states that the reactor power equals the difference between the total heat rate out of the pressure vessel and the total heat rate into the pressure vessel. The greatest latitude for significant error exists in the "power-out" in the primary steam and the "power-in" in the feedwater. For determination of "powerout", the steam quality at the drum outlet has been assumed to be $99.9 \%$. The plant instrumentation (factory-calibrated Bailey) gives readouts, recordings and time integration of both feedwater and steam flows. The agreement between these two flow values has been generally good. It is estimated that the accuracy of the instruments is, about $\pm 3 \%$, which implies a comparable accuracy in reactor thermal power. Individual plant instrumentation accuracies are presented in Table D-2.

Time-integration of power is carried out using the heat balance data and gross-electrical megawatt-hour integrator. Once per shift, one-hour integrator differences are taken on steam flow, feedwater flow and gross-electrical output. The flows are used to calculate thermal power, which is divided into the electrical generation to yield a value of gross cycle efficiency. The three cycle efficiency válues obtained during a single day's operation are then averaged numerically with the 18 efficiency values from the previous 6 day's operation for a 7-day average cycle efficiency value. The resulting average efficiency is divided into the day's gross electrical generation to yield a time-integrated value of thermal megawatt-hours for the particular day. Hence, 
TABLE D-1

\section{ESTIMATED UNCERTAINTIES IN INDIAN POINT PRIMARY MEASUREMENTS}

\section{Percent Power}

Nuclear Input, $10^{6}$ Btu/hr

\section{Errors}

Feedwater flow

Steam quality

Feedwater temperature

Steam pressure
100

$\frac{1956.1}{\frac{10^{6} \mathrm{Btu} / \mathrm{hr}}{19.75} \cdot \frac{\text { Percent }}{1.01}}$

$$
11.66
$$

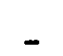

0.18

$$
0.01
$$

0.70

2.59

0.13

0.02

0.07

1.71

Radiation

Electrical input

Expected overall accuracy

$$
0.22
$$

0.60

0.01

0.02

0.04

0.04

0.04

\begin{tabular}{|c|c|c|}
\hline 1467.1 & 978.1 & 489.0 \\
\hline Percent & Percent & Percent \\
\hline 1.35 & 2.02 & 4.04 \\
\hline 0.22 & 0.22 & 0.22 \\
\hline
\end{tabular}

0.18

0.17

0.60

0.60

0.60

$-$

0.04

0.04

0.35

$-$

$-$

0.09

$-12$

$-$

0.09

0.

0.17

$\begin{array}{lll}0.12 & 0.09 & 0.17\end{array}$

$1.21 \quad 1.51 \quad 2.13$

\section{5}

Remarks

Assumed that for a true moisture content of $0.50 \%$ calorimetric readings may vary from $0.25 \%$ to $0.75 \%$.

Assumed that there may be an error of $\pm 5.0^{\circ} \mathrm{F}$ in feedwater temperature.

Assumed error of \pm 5.0 psi in steam pressure. This has a negligible effect.

Assumed $36,000 \mathrm{lb} / \mathrm{hr}$ primary blowdown at all loads and that flow readings may be in error by $\pm 10.0 \%$.

Assumed $1.0 \%$ secondary blowdown and that flow estimates may be in error by $\pm 25 \%$.

Assumed $25 \%$ error in determination of heat to fresh water.

Assumed error in electrical power usage of $\pm 5.0 \%$. No watthour meter has been provided for primary coolant pump power usage.

4.11 The expected overall accuracy is derived by obtaining the square root of the sum of the squares of the individual factors.

For a loading cycle similar to that of the Astoria units, the expected error in determination of nuclear output is $\pm 1.3 \%$. 
Measurement

DRUM PRESSURE

REACTOR PRESSURE

CORE PRESSURE DROP

PLANT POWER

RECIRCULATION PUMP CURRENTS

RECIRCULATION PUMP HEAD

STEAM FLOW

FEEDWATER FLOW

FEEDWATER TEMPERATURE

ROD DRIVE FLOW TEMPERATURE

ROD DRIVE FLOW

CLEANUP SYSTEM FLOW

CLEANUP TEMPERATURE FROM REACTOR

CLEANUP TEMPERATURE TO REACTOR

PICOAMMETER READINGS

IN-CORE ION CHAMBERS

IN-CORE FLOWS

IN-CORE TEMPERATURES
Uncertainty

$1 / 2 \%$

$1 / 2 \%$

I/2 Psi

1/2 Mwe

3 Amperes

$1 / 2 \%$

$2 \%$

$1 \%$

$2^{\circ} \mathrm{F}$

$I^{\circ} \mathrm{F}$

$0 \%$ *

$2 \%$

$2^{\circ} \mathrm{F}$

$2^{\circ} \mathrm{F}$

$1 / 2 \%$

$2 \%$

$1 \%$

$3^{\circ} \mathrm{F}$

* Positive Displacement Pump 
calculation of total reactor thermal output is very closely tied into the heatbalance data, there being no intermediate instmument to be read or calibrated. It should be noted that the plant cycle efficiency is nearly independent of power, down to half-power so that its systematic determination provides a continual check on consistency of overall results.

III. Humboldt Bay

Reactor power is determined by computing the total thermal energy entering and leaving the system per unit time. The thermal energy input is through the feedwater, the water returning from the cleanup system, and the control-rod hydraulic water. The thermal energy output is through the main steam flow, the reactor water to the cleanup system, and the reactor system radiation and convection loss terms. Plant instrumentation is available fo'm measuring all required flows. However, for greater accuracy, steam flow is obtained from the measured feedwater and control-rod water flows. Sufficient instmumentation is also available to permit determination of the enthalpy of all flows except the steam flow. In the case of main steam flow, a series of radioactive tracer tests were performed from which it was determined that the steam moisture content is in the range of $0.001 \%$ to $0.05 \%$ by weight during normal operation. Moisture content is arbitrarily assumed to be $0.1 \%$ in heat balance calculations; the enthalpy difference between $1000 \mathrm{psig}$ saturated steam and steam with $0.1 \%$ moisture is only about $0.6 \mathrm{Btu} / \mathrm{Ib}$ compared to $1190 \mathrm{Btu} / \mathrm{lb}$ for the enthalpy of the saturated steam so that the error due to this assumption is negligible.

The thermal radiation and convection heat losses from the system are essentially independent of power level. These heat losses were determined by measuring the heat removal by the drywell air coolers and biological shield cooling system. On the basis of these measurements, a value of 0.1 Mwt is used in the heat balance calculations.

The principal uncertainty in the heat balance determination is in the measurement of feedwater flow. The manufacturer's stated accuracy for the flow measurement installation is $\pm 2 \%$ (one standard deviation). Since the effect of measurement uncertainty in the other heat-flow components is small by comparison, the overall accuracy of the heat balance is estimated to be $\pm 2 \%$ (one standard deviation).

Three channels of linear power level nuclear instrumentation are provided. The instmmentation is calibrated against the heat-balance. determination of reactor power. Normal practice is to permit the calibration for rated power to vary between $98 \%$ and $103 \%$ rated power indication. The calibration is adjusted only when it is found to be outside these limits, as based on once-each-shift heat balances. The typical frequency of recalibration is about once every 2 to 4 weeks when operating on the same basic rod pattern. The basic rod pattern is changed every 2 to 3 months to equalize fuel burnup; a major!calibration change is usually necessary at these times.

\section{Dresden I}

!

' J

The heat-balance procedures are essentially as indicated-above for Big Rock Point and Humboldt Bay. The most critical measurement is of the feedwater flows to the primary and secondary systems. The accuracy of the flow nozzles used to determine the flow rates was demonstrated in tests wherein calibrated flow sections were installed in series with the flow nozzles in the flow lines. A curve was developed correlating the station flow (as indicated by the flow nozzles) and the calibrated flow measurements. At high and intermediate flows, the agreement, between the station flow and calibrated flow measurements was 
excellent and, therefore, the correction was very small. This curve is used to correct the flow data which is evaluated monthly.

Table D-3 presents an estimate of the uncertainties in obtaining the reactor total thermal output. The breakdown of the systems in percent of total output is for the plant at 210 Mwe. The percent uncertainty in the performance data is based on the possible errors in the measuring instruments.

TABLE D-3

\section{ESTIMATED UNCERTAINTIES IN DRESDEN I POWER-LEVEL MEASUREMENT.}

\begin{tabular}{|c|c|c|c|c|}
\hline System & $\therefore$ & $\begin{array}{c}\% \text { of Total } \\
\text { Output } \\
\end{array}$ & $\begin{array}{l}\% \text { Uncertainty } \\
\text { in Data } \\
\end{array}$ & $\begin{array}{l}\% \text { Uncertainty } \\
\text { on Total }\end{array}$ \\
\hline Primary & $\therefore$ & 55.0 & \pm 1.36 & \pm 0.74 \\
\hline Se condary & & 43.5 & \pm 1.74 & \pm 0.71 \\
\hline $\begin{array}{l}\text { Water Cleanup } \\
\text { and Blowdown }\end{array}$ & , & 1.0 & \pm 0.7 & \pm 0.01 \\
\hline $\begin{array}{l}\text { Radiation and } \\
\text { Misc. Losses }\end{array}$ & & 0.5 & \pm 0.7 & \pm 0.01 \\
\hline & & & Total & \pm 1.5 \\
\hline
\end{tabular}

\section{Shippingport}

The usual heat-balance approach is used for the basic determination of total thermal output. The power level in the reactor core is taken equal to the heat rate as measured for the secondary steam system. The secondary steam is used instead of the primary system (reactor coolant water system) because the measurements are more precise and fewer variables need to be measured. The assumption is made that the heat input into the secondary system through system pumping power is equal to the heat loss from the system due to radiation, convection, and component cooling; on this basis, the secondary-system calorimetrics can be considered as exactly representative of the reactor core output.

A secondary system calorimetric computer using analog techniques supplies a continuously computed output of reactor total thermal output which is used for calibration of the: nuclear instrumentation. The maximum calorimetric computer signal error expected at full power is $2.50 \%$ (2.95\% including readout). Total error increases atr reduced power due to reduced accuracy in the flow and temperature measurements.

$$
\text { b: }
$$

Four individual power range channels of nuclear instrumentation are used to monitor the reactor. during steady-state power operation. The individual outputs are combined in an averaging resistance network to produce an average nuclear 
level signal. This signal is continuously compared with the signal from the secondary system calorimetric computer to determine when recalibration is necessary. This signal is also recorded. When the average nuclear level differs by $3 \%$ or more from the indicated secondary plant calorimetric, the necessary gain adjustment is made to the nuclear channels to obtain agreement between the calorimetric and average nuclear level signals.

\section{Hallam}

Heat balance calculations for reactor thermal power output are based on the enthalpy rise of the feedwater and steam through the three steam generator units. output superheated steam enthalpy is a local enthalpy determined from steam conditions measured at the three steam generator outlets. Readings for temperature and pressure at each of the three outlets are averaged to give an overall average of local temperature and local pressure from which a value of outlet steam enthalpy is determined. Under normal operating conditions, sodium flow in the three circuits is balanced; thus the flow in the three steam loops is balanced also.

Supply feedwater enthalpy is based on feedwater conditions measured in the common supply line to the three steam generator units.

The steam-flow value used in the calculations is an average value of steam flow determined from readings of a total steam flow integrator meter taken over a given time interval. The accuracy of the average value depends on the meter's accuracy, on the length of the time interval for integration, and on the reader's skill in timing and reading the meter.

The Hallam reactor and heat transfer system is considered to operate at constant temperatures over the normal load range; changes in heat transfer rate are accomplished by changing the sodium flow rate. Thus the system heat losses are considered constant over the normal power range. The assigned value of heat loss is 1.5 Mwt which is added to the enthalpy input in the three steam generators to obtain the reactor total thermal output.

Power range nuclear channels are provided to monitor the neutron flux. Particular care is taken to insure that the output of these channels is in continuous agreement with heat balance calculations. Heat balance calculations are made frequently, even daily, after periods of core disturbance. Generally speaking, the frequency of heat balance comparisons is dictated by the amount of deviation among chambers in the five nuclear instrument chamber outputs. Integrated power is found by integrating the area under the channel recorder traces after the recorder power level is corrected by the heat balance data adjustment.

An estimate of the accuracy of the heat balance calculation to obtain reactor total thermal output has been supplied by the Hallam operators. The detailed considerations involved are as follows:

(1) The estimated accuracy of the outlet steam temperature indications is $\pm 10^{\circ} \mathrm{F}$ and of the steam pressure indications is $\pm 15 \mathrm{psi}$.

(2) The estimated accuracy of the feedwater temperature indication is $\pm I^{\mathrm{O}} \mathrm{F}$.

(3) At full scale, which is $900,000 \mathrm{lb} / \mathrm{hr}$, the accuracy of the steam flow integrating meter is estimated to be $\pm 1 \%$. At a flow rate of $360,000 \mathrm{lb} / \mathrm{hr}$, which corresponds to half power, the accuracy is therefore $2.5 \%$. At full power, the corresponding accuracy value is about $\pm 1.2 \%$. 
(4) The 1.5 Mwt heat-loss value is probably accurate to within about $\pm 10 \%$. The magnitude of this term is small compared to that for total heat transferred and hence the heat loss error factor is neglected.

The results of combination of the above errors is a maximum possible total error of $\pm 1.8 \%$ at full power and $\pm 3.1 \%$ at half power.

VII. Pathfinder

The system boundary for the heat balance includes the reactor vessel and recirculation pump and piping so that all heat losses and external energy sources are considered. The energy removed from the system is the sum of the following variables:

(1) Energy in steam flow to turbine plant

Steam pressure, temperature, and mass flow are continuously recorded.

(2) Energy in reactor water blowdown to purification system

Blowdown temperature and flow are indicated and recorded on hourly log:

(3) Energy in system boundary thermal insulation losses

Experimental curve will be derived of insulation losses versus reactor water temperature.

(4) Energy in nuclear radiation losses

Losses to biological shield and reactor shield pool will be determined as a function of reactor power level. It is anticipated that a calculation can be partially verified by integration of shield coolant requirements.

The energy added to the system is the sum of the following variables:

(1) Energy in reactor feedwater flow

The feedwater temperature and mass flow are continually monitored.

(2) Energy invested in reactor water by recirculation pump operation

Pumping energy as a function of recirculation flow rate is calculated.

(3) Energy in recirculation pump seal water flow

Seal water supply and leakoff flows and temperatures are indicated and recorded in hourly logs. The difference between inlet and leakoff flows is the injection flow to the reactor system.

The reactor thermal output is the difference between energy removal from, and energy input to, the system. The most crucial measurements are of the feedwater and steam flow rates. These flows are measured with Bailey Meter flow nozzles and Bailey Type CJ differential transducers. These flows are recorded and integrated. Calibration is done by application of test differential pressures at the dp transmitters. The flow nozzles are uncalibrated. Feedwater, 
steam, and blowdown flow measurements are estimated to be accurate to about $\pm 2.5 \%$. It is hence expected that the overall accuracy will be of the order of $\pm 2.5 \%$ to $\pm 3.0 \%$.

VIII. Saxton

The reactor thermal output is obtained by a heat balance on the steam generator. The heat balance is performed at two-hour intervals or less during chemical shim operation of the reactor, and as required, but not less than once a shift during non-chemical shim operation. Continuous power: level recording in the control room is accomplished by one of three nuclear power channels; the channel outputs are continually renormalized to conform with the heat balance data. A correction for steam generator blowdown is added to the enthalpy input in the steam generator; the blowdown is assumed to be saturated water at 90 psia and its flow is known by the setting of the calibrated blowdown-flow valve. When the purification system for the reactor main coolant loop is in operation, this heat loss is accounted for. Heat loss in the secondary system steam lines is considered negligible and the heat input to the main coolant system by the main coolant pump almost exactly balances the heat loss from this system.

$$
\text { ji }
$$

No estimate of obtainable accuracy of reactor thermal output determination is available.

\section{Carolinas-Virginia}

The integrated thermal core power is determined for each reporting period. For CVTR, the reactor thermal power consists of two parts: ( 1 ) thermal power in the primary coolant leaving the reactor; and (2) thermal power loss to the moderator. The sum of these two parts established the thermalf power level of the reactor.

The power leaving the reactor in the primary coolant is calculated from measured values of primary coolant flow and of the change in primary coolant temperature across the steam generator for a fixed reactor inlet temperature. A correction is made for piping heating losses and pump heat.

The power loss to the moderator is calculated from measured values of moderator flow and the moderator temperature rise across the reactor. The moderator loss is divided into a part representing power deposited in the moderator by gamma and neutron radiation and a part representing power conducted to the moderator through the U-tube walls. The calculation of the part representing conducted losses is based on experiments using non-nuclear heat performed during the CVTR Startup Test Program. The calculation of the part representing the radiation loss is based on the difference between the measured total loss and the calculated conducted loss.

Three nuclear power channels are set to read percent of licensed power ( $44.3 \mathrm{Mw}$ gross thermal). These instruments are checked against a heat balance taken once a week.

The estimated thermocouple uncertainty is $\pm 1^{\circ} \mathrm{F}$ for the $\mathrm{p}^{\text {pit }}$ primary coolant temperature rise across the reactor of $539-505=34^{\circ} \mathrm{F}$. The associated error in thermal output is hence $\pm 3 \%$. The estimated uncertainty in measurement of coolant flow is $\pm 0.6 \%$. Statistical combination of these uncertainty factors results in an overall uncertainty in the reactor total thermals.output of $\pm 3.1 \%$. 
X. Piqua

The heat balance is based on measurements on both the organic side and the steam side of the steam generator. The measurements are of the primary (organic) and secondary (water) flows through the steam generator and of the temperature differences for both heat-transfer media across the steam generator. The two heat balances agree within $\pm 2 \%$ to $\pm 3 \%$ at full power. An average of the two heat rates is used for the recorded power levels.

Three uncompensated ion chambers are used for continuous power recording. The recorders are normally recalibrated once every ninety days. However, three (once per shift) power calculations from the heat balance data are performed each day which is the basis for burnup calculations.

Estimated individual measurement accuracies are given in Table D-4.

$$
\text { TABLE D-4 }
$$

\section{ESTIMATED UNCERTAINTIES IN PIQUA PRIMARY MEASUREMENTS}

Measurement

MAIN LOOP FLOW

REACTOR OUTLET TEMPERATURE

REACTOR INLET TEMPERATURE

DEGASIFIER LOOP FLOW

DEGASIFIER RETURN TEMPERATURE $\therefore:$

INTERMEDIATE CHANNEL READINGS $\therefore$

FEEDWATER SUPPLY TEMPERATURE

FEEDWATER FLOW

(20\% to $100 \%$ Power)

SUPERHEATED STEAM TEMPERATURE

SUPERHEATED STEA'M PRESSURE

SUPERHEATED STEAM FLOW

(20\% to $100 \%$ Power).

\section{Uncertainty}

$\pm 2 \%$ to $3 \%$

$+1 \%$

$\pm 1 \%$

$\pm 2 \%$ to $3 \%$

$\pm 1 \%$

$\pm 3 \%$ to $4 \%$

$\pm 1 \%$

$\pm 1 \%$

$\pm 1 \%$

$\pm 1 \%$

$\pm 1 \%$

s?:

The overall accuracy of total thermal output determination is indicated to be of the order of $\pm 3 \%$. 
XI. Yankee

Accounting sheets detailing the numerous heat-flow components are used. The heat balances involve the same approaches and the same measurement and calculational procedures as described in the previous sections; hence, only a brief account of the procedures is given herein.

The approach involves balancing of the heat outputs and heat inputs to yield core thermal output. The heat output from the secondary (steam) side of the steam generators (referred to as $Q$ calorimetric) is obtained by the relationship $Q=M \Delta H$. The mass flow $M$ is obtained from calibrated feedwater and steam flow integrators corrected for temperature and pressure. The integrators are read for a period of time ( 4 to 8 hours) and the average flow ( $1 \mathrm{~b} / \mathrm{hr}$ ) is obtained. The term $\Delta H$ is the difference in enthalpy of the feedwater entering the steam generators at its temperature and pressure and the enthalpy of the steam leaving corrected for its moisture content. The moisture content as determined by use of the throttling calorimeters gives average results of $0.6 \%$ moisture.

The $Q$ output of the core is obtained from the equation:

$$
Q_{\text {core }}=\dot{Q} \text { calor. sec. Ioss }+Q \text { prim. loss }-Q \text { M.C. pump }
$$

Typical results at 120 Mwe power output give:

$$
\begin{aligned}
& \text { Secondary system heat losses, } Q_{\text {sec. Ioss }}=4.2 \times 10^{6} \mathrm{Btu} / \mathrm{hr} \\
& \text { Primary system heat losses, } \mathrm{Q}_{\text {prim. loss }}=1.6 \times 10^{6} \cdot \mathrm{Btu} / \mathrm{hr} \\
& \text { Heat input of main circ. pumps, Q } \text { M. C. pump }=13.4 \times 10^{6} \mathrm{Btu} / \mathrm{hr} \\
& \text { Hence, } \mathrm{Q}_{\text {core }}=Q_{\text {calor. }}-7.6 \times 10^{6} \mathrm{Btu} / \mathrm{hr} \\
& \text { Measurement of } \mathrm{Q} \text { gives } 1340 \times 10^{6} \mathrm{Btu} / \mathrm{hr} \text { so that, within } 0.6 \% \text {, } \\
& \text { calor. } \\
& \text { Q }=\text { Q } \quad \text { calor. }
\end{aligned}
$$

An error analysis for $Q_{\text {core }}$ hence reduces to evaluation of the errors involved in determining $Q_{\text {calor. }}$. For determination of secondary feedwater flow, an error of $\pm 1.0 \%$ is estimated provided that the time of measurements is long enough to eliminate reading errors. The accuracy of enthalpy determinations is estimated as: $\pm 0.5 \%$ for the inlet feedwater using calibrated steam and $\pm 0.7 \%$ for the outlet steam enthalpy. Hence, the overall accuracy is estimated to be about $\pm 1.5 \%$.

It was observed through Core I lifetime that the calorimetric data changed $2 \%$ at full load. It is not known what caused this change. It could be changing performance of secondary equipment or a measure of calorimetric repeatability. From this observation and the preceding error analysis, it is concluded that the reactor integrated power has an error of less than $\pm 3 \%$. 